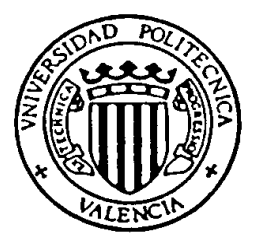

\title{
Aproximación genómica al estudio de la abscisión de frutos cítricos: análisis transcriptómico de la zona de abscisión $\mathrm{C}$
}

Tesis doctoral presentada por

Paz Merelo Cremades

Directores:

Dr. Francisco Ramón Tadeo Serrano

Dr. Manuel Talón Cubillo 





\section{AGRADECIMIENTOS}

Me gustaría dar las gracias, en primer lugar, a mis directores Quico Tadeo y Manolo Talón por su atención, sus consejos y el apoyo recibido durante mi estancia en el IVIA. Su gran experiencia y capacidad científica así como su calidad humana han sido esenciales para poder llevar a término esta tesis. También me gustaría agradecer la ayuda prestada durante estos años por el profesor Ramón Serrano, mi tutor de la Universidad Politécnica de Valencia.

Durante el desarrollo de esta tesis he tenido la gran suerte, además, de disfrutar del compañerismo del grupo de doctorandos, postdoctorales y auxiliares que forman o han formado parte del departamento de genómica del IVIA. Así, quisiera agradecer, especialmente, el apoyo y la amistad que me han ofrecido mis compañeros de tesis, y ya doctores, Javier Agustí, Fernando Andrés y Javier Brumós. También agradezco la colaboración y, sobre todo, el compañerismo de Ángel Boix, Elena Blázquez, Mati Sancho, Cristina Martínez, Toni López, Juan Vicente Muñoz, Natalia, Leandro Estornell, Vicky Ibáñez, Amparo Herrero, Alicia del Carpio, Isabel Sanchís, Isabel López, Ana Almenar, Enri Alós, y Guillermo Soler. Además, he tenido la oportunidad de trabajar con Manolo Cercós, Raphaël Morillon, Concha Domingo, Miguel Ángel Naranjo, Domingo Iglesias, Javier Terol, Chema Colmenero, Gabino Ríos, Esther Carrera y Omar Ruiz, de quienes he podido aprender y quienes me han brindado su ayuda siempre que la he necesitado.

Quisiera dar las gracias a aquellas personas que han pasado por el laboratorio y con las que he tenido el placer de trabajar y establecer colaboraciones muy enriquecedoras. Entre estas personas se encuentran los doctores Lucas Daurelio, Cristina Trullo, Marco Caruso y María Fernández, y la doctoranda Ivana Kraiselvurd. También agradezco a los doctores Vicent Arbona, Aurelio Gómez-Cadenas, Elena Orellano, Patrice Lerouge, Azeddine Driouich y Sílvia Coimbra, así como a los doctorandos Aline Voxeur y Mário Costa, las facilidades y el apoyo técnico ofrecido durante las diferentes colaboraciones establecidas.

A Pepe Gadea, Ma Ángeles Martínez y Javier Forment del laboratorio de genómica del IBMCP les agradezco su ayuda y el hecho de facilitar el microchip del Proyecto de 
Genómica Funcional de Cítricos (CFGP), que tan útil ha sido para la realización de esta tesis.

Me gustaría, además, dar las gracias al Instituto Nacional de Investigaciones Agrarias (INIA) por la financiación económica que ha hecho posible completar mi formación académica.

Agradezco enormemente el apoyo incondicional de los amigos que habéis estado siempre: Silvia E., Meri, Silvia A., Amparo, Delia, Ana, Luca, Maja, Naiara, Laura, Inma, María, J. Agustí, J. Gallego, Carlos, Kurry, Germi, Brumi, Ángel, Paco, Ricardo y Abel. Y a aquellos amigos que os habéis interesado por el estado de mi tesis durante estos años, aunque no os enumero, os agradezco también vuestro interés y lo tengo muy presente.

Por último, quisiera agradecer profundamente la comprensión, el apoyo y la confianza permanente de mis padres, mi hermano y mi abuelo. Gracias por alegraros y preocuparos conmigo y por acompañarme siempre. 
Índice 



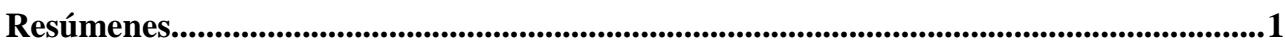

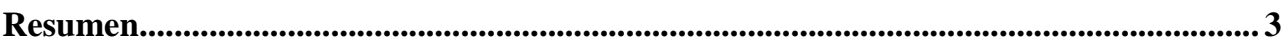

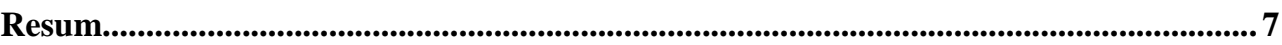

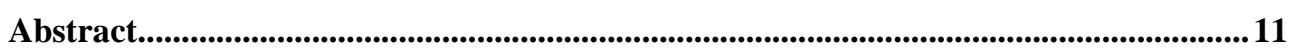

Abreviaturas............................................................................................................................... 15

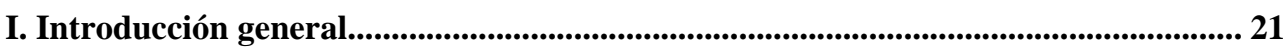

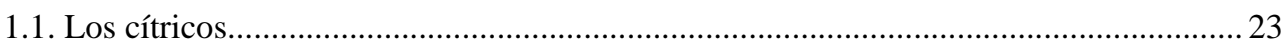

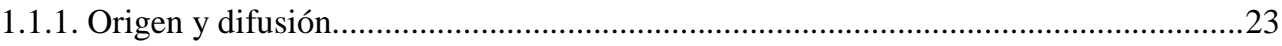

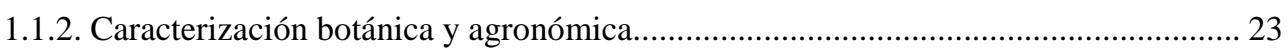

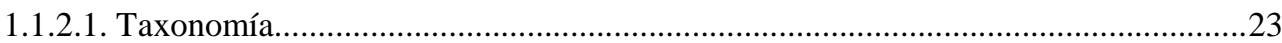

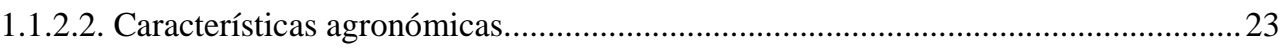

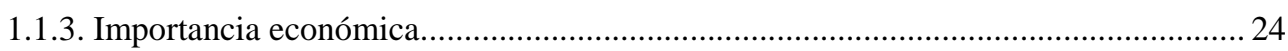

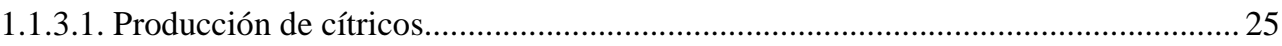

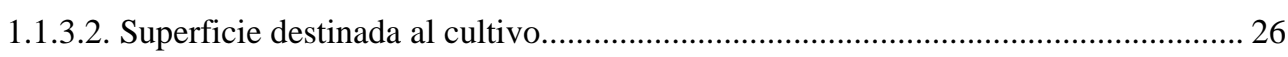

1.2. La abscisión es un proceso de separación celular......................................................... 26

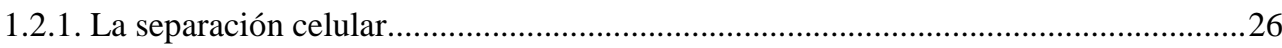

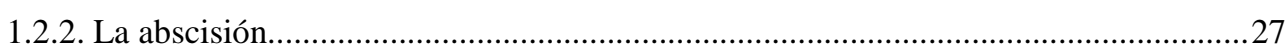

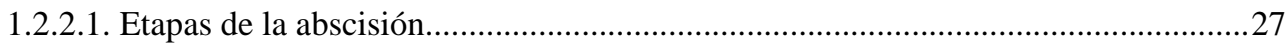

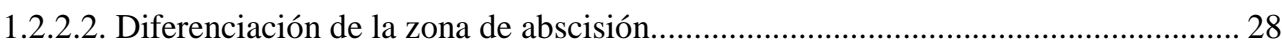

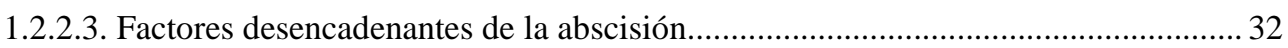

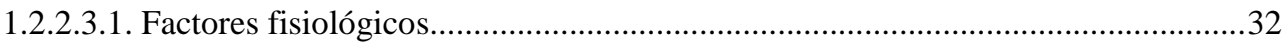

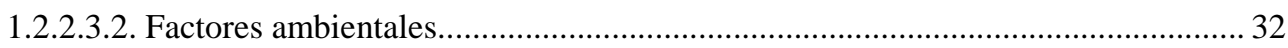

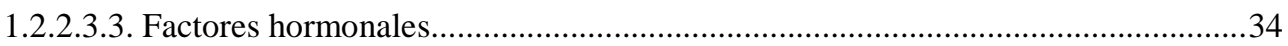

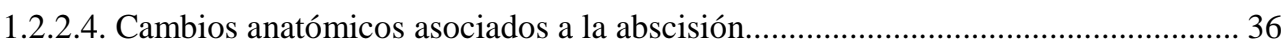

1.2.2.5. Cambios bioquímicos y moleculares asociados a la abscisión.................................. 37

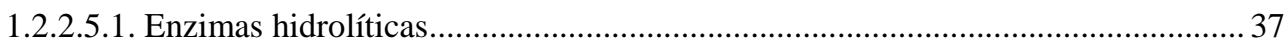

1.2.2.5.2. Enzimas relacionadas con la defensa frente a patógenos........................................39

1.2.2.5.3. Otras enzimas implicadas en el proceso de abscisión............................................. 40

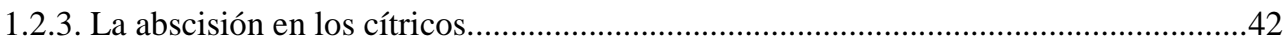

1.2.3.1. Zonas de abscisión en hojas y frutos de cítricos....................................................... 44

1.2.3.2. Control hormonal de la abscisión en los cítricos......................................................

1.2.3.3. Cambios en la expresión génica y en la actividad enzimática durante la abscisión en

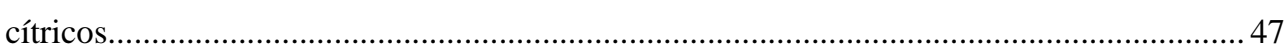

1.2.3.4. Estudio de la abscisión en cítricos: finalidad y perspectivas......................................48 
III. Análisis de la expresión génica en la zona de abscisión $\mathrm{C}$ de frutos cítricos durante la abscisión inducida por etileno................................................................................5

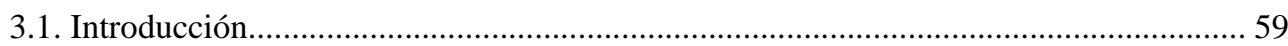

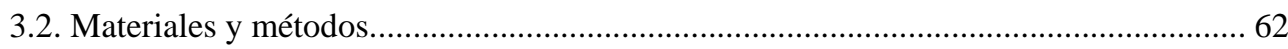

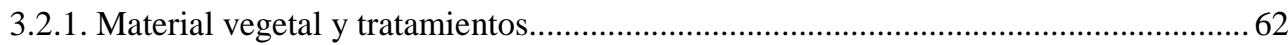

3.2.1.1. Tratamiento in vitro con etileno a frutos de la variedad 'Washington

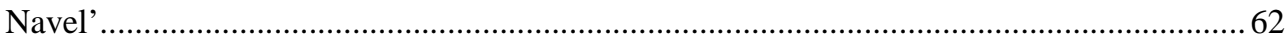

3.2.1.2. Tratamiento in vitro con ácido 1-aminociclopropano-1-carboxílico (ACC) a frutos

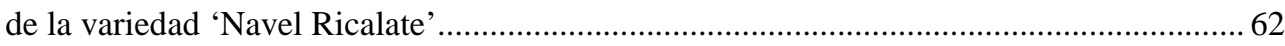

3.2.2. Determinación de la fuerza de retención de los frutos................................................ 63

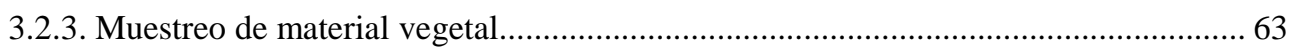

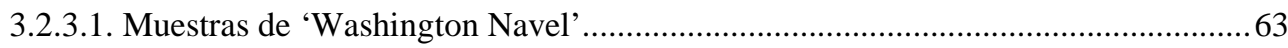

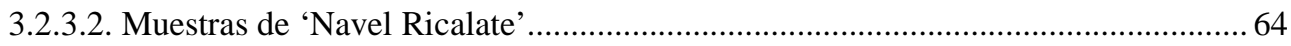

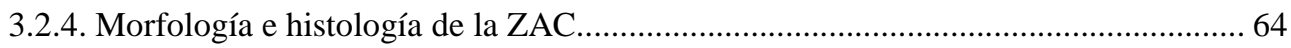

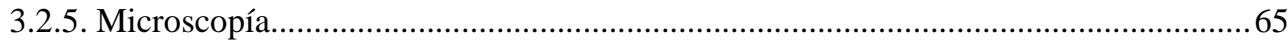

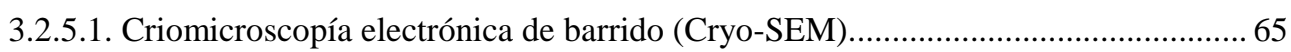

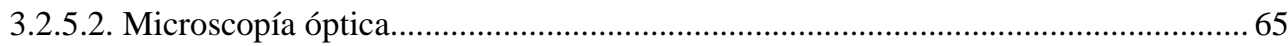

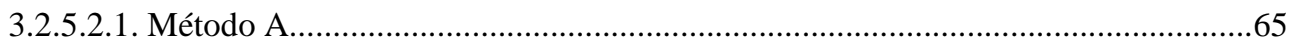

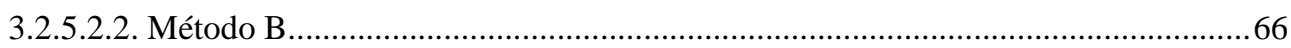

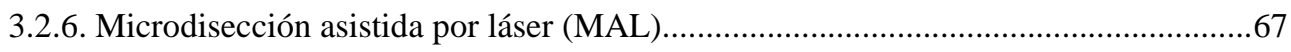

3.2.6.1. Crioinclusión del material vegetal y montaje de los portaobjetos...........................67

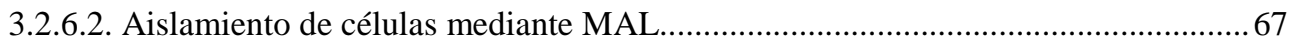

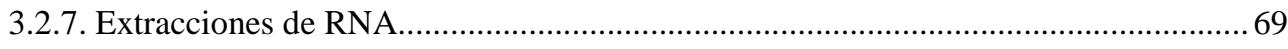

3.2.7.1. Extracción de RNA de las muestras que componen la referencia...........................69

3.2.7.2. Microextracción de RNA a partir de muestras obtenidas mediante microdisección

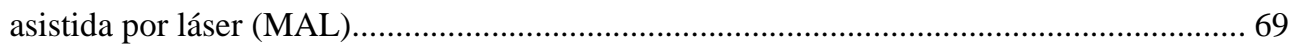

3.2.8. Análisis de expresión génica mediante la hibridación de micromatrices de cDNA de

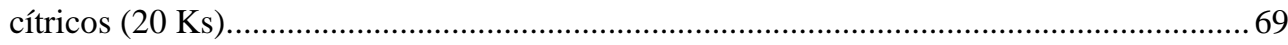

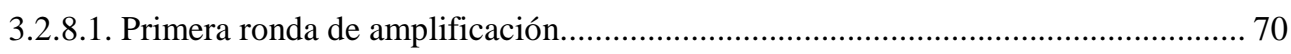

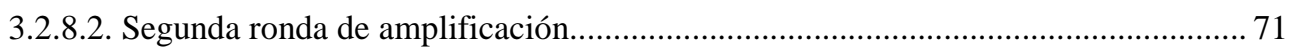

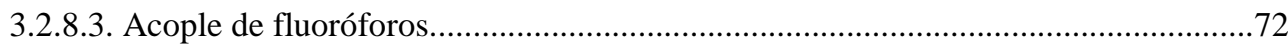

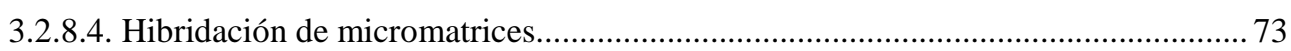

3.2.8.4.1. Preparación de las micromatrices (prehibridación)...............................................73 


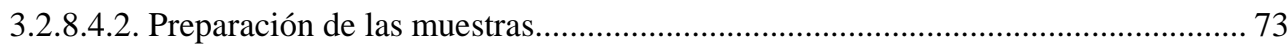

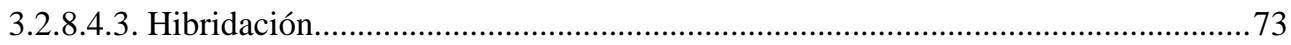

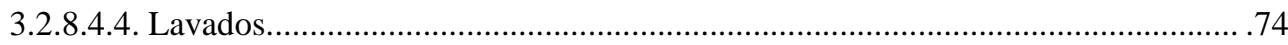

3.2.8.5. Escaneado de las micromatrices y adquisición de datos.......................................... 74

3.2.9. Normalización, control de calidad y análisis de las micromatrices............................. 75

3.2.10. Agrupación en 'clusters' de los unigenes regulados por etileno en la ZAC...

3.2.11. Asignación de categorías funcionales a los unigenes regulados

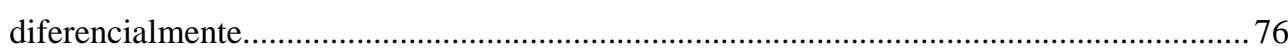

3.2.12. Análisis de metabolitos mediante HPLC acoplada a espectrometría de masas en

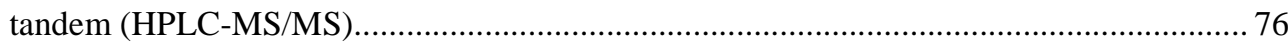

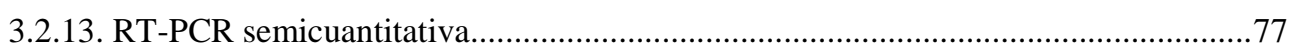

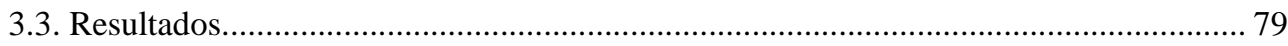

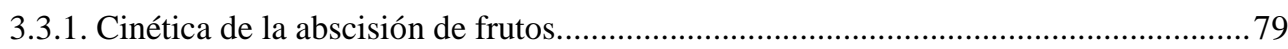

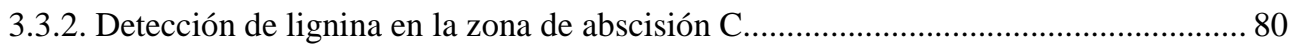

3.3.3. Caracterización morfológica de la zona de abscisión $\mathrm{C}$ de los frutos......................... 81

3.3.3.1. Caracterización morfológica de la ZAC mediante microscopía electrónica de

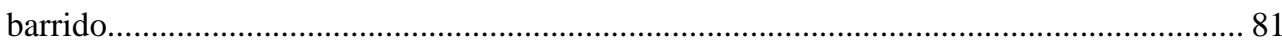

3.3.3.2. Caracterización anatómica de la ZAC mediante microscopía óptica........................83

3.3.4. Expresión génica regulada por etileno en la zona de abscisión $\mathrm{C}$ y en la corteza del

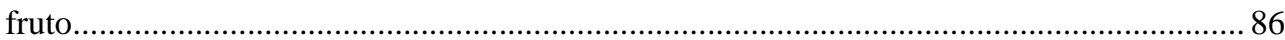

3.3.5. Perfiles de expresión de los genes regulados por etileno en la zona de abscisión C........

3.3.6. Clasificación funcional de los unigenes regulados por etileno en la zona de abscisión $\mathrm{C}$ y en la corteza del fruto. 88

3.3.7. Clasificación funcional de los unigenes regulados por etileno exclusivamente en la zona de abscisión C.......................................................................................................... 90

3.3.8. Validación del análisis de expresión mediante micromatrices por RT-PCR

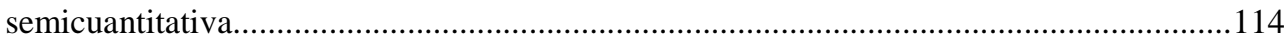

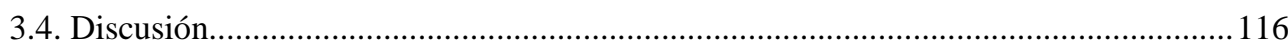

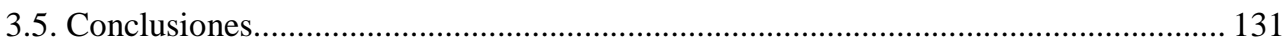

IV. Identificación de genes relacionados con el tráfico intracelular de vesículas en la zona de abscisión C......................................................................................................... 133

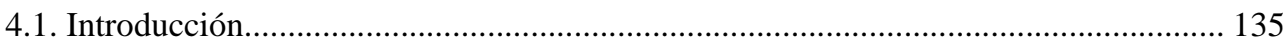


4.2.1. Material vegetal y tratamientos.

4.2.2. Clasificación y análisis de perfiles de expresión de genes relacionados con el transporte intracelular de vesículas.

4.3. Resultados 139

4.3.1. Estudio de los perfiles de expresión de genes relacionados con el tráfico intracelular de vesículas en la ZAC y en la CF.

4.3.1.1. Proteínas implicadas en la formación de vesículas en los orgánulos donadores. 139

4.3.1.2. Proteínas implicadas en la fusión de membranas 142

4.3.1.3. Otras proteínas implicadas en el tráfico intracelular de vesículas 145

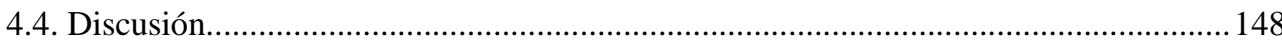

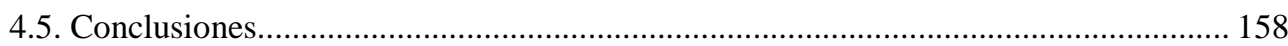

V. Identificación de genes relacionados con la remodelación de la pared celular durante la abscisión de frutos cítricos...................................................................159

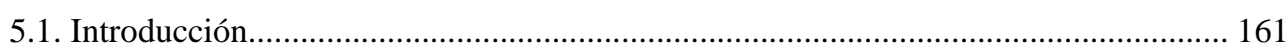

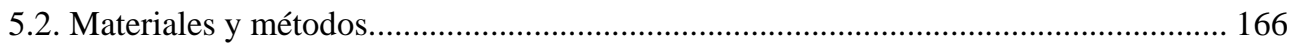

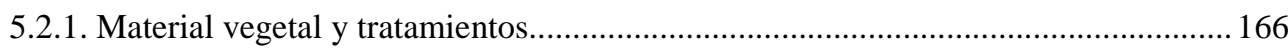

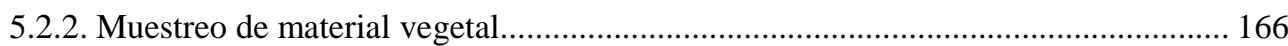

5.2.3. Análisis filogenético y estudio de la estructura proteica de familias génicas relacionadas con la modificación de la pared celular......................................................... 166

5.2.4. Análisis de expresión génica según la frecuencia de ESTs.....................................167

5.2.5. Aislamiento y análisis de promotores................................................................ 168

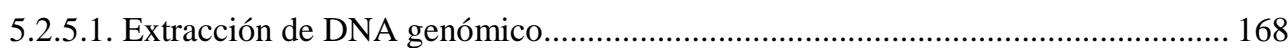

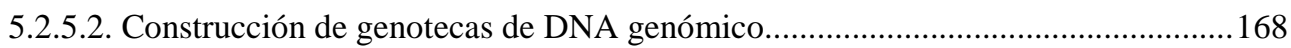

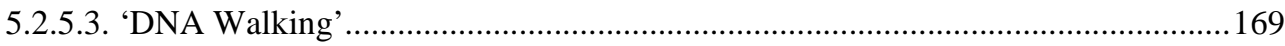

5.2.5.4. Ligación de productos de PCR, clonación en Escherichia coli y purificación de

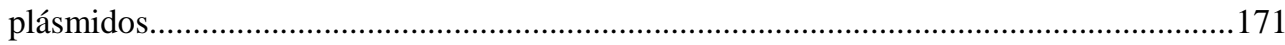

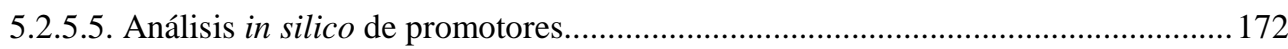

5.2.6. Análisis de la composición de monosacáridos de las paredes celulares de la ZAC

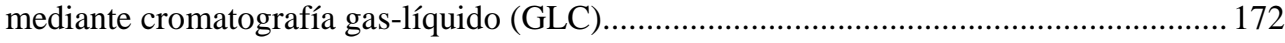

5.2.7. Inmunolocalización de polímeros pécticos en la ZAC .............................................173

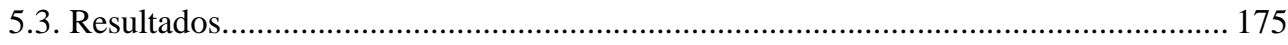


5.3.1. Análisis filogenético y estudio de la estructura proteica de familias de proteínas relacionadas con la modificación de la pared celular.

5.3.1.1. Endo- $\beta$ - $(1 \rightarrow 4)$-glucanasas o Celulasas (EGasas o CELs; familia GH9 de glicósido hidrolasas).....

5.3.1.2. Poligalacturonasas (PGs; familia GH28 de glicósido hidrolasas). 179

5.3.1.3. $\beta$-xilosidasas ( $\beta$-XYLs; familia 3 de glicósido hidrolasas), $\alpha$-xilosidasas ( $\alpha$-XYLs; familia 31 de glicósido hidrolasas) y $\alpha$-L-arabinofuranosidasas (ASDs; familia 51 de glicósido hidrolasas).

5.3.1.4. Xiloglucano transglicosilasas/hidrolasas (XTHs; familia 16 de glicósido hidrolasas). 188

5.3.1.5. $\quad \beta$-galactosidasas ( $\beta$-GALs; familias 2 y 35 de glicósido hidrolasas)

192

5.3.1.6. Pectin metilesterasas (PMEs; familia 8 de carbohidrato

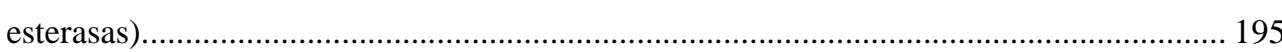

5.3.1.7. Pectin acetilesterasas (PAEs; familia 13 de carbohidrato

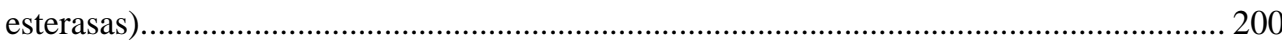

5.3.1.8. Pectato liasas (PLs; familia 1 de polisacárido liasas)...............................................202

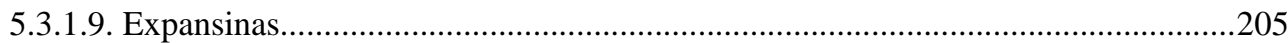

5.3.2. Detección de expresión génica diferencial en zonas de abscisión según la frecuencia de ESTs.

209

5.3.3. Aislamiento y análisis in silico de los promotores de posibles genes específicos del proceso de abscisión

210

5.3.4. Composición de monosacáridos de las paredes celulares de la ZAC durante la abscisión inducida por etileno. 212

5.3.5. Inmunolocalización de $(1 \rightarrow 4)-\beta$-D-galactano, $(1 \rightarrow 5)-\alpha$-L-arabinano $y$ homogalacturonano en la ZAC inducida por ACC...................................................... 213

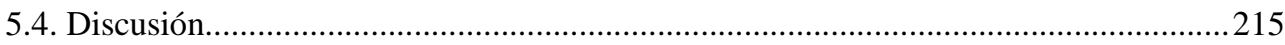

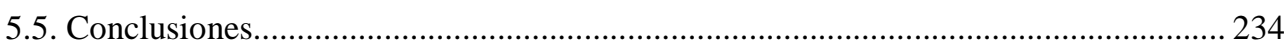

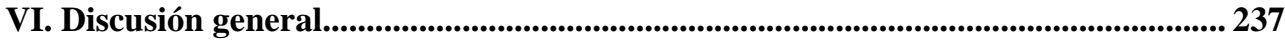

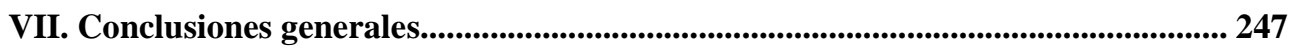

VIII. Referencias bibliográficas..................................................................................... 253

IX. Anexos (Ver CD) 

Resúmenes 


\section{RESUMEN}

El cultivo de los cítricos representa la mayor producción de frutos en el mundo, superando los 100 millones de toneladas en el año 2008 (www.fao.org). España se sitúa entre los principales países productores a nivel mundial y es el mayor exportador de cítricos para consumo en fresco. La citricultura constituye, por tanto, una importante fuente de riqueza para el sector agroalimentario mundial y nacional. La producción final depende de los factores fisiológicos inherentes al propio desarrollo del fruto así como de su capacidad para sobrellevar las condiciones ambientales adversas y permanecer en la planta, superando así la abscisión. El conocimiento actual sobre el proceso de abscisión a nivel molecular es limitado si se compara con el volumen de datos asociados a otros procesos físiológicos. Con el propósito de ampliar dicho conocimiento, en el presente trabajo se ha llevado a cabo un análisis global de los cambios que se producen a nivel anatómico, transcriptómico y bioquímico durante el desarrollo del proceso de abscisión de los frutos cítricos.

La primera aproximación consistió en la caracterización anatómica de la zona de abscisión C del fruto (ZAC) durante la activación del proceso. Para ello, se estableció una cinética de abscisión de frutos en dos variedades de naranjo dulce [Citrus sinensis (L.) Osb. cv. 'Washington Navel' y cv. 'Navel Ricalate'] bajo tratamientos in vitro con etileno y ácido 1-aminociclopropano-1-carboxílico. En base a estas cinéticas, se determinó la serie temporal de muestras a estudiar mediante diferentes técnicas de microscopía e histoquímica. El estudio anatómico de la ZAC permitió delimitar los cambios específicos que se producen a nivel celular durante la activación del proceso de abscisión en frutos y determinar con exactitud el número y las características de las capas celulares que conforman la ZAC, hecho que facilitó el posterior aislamiento de muestras específicas de este tejido.

El análisis de los cambios que se producen a nivel transcriptómico durante el proceso de abscisión se llevó a cabo utilizando la micromatriz de cDNA del Proyecto Español de Genómica Funcional de Cítricos (CFGP; Martínez-Godoy et al., 2008), que contiene 21.081 unigenes. Sobre esta micromatriz se hibridaron muestras aisladas mediante microdisección asistida por láser de la ZAC y de la corteza del fruto $(\mathrm{CF})$. La serie temporal de muestras a hibridar se estableció a partir de la cinética de abscisión de frutos tratados con etileno. La comparación de la expresión génica asociada a cada tejido a lo largo del 
tratamiento con etileno permitió identificar genes o grupos de genes con una función reguladora potencial del proceso de abscisión.

Los resultados de expresión sugieren una actuación secuencial de la maquinaria celular durante el desarrollo de la abscisión. La ZAC activa rutas de señalización mediadas por hormonas y especies reactivas del oxígeno (ROS), hecho que queda reflejado en la activación de factores de transcripción de respuesta a hormonas, proteínas implicadas en la biosíntesis de hormonas y proteínas de destoxificación de ROS. Por otra parte, se inducen genes que codifican quinasas y proteínas de tipo receptor, que serían responsables de la transducción de las señales activadoras de la abscisión. Además, se produce un recambio de proteínas (síntesis y degradación) para poder afrontar el nuevo metabolismo y actividad de las células de la ZAC. Asimismo, se activa el control de la transcripción mediante la inducción de factores de transcripción pertenecientes a diferentes familias génicas (MADSbox, bHLH o MYB). Por otra parte, la inducción de genes relacionados con el tráfico intracelular de vesículas estaría asociada a la redistribución de proteínas en la ZAC. Finalmente, se activa la maquinaria de remodelación de la pared celular, que permitirá la separación efectiva del órgano, y rutas de defensa frente a patógenos como medida preventiva. Paralelamente, los resultados de expresión referentes a la síntesis de lignina y cutina sugieren que estos polímeros se sintetizan y depositan en la ZAC. Estos últimos datos fueron confirmados, además, mediante tinciones específicas de la ZAC y a través de la cuantificación de intermediarios de su ruta de biosíntesis en células de la ZAC.

El estudio en profundidad de los perfiles de expresión de genes relacionados con la síntesis y el transporte de vesículas en la ZAC y en la CF permitió determinar su posible función en el proceso de abscisión. Además, este análisis reveló que las células de la ZAC promueven, mayoritariamente, la ruta secretora y reducen la actividad de las vías de tráfico endocítico, vacuolar y de reciclaje. Este transporte estaría relacionado con el aporte extracelular de las enzimas de modificación de pared necesarias para la separación celular y de los monómeros de lignina y cutina necesarios para facilitar la rotura mecánica de la ZAC y permitir el sellado de la herida tras la abscisión.

Un análisis más exhaustivo de las familias génicas relacionadas con la modificación de la pared celular permitió establecer, dentro del elevado número de proteínas que normalmente conforman estas familias, aquellas enzimas que podrían actuar de manera 
específica en el proceso de abscisión. Para ello, además del análisis de los perfiles de expresión de estos genes en la ZAC y en la CF, se realizó un estudio filogenético con las posibles proteínas relacionadas con la remodelación de la pared celular localizadas en la versión v0.9 del ensamblaje del genoma haploide de Citrus clementina, las reguladas por etileno en las células de la ZAC y/o de la CF y las descritas en la literatura como asociadas a la abscisión en otras especies vegetales. Por otra parte, se ha analizado in silico la expresión diferencial de los genes de cítricos pertenecientes a este tipo de familias en diferentes ZAs así como la región promotora de algunas proteínas relacionadas con la modificación de la pared potencialmente implicadas en la abscisión de frutos cítricos. Además, este estudio se complementó con el análisis mediante cromatografía gas-líquido de la composición de monosacáridos de las paredes celulares de la ZAC y mediante la inmunolocalización de polisacáridos pécticos en las paredes de la ZAC durante el desarrollo del proceso de abscisión. Los resultados indicaron que los cambios en la organización de los polisacáridos de la pared celular son suficientes para reducir la adhesión entre las células de la ZAC y permitir la separación efectiva del fruto. Además, los datos de inmunolocalización correlacionaban con los datos de expresión de genes que codifican enzimas que actúan sobre los polisacáridos pécticos estudiados (pectin metilesterasas, pectin acetilesterasas, poligalacturonasas, pectato liasas, $\beta$-galactosidasas y $\beta$-xilosidasas). 


\section{RESUM}

El cultiu del cítrics representa la major producció de fruits en el món, superant els 100 milions de tones en l'any 2008 (www.fao.org). Espanya es situa entre els principals països productors a nivell mundial i és el major exportador de cítrics per a consum en fresc. La citricultura consitueix, per tant, una important font de riquesa per al sector agroalimentari mundial i nacional. La producció final depén dels factors fisiològics inherents al desenvolupament del fruit així com de la capacitat per a suportar les condicions ambientals adverses i persistir en la planta, superant l'abscissió. El coneixement actual sobre el procés d'abscissió a nivell molecular és limitat si es compara amb el volum de dades associades a altres processos fisilògics. Amb el propòsit d'ampliar aquest coneixement, en el present treball s'ha realitzat un anàlisi global del canvis que es produeixen a nivell anatòmic, transcriptòmic i bioquímic durant el desenvolupament del procés d'abscissió dels fruits cítrics.

La primera aproximació va consistir en la caracterització anatòmica de la zona d'abscissió C del fruit (ZAC) durant l'activació del procés. En primer lloc, es va establir una cinètica d'abscissió de fruits en dos varietats de taronger dolç [Citrus sinensis (L.) Osb. cv. 'Washington Navel' i cv. 'Navel Ricalate'] davall tractaments in vitro amb etilé i àcid 1-aminociclopropà-1-carboxílic. A partir d'aquestes cinètiques, es va determinar la sèrie temporal de mostres a estudiar amb diferents tècniques de microscopia i histoquímica. L'estudi anatòmic de la ZAC va permetre delimitar els canvis específics que es produeixen a nivell cel-lular durant l'activació del procés d'abscissió en fruits i determinar amb exactitud el número i les característiques de les capes cel-lulars que conformen la ZAC, fet que va facilitar el posterior aillament de mostres específiques d'aquest teixit.

L'anàlisi dels canvis que es produeixen a nivell transcriptòmic durant el procés d'abscissió es va realitzar utilizant la micromatriu de cDNA del Projecte Espanyol de Genòmica Funcional de Cítrics (CFGP; Martínez-Godoy et al., 2008), que conté 21.081 unigens. Sobre aquesta micromatriu es van hibridar mostres aïllades mitjançant microdissecció assistida per láser de la ZAC i de la corfa del fruit (CF). La sèrie temporal de mostres a hibridar es va establir a partir de la cinètica d'abscissió de fruits tractats amb etilé. La comparació de l'expressió gènica associada a cada teixit durant el tractament amb 
etilé va permetre identificar gens o grups de gens amb una funció reguladora potencial del procés d'abscissió.

Els resultats d'expressió suggereixen una actuació seqüencial de la maquinària cel-lular durant el desenvolupament de l'abscissió. La ZAC activa rutes de senyalització per hormones i espècies reactives de l'oxigen (ROS), fet que es reflectix en l'activació de factors de transcripció de resposta a hormones, proteïnes implicades en la biosíntesi de hormones i proteïnes de destoxificació de ROS. Per altra banda, s'indueixen gens que codifiquen quinases i proteïnes de tipus receptor, que serien responsables de la transducció de les senyals activadores de l'abscissió. A més, es produeix un recanvi de proteïnes (síntesi i degradació) per a poder afrontar el nou metabolisme i activitat de les cèl·lules de la ZAC. Així mateix, s'activa el control de la transcripció mitjançant l'inducció de factors de transcripció que pertanyen a diferents famílies gèniques (MADS-box, bHLH o MYB). L'inducció de gens relacionats amb el tràfic intracel·lular de vesícules estaria associada a la redistribució de proteïnes en la ZAC. Finalment, s’activa la maquinaria de remodelació de la paret cel-lular, que permetrà la separació efectiva de l'òrgan, i rutes de defensa contra patògens com a mesura preventiva. Paral-lelament, els resultats d'expressió referents a la síntesi de lignina i cutina suggereixen que aquests polímers es sintetitzen i depositen en la ZAC. Aquestes últimes dades foren confirmades, a més, mitjançant tincions específiques de la ZAC i amb la cuantificació d'intermediaris de la seua ruta de biosíntesi en cèl-lules de la ZAC.

L'estudi en profunditat dels perfils d'expressió de gens relacionats amb la síntesi i el transport de vesícules en la ZAC i en la CF va permetre determinar la seua possible funció en el procés d'abscissió. A més, aquest anàlisi revelà que les cèl·lules de la ZAC promouen, majoritàriament, la ruta secretora i reduixen l'activitat de les vies de tràfic endocític, vacuolar i de reciclatge. Aquest transport estaria relacionat amb l'aporte extracel-lular dels enzims de modificació de paret necessaris per a la separació cel·lular i dels monòmers de lignina i cutina necessaris per a facilitar el trencament mecànic de la ZAC i permetre el segellament de la ferida després de l'abscissió.

Un análisi més exhaustiu de les famílies gèniques relacionades amb la modificació de la paret cel·lular va permetre establir, dins de l'elevat número de proteïnes que normalment conformen aquestes famílies, aquells enzims que podrien actuar de manera específica en el 
procés d'abscissió. Per a aconseguir això, a més de l'anàlisi d'expressió d'aquests gens en la ZAC i en la CF, es va realitzar un estudi filogenètic amb les possibles proteïnes relacionades amb la remodelació de la paret cel-lular localitzades en la versió v0.9 de l'engalzament del genoma haploide de Citrus clementina, les regulades per l'etilé en les cèl-lules de la ZAC i/o de la CF i les descrites en la literatura com associades a l'abscissió en altres espècies vegetals. Per altra banda, s'ha analitzat in silico l'expressió diferencial dels gens de cítrics pertanyents a aquest tipus de famílies en diferents ZAs així com la regió promotora d'algunes proteïnes relacionades amb la modificació de la paret potencialment implicades en l'abscissió de fruits cítrics. A més, aquest estudi es va complementar amb l'anàlisi amb cromatografia gas-líquid (GLC) de la composició de monosacàrids de les parets cel-lulars de la ZAC i mitjançant l'inmunolocalització de polisacarids pèctics en les parets de la ZAC durant el desenvolupament del procés d'abscissió. Els resultats indicaren que els canvis en l'organització dels polisacàrids són suficients per a reduir l'adhesió entre les cèl-lules de la ZAC i permetre la separació efectiva del fruit. A més, les dades d'inmunolocalització correlacionaven amb les dades d'expressió de gens que codifiquen enzims que actuen sobre els polisacarids pèctics estudiats (pectin metilesterases, pectin acetilesterases, poligalacturonases, pectat liases, $\beta$-galactosidases i $\beta$-xilosidases). 


\section{ABSTRACT}

Citrus crop represents the highest fruit production in the world. The production in 2008 was more than 100 million tones (www.fao.org). Spain is one of the main producer countries in the world and the principal exporting country of citrus fruits for fresh consumption. Therefore, citrus crop constitutes an important source of wealth for the worldwide and national agricultural sector. The final production depends on physiological factors inherent to fruit development and its ability to resist adverse environmental conditions and remain attached to the main body of the plant, overcoming the abscission. The current knowledge of abscission at the molecular level is limited if it is compared with the large volume of data related to other physiological processes. In order to extend this knowledge, this work focuses on the global analysis of the anatomical, transcriptomic and biochemical changes during citrus fruit abscission.

The first approach carried out was the anatomical characterization of the fruit abscission zone $\mathrm{C}$ (AZ-C) during the activation of the process. For this purpose, abscission kinetics was established in two varieties of sweet orange [Citrus sinensis (L.) Osb. cv. 'Washington Navel' and cv. 'Navel Ricalate'] under in vitro ethylene and 1aminocyclopropane-1-carboxylic acid treatments. Based on abscission kinetics a temporal sequence of samples was determined to study the abscission zone anatomy using different microscopy and histochemical techniques. The anatomical study of the AZ-C allowed to define the specific changes that occur during the activation of the fruit abscission at the cellular level and determine exactly the number of cell layers that constitute the AZ-C. This fact made possible to isolate specific cells from this tissue for further work.

The analysis of the transcriptomic changes brought about during abscission was achieved using the Spanish Citrus Functional Genomics Project (CFGP) cDNA microarray (Martínez-Godoy et al., 2008) that contains 21.081 unigenes. The microarray was hybridized with samples from the AZ-C and fruit rind that were isolated using laser capture microdissection. The temporal sequence of samples was determined after the establishment of the abscission kinetics of ethylene-treated fruits. By comparing the associated gene expression for each tissue during the ethylene treatment, genes or groups of genes with a potential role in the abscission process were determined. 
The results of the expression analysis suggest a sequential action of the cellular machinery during the development of the abscission process. The AZ-C induces hormone and reactive oxygen species (ROS) mediated signaling pathways, a fact reflected in the activation of hormone response transcription factors and proteins involved in hormone synthesis and ROS detoxification. On the other hand, genes encoding kinases and receptorlike proteins are induced in the AZ-C. These proteins would be responsible of the transduction of abscission signals. Moreover, there is a protein turnover (synthesis and degradation) in response to the new metabolism and activity of the AZ-C cells. At the same time, the AZ-C activates transcription regulation by inducing transcription factors of different gene families (MADS-box, bHLH or MYB). On the other hand, the up-regulation of genes related to intracellular trafficking of vesicles would be associated with the redistribution of proteins in the AZ-C. Finally, the AZ-C activates the machinery of cell wall remodeling, which will enable the effective separation of the organ, and defense pathways against pathogens as prevention. In parallel, the expression results concerning the synthesis of lignin and cutin suggest that these polymers are synthesized and deposited in the AZ-C. These data were confirmed also by specific staining of the AZ-C and through the quantification of intermediates of the biosynthesis pathway in the AZ-C cells.

The expression profile analysis in the AZ-C and the fruit rind of genes associated with the traffic of vesicles allowed to determine their putative function in the abscission process. This study revealed that AZ-C cells promote mainly the secretory pathway and reduce the activity of endocytic, vacuolar and recycling pathways. This traffic would be related to the extracellular contribution of cell wall modifying enzymes, that lead to cell separation during abscission, and lignin and cutin monomers that facilitate the mechanical breakdown of the AZ-C and seal the wound produced after abscission.

An exhaustive analysis of the gene families related to cell wall modification allowed to identify, within the large number of proteins that normally constitute these families, those enzymes that could act specifically in the abscission process. For this purpose, a phylogenetic study was carried out. This analysis included the putative cell wall modifying enzymes identified in the version v0.9 of the assembly of the Citrus clementina haploid genome, ethylene-regulated proteins in AZ-C and fruit rind cells and abscission-related proteins from other plant species. On the other hand, an in silico differential gene expression analysis of the citrus genes from these families in different AZs as well as a 
promoter sequence analysis of some cell wall-related proteins involved in citrus fruit abscission was carried out. Moreover, this study was supplemented with an analysis of monosaccharide composition of the AZ-C cell walls using gas-liquid chromatography and with the immunolocalization of pectic polysaccharides of the AZ-C cell walls during the development of the abscission process. The results of this part of the work showed that changes in the organization of the cell wall polysaccharides are sufficient to reduce adhesion between cells and allow the effective separation of the fruit AZ-C. In addition, immunolocalization data correlated with the expression data of genes encoding enzymes that act on the pectic polysaccharides studied (pectin methylesterases, pectin acetylesterases, polygalacturonases, pectate lyases, $\beta$-galactosidases and $\beta$-xylosidases). 
ABREVIATURAS

1-MCP

4CL

AA-aRNA

ABA

$\mathrm{ABI} 3$

ACC

$\mathrm{ACO}$

ACS

ADPG1/2

AGL3/15

AGP

ALC

$\mathrm{Amp}^{\mathrm{R}}$

AP

AP1/2

Ara

Arf

ARF

Arf-GAP

Arf-GEFs

ASD

AtZFP2

Aux/IAA

bHLH

BLAST

BSA

bZIP

c.s.p

CAZy

CBM49 1-metilciclopropeno

4-cumarato-Coenzima A ligasa

aminoalil-RNA amplificado

ácido abscísico

ABSCISIC ACID-INSENSITIVE3

ácido 1-aminociclopropano-1-carboxílico

ACC-oxidasa

ACC-sintasa

ARABIDOPSIS DEHISCENCE ZONE

POLYGALACTURONASE1/2

AGAMOUS-LIKE3/15

arabinogalactan-protein

ALCATRAZ

resitencia a ampicilina

proteína adaptadora de clatrina

adaptor primer $1 / 2$

arabinosa

ADP-ribosylation factor

auxin response factor

ADP-ribosylation factor GTPase activating protein

ADP-ribosylation factor GTP-exchange factors

$\alpha$-L-arabinofuranosidasa

ZINC FINGER PROTEIN2

auxin/indole-3-acetic cid

basic helix-loop-helix

Basic Local Alignment Sequence Tool

seroalbúmina bovina

basic leucine zipper

cantidad suficiente para

Carbohydrate-Active Enzymes database

carbohydrate binding module 49 


$\begin{array}{ll}\text { CCR } & \text { cinamoil-Coenzima A reductasa } \\ \text { cDNA } & \text { DNA complementario } \\ \text { CDS } & \text { coding sequence } \\ \text { CE } & \text { carbohidrato esterasa } \\ \text { CEL } & \text { celulasa } \\ \text { CF } & \text { corteza del fruto } \\ \text { CFGP } & \text { Citrus Functional Genomics Project } \\ \text { CitCEL } & \text { Citrus celulase } \\ \text { CitPG } & \text { Citrus polygalacturonase } \\ \text { CMNP } & \text { 5-cloro-3-metil-4-nitro-1H-pirazol } \\ \text { COMT } & \text { O-metiltransferasas del ácido cafeico } \\ \text { COP } & \text { coat protein complex } \\ \text { CPV } & \text { compartimento prevacuolar } \\ \text { cRNA } & \text { RNA complementario } \\ \text { CsPLD } 1 / \text { CsPDL } \gamma 1 & \text { fosfolipasa } \\ \text { Cy } & \text { cianina } \\ \text { d/n } & \text { durante la noche } \\ \text { dab } & \text { delayed floral organ abscission } \\ \text { dATP } & \text { 2'-desoxiadenosina 5'-trifosfato } \\ \text { dCTP } & \text { 2'-desoxicitosina 5'-trifosfato } \\ \text { DEPC } & \text { dietil pirocarbonato } \\ \text { dGTP } & \text { 2'-desoxiguanosina 5'-trifosfato } \\ \text { DNA } & \text { ácido desoxi-ribonucleico } \\ \text { dNTPs } & \text { desoxinucleótidos trifosfato } \\ \text { DOF } & \text { DNA binding with one finger } \\ \text { DTT } & \text { 1,4-ditio-DL-treitol } \\ \text { dTTP } & \text { et'-desoxitimina 5'-trifosfato } \\ \text { EDTA } & \text { etilen-diamino-tetraacetato } \\ \text { EG } & \text { endo- } \beta \text {-(1 } \rightarrow 4 \text {-'glucanasa } \\ \text { ERF } & \text { ethylene response factor } \\ \text { ESCRT } & \text { endosomal sorting complexes required for transport } \\ \text { EST } & \\ \text { ETR1 } & \end{array}$




\begin{tabular}{|c|c|}
\hline EVR & EVERSHED \\
\hline EXP & expansina \\
\hline FIL & FILAMENTOUS FLOWER \\
\hline FR & fuerza de retención \\
\hline FUL & FRUITFULL \\
\hline Gal & galactosa \\
\hline GAL & GenePix Array List \\
\hline GalUA & ácido galacturónico \\
\hline GFP & green fluorescent protein \\
\hline $\mathrm{GH}$ & glicósido hidrolasa \\
\hline GLC & cromatografía gas-líquido \\
\hline Glc & glucosa \\
\hline GSP1/2 & gene-specific primer $1 / 2$ \\
\hline GTPasa & guanosina trifosfatasa \\
\hline GUS & $\beta$-glucuronidasa \\
\hline HAE & HAESA \\
\hline HD-Zip & homeobox leucine zipper \\
\hline HGA & homogalacturonano \\
\hline HMG-IY & high mobility group protein isoform I and Y \\
\hline \multirow[t]{2}{*}{ HPLC-MS/MS } & High-Pressure Liquid Chromatography tandem Mass \\
\hline & Spectrometry \\
\hline HY5 & LONG HYPOCOTYL 5 \\
\hline IAA & ácido indol-acético \\
\hline $\mathrm{IAAd}_{2}$ & ácido indolacético deuterado \\
\hline ICGC & International Citrus Genome Consortium \\
\hline IDA & INFLORESCENCE DEFICIENT IN ABSCISSION \\
\hline IND & INDEHISCENT \\
\hline JA & ácido jasmónico \\
\hline $\operatorname{kgf}$ & kilogramo-fuerza \\
\hline LB & triptona $1 \%$, extracto de levadura $0.5 \%, \mathrm{NaCl} 1 \%$ \\
\hline LIMMA & Linear Models in Microarrays \\
\hline LRR-RLK & proteína quinasa de tipo receptor con repeticiones ricas \\
\hline
\end{tabular}


Ls

$\mathrm{mAb}$

MADS box

MAL

Man

MAP

$\mathrm{Mb}$

MEC

MIPS

MKK

MP

mRNA

NAC

NBS-LRR

NCBI

NEV

NR

ORF

PAE

PAL

PAP

PAS

PBS

PC

PCR

PG

PGAZAT

PGAZBRAN

PL

PME

PR
Lateral supresor

anticuerpo monoclonal

MCM1- AGAMOUS- DEFICIENS-SRF box

microdisección asistida por láser

manosa

mitogen-activated protein

Megabase

matriz extracelular

Munich Information Center for Protein Sequences

mitogen-activated protein kinase kinase

membrana plasmática

RNA mensajero

NAM-ATAF-CUC

nucleotide-binding site leucine-rich repeat protein

National Center for Biotechnology Information

\section{NEVERSHED}

Never-ripe

open reading frame

pectin acetilesterasa

fenilalanina amonio-liasa

purple acid phosphatase

ácido periódico y reactivo de Schiff

$\mathrm{Na}_{3} \mathrm{PO}_{4} 50$ mM, ph 7.0; $\mathrm{NaCl} 150 \mathrm{mM}$

pared celular

polymerase chain reaction

poligalacturonasa

POLYGALACTURONASE ABSCISSION ZONE

ARABIDOPSIS THALIANA

POLYGALACTURONASE ABSCISSION ZONE

BRASSICA NAPUS

pectato liasa

pectin metilesterasa

pathogen-related protein 
PSORT

QRT2

$\mathrm{Rab}$

RE

RG

Rha

RNA

ROS

RPL

RT-PCR

$\mathrm{SAd}_{4}$

SCAMP

SDS

SHP

SKS

SMART

SNARE

SPT

SQUA

SSC

TAIR

TAPG1/2/4

TCP

T-DNA

TE

TGN

TIBA

Tris

UBC

VIGS

VP1
Prediction of Protein Sorting Signals and Localization Sites in Amino Acid sequences

QUARTET2

Ras-related GTP-binding protein

retículo endoplasmático

ramnogalacturonano

ramnosa

ácido ribonucleico

especies reactivas del oxígeno

REPLUMLESS

reverse transcription polymerase chain reaction

ácido salicílico deuterado

secretory carrier membrane proteins

sodio dodecil sulfato

SHATTERPROOF

multicopper oxidase

Single Modular Architecture Research Tool

soluble N-ethylmaleimide-sensitive factor activating protein receptor

SPATULA

SQUAMOSA

$\mathrm{Na}_{3}$ Citrato $0.15 \mathrm{M} \mathrm{pH} 7, \mathrm{NaCl} 1.5 \mathrm{M}$

The Arabidopsis Information Resource

TOMATO POLYGALACTURONASE1/2/4

TB1-CYC-PCFs

transfer DNA

$10 \mathrm{mM}$ Tris-Cl, $\mathrm{pH}$ 7.5, $1 \mathrm{mM}$ EDTA

trans-Golgi network

ácido 2,3,5-triyodobenzoico

2-amino-2-hidroximetil-1,3-propanodiol

ubiquitin-conjugating protein

silenciamiento génico inducido por virus

VIVIPAROUS1 


$\begin{array}{ll}\text { XGA } & \text { xilogalacturonano } \\ \text { XTH } & \text { xiloglucano transglicosilasa/hidrolasa } \\ \text { Xyl } & \text { xilosa } \\ \text { YAB3 } & \text { YABBY3 } \\ \text { ZA } & \text { zona de abscisión } \\ \text { ZAC } & \text { zona de abscisión C (unión cáliz-fruto) } \\ \text { ZAL } & \text { zona de abscisión laminar (unión limbo-peciolo) } \\ \text { ZD } & \text { zona de dehiscencia } \\ \text { ZEP } & \text { zeaxantina epoxidasa } \\ \alpha-X Y L & \alpha \text {-xilosidasa } \\ \beta-G A L & \beta \text {-galactosidasa } \\ \beta-M A N & \beta \text {-manosidasa } \\ \beta-X Y L & \beta \text {-xilosidasa }\end{array}$


I. Introducción general 


\subsection{Los cítricos}

\subsubsection{Origen y difusión}

Actualmente, el cultivo de los cítricos se extiende por la mayor parte de las regiones tropicales y subtropicales comprendidas entre los paralelos $44^{\circ} \mathrm{N}$ y $41^{\circ} \mathrm{S}$. Su origen se localiza hace unos 20 millones de años en Asia oriental, en una zona que abarca desde la vertiente meridional del Himalaya hasta China meridional, Indochina, Tailandia, Malasia e Indonesia (Agustí, 2003). La dispersión de los cítricos se debió, fundamentalmente, a grandes movimientos migratorios y acontecimientos históricos, como las conquistas de Alejandro Magno, la expansión del Islam, las cruzadas y el descubrimiento de América, que contribuyeron a su expansión por las regiones en las que las condiciones medioambientales eran propicias para su desarrollo (Zaragoza, 1993).

\subsubsection{Caracterización botánica y agronómica}

\subsubsection{Taxonomía}

Las especies de cítricos con interés comercial pertenecen a la familia de las Rutaceas, subfamilia Aurantioideas. Esta familia se encuentra dentro de la división Embryophita Siphonogama, subdivisión Angiospermae, clase Dicotyledonae, subclase Rosidae, superorden Rutanae, orden Rutales. Dentro de este orden se incluyen, según Swingle (1967), las tribus Clauseneae y Citreae. La tribu Citreae, a su vez, se subdivide en tres subtribus, una de las cuales, la Citrinae, contiene todos los géneros a los que pertenecen los cítricos cultivados: Fortunella, Poncirus y Citrus. Las especies del género Citrus son las más importantes desde el punto de vista agronómico.

\subsubsection{Características agronómicas}

La característica más notable que presentan las especies del género Citrus es su peculiar fruto en forma de baya, que recibe el nombre de hesperidio (Amorós, 2003). Desde el punto de vista comercial, los dos grupos más importantes de cítricos son los mandarinos y los naranjos. 
El grupo agronómico de los mandarinos es uno de los más complejos del género Citrus, e incluye un gran número de especies que se pueden clasificar en: grupo Satsumas (C. unshiu), grupo Clementinas (C. clementina) y otros mandarinos (Amorós, 2003). En España, dentro del grupo Clementinas, destaca la variedad 'Clemenules' por la calidad de su fruta y por la gran extensión dedicada a su cultivo. Esta variedad se originó a partir de una mutación espontánea de la Clementina ‘Fina', en Nules (Castellón), en 1953.

Por otra parte, las principales variedades de naranjo dulce [Citrus sinensis (L.) Osbeck] cultivadas en España se encuentran dentro de tres grupos: Navel, Blancas y Sanguinas. El grupo de variedades que se cultiva mayoritariamente en España es el grupo Navel y se distingue por la presencia de un segundo verticilo carpelar que, al desarrollarse, da lugar a un segundo fruto que queda incluido en el fruto principal por su zona estilar (Agustí, 2003). Una de las variedades más importantes de este grupo es la 'Washington Navel'. Aunque su origen es incierto, parece que podría haberse introducido en Portugal desde China en el siglo XVIII y desde allí en Brasil. Sin embargo, su expansión se produjo desde E.E.U.U. a finales del siglo XIX. El árbol es de buen tamaño y vigor, con tendencia a florecer abundantemente. Presenta un fruto de tamaño medio a grande cuya corteza, ligeramente rugosa, es fácil de pelar y de color naranja intenso en las condiciones climáticas mediterráneas. Produce una alta cantidad de zumo, con excelentes cualidades organolépticas. Es una variedad de recolección temprana a media, aunque en la actualidad ha sido desplazada hasta media campaña por la existencia de otras variedades más precoces y por su adecuada respuesta a los tratamientos específicos para su conservación en el árbol (Agustí, 2003).

En España, se cultivan otras variedades de naranja del grupo Navel, muchas de las cuales se han originado por mutaciones de 'Washington Navel'. Entre ellas se encuentran la variedad 'Navelate', 'Newhall', 'Thompson Navel', 'Lane Late' o 'Navel Ricalate'.

\subsubsection{Importancia económica}

Los cítricos suponen una importante fuente de riqueza para el sector agroalimentario mundial y nacional. En España, la citricultura ocupa un importante papel en la economía, 
ya que proporciona un elevado número de divisas y representa una de las primeras partidas de ingresos en el capítulo general de las exportaciones nacionales (Zaragoza, 1993). Así, en el año 2008 se llegaron a generar más de 1.200 millones de dólares (www.fao.org), de los cuales 591 millones procedían de las exportaciones de mandarinas y 501 millones de la venta de naranjas.

\subsubsection{Producción de cítricos}

Actualmente, el cultivo de los cítricos representa la mayor producción de frutos del mundo, superando los 100 millones de toneladas en el año 2008 (www.fao.org). Los mayores productores a nivel mundial son China $(22.328 .430 \mathrm{t})$, Brasil $(20.583 .114 \mathrm{t})$ y E.E.U.U. (11.106.660 t), seguidos de otros países con producciones similares, entre los cuales destaca España con 6.309.720 toneladas (Figura 1). Esta producción se distribuía en 3.367.000 t de naranjas, 2.212.700 t de mandarinas, $688.900 \mathrm{t}$ de limones y $41.120 \mathrm{t}$ de pomelos (www.fao.org).

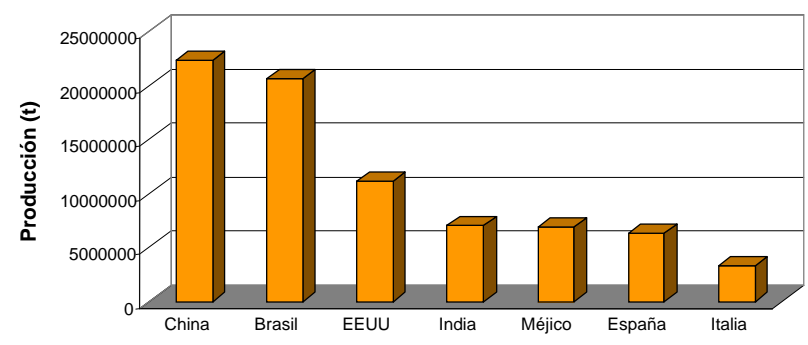

Figura 1. Principales países productores de frutos cítricos en 2008 (FAO).

España es el mayor exportador de cítricos para consumo en fresco a nivel mundial, siendo sus principales importadores: Alemania, Francia, Países Bajos, Reino Unido, Bélgica y Polonia (www.fao.org). España destina casi el 55\% de su producción de cítricos a este concepto, alcanzando el $60 \%$ en el caso de las mandarinas, especialmente, las Clementinas, de las que exporta más del $70 \%$ de su producción. El resto de la producción de cítricos se reparte con un 25\% para el consumo en fresco del país, y el $20 \%$ restante se destina a la industria (Agustí, 2003; FAO, 2006). La comunidad autónoma que más cítricos produce es la Comunidad Valenciana, cifrándose la producción de la campaña 2008/2009 
en 3.249.558 t (www.gva.es). Estas cifras englobaban la producción de naranjas (1.478.642 t), mandarinas (1.611.984 t) y limones (158.932 t).

\subsubsection{Superficie destinada al cultivo}

La superficie citrícola en España asciende a, aproximadamente, 300.000 ha (www.gva.es). En la Comunidad Valenciana, los cítricos ocupan 178.203 ha de las tierras de cultivo. Esta superficie se distribuye de la siguiente forma: $50.9 \%$ de la superficie destinada a mandarinas, $43.2 \%$ destinada a naranja dulce y $5.9 \%$ a limón. La distribución de la superficie dedicada al cultivo de los cítricos varía en función de cada provincia. Así, en Alicante es mayor la superficie de cultivo destinada al limón, en Castellón predomina la superficie destinada a mandarinas y en Valencia la destinada a naranja dulce (Figura 2).
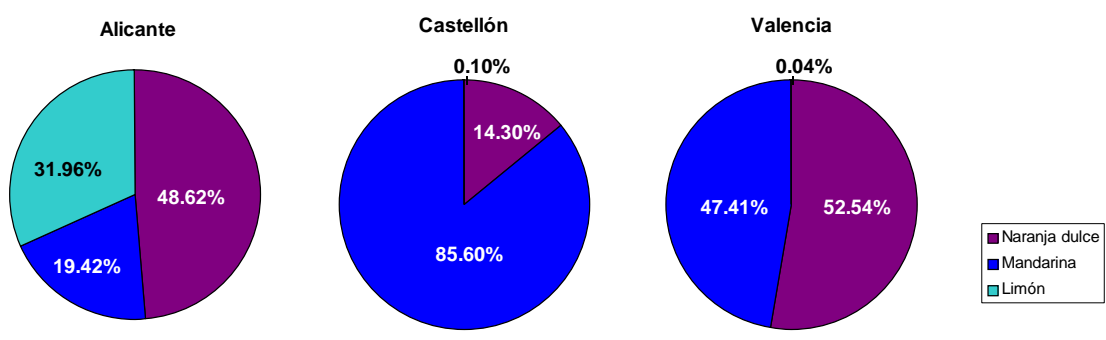

Figura 2. Distribución de la superficie citrícola en la Comunidad Valenciana (GVA, 2009).

\subsection{La abscisión es un proceso de separación celular}

\subsubsection{La separación celular}

Las células de las plantas se mantienen unidas mediante una matriz adhesiva denominada lámina media que está compuesta, principalmente, de pectina (Roberts et al., 2002). La adhesión entre las células vegetales es una característica fundamental del crecimiento y el desarrollo de las plantas, y una parte esencial de la estrategia a través de la cual consiguen rigidez y fuerza mecánica (Jarvis et al., 2003). En la mayoría de los casos, las estructuras formadas mediante la unión entre células se mantienen durante todo el ciclo vital, sin embargo, en algunos momentos del desarrollo es crucial que se produzca una separación efectiva entre células contiguas (Roberts et al., 2000). 
Por separación celular se entiende el proceso mediante el cual se disuelve la lámina media que mantiene unidas las células y/o se degrada su pared celular (Lewis et al., 2006). Es un proceso asociado a gran variedad de fenómenos fisiológicos, como la emergencia de raíces primarias y secundarias y su penetración en el suelo, la expansión de cotiledones y hojas, la formación de estomas y de espacios de aire intercelulares, la dispersión del polen desde las anteras, el ablandamiento del fruto durante la maduración, la dehiscencia de la vaina del fruto y la abscisión de órganos (Roberts et al., 2002). Aunque la naturaleza de la degradación de la pared celular sea comparable o prácticamente igual en muchos casos, es probable que las señales que inducen estos cambios sean diferentes (Roberts et al., 2002), por lo que los primeros eventos a nivel de transducción de señales y activación de la maquinaria molecular que culmina con la separación efectiva deben ser también particulares para cada caso. Las diferencias en cuanto a las señales inductoras serían las responsables de que los diferentes procesos de separación celular sólo se produzcan en determinados contextos espacio-temporales, aunque algunos autores han propuesto que estas podrían ser similares (Ferrándiz, 2002; Jenkins et al., 1999; Sander et al., 2001).

\subsubsection{La abscisión}

La abscisión es un proceso de separación celular altamente coordinado que implica el desprendimiento de los órganos de la planta. Es un proceso universal ya que ocurre en todas las plantas superiores $\mathrm{y}$, gracias a su activación, pueden desprenderse de diversas estructuras aéreas como polen, semillas y frutos, garantizando así una propagación eficiente de la especie. Además, permite la supresión de órganos senescentes o no funcionales así como de órganos dañados o infectados (Bleecker y Patterson, 1997; Patterson, 2001). Sin embargo, desde un punto de vista agronómico, la abscisión puede suponer una desventaja ya que repercute directamente sobre la producción.

\subsubsection{Etapas de la abscisión}

El modelo aceptado actualmente que explica el desarrollo del proceso de abscisión es el propuesto por Patterson (2001) y comprende cuatro etapas diferenciadas (Figura 3). La primera etapa implica la ontogenia de la zona de abscisión a partir de tejido indiferenciado. Los órganos susceptibles de desprendimiento generan durante su desarrollo un tejido 
especializado que recibe el nombre de zona de abscisión (ZA) y se localiza en regiones concretas y predeterminadas de su anatomía. A continuación, la zona de abscisión ya diferenciada debe adquirir la competencia para poder responder a las señales inductoras de la abscisión, que pueden ser de tipo hormonal, fisiológico o ambiental. Cuando la zona de abscisión recibe las señales adecuadas activa la maquinaria necesaria para desencadenar el proceso, que culmina con la separación celular efectiva y con la consecuente abscisión del órgano. En algunas especies, esta etapa ( $\mathbf{C}$ en la Figura 3) finaliza con la elongación o expansión de las células de la superficie de la zona efectiva de separación. La última etapa consiste en la diferenciación de una capa protectora que sella la herida que queda en la planta y que actuará como barrera ante posibles ataques patogénicos (Bleecker y Patterson, 1997; Patterson, 2001).

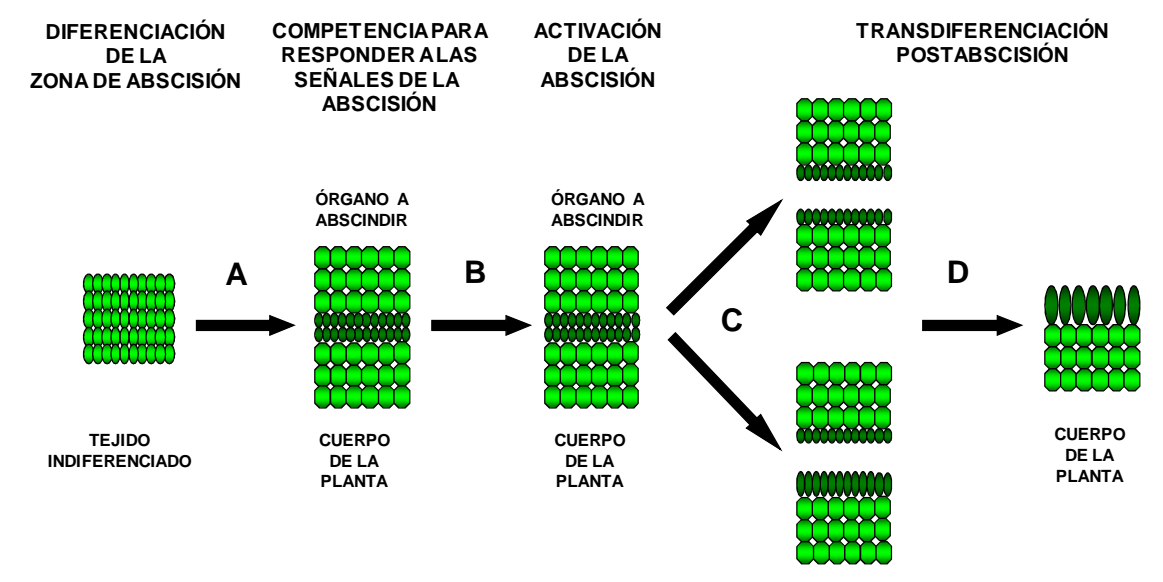

Figura 3. Etapas de la abscisión. Modelo adaptado de Patterson (2001).

\subsubsection{Diferenciación de la zona de abscisión}

El concepto de zona de abscisión implica la diferenciación de tipos celulares en posiciones concretas de la planta y con una especialización funcional determinada. Normalmente, la diferenciación de la ZA se produce durante el desarrollo del órgano al que está asociada (Addicott, 1982; Osborne, 1989) aunque, en ocasiones, puede ocurrir como respuesta ante determinados estímulos en órganos completamente desarrollados, como es el caso de las zonas de abscisión secundarias (Roberts et al., 2002). 
El conocimiento actual acerca de la diferenciación de la ZA proviene de la caracterización de mutantes en los que el proceso de abscisión está bloqueado o seriamente restringido. El mutante jointless de tomate (Solanum lycopersicon), en el que no se produce diferenciación de la ZA del pedúnculo de la flor y del fruto, presenta un patrón de abscisión aberrante (Mao et al., 2000). El gen JOINTLESS codifica un factor de transcripción de tipo MADS-box que contribuye al establecimiento de sitios específicos de diferenciación celular. El mutante de tomate lateral supressor $(l s)$ también presenta problemas en el desarrollo de la ZA del pedúnculo. Aunque la función precisa de $L s$ es desconocida, se sabe que codifica una proteína VHID (Schumacher et al., 1999) y que posee una alta homología con algunas proteínas transductoras de la señal de las giberelinas, como GAI, RGA, Rht-1 o d8, por lo que se ha sugerido que podría estar directamente relacionada con la modulación de la respuesta localizada a estas hormonas (Peng et al., 1999).

El gen KNATl de Arabidopsis thaliana codifica un factor de transcripción de la familia homeobox y su mutante también presenta anomalías en el desarrollo de las distintas zonas de abscisión (Wang et al., 2006). Se ha aislado, también, un regulador de respuesta de tipo A que se expresa en la ZA localizada en la unión entre la semilla en desarrollo y el funículo de Arabidopsis thaliana (Gattolin et al., 2002), por lo que se ha planteado la posibilidad de que este tipo de reguladores puedan estar implicados en la formación de la ZA.

Recientemente, el trabajo de McKim et al. (2008) ha permitido identificar dos factores de transcripción redundantes, BLADE-ON-PETIOLE 1 (BOP1) y BOP2, que controlan el desarrollo morfológico de la hoja y de los órganos florales de Arabidopsis thaliana y la subsiguiente diferenciación de las zonas de abscisión.

Diversos estudios sobre el proceso de domesticación que llevó a la pérdida de la capacidad de dispersión de las semillas en las especies cultivadas de arroz han permitido identificar algunos genes clave en el desarrollo de la zona de abscisión de las semillas (Konishi et al., 2006; Li et al., 2006; Onishi et al., 2007). Los genes qSH1, qSH3 y qSH4 son los principales responsables de la reducción en la dispersión de las semillas y cada uno de ellos tiene un efecto distinto sobre el proceso. Los resultados obtenidos sugieren que $q S H 1$ actúa en la formación de la zona de abscisión y aguas arriba de $q S H 4$, mientras que 
qSH4 actúa durante la activación del proceso una vez se ha formado la zona de abscisión. Por otra parte, se ha visto que $q S H 3$ tiene un efecto menor que $q S H 1$ y $q S H 4$ sobre el proceso y que, a diferencia de $q S H 1$ y $q S H 4$, una mutación en este gen no es suficiente para bloquear la abscisión de las semillas.

Otro trabajo llevado a cabo en arroz (Ji et al., 2010) ha permitido aislar una fosfatasa nuclear (OsCPL1) implicada en la diferenciación de la zona de abscisión de las semillas. En este trabajo los autores demuestran que dos líneas de inserción de T-DNA, una línea con una mutación puntual del gen y diversas líneas transgénicas de RNA de interferencia presentaban mayor incidencia del proceso de abscisión de la semilla.

Otros procesos de separación celular, especialmente la dehiscencia de las anteras y de la vaina del fruto, podrían presentar elementos comunes en su regulación con el proceso de abscisión (Ferrándiz, 2002). Por tanto, los trabajos realizados en Arabidopsis thaliana sobre el desarrollo de los distintos tipos celulares que constituyen la zona de dehiscencia (ZD) de la vaina del fruto podrían resultar de gran ayuda para el estudio del patrón de desarrollo de la zona de abscisión. Los factores de transcripción de la familia MADS-box SHATTERPROOF1 (SHP1) y SHATTERPROOF2 (SHP2), cuya función es redundante, son necesarios para la correcta especificación de los diferentes tipos celulares que coexisten en el margen de la valva y en la ZD (Ferrándiz, 2002; Liljegren et al., 2000). FRUITFULL (FUL), otro factor MADS-box, participa en la diferenciación de las células de la valva durante el desarrollo del carpelo (Gu et al., 1998). Es un regulador negativo de la expresión de SHP1 y SHP2 (Ferrándiz et al., 2000). La expresión constitutiva de FUL y la pérdida de función del doble mutante shp1 shp2 da lugar a plantas con frutos indehiscentes. REPLUMLESS (RPL) codifica una homeoproteína que controla el desarrollo del replum en la valva (Roeder et al., 2003). En las plantas que carecen de actividad RPL, las células del margen de la valva pasan a ocupar el dominio normalmente ocupado por las células del replum. Los resultados de este trabajo sugieren que RPL debe reprimir la expresión de los genes $S H P 1 / 2$. Por tanto, FUL y RPL funcionan ambos como represores pero con dominios de actuación distintos. FUL actúa en la valva mientras que RPL lo hace en el replum, de modo que la expresión de los genes $S H P 1 / 2$ queda confinada a una estrecha línea de células situada en la unión entre la valva y el replum, donde se diferencia, finalmente, la zona de dehiscencia (van Nocker, 2009). 
Algunos factores de transcripción de la famila bHLH (basic helix-loop-helix) también participan en la dehiscencia del fruto. El gen ALCATRAZ $(A L C)$ se expresa en los márgenes de las valvas de la vaina de Arabidopsis thaliana y es necesario para la formación de una capa de células con paredes no lignificadas que se localiza en la ZD y que hace posible la apertura mecánica de las valvas (Rajani y Sundaresan, 2001). Otro factor de transcripción bHLH, SPATULA (SPT), se expresa, además de en el estomium de la antera y en la ZA del funículo del óvulo, en la ZD del fruto (Heisler et al., 2001). Su patrón de expresión espaciotemporal en los márgenes de las valvas de la vaina es idéntico al descrito para los factores MADS-box SHP1 y SHP2. Sin embargo, en los mutantes spatula no está afectado el proceso de dehiscencia, por tanto, el gen $S P T$ podría tener una función redundante a la de los genes SHPs. El tercer miembro de la familia bHLH implicado en el desarrollo de la ZD es INDEHISCENT (IND), que dirige la diferenciación de la capa de separación y la capa adyacente de células lignificadas de la valva (Liljegren et al., 2004).

Además, se han identificado tres reguladores clave de la expresión de SHP y FUL: FILAMENTOUS FLOWER (FIL; Kanaya et al., 2001), YABBY3 (YAB3; Siegfried et al., 1999) y JAGGED (JAG; Ohno et al., 2004). En los mutantes fil yab3, cuyo fruto es indehiscente, no se detecta expresión del gen $F U L$ en las valvas y la expresión de $S H P$ disminuye considerablemente en los márgenes de las valvas de la mitad apical del fruto en comparación con el genotipo silvestre. La supresión de la actividad JAG, en frutos fil yab3 jag provoca una disminución importante de la expresión de $S H P$ en los márgenes de las valvas. Estos resultados indican que $F I L, Y A B 3$ y $J A G$ contribuyen de forma redundante en el desarrollo del margen de la valva promoviendo la expresión de FUL y SHP (Dinneny et al., 2005).

Así, las evidencias actuales sugieren que la red transcripcional que controla la diferenciación de los distintos tipos celulares de la ZD está compuesta al menos por $F I L$, $Y A B 3, J A G, I N D, A L C, S P T, F U L, R P L$ y los factores MADS-box redundantes $S H P 1 / 2$. 


\subsubsection{Factores desencadenantes de la abscisión}

La zona de abscisión se diferencia en una etapa temprana del desarrollo del órgano asociado y permanece inactiva hasta que recibe el estímulo apropiado que desencadena la abscisión (Taylor y Whitelaw, 2001). El tiempo que transcurre desde la formación hasta la activación de la ZA varía entre órganos, así, mientras en las flores los dos procesos pueden estar relativamente próximos, en las hojas pueden estar separados varios meses (Roberts et $a l .$, 2002). Aunque, actualmente, se desconoce si las señales que inducen la abscisión son comunes para los distintos órganos vegetales, está bien establecido que los factores de tipo fisiológico (asociados a senescencia), ambiental (asociados a estreses) y hormonal son cruciales.

\subsection{Factores fisiológicos}

La abscisión se relaciona frecuentemente con la senescencia ya que ambos procesos son desencadenados, en muchos casos, por los mismos factores. Sin embargo, la senescencia conlleva el envejecimiento o la muerte de un órgano o parte del mismo, mientras que la abscisión ocurre como consecuencia de esta degradación y con el fin de eliminar dicho órgano (Taylor y Whitelaw, 2001). Se trata de dos procesos fisiológicos independientes que pueden o no estar acoplados, ya que en determinadas circunstancias la abscisión puede ocurrir sin que se produzca senescencia y viceversa. Un ejemplo claro de abscisión activada como consecuencia de la senescencia de un órgano es el de la caída otoñal de las hojas. Una vez la tasa fotosintética desciende por debajo de un determinado nivel, la senescencia y la abscisión de la hoja se suceden ordenadamente con el fin de prevenir una situación en la que el consumo de agua y nutrientes supere la contribución de carbono fijado (Batt y Woolhouse, 1975; Hensel et al., 1993).

\subsection{Factores ambientales}

\section{a) Fotoperiodo y temperatura}

Algunos trabajos sugieren que la reducción del fotoperiodo puede actuar como señal activadora de un interruptor entre la expresión de genes que codifican enzimas necesarias 
para la fotosíntesis y la expresión de genes que codifican enzimas relacionadas con la senescencia y la abscisión (Taylor y Whitelaw, 2001). Los estudios fisiológicos llevados a cabo en Coleus blumei (Mao et al., 1989), Capsicum annum (Wien y Turner, 1989) y Lilium (Van Meeteren y De Proft., 1982) confirman que las condiciones de oscuridad y baja luminosidad promueven la abscisión de flores, yemas florales, hojas y frutos. Por otra parte, en un estudio llevado a cabo en soja (Glycine maxima cv. Young), observan que el sombreado de las plantas provoca la reducción de la tasa fotosintética y la activación de la senescencia y la abscisión de las hojas (Burkey y Wells, 1991). Zhou et al. (2008) demuestran, también, que el sombreado induce la abscisión de frutos de manzano (Malus domestica cv. Empire) y promueve la expresión diferencial de una serie de genes tras distintos tiempos de sombreado.

Las temperaturas extremas también pueden activar la abscisión de diferentes órganos en la planta. Así, por ejemplo, se ha observado que en pimiento (Capsicum annum) y en guisante (Pisum sativum) las altas temperaturas causan la abscisión de flores (GonzálezDugo et al., 2007; Guilioni et al., 1997). Mientras que, en la planta ornamental 'madreselva' (Lonicera maacki), las bajas temperaturas promueven la caída de frutos (Bartuszevige et al., 2006).

\section{b) Estrés hídrico}

Las condiciones de sequía y otros estreses que causan déficit hídrico, como la salinidad y las temperaturas extremas, promueven la abscisión en un elevado número de especies (Tadeo y Gómez-Cadenas, 2008). La abscisión debida al estrés hídrico es un suceso común en especies de hoja caduca que crecen en climas tropicales y subtropicales (e.g. especies del género Spondias), y es necesaria para reducir la velocidad de transpiración y la competencia por la luz (Addicott, 1982; Janzen, 1970; Taylor y Whitelaw, 2001). Este fenómeno se conoce como 'abscisión higrofóbica' y se manifiesta también en especies que presentan caída de hojas en épocas húmedas tras un periodo de sequía, como ocurre en el Mediterráneo. Los cítricos también presentan abscisión de órganos durante la rehidratación después de un periodo de estrés (Tudela y Primo-Millo, 1992). 
En un trabajo reciente realizado en Raphanus raphanistrum (rábano silvestre) observan cambios en la anatomía de la ZA del fruto como respuesta al déficit hídrico. El estrés hídrico provoca un aumento del tamaño de las células de la zona de separación así como un incremento del diámetro de la cicatriz generada tras la abscisión (Taghizadeh et al., 2009).

\section{c) Heridas y patogénesis}

Las heridas y el ataque de patógenos pueden considerarse conjuntamente por producir el mismo tipo de estímulo en la planta. Los daños mecánicos constituyen posibles puntos de entrada para patógenos, por lo que la planta induce una respuesta de defensa que conlleva una importante alteración de la expresión génica. La principal finalidad de la respuesta defensiva es cicatrizar la herida y prevenir la invasión patogénica. Esto se consigue mediante el refuerzo de la pared celular por deposición de calosa, lignina y glicoproteínas ricas en hidroxiprolina, y mediante la síntesis de compuestos antimicrobianos como las fitoalexinas, los inhibidores de proteinasa y las proteínas de respuesta a patógenos. Si no se activa este tipo de respuesta defensiva, se produce la invasión patogénica y las plantas responden entonces de forma distinta, se desprenden del órgano infectado con el fin de evitar la propagación de la infección (Taylor y Whitelaw, 2001).

\subsubsection{Factores hormonales}

Como se ha comentado en apartados anteriores, la senescencia y determinadas situaciones de estrés están relacionadas con la abscisión. En general, tanto en tejidos senescentes como estresados, se observa un incremento en la síntesis de etileno, lo que sugiere que esta hormona es un regulador positivo de la abscisión (Brown, 1997; Jackson y Osborne, 1970). El etileno induce la síntesis y secreción de enzimas hidrolíticas de la pared celular así como la expresión de los genes que codifican estas enzimas (Brummell et al., 1999; del Campillo y Bennett, 1996). Además, su aplicación exógena acelera la abscisión de hojas, flores y frutos (Addicott, 1982), y el tratamiento con inhibidores de la síntesis o acción del etileno provoca retraso en la abscisión así como menor incidencia del proceso (Brown, 1997; Sexton y Roberts, 1982). 
La caracterización de plantas de Arabidopsis thaliana, tanto de plantas transgénicas que expresan algunos de los genes biosínteticos en antisentido (Ecker y Theologis, 1994) como de mutantes insensibles al etileno (Bleecker y Patterson, 1997; Chao et al., 1997), ha permitido implicar inequívocamente a esta hormona en el proceso de abscisión. Sin embargo, la identificación de los mutantes dab (delayed floral organ abscission), que muestran un retraso en la abscisión pero no presentan alteraciones en la percepción o sensibilidad al etileno, ha mostrado que la acción de la hormona no es imprescindible en la inducción del proceso de abscisión (Patterson y Bleecker, 1997; 2004) y que, por tanto, deben existir otras rutas independientes del etileno controlando la activación del proceso.

Actualmente, se cree que el balance hormonal entre etileno y auxinas controla la cinética de desarrollo del proceso, en la que el etileno actuaría como un acelerador y las auxinas como retardadoras (Taylor y Whitelaw, 2001). Este modelo de regulación podría constituir un mecanismo de control para prevenir la abscisión en momentos en los que esta sería inoportuna como, por ejemplo, durante la maduración de los frutos climatéricos (Roberts et al., 2002). Los trabajos llevados a cabo por Lin et al. (2008 y 2009) muestran que dos genes ortólogos que codifican una proteína con motivos TPR (tetratricopeptide repeat) en tomate $\mathrm{y}$ Arabidopsis thaliana (SITRP1 y AtTRP1, respectivamente) interaccionan con los receptores de etileno NR (Never-ripe) y ETR1 (Ethylene Tripleresponse 1). La sobreexpresión de ambos genes provoca alteraciones en el proceso de abscisión y en la respuesta a etileno y auxinas, así como en la expresión de genes inducibles por estas hormonas.

Algunos trabajos han demostrado que los tratamientos con auxinas son capaces de suprimir parcialmente la expresión de genes que codifican enzimas hidrolíticas de la pared celular (Kalaitzis et al., 1995; Koehler et al., 1996). Además, los tratamientos con auxinas de síntesis se han utilizado de forma efectiva para bloquear o retrasar la abscisión de frutos en algunas especies frutales, como los cítricos (Agustí, 2003).

Diferentes trabajos incluyen a otras hormonas dentro de la compleja red de factores que puede estar controlando el proceso de abscisión (Binder y Patterson, 2009; Taylor y Whitelaw, 2001). El ácido abscísico (ABA), asociado inicialmente a la abscisión, parece desempeñar un papel secundario en algunas especies (Roberts et al., 2002) e indirecto en 
otras (Gómez-Cadenas et al., 1996). El ácido jasmónico (JA) es un compuesto de naturaleza hormonal relacionado principalmente con las respuestas de las plantas al estrés por heridas y por ataque de patógenos, aunque se ha implicado también en el proceso de abscisión (Beno-Moualem et al., 2004; Hartmond et al., 2000; Miyamoto et al., 1997; Ueda et al., 1996). Un estudio reciente (Ogawa et al., 2009) sugiere que el ABA y el JA podrían regular junto con el etileno la abscisión de órganos florales de Arabidopsis thaliana, promoviendo la expresión del gen QUARTET2 (QRT2), que codifica una poligalacturonasa implicada en el proceso.

\subsubsection{Cambios anatómicos asociados a la abscisión}

Las células de la ZA, a diferencia de las de las regiones adyacentes, detienen su desarrollo y mantienen una apariencia meristemática. Son células isodiamétricas y más pequeñas que las que se localizan en los tejidos adyacentes, con numerosas conexiones plasmodésmicas, un citoplasma más denso y paredes celulares menos engrosadas. Esta propiedad, especialmente en especies leñosas, se debe a que las células de la ZA no suelen presentar crecimiento secundario (Addicott, 1982; Roberts et al., 2000). Estas células se organizan en dos o más capas celulares comprimidas que forman un tejido morfológicamente distinguible (Addicott, 1982). A medida que avanza la separación, se observa un aumento de retículo endoplasmático rugoso, de vesículas y de áreas de Golgi en las proximidades de la pared celular, lo que sugiere que se activa el tráfico intracelular de vesículas (Addicott, 1982). Antes de la separación celular, la lámina media de la pared se vuelve muy electrodensa y la pared primaria adquiere una apariencia menos fibrosa debido a la degradación de los componentes de la lámina media y a la disociación de las microfibrillas de celulosa (Roberts et al., 2002). A continuación, las células de la zona de separación aumentan su volumen y adquieren una forma redondeada (Sexton y Redshaw, 1981). Los análisis mediante microscopía electrónica de barrido muestran frecuentemente signos de expansión celular en la superficie de una o ambas zonas de separación (Addicott, 1982). Los cambios ultraestructurales que se observan durante el proceso de separación son, a grandes rasgos, comunes a todas las zonas de separación y son los responsables de la reducción de la fuerza de adherencia del órgano al cuerpo principal de la planta que facilita su desprendimiento (Addicott, 1982). 


\subsubsection{Cambios bioquímicos y moleculares asociados a la abscisión}

La abscisión va acompañada de una serie de cambios en la expresión génica y en la actividad enzimática de las células de la ZA, que llevan, en última instancia, a la separación efectiva del órgano.

Las estrategias utilizadas hasta el momento para elucidar parte de la complejidad de los procesos biológicos que se modifican en la ZA han consistido en el estudio de genes potencialmente implicados en el proceso de abscisión, como las hidrolasas de pared celular, y en la caracterización de mutantes que retrasan o bloquean el proceso.

\subsection{Enzimas hidrolíticas}

A nivel celular, la abscisión consiste en la hidrólisis de la lámina media y las paredes de las células que constituyen la ZA, por ello, este proceso se ha relacionado, tradicionalmente, con el incremento en la actividad de enzimas que hidrolizan los polisacáridos estructurales. Una de las primeras enzimas estudiada fue una $\beta$-1,4-glucanasa o celulasa (Horton y Osborne, 1967). En este trabajo, llevado a cabo en explantes de judía tratados con etileno in vitro, observaron una correlación entre el aumento de la actividad celulasa y el progreso de la abscisión. Posteriormente, Tucker et al. (1988) clonaron el gen responsable de la acumulación de celulasa en la ZA de judía y demostraron que el etileno inducía significativamente su expresión en la ZA, mientras que el ácido indol-acético (IAA) la reprimía. A raíz de estos primeros trabajos, se caracterizó la expresión diferencial de genes de esta familia en la ZA de otras especies como Sambucus nigra (Taylor et al., 1994), tomate (Lashbrook et al., 1994, del Campillo y Bennet, 1996; Brummell et al., 1999), pimiento (Ferrarese et al., 1995), aguacate (Tonutti et al., 1995) o cítricos (Burns et al., 1998).

Algunos trabajos más recientes realizados en otras especies de interés agronómico han implicado también a genes de la familia de las celulasas en el proceso de abscisión. En la ZA de frutos de manzano tratados con inhibidores de la síntesis o de la acción del etileno (aminoetoxivinilglicina y 1-metilciclopropeno, respectivamente) y con ácido naftalenacético, la expresión de la celulasa MdEGl disminuía considerablemente (Li y Yuan, 2008). En el trabajo de Mishra et al. (2008) detectaban mayor actividad enzimática 
así como mayor acumulación de transcrito de una celulasa (GhCell) en la ZA de explantes de hoja de algodón tratados con etileno. Sin embargo, cuando los explantes se trataban con 1-metilciclopropeno (1-MCP), previamente al tratamiento con etileno, tanto la expresión como la actividad enzimática se inhibían. Por otra parte, el tratamiento con etileno de hojas y frutos de melocotón inducía la expresión de una celulasa (PpEG4) exclusivamente en las ZAs (Trainotti et al., 2006).

Otra familia de enzimas importantes en la abscisión es la de las poligalacturonasas (PGs). La correlación entre el incremento de la actividad enzimática y la separación celular se detectó por primera vez durante la maduración del fruto (Huber, 1983). Actualmente, se han aislado y caracterizado diferentes genes que codifican poligalacturonasas que participan en el proceso de abscisión. En tomate se han aislado tres PGs implicadas en la abscisión (TAPG1, TAPG2 y TAPG4). Estos tres genes presentan una homología entre sí a nivel de nucleótidos cercana al 90\%. Sin embargo, la homología con la PG caracterizada durante el ablandamiento del fruto es inferior al 50\%, y los transcritos que codifican son de menor tamaño (Kalaitzis et al., 1997). Posteriormente, Jiang et al. (2008) confirmaron el papel de TAPG1 en la abscisión bloqueando su expresión mediante silenciamiento génico inducido por virus (VIGS). Los resultados mostraban un retraso en la abscisión y un aumento en la fuerza de retención de la ZA de explantes de hoja tratados con etileno.

Recientemente, se ha relacionado la expresión de una PG (PGAZAT) con la abscisión de órganos florales de Arabidopsis thaliana (González-Carranza et al., 2007). En este trabajo utilizan la estrategia de silenciamiento génico por inserción de T-DNA para bloquear la expresión de PGAZAT y obtienen líneas con un retraso considerable en la abscisión. Previamente a este trabajo, se había localizado su expresión en la ZA de los órganos florales de Arabidopsis mediante la fusión de su promotor a los genes delatores GUS ( $\beta$-glucuronidasa) y GFP (green fluorescent protein) (González-Carranza et al., 2002).

Los análisis de función génica así como los experimentos de complementación de mutaciones llevados a cabo por Ogawa et al. (2009) muestran la participación de tres poligalacturonasas, ARABIDOPSIS DEHISCENCE ZONE POLYGALACTURONASE 1 (ADPG1), ADPG2 Y QUARTET2 (QRT2), en los procesos de abscisión y dehiscencia de Arabidopsis thaliana. Los análisis genéticos demuestran que ADPG2 y QRT2 participan en 
la abscisión de los órganos florales, $A D P G 1$ y $A D P G 2$ son esenciales para la dehiscencia de la vaina del fruto, y los tres genes contribuyen en la dehiscencia de las anteras.

Las expansinas representan otra clase de enzimas que participan en la modificación de la pared celular durante los procesos de elongación celular (McQueen-Mason y Cosgrove, 1995) y maduración del fruto (Rose et al., 1997). Belfield et al. (2005) clonaron y caracterizaron dos genes que codifican expansinas en Sambucus nigra (SniExp2 y SniExp4), y demostraron una correlación entre la expresión y el incremento en la actividad expansina durante la abscisión inducida por etileno en la ZA de foliolos.

En un trabajo realizado en rosa (Rosa bourboniana) observan un aumento de la expresión de una expansina (RbEXPAl) durante el transcurso de la abscisión natural de los pétalos y tras la inducción del proceso con etileno (Sane et al., 2007). Además, cuando tratan con 1-MCP detectan tanto retraso de la abscisión como reducción de la expresión de RbEXPA1. Por otra parte, no observan expresión de esta expansina durante el desarrollo de la flor, sugiriendo que no debe tratarse de un gen relacionado con la expansión celular sino con la modificación de la pared que lleva, finalmente, a la abscisión de los pétalos.

Se ha sugerido la posibilidad de que otras familias estén colaborando en la degradación de la lámina media y la pared celular durante el proceso, como las xiloglucano endotransglicosilasas, las pectin metilesterasas o las pectato liasas (Cai y Lashbrook, 2008; Fry et al., 1992; Lasbrook y Cai, 2008; Sun y van Nocker, 2010).

El papel de las enzimas hidrolíticas en el proceso de abscisión se trata con mayor profundidad en el Capítulo $\mathbf{V}$.

\subsubsection{Enzimas relacionadas con la defensa frente a patógenos}

Los tejidos contiguos a los órganos que se desprenden de la planta quedan desprotegidos tras la abscisión, proporcionando un espacio propicio y accesible a los ataques patogénicos (Roberts et al., 2002). Esta es la razón por la que a medida que se desarrolla el proceso de abscisión, la planta activa una serie de medidas preventivas destinadas a protegerse ante estos ataques potenciales. Diversos trabajos han documentado 
la inducción de la síntesis de proteínas de defensa como las quitinasas, las $\beta$-1,3-glucanasas (del Campillo y Lewis, 1992) y otras como las PR, de respuesta a patógenos, y las WIN, inducibles por herida durante la abscisión (Harris et al., 1997; Roberts et al., 1997). La coordinación de la expresión de estas proteínas durante el proceso de abscisión es incierta, aunque podría estar relacionada con la presencia de intermediarios reactivos del oxígeno (Lamb, 1994; Roberts et al., 2002). Las proteínas tipo metalotioneína se han propuesto como secuestradoras de los radicales libres que se generarían en este contexto, evitando la acumulación de estos en la ZA (Coupe et al., 1995). La familia de las metalotioneinas se ha implicado también en la senescencia foliar (Buchanan-Wollaston, 1994) y en la maduración del fruto (Ledger y Gardner, 1994), procesos en los que el etileno y la separación celular son importantes. Por otra parte, algunos genes que codifican peroxidasas también incrementan notablemente sus niveles de expresión en la ZA durante la abscisión (McManus, 1994). En principio, la actividad de estas proteínas se relacionó con una posible descarboxilación del IAA durante la abscisión, aunque también se ha especulado con su posible participación en la biosíntesis de la lignina que se deposita durante el sellado del tejido que permanece en la planta tras la separación efectiva del órgano (Agustí et al., 2008; van Nocker, 2009).

\subsection{Otras enzimas implicadas en el proceso de abscisión}

Numerosos estudios sobre la abscisión de órganos florales llevados a cabo en Arabidopsis thaliana han permitido implicar a diferentes genes en el control del proceso, incluyendo factores de transcripción, ligandos, receptores, efectores citoplasmáticos y otros productos génicos.

Una estrategia que ha permitido detectar la expresión de nuevos genes en la ZA es la transformación de plantas con construcciones que contienen el promotor de un gen unido a un gen delator como GUS o GFP. Así, se ha demostrado la participación de factores transcripcionales como AGL15 (AGAMOUS-like 15) o AtZFP2 (ZINC FINGER PROTEIN2). Aunque AGL15, un factor de transcripción de tipo MADS-Box, se expresa preferentemente en embriones en desarrollo (Heck et al., 1995), el estudio de las plantas transgénicas AGL15::GUS también mostró su expresión en las células del receptáculo y de la ZA de los órganos florales (Fernandez et al., 2000). Las plantas que expresan 
constitutivamente $A G L-15$ experimentan un retraso en la abscisión de órganos florales que no implica ni modificaciones en la estructura o funcionalidad de las células de la ZA ni en la respuesta al etileno, por lo que se ha sugerido que $A G L-15$ actúa en la activación del proceso de abscisión.

Tras el análisis transcriptómico de la ZA de los estambres de Arabidopsis thaliana (Cai y Lashbrook, 2008), los autores sugerían que el factor de transcripción AtZFP2 podía estar implicado, directa o indirectamente, en el proceso de abscisión. Su expresión se localizó en las ZAs de estambres, pétalos y sépalos y, además, las plantas transgénicas que sobreexpresaban $A t Z F P 2$ presentaban un retraso importante en la abscisión.

Mediante el análisis histológico de la expresión del gen GUS bajo el control del promotor de HAESA (HAE), que codifica una proteína quinasa de tipo receptor con repeticiones de leucina (LRR-RLK), se ha comprobado que este gen se expresa en el peciolo de las hojas, en el pedúnculo de las flores y en las ZAs de los pétalos y los estambres (Jinn et al., 2000). Las plantas que expresan el gen en antisentido de forma constitutiva no presentan abscisión de órganos florales y, en base a esto, los autores proponen que HAESA podría ser un regulador específico del proceso.

El gen INFLORESCENCE DEFICIENT IN ABSCISSION (IDA; Butenko et al., 2003) fue identificado mediante la caracterización de un mutante de Arabidopsis thaliana en el que la abscisión de órganos florales estaba totalmente bloqueada. IDA codifica una pequeña proteína con un péptido señal en su región amino-terminal cuya naturaleza sugiere que podría ser el ligando de un receptor que estaría implicado en el control de la abscisión de los órganos florales. En este trabajo se mostraba la coexpresión de IDA y HAESA tanto en la ZA de los órganos florales como en la ZD de las silicuas, lo que sugería que IDA podría funcionar como ligando de HAESA. Posteriormente, en el estudio llevado a cabo por Stenvick et al. (2008) identificaban cinco genes homólogos a IDA (IDL; IDA-like) y mostraban que tanto HAESA como HAESA-LIKE2 (HSL2), un gen con elevada homología a HAESA y con el mismo patrón de expresión espacio-temporal, eran epistáticos a IDA. La sobreexpresión de IDA en el doble mutante hae hsl2 no restauraba el fenotipo de abscisión, por tanto, debían actuar en la misma ruta génetica que regula la abscisión de los órganos florales. Un segundo trabajo (Cho et al., 2008) añadía a esta ruta de señalización una 
cascada de efectores citoplasmáticos de tipo MAP quinasa (Mitogen-activated protein kinase) basándose en el estudio de interacciones géneticas (Figura 4.A).

Recientemente, los genes NEVERSHED (NEV) y EVERSHED (EVR), que codifican una ARF-GAP (ADP-ribosylation factor-GTPase-activating protein) y una LRR-RLK, respectivamente, han sido implicados también en la abscisión de órganos florales (Leslie et al., 2010; Liljegren et al., 2009). El gen NEV regula el transporte de moléculas necesarias para la separación celular mientras que el gen $E V R$ funciona como inhibidor de la abscisión actuando sobre otras quinasas desde la membrana plasmática. Los resultados de estos trabajos sugieren que $N E V$ y EVR podrían actuar aguas arriba de IDA/IDL y HAE/HSL2, o en una ruta paralela que convergería en $H A E / H S L 2$ o en un punto aguas abajo de estos

(Figura 4.B).

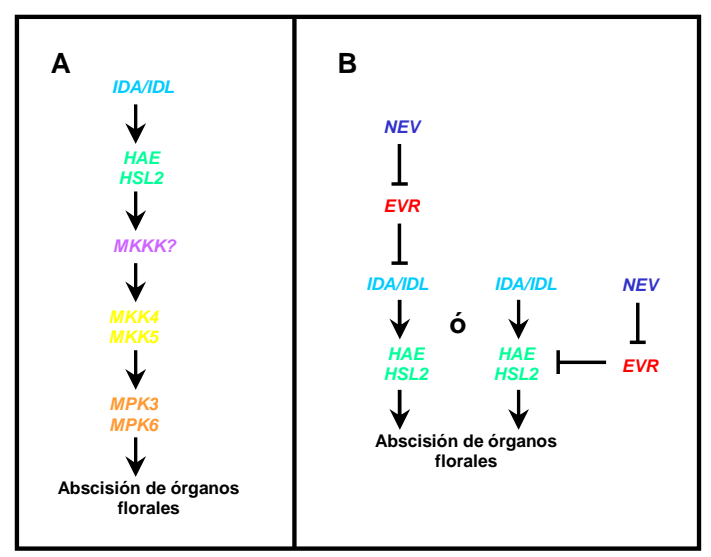

Figura 4. Modelos propuestos sobre la acción secuencial de genes que regulan la abscisión de órganos florales en Arabidopsis thaliana. A. Modelo adaptado de Cho et al. (2008). B. Modelo adaptado de Leslie et al. (2010).

\subsubsection{La abscisión en los cítricos}

En algunas especies comerciales, como los cítricos, la abscisión adquiere una especial importancia debido a sus repercusiones económicas y comerciales. Los cítricos son plantas que producen un número de flores muy superior al de frutos que son capaces de mantener hasta su madurez. El periodo de cuajado del fruto está marcado, inicialmente, por el balance hormonal y, posteriormente, por un fenómeno de competencia por los fotoasimilados que implica el desprendimiento de un número variable de flores y de ovarios en crecimiento. 
Este fenómeno de competencia se da en todas las especies frutales y es responsable de la relación inversa característica entre el número de inflorescencias o frutos por árbol y el tamaño final de los mismos (Agustí et al., 1982). En los cítricos, la abscisión de flores, ovarios o frutos pequeños en desarrollo se produce, en principio, en tres periodos diferenciados, aunque estos pueden solaparse en el tiempo (Erikson y Brannamann, 1960). En el primer periodo abscinden brotes florales o flores completas. El segundo, denominado 'caída post-floración', tiene lugar inmediatamente después de la caída de pétalos de la flor, mientras que durante el tercero, conocido en el hemisferio norte como 'caída fisiológica' o ‘caída de junio' (Figura 5), el árbol se desprende de frutos pequeños en desarrollo (Tadeo, 1988), siendo éste el periodo en el que se produce el máximo de abscisión en peso. Si esta abscisión es masiva la cosecha será escasa, mientras que si cuaja un número excesivo de frutos, su tamaño final no alcanzará el calibre comercial adecuado.

Existe una cuarta oleada de abscisión de estructuras reproductivas que recibe el nombre de 'abscisión precosecha' (Figura 5), y coincide con la maduración del fruto (Tadeo et al., 2003). Este periodo de caída no se da en todas las variedades, aunque en algunas, especialmente en las del grupo Navel, es muy importante. La abscisión precosecha se produce porque la fuerza con la que los frutos están unidos al árbol se va debilitando progresivamente a medida que avanza la maduración del fruto hasta que, finalmente, estos se desprenden. Si por razones comerciales es necesario retrasar la recolección, las posibilidades de desprendimiento de la fruta aumentan y el volumen de la cosecha puede verse así comprometido.

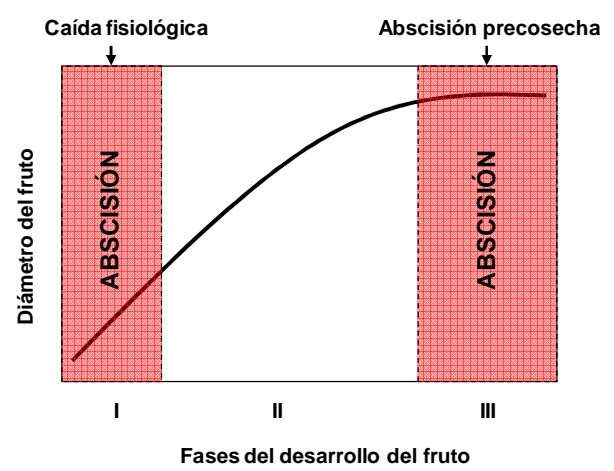

Figura 5. Periodos de abscisión durante el desarrollo del fruto que limitan la producción citrícola. 
Las condiciones medioambientales adversas, como el estrés hídrico o salino, son condiciones a las que los cítricos se enfrentan a menudo y suelen provocar el deterioro de hojas y frutos produciéndose, en último término, su abscisión (Tadeo, 2000).

\subsubsection{Zonas de abscisión en hojas y frutos de cítricos}

Las hojas de los cítricos presentan dos zonas de abscisión: la zona de abscisión laminar (ZAL) o zona de abscisión limbo-peciolo (ZA-L/P), situada entre el extremo basal del limbo y la porción apical del peciolo, y la zona de abscisión peciolo-rama (ZA-P/R), localizada entre la base del peciolo y su unión a la rama (Figura 6). La activación de una u otra zona de abscisión foliar es particular. Las hojas senescentes se desprenden por la ZA$\mathrm{P} / \mathrm{R}$, mientras que las hojas en desarrollo lo hacen por la ZAL como respuesta a diferentes estreses (Tadeo et al., 2003).

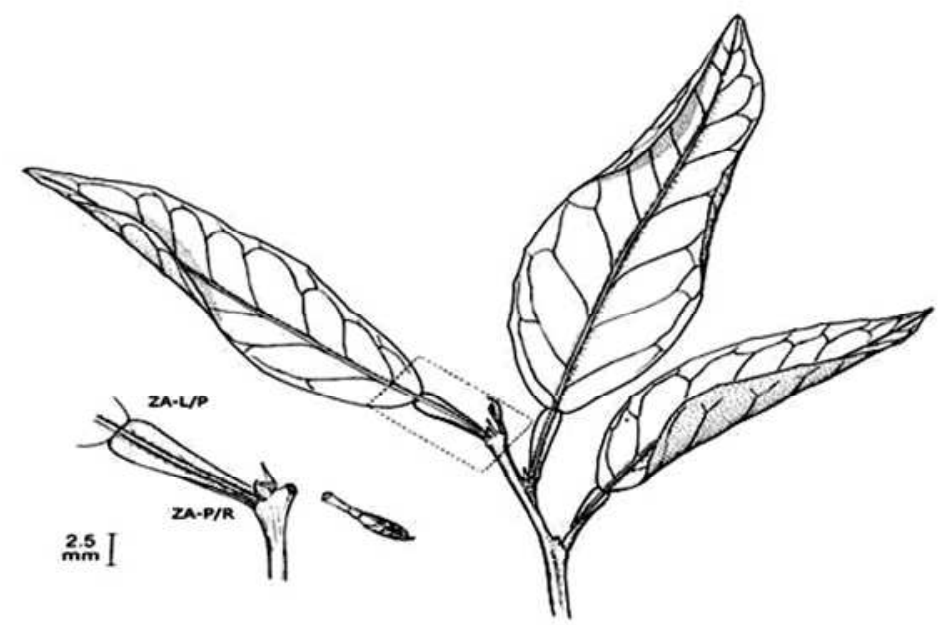

Figura 6. Zonas de abscisión de la hoja de los cítricos. Adaptado de Addicott (1982). ZA-L/P: zona de abscisión entre el limbo foliar y el peciolo. ZA-P/R: zona de abscisión entre el peciolo y la rama.

Los órganos reproductivos poseen también distintas zonas de abscisión (Figura 7): una situada entre el pedúnculo y el tallo, que recibe el nombre de zona de abscisión A (ZAA), y otra localizada en la unión del cáliz con el ovario/fruto, la zona de abscisión C (ZAC). La activación de una u otra zona es variable en el tiempo. Las flores y los ovarios se desprenden por la ZAA, mientras que los frutos que abscinden durante la caída de junio o durante la abscisión precosecha lo hacen por la ZAC. Aunque se desconocen las señales 
capaces de activar o inactivar una u otra zona de abscisión, se ha sugerido que su origen es hormonal (Greenberg et al., 1975).
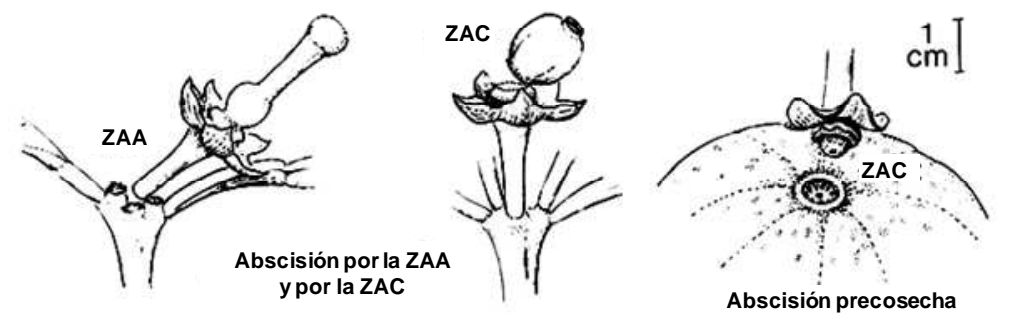

Figura 7. Zonas de abscisión del ovario y del fruto de los cítricos. Adaptado de Addicott (1982). ZAA: zona de abscisión entre el pedúnculo y el tallo. ZAC: zona de abscisión entre el cáliz y el ovario/fruto.

\subsubsection{Control hormonal de la abscisión en los cítricos}

En los cítricos, las condiciones de estrés que provocan abscisión van precedidas de un incremento en los niveles de ACC (ácido 1-aminociclopropano-1-carboxílico; precursor del etileno) y de etileno. El estrés hídrico induce una acumulación transitoria de ACC en las raíces (Tudela y Primo-Millo, 1992), mediada por una acumulación previa de ácido abscísico (Gómez-Cadenas et al., 1996). La rehidratación de las plantas permite que el ACC se transloque hasta las hojas, donde se oxida a etileno y desencadena la abscisión foliar. La salinidad también puede provocar una acumulación similar de ACC tanto en la raíz como en las hojas de los cítricos, estimulando el consecuente aumento en la producción de etileno y, en último término, la absicisión (Gómez-Cadenas et al., 1996). En ambos casos, el tratamiento con inhibidores del etileno en aquellos órganos en los que este se sintetiza reduce la abscisión.

El estrés por carencia de carbohidratos en los frutos, originado por la defoliación, provoca los mismos cambios en la biosíntesis de etileno (Gómez-Cadenas et al., 2000; Mehouachi et al., 1995). Por tanto, bajo condiciones de cultivo adversas, la ruta hormonal de transmisión de la señal de abscisión en los cítricos es: estrés $\rightarrow \mathrm{ABA} \rightarrow \mathrm{ACC} \rightarrow$ etileno $\rightarrow$ abscisión. 
La aplicación de etileno, de compuestos que liberan etileno, como el etefón, o de compuestos que inducen la síntesis de etileno, como el CMNP (5-cloro-3-metil-4-nitro-1Hpirazol), la coronatina o el metil-jasmonato promueve la abscisión en cítricos (Agustí et al., 2008; Burns, 2002; Burns et al., 2003; 2006; Hartmond et al., 2000), mientras que el 1MCP (1-metilciclopropeno), un inhibidor de la unión del etileno a sus receptores, la reduce (Pozo et al., 2004).

El nivel de auxinas en los frutos en desarrollo aumenta en las fases I y II, que corresponden a la división y elongación celular, respectivamente (Talón et al., 1990). Sin embargo, el tratamiento con auxinas, naturales o sintéticas, no afecta a la abscisión que se produce durante el cuajado, aunque se emplea con éxito en el control de la abscisión precosecha (Agustí et al., 1995). Los tratamientos in vitro sobre explantes de cítricos han corroborado el papel de las auxinas como agentes retardadores de la abscisión y bloqueantes de la actividad de enzimas hidrolíticas (Goren y Huberman, 1976). Además, los inhibidores del transporte de auxinas, como el TIBA (ácido 2,3,5-triyodobenzoico), la naringenina o la quercetina potencian el efecto de algunos agentes abscisores (Yuan et al., 2003).

Algunos trabajos sugieren que el balance entre auxinas y ABA en la ZA podría condicionar la respuesta de los cítricos a los agentes abscisores (Yuan et al., 2001). Sin embargo, otros estudios sugieren que la función del ABA en la abscisión de los cítricos podría ser indirecta (Gómez-Cadenas et al., 1996, 1998, 2000; Talón et al., 1997).

El tratamiento con giberelinas durante la antesis mejora el cuajado del fruto en el madarino Clemenules, sugiriendo que el contenido endógeno de esta hormona en los ovarios es un factor limitante en el cuajado del fruto de variedades partenocárpicas (Talón et al., 1992). Además, se ha visto que la aplicación de paclobutrazol, un inhibidor de la acción de las giberelinas, incrementa la abscisión de frutos en desarrollo (Ben-Cheikh et al., 1997). 


\subsubsection{Cambios en la expresión génica y en la actividad enzimática durante la}

abscisión en cítricos

En diversos trabajos centrados en el proceso de abscisión en cítricos, se ha observado un paralelismo entre la evolución de la abscisión y los cambios en la actividad de las enzimas hidrolíticas en las disitintas ZAs (Burns et al., 1998; Huberman y Goren, 1979). En la variedad de naranjo dulce Valencia, la abscisión provoca un incremento de las actividades celulasa (Cel) y poligalacturonasa (PG) en la ZA del cáliz (Burns et al., 1998). En este mismo trabajo, los autores clonaron dos fragmentos de cDNA correspondientes a dos celulasas (Cela y Celb) que se expresan en las ZAs del fruto (ZAs A y C) y de la hoja (ZAL) activadas por etileno. Otras enzimas que se han relacionado con el proceso de abscisión en cítricos son las pectin metilesterasas (CsPME1 y CsPME3; Nairn et al., 1998), que participan en el recambio de componentes de la pared celular, y las $\beta$-galactosidasas, que hidrolizan los residuos terminales $\beta$-D-galactosilo no reducidos (Wu y Burns, 2004).

El trabajo llevado a cabo por Yuan et al. (2005) establecía una conexión entre la señalización acoplada a proteínas $\mathrm{G}$, la biosíntesis de etileno y la abscisión foliar. El tratamiento con guanfacina, un agonista de los $\alpha 2 \mathrm{~A}$-adrenoreceptores acoplados a proteínas $\mathrm{G}$, reducía significativamente la abscisión de hojas inducida por etileno y suprimía la expresión de algunos genes implicados en la biosíntesis de etileno (ACS1 y ACO) en la ZAL. En un trabajo posterior (Malladi y Burns, 2008), aislaron y caracterizaron dos fosfolipasas ( $C s P L D \alpha 1$ y $C s P D L \gamma 1)$ que participan en la misma ruta de señalización de las proteínas G. Ambos genes eran regulados de forma diferencial en la ZAL tras el tratamiento con etileno; así, la expresión de $C s P D L \gamma 1$ aumentaba considerablemente mientras que la de CsPLD $\alpha 1$ era suprimida. Tras los resultados obtenidos, los autores sugieren que la señalización dependiente de fosfolipasas podría estar implicada en la regulación de la sensibilidad de la ZA a factores inductores del proceso.

El estudio de la abscisión en los cítricos ha aportado datos nuevos acerca de proteínas que no se habían relacionado antes con el proceso. Este es el caso de las proteínas de transferencia de lípidos (LTP), que podrían estar relacionadas con la deposición de monómeros de cutina en el plano de fractura de la ZA (Wu y Burns, 2003) o de la fenilalanina amonio-liasa (PAL), una enzima clave en el metabolismo de los polifenoles y 
la primera enzima en las rutas de biosíntesis de lignina y de flavonoides (Kostenyuk et al., 2002).

Otros trabajos recientes, basados en el análisis de expresión diferencial de la ZAL (Agustí et al., 2008; 2009), han resaltado la posible participación en el proceso de nuevos genes relacionados con la modificación de la pared celular, el transporte de lípidos, la biosíntesis y degradación de proteínas, la transducción de señales o el control transcripcional. Además, los autores proponen que, durante la abscisión foliar, el peciolo debe desempeñar junto con la ZAL un papel coordinado y complementario.

\subsubsection{Estudio de la abscisión en cítricos: finalidad y perspectivas}

La aplicación de nuevas herramientas biotecnológicas al estudio de procesos fisiológicos en especies de interés comercial, como es el caso de los cítricos, adquiere especial relevancia por su impacto sobre el proceso productivo y la calidad de la cosecha.

En los últimos años se han realizado importantes avances en relación a los procesos de separación celular, entre los que se encuentra la abscisión de órganos. Así, la caracterización de mutantes en diversas especies, la utilización de técnicas que permiten localizar la expresión génica en células concretas o los análisis transcripcionales a gran escala, han proporcionado información muy útil acerca del proceso de abscisión.

Los proyectos internacionales de genómica de cítricos, entre los cuales se encuentra el Proyecto de Genómica Funcional de Cítricos (CFGP, http://bioinfo.ibmcp.upv.es) desarrollado entre tres centros de investigación de la Comunidad Valenciana (I.B.M.C.P., I.V.I.A. e I.A.T.A.), han permitido profundizar en el estudio de los mecanismos celulares subyacentes al funcionamiento de este cultivo. Estos proyectos han generado una extensa colección de ESTs (expressed sequence tag) procedentes de diferentes especies de cítricos y de tejidos en distintas fases de desarrollo y bajo determinados tratamientos y condiciones de estrés. Por otra parte, el proyecto de secuenciación llevado a cabo por el ICGC (the International Citrus Genome Consortium), Genoscope (Evry, Francia), el IGA (Istituto di Genomica Applicata, Udine, Italia) y el JGI (Joint Genome Institute, Walnut Creek, California, USA) ha liberado recientemente la versión v0.9 del ensamblaje del genoma 
haploide de Citrus clementina. Esta versión del ensamblaje es de $296 \mathrm{Mb}$, repartidas en 1.128 scaffolds con un 2,3\% de gaps y una cobertura de 6.5 equivalentes genómicos, y ha sido generada utilizando la tecnología de secuenciación 'shotgun' (http://www.phytozome.net).

En el presente estudio se ha empleado esta información, y las nuevas tecnologías derivadas de la misma, para tener una visión más amplia del proceso de abscisión en cítricos. Las aplicaciones biotecnológicas que pueden derivar de este tipo de estudios pueden ser de gran interés y tendrían como objetivo último el control de la abscisión de órganos concretos en momentos determinados del desarrollo de la planta, lo que, finalmente, repercutiría de forma positiva sobre la producción. 
II. Objetivos 
El principal objetivo planteado en este trabajo consiste en llevar a cabo un análisis transcripcional a gran escala del proceso de abscisión en frutos maduros de cítricos. Este trabajo ha sido complementado con diferentes estudios de tipo anatómico, morfológico, bioquímico e inmunohistoquímico y valiéndose, además, de herramientas bioinformáticas de análisis de expresión global y de análisis de secuencias. Para alcanzar este objetivo se han establecido los siguientes objetivos parciales:

1) Caracterizar morfológica $\mathbf{y}$ anatómicamente la zona de abscisión $\mathrm{C}$ del fruto (ZAC) durante la activación del proceso de abscisión. Para ello se plantea la siguiente estrategia de trabajo:

- Determinar la evolución de la fuerza de retención del fruto a tiempos crecientes de tratamiento in vitro con etileno o ácido 1-aminociclopropano-1-carboxílico (ACC) para establecer la secuencia temporal a estudiar.

- Detectar el momento de la activación del proceso de abscisión con etileno o ACC a través de la tinción con phloroglucinol de secciones de material vegetal fresco que contienen la ZAC.

- Examinar mediante microscopía electrónica de barrido los cambios de la ZAC a nivel celular durante la abscisión activada por etileno.

- Estudiar la anatomía de la ZAC durante el proceso de abscisión mediante microscopía óptica.

2) Analizar la expresión génica de la ZAC tras la activación por etileno del proceso de abscisión. Para llevar a cabo este objetivo se ha establecido la siguiente estrategia de trabajo:

- Aislar mediante microdisección asistida por láser (MAL) células de la ZAC y de la corteza del fruto $(\mathrm{CF})$ a diferentes tiempos de tratamiento con etileno.

- Hibridar sobre la última versión de la micromatriz de cDNA del Proyecto de Genómica Funcional de Cítricos (Martínez-Godoy et al., 2008) muestras de RNA de la ZAC y de la CF procedentes de los tratamientos con etileno. 
- Comparar el patrón de expresión de ambos tejidos, ZAC y CF, para determinar posibles genes o grupos de genes implicados en el proceso de abscisión activado por etileno.

- Adaptar la metodología de aislamiento de células mediante MAL a la técnica de HPLC acoplada a espectrometría de masas para cuantificar metabolitos en células de la ZAC.

3) Determinar qué genes relacionados con el tráfico intracelular de vesículas pueden estar implicados en el proceso de abscisión y de qué manera. Para ello se compararán los perfiles de expresión en la ZAC y en la CF de genes implicados en el tráfico intracelular de vesículas.

4) Caracterizar familias génicas relacionadas con la modificación de la pared celular y estudiar los cambios bioquímicos y ultraestructurales que se producen como consecuencia de la actividad de este tipo de enzimas durante la abscisión de frutos. Para ello se ha seguido el siguiente planteamiento:

- Comparar los perfiles de expresión en la ZAC y en la CF de genes implicados en la remodelación de la pared celular.

- Localizar en el genoma haploide de Citrus clementina los locus correspondientes a proteínas de estas familias y estudiar las relaciones filogenéticas entre las proteínas de C. clementina, las proteínas reguladas por el etileno en la ZAC y/o en la CF y las proteínas descritas en la literatura como asociadas a la abscisión en otras especies vegetales.

- Identificar genes relacionados con la modificación de la pared celular con una probabilidad elevada de ser específicos de la ZAC mediante un análisis de expresión génica diferencial in silico.

- Aislar la región promotora de genes correspondientes a hidrolasas de la pared celular potencialmente específicas de la ZAC y determinar los posibles elementos reguladores en cis mediante análisis in silico de las secuencias.

- Acoplar la metodología de aislamiento de células mediante MAL a la técnica de cromatografía gas-líquido para determinar los cambios que se producen en la 
composición de monosacáridos de las paredes celulares de la ZAC durante la activación del proceso de abscisión.

- Estudiar las modificaciones que se producen en los polisacáridos de las paredes celulares de la ZAC durante la abscisión mediante la inmunolocalización de epítopos de diferentes carbohidratos de la pared celular. 
III. Análisis de la expresión génica en la zona de abscisión C de frutos cítricos durante la abscisión inducida por etileno 


\subsection{Introducción}

El etileno es considerado el regulador natural del proceso de abscisión (Brown, 1997; Jackson y Osborne, 1970). Se ha visto que la producción de etileno durante la abscisión aumenta y que, además, está precedida por la inducción de la expresión de genes que codifican las enzimas clave de su ruta biosintética: las ácido 1-aminociclopropano-1carboxílico sintasas (ACC-sintasas) y las ACC-oxidasas (Blume y Grierson, 1997; Clark et al., 1997). Otros trabajos han demostrado que la aplicación exógena de etileno acelera la abscisión de hojas, flores y frutos (Addicott, 1982), mientras que el tratamiento con inhibidores de la síntesis o acción del etileno provoca retraso en la abscisión así como menor incidencia del proceso (Brown, 1997). Además, el etileno induce la expresión de los genes que codifican enzimas hidrolíticas de la pared celular así como su síntesis y su secreción a la pared, necesarias para la separación efectiva del órgano (Brummell et al., 1999; Burns et al., 1998; del Campillo y Bennett, 1996).

El estudio de los genes implicados en la biosíntesis y en la transducción de la señal del etileno ha contribuido a la comprensión de la posible función de esta fitohormona en la abscisión. Las plantas transgénicas de Arabidopsis thaliana que expresan un gen de la familia de ACC-sintasas en antisentido presentan un descenso de la síntesis de etileno y retraso en la abscisión (Ecker y Theologis, 1994). Los mutantes de respuesta a etileno etrl, ein2, ein 3 y ers 2 de Arabidopsis thaliana también muestran retraso en la abscisión de órganos florales; sin embargo, en todos ellos, una vez se ha iniciado la abscisión, esta transcurre de forma normal (Bleecker y Patterson, 1997; Chao et al., 1997). Estas observaciones sitúan al etileno en la cadena de eventos que regulan la activación de la abscisión pero indican que su contribución al desencadenamiento del proceso no es un requerimiento absoluto (Roberts et al., 2002). La identificación de los mutantes dab (delayed floral organ abscission) de Arabidopsis thaliana, que muestran un retraso importante en la abscisión pero no presentan alteraciones en la percepción o sensibilidad al etileno, ha mostrado también que la acción de la hormona no es imprescindible en la inducción del proceso de abscisión y que, por tanto, deben existir otras rutas independientes del etileno que también pueden participar en la activación del proceso (Patterson y Bleecker, 2004). 
En los cítricos, las condiciones de estrés que provocan abscisión como el estrés hídrico, la salinidad o la falta de aporte de carbohidratos al fruto, van precedidas de un incremento en los niveles de ACC y de etileno (Gómez-Cadenas et al., 1996; 2000; Mehouachi et al., 1995; Tudela y Primo-Millo, 1992). Además, la aplicación directa de etileno o de compuestos que liberan etileno, como el etefón, o que activan la síntesis de etileno, como el CMNP (5-cloro-3-metil-4-nitro-1H-pirazol), la coronatina o el metiljasmonato promueve la abscisión (Agustí et al., 2008; Burns, 2002; Burns et al., 2003; 2006; Hartmond et al., 2000). Por otro lado, el 1-MCP (1-metilciclopropeno), un inhibidor de la unión del etileno a sus receptores, reduce la abscisión foliar inducida por etefón o CMNP (Pozo et al., 2004). Este tipo de tratamientos ha permitido clonar, por ejemplo, una celulasa ácida (Cel-al; Burns et al., 1998), una fosfolipasa D implicada en la transducción de señales de fosfolípidos (CsPLD 1 ; Malladi y Burns, 2008), una $\beta$-galactosidasa (Wu y Burns, 2004) o una proteína de transferencia de lípidos (CsLTP; Wu y Burns, 2003) en las ZAs de los cítricos.

Los tratamientos con etileno realizados en explantes son muy efectivos en la aceleración de la abscisión y han sido ampliamente utilizados en el estudio de los cambios moleculares y bioquímicos asociados al proceso (Sexton y Roberts, 1982). Este tipo de estudios han sido utilizados recientemente para analizar la abscisión foliar en los cítricos (Agustí et al., 2008, 2009) y son de gran utilidad en la búsqueda de nuevos genes candidatos a estar regulando el proceso.

En los cítricos, debido a que se trata de una especie de gran interés agronómico y comercial, es importante dirigir la investigación del proceso de abscisión hacia las estructuras reproductivas (flores, ovarios en desarrollo y frutos). El trabajo expuesto en el presente capítulo se centra en el estudio de los cambios anatómicos y moleculares que se producen en la zona de abscisión C (ZAC) de frutos maduros, localizada en la unión del cáliz con el fruto. La ZAC de los frutos cítricos contiene aproximadamente 10-15 capas celulares, a diferencia de otras especies como Arabidopsis thaliana, con una o dos capas celulares, o Phaseolus vulgaris, con una única capa de células (Roberts et al., 2000; Wright y Osborne, 1974). Estas características permiten disponer de una cantidad de material manejable para estudios moleculares o bioquímicos del proceso y, aunque en la unión cálizfruto coexisten varios tejidos, gracias a técnicas como la microdisección asistida por láser, 
se pueden aislar células exclusivas de la ZAC (Agustí et al., 2009), evitando así la contaminación con tejidos contiguos.

A continuación, se presentan los resultados del análisis anatómico y de expresión génica a gran escala de la ZAC. El análisis de expresión se ha llevado a cabo mediante la hibridación de la micromatriz de cDNA diseñada por Martínez-Godoy et al., (2008), que contiene 21.081 unigenes de la colección de ESTs (expressed sequence tag) del Proyecto de Genómica Funcional de Cítricos. Para la hibridación, se ha aislado, amplificado y marcado mRNA procedente de células de la ZAC y de la corteza del fruto (CF) obtenidas mediante microdisección asistida por láser. Las muestras de hibridación se han seleccionado en base a la comparación previa de las cinéticas de abscisión establecidas en frutos tratados con etileno in vitro y frutos no tratados. Finalmente, se han comparado los análisis de 'time course' de cada tejido y se han seleccionado los genes que se expresan únicamente en la ZAC durante el proceso de abscisión inducido por etileno. 


\subsection{Materiales y métodos}

\subsubsection{Material vegetal $y$ tratamientos}

Para llevar a cabo los experimentos recogidos en la presente tesis doctoral se han seleccionado diferentes variedades de naranjo dulce [Citrus sinensis (L.) Osb.] del grupo Navel ('Washington Navel' y 'Navel Ricalate') así como diferentes tratamientos activadores de la abscisión.

\subsubsection{Tratamiento in vitro con etileno a frutos de la variedad 'Washington} Navel'

Se emplearon frutos maduros de la variedad de naranjo dulce 'Washington Navel' [Citrus sinensis (L.) Osb.]. Estos frutos procedían de árboles cultivados bajo condiciones estándar en una parcela experimental del Instituto Valenciano de Investigaciones Agrarias (I.V.I.A.). Las muestras se recolectaron una vez se había producido el cambio de color de los frutos, momento a partir del cual la fuerza de retención del fruto al árbol comienza a descender progresivamente hasta que se produce su desprendimiento del árbol. Este proceso se conoce como abscisión precosecha. Los frutos se separaron del árbol dejando 2 $\mathrm{cm}$ de pedúnculo para no dañar la ZAC que, posteriormente, se aislaría. Las muestras se incubaron en un desecador cerrado herméticamente a $22{ }^{\circ} \mathrm{C}$ durante distintos tiempos $(0,6$, 12, 24, 48 y 96 h) en presencia de etileno $(10 \mu \mathrm{l} / \mathrm{l})$ o en aire (Figura 8.A).

\subsubsection{Tratamiento in vitro con ácido 1-aminociclopropano-1-carboxílico (ACC)} a frutos de la variedad 'Navel Ricalate'

Para el tratamiento con ACC se utilizaron frutos maduros de naranjo dulce cv. 'Navel Ricalate' procedentes de árboles cultivados bajo condiciones estándar en una parcela experimental del I.V.I.A. Las muestras se recolectaron una vez se había producido el cambio de color de los frutos. Los frutos de esta variedad no presentan problemas de abscisión precosecha. Los frutos se separaron del árbol dejando $2 \mathrm{~cm}$ de pedúnculo para acoplar sobre el mismo una pipeta 'Pasteur' ( $3 \mathrm{ml})$, que contenía una solución de ACC (0.1 
$\mathrm{mM}$ ) o agua (Figura 8.B). Los frutos se incubaron a $22^{\circ} \mathrm{C}$ durante $0,12,24,36,48,120$ y $192 \mathrm{~h}$ con ACC o con agua.
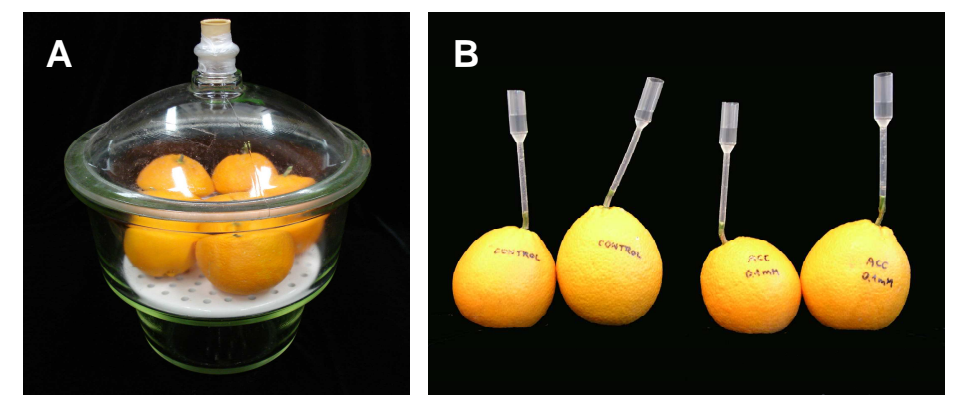

Figura 8. A. Desecador utilizado para las incubaciones de frutos de 'Washington Navel' en atmósfera de etileno o en atmósfera de aire. B. Frutos de 'Navel Ricalate' tratados con ACC junto con frutos incubados con agua (frutos control).

\subsubsection{Determinación de la fuerza de retención de los frutos}

Con el fin de establecer una cinética de abscisión de frutos bajo tratamientos activadores del proceso, se determinó la fuerza de retención mediante un dinamómetro Compact Gauge 200N (Mecmesin; Ref: 02/0073/06), siguiendo las indicaciones del fabricante. La cinética de abscisión de los frutos se expresó como kgf (kilogramo-fuerza) necesarios para separar el pedúnculo del fruto por la zona de abscisión tras distintos tiempos de tratamiento. Tanto para el experimento con etileno como para el experimento con ACC, se midió la fuerza de retención de frutos tratados y frutos no tratados a los tiempos descritos en los apartados 3.2.1.1 y 3.2.1.2, respectivamente. Finalmente, se comparó la cinética de abscisión de frutos tratados con la cinética de abscisión de frutos no tratados (ver Figura 12).

\subsubsection{Muestreo de material vegetal}

\subsubsection{Muestras de 'Washington Navel'}

En función de las diferencias observadas entre la cinética de frutos tratados y la cinética de frutos no tratados, y con el objetivo de llevar a cabo un análisis transcriptómico 
mediante micromatrices de cDNA, se tomaron muestras a las 0,12 y $24 \mathrm{~h}$ de tratamiento con etileno. Para cada uno de estos puntos de muestreo, se aislaron mediante microdisección asistida por láser (MAL; apartado 3.2.6.2) tres muestras independientes de ZAC y de corteza del fruto (CF) previamente preparadas como se explica en el apartado 3.2.6.1. Las muestras que componían la referencia se incubaron en presencia de etileno y en aire durante los tiempos especificados en el apartado 3.2.1. Estas muestras se diseccionaron manualmente utilizando una cuchilla convencional y contenían, además de la ZAC, otros tejidos adyacentes (Figura 9. B). De esta forma, se pretendía obtener una muestra de referencia lo más representativa posible. Seguidamente, las muestras se almacenaron a -80 ${ }^{\circ} \mathrm{C}$ hasta la extracción de RNA.

\subsubsection{Muestras de 'Navel Ricalate'}

En base a las diferencias observadas entre la cinética de abscisión de frutos tratados y la de frutos no tratados, se tomaron muestras a las $0,12,24,36$ y $48 \mathrm{~h}$ de tratamiento con ACC. Estas muestras se prepararon tal y como se describe en el apartado 3.2.5.2 para llevar a cabo una caracterización morfológica y una cuantificación de metabolitos mediante HPLC acoplada a espectrometría de masas de la ZAC de los frutos.

\subsubsection{Morfología e histología de la ZAC}

Con el fin de detectar la activación efectiva del proceso de abscisión con los tratamientos realizados, se llevó a cabo una tinción con phloroglucinol de secciones de material vegetal fresco. El tejido que contenía la ZAC de frutos tratados durante 0,24 y 48 $\mathrm{h}$ con etileno o ACC se diseccionó con ayuda de una cuchilla. Las muestras se cortaron longitudinalmente (Figura 9.B) para facilitar el proceso de tinción y la posterior adquisición de las imágenes. Se aplicó directamente sobre el tejido cortado una solución saturada de phloroglucinol (Sigma-Aldrich, Ref.: P3502) preparada con $\mathrm{HCl}$ al 20\%. Las muestras se observaron en una lupa binocular estereoscópica Olympus SZ61 equipada con una fuente de luz fría KL 1500 LCD y una cámara Olympus C3040-ADU. 


\subsubsection{Microscopía}

\subsubsection{Criomicroscopía electrónica de barrido (Cryo-SEM)}

Se examinó mediante Cryo-SEM el plano de fractura proximal (cáliz) y distal (fruto) de la ZAC así como secciones longitudinales de la misma tras 24, 48 y 96 h de tratamiento con etileno. En el primer caso, se separó de manera forzada el pedúnculo del fruto por la ZAC. En el segundo caso, se realizaron cortes longitudinales de la ZAC unida al fruto con ayuda de una cuchilla hasta obtener piezas de tejido de $1 \mathrm{~cm}$ aproximadamente. Las porciones de tejido se montaron sobre bloques portamuestras unidos al brazo portamuestras de un CT-1000C Cryo-transfer system (Oxford Instruments) y se congelaron en nitrógeno líquido $\left(-210{ }^{\circ} \mathrm{C}\right)$ inmediatamente. Las muestras congeladas se transfirieron a la crioplataforma de un microscopio JEOL JSM-5410 y, de ahí, a la plataforma de observación de las muestras, donde se provocó la sublimación del agua superficial condensada atemperándolas a $-85^{\circ} \mathrm{C}$. Tras esto, las muestras montadas se transfirieron de nuevo a la crioplataforma y se cubrieron con una fina capa de oro. En todos los casos, las muestras se fotografiaron a un aumento de 50X y 500X y a un voltaje de aceleración de 10 $\mathrm{keV}$.

\subsubsection{Microscopía óptica}

\subsection{Método A}

Este método se utilizó para la tinción con ácido periódico y reactivo de Schiff (PAS) y el posterior estudio histológico de la ZAC tras 0,24 y $48 \mathrm{~h}$ de tratamiento con ACC. El material vegetal se cortó en porciones de $0.3 \mathrm{~cm}$ x $0.3 \mathrm{~cm}$ x $0.3 \mathrm{~cm}$ de tamaño que se introdujeron en una solución de para-formaldehído al 4\% en tampón PBS $\left(\mathrm{Na}_{3} \mathrm{PO}_{4} 50 \mathrm{mM}\right.$, ph 7.0; $\mathrm{NaCl} 150 \mathrm{mM}$ ) para su fijación $\mathrm{d} / \mathrm{n}$ a $4{ }^{\circ} \mathrm{C}$. Al inicio de este periodo, se realizó una desgasificación de 30 minutos para que la imbibición de las muestras fuera completa. A continuación, se realizaron 4 lavados de 15 minutos con tampón PBS. Posteriormente, se deshidrataron las muestras utilizando series crecientes de etanol (50\%, 70\%, 85\%, 95\% y 100\%). Las muestras permanecieron 1 hora en cada solución, excepto en la de etanol 100\%, donde se realizaron 3 lavados de 1 hora y un lavado $\mathrm{d} / \mathrm{n}$. Una vez deshidratadas las 
muestras, se infiltraron gradualmente en resina LR White (London Resin, Ref.: 02646-AB) con series crecientes de resina-etanol (1:2, 1:1 y 2:1) permaneciendo 60 minutos en cada una de ellas. Por último, se introdujeron en resina pura al menos una noche a $4{ }^{\circ} \mathrm{C}$. Para la inclusión se emplearon cápsulas de gelatina de 0.5-1 $\mathrm{ml}$ rellenas de resina LR White pura en las que se depositó la muestra. Se mantuvieron en una estufa a $57^{\circ} \mathrm{C}$ durante 24 horas para su solidificación. Las muestras se seccionaron a $1 \mu \mathrm{m}$ de espesor con la ayuda de un microtomo de rotación Leica RM2165 y se depositaron en un portaobjetos convencional de cristal. Finalmente, las secciones se tiñeron con PAS (Sigma-Aldrich, Ref.: 395-1 y 395-2, respectivamente), se secaron y se cubrieron con 'DPX Mountant' y un cubreobjetos. Las muestras se observaron en un microscopio Leica DMLA equipado con el software 'Leica ASMLD Version 4.0', que permite llevar a cabo la adquisición de las imágenes.

\subsubsection{Método B}

Este método se ha utilizado para la tinción de criocortes de tejido con phloroglucinol y Sudán IV y la posterior caracterización histológica de la ZAC tras 0,24 y $48 \mathrm{~h}$ de tratamiento con etileno. La crioinclusión del material vegetal se realizó de forma análoga a la descrita en el apartado 3.2.6.1. Los cortes se realizaron a $14 \mu \mathrm{m}$ de espesor utilizando un criostato Leica CM1900 y el equipo 'CryoJane® Tape-Transfer' (Instrumedics, Hackensack, NJ) y se montaron sobre portaojetos 'CryoJane ${ }^{\circledR}$ Adhesive Coated Slide' (Instrumedics, Ref.: 39475208), siguiendo las indicaciones del fabricante. Seguidamente, se almacenaron a $-80{ }^{\circ} \mathrm{C}$ hasta el momento de las tinciones. Se realizaron tinciones con phloroglucinol (Sigma-Aldrich, Ref.: P3502) en $\mathrm{HCl}$ al 20\% y con una dilución 3:2 de Sudán IV (Sigma-Aldrich, Ref.: S4261) en isopropanol al 0.1\%. Tras secar las secciones, se cubrieron con 'DPX Mountant' (Fluka, Ref.: 44581) y un cubreobjetos para el montaje definitivo. La observación de las muestras se realizó tal y como se detalla en el apartado

3.2.5.2.1. 


\subsubsection{Microdisección asistida por láser (MAL)}

\subsubsection{Crioinclusión del material vegetal y montaje de los portaobjetos}

El material vegetal fresco se cortó con una cuchilla en piezas de $0.5 \mathrm{~cm}$ x $0.5 \mathrm{~cm}$ x 0.5 cm de tamaño aproximadamente, que contenían, entre otros tejidos, la zona de abscisión C (Figura 9.B). A continuación, las piezas de tejido del cáliz se incluyeron en OCT (Labonord Cryoblock; Ref.: 07111245) con la orientación adecuada para su posterior corte. La inclusión se realizó en recipientes de plástico mediante 'snap-freezing' (Figura 9.C) y se almacenaron a $-80^{\circ} \mathrm{C}$ hasta su utilización. Los cortes se realizaron a un espesor de $12 \mu \mathrm{m}$ con la ayuda de un criostato Leica CM1900 y se montaron sobre portaobjetos 'Frameslide PET-membrane' de $1.4 \mu \mathrm{m}$ de espesor (Leica; Ref.: 11505151; Figura 9.D).
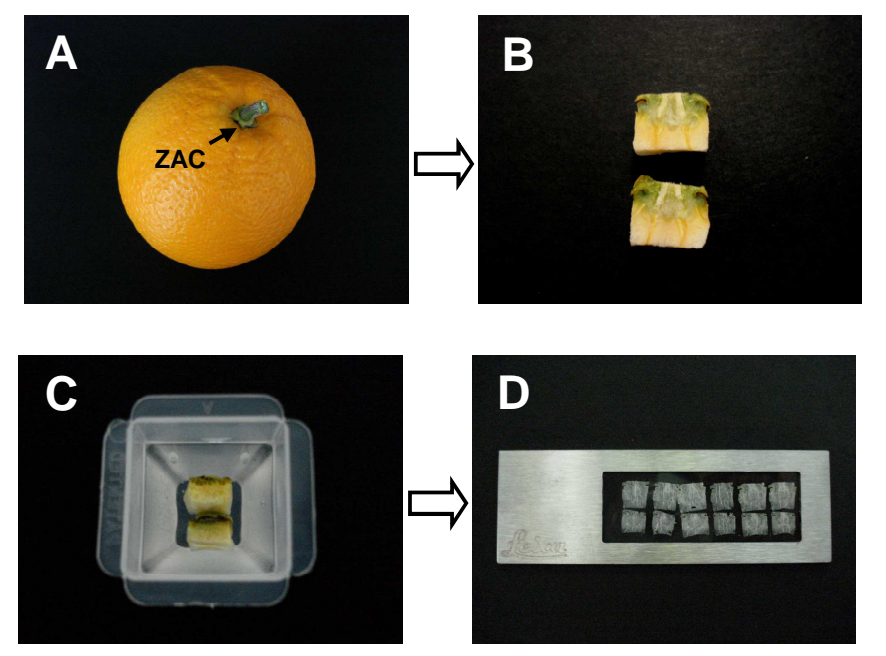

Figura 9. Crioinclusión de muestras de la ZAC y montaje de portaobjetos. A. ZAC de frutos de naranjo 'Washington Navel'. B. Disección manual del tejido que contiene la ZAC. C. Inclusión del tejido diseccionado en OCT. D. Montaje de los portaobjetos 'Frameslide PET-membrane' utilizados en la microdisección asistida por láser.

\subsubsection{Aislamiento de células mediante MAL}

La microdisección de las muestras se llevó a cabo mediante el microscopio Leica DMLA acoplado a la fuente de láser ASLMD (Leica Microsistemas) y equipado con el 
software 'Leica ASLMD Version 4.0', siguiendo las instrucciones del fabricante. Este software permitía seleccionar las áreas de tejido a diseccionar antes de comenzar el proceso. Una vez seleccionadas las áreas, el láser incidía verticalmente desde arriba cortando el material y haciéndolo caer sobre la tapa de un microtubo ( $0.5 \mathrm{ml}$ de capacidad) en la que se había depositado previamente el tampón de extracción RLT del kit 'RNeasy®' de QIAGEN (Hilden, Alemania) con un $1 \%$ de $\beta$-mercaptoetanol. Todas las muestras fueron diseccionadas utilizando el objetivo 10X y los parámetros de corte del láser que se especifican en la Tabla 1.

Tabla 1. Parámetros de corte con el láser ASLMD (software Leica ASLMD Versión 4.0).

\begin{tabular}{cc}
\hline Parámetros de corte & Valores software \\
\hline Apertura & 16 \\
Intensidad & 46 \\
Velocidad & 3 \\
\hline
\end{tabular}

Tras la microdisección, se cerró el tubo, se centrifugó brevemente para recoger el material microdiseccionado en el fondo y se almacenó a $-80{ }^{\circ} \mathrm{C}$ hasta el momento de la extracción de RNA. Se recogieron tres muestras independientes de cada tejido (ZAC y CF; Figura 10) y tiempo de tratamiento con etileno (0, 12 y 24 h). Cada una de las muestras contenía, aproximadamente, 40.000 células.

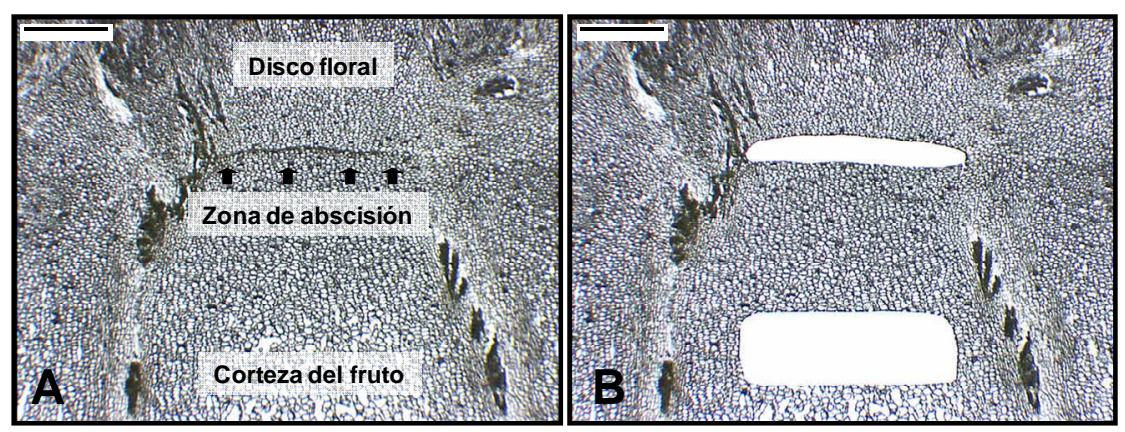

Figura 10. Aislamiento mediante microdisección asistida por láser de células de la ZAC y de la CF. A. Visión del tejido antes de microdiseccionar. B. Visión del tejido tras microdiseccionar la ZAC y la CF. Barras: $500 \mu \mathrm{m}$. Objetivo: $4 \mathrm{X}$. 


\subsubsection{Extracciones de RNA}

\subsubsection{Extracción de RNA de las muestras que componen la referencia}

Para cada una de las muestras $(0,6,12,24,48$ y 96 h en etileno y en aire), el material vegetal se pulverizó en nitrógeno líquido con ayuda de un mortero hasta reducirlo a un polvo fino. Se realizaron extracciones independientes de RNA de cada una de las muestras siguiendo el protocolo del kit 'RNeasy® Plant Mini' (QIAGEN; Ref.: 74904). Se utilizó una cantidad de material vegetal de partida de $100 \mathrm{mg}$ y el volumen final de elución en agua fue de $100 \mu \mathrm{l}$. Durante el proceso de purificación las muestras fueron tratadas con la enzima DNase I (RNase-Free DNase Set, QIAGEN; Ref.: 79254) con el fin de eliminar el posible DNA genómico arrastrado durante la extracción. La concentración y calidad del RNA se evaluó mediante el espectrofotómetro NanoDrop® ND-1000 y por electroforesis en gel de agarosa (Sambrook et al., 1989). Finalmente, la muestra de referencia se formó a partir de una mezcla que contenía la misma cantidad de RNA total ( $3 \mu \mathrm{g})$ de cada una de las extracciones independientes.

\subsubsection{Microextracción de RNA a partir de muestras obtenidas mediante} microdisección asistida por láser (MAL)

Se utilizó el kit ‘RNeasy® Micro’ (QIAGEN; Ref.: 74004), siguiendo las indicaciones del fabricante y recogiendo el RNA total en un volumen final de elución en agua de $20 \mu$ l. Se realizaron tres microextracciones independientes por cada tejido (ZAC y CF) y tiempo de tratamiento con etileno $(0,12$ y $24 \mathrm{~h})$, correspondientes a las muestras independientes microdiseccionadas. La concentración e integridad del RNA se determinó mediante el espectrofotómetro NanoDrop®.

3.2.8. Análisis de expresión génica mediante la hibridación de micromatrices de cDNA de cítricos $(20 \mathrm{~K})$

El RNA total extraído de cada muestra individual se utilizó para sintetizar cRNA antisentido marcado con el fluoróforo Cy5 y se hibridó contra cRNA antisentido marcado con Cy3 sintetizado a partir del RNA total procedente de la muestra de referencia. Este 
método permite calcular directamente la expresión diferencial de una pareja de muestras a partir de la relación de sus hibridaciones con la referencia, evitando los cálculos múltiples que se requieren con otros diseños experimentales como el diseño circular (Churchill, 2002; König et al., 2004; Novoradovskaya et al., 2004).

La micromatriz de cDNA utilizada en este experimento fue desarrollada por el Proyecto de Genómica Funcional de Cítricos (CFGP) y contenía 21.081 posibles unigenes de cítricos (Martínez-Godoy et al., 2008). A continuación, se representa de forma esquemática el proceso de hibridación de una micromatriz de cDNA (Figura 11).

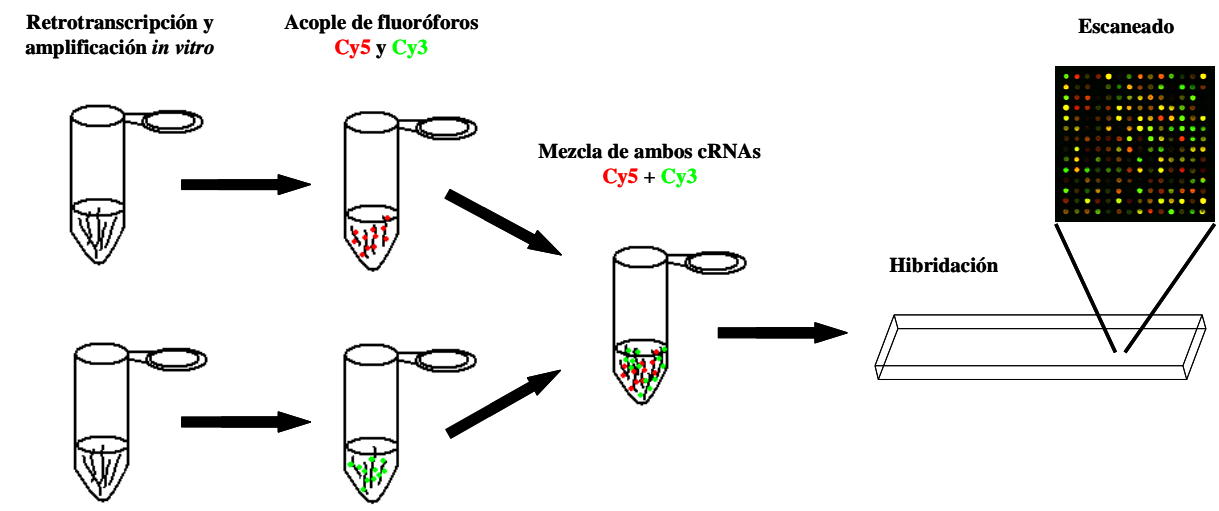

Figura 11. Proceso de hibridación de micromatrices con muestras de cRNA marcadas con dos fluoróforos distintos.

\subsubsection{Primera ronda de amplificación}

a) Síntesis de la doble cadena de cDNA

Se utilizó el kit de Epicentre Biotechnologies 'TargetAmp ${ }^{\mathrm{TM}}$ 2-Round AminoallylaRNA Amplification Kit 1.0' con número de referencia TAA2R4924, siguiendo las indicaciones del fabricante. Todos los reactivos son suministrados por el kit, excepto las retrotranscriptasas SuperScript II y SuperScript III (200 U/ $\mu$ l) de Invitrogen, con números de referencia 18064-014 y 18080-044, respectivamente, y el kit de purificación de RNA (QIAGEN). 
En cada caso se partió de 500 pg totales de RNA, que es la máxima cantidad de partida recomendada por el kit. Se preparó la reacción de síntesis de la primera cadena de cDNA en un tubo que contenía el volumen equivalente a 500 pg de RNA total, $1 \mu 1$ de T7Oligo(dT) Primer B y c.s.p. de $\mathrm{H}_{2} \mathrm{O}$ hasta un volumen total de $3 \mu$ l. La mezcla se incubó a $65^{\circ} \mathrm{C}$ durante 5 minutos para favorecer la unión del Oligo(dT) a la cola poly- $\mathrm{A}^{+}$del mRNA. A continuación, se añadieron $0.25 \mu \mathrm{l}$ de SuperScript III Reverse Transcriptase, 1.5 $\mu l$ de Reverse Transcription PreMix-SS y $0.25 \mu \mathrm{l}$ de DTT, y se incubó la mezcla durante 30 minutos a $50{ }^{\circ} \mathrm{C}$. Seguidamente, se sintetizó la segunda cadena de cDNA añadiendo $0.5 \mu \mathrm{l}$ de DNA Polymerase-SS 1 y $4.5 \mu \mathrm{l}$ de Pol PreMix-SS 1, e incubando la mezcla a $65{ }^{\circ} \mathrm{C}$ durante 10 minutos. La reacción se detuvo incubando la muestra 3 minutos a $80{ }^{\circ} \mathrm{C}$ y 1 minuto en hielo, tras lo que se añadió $1 \mu$ de Finishing Solution-SS y se incubó la muestra a $37{ }^{\circ} \mathrm{C}$ durante 10 minutos y a $80^{\circ} \mathrm{C}$ durante 3 minutos.

\section{b) Transcripción in vitro}

El cDNA sintetizado se combinó con $4 \mu \mathrm{l}$ de T7 RNA Polymerase, $4 \mu \mathrm{l}$ de Transcription Buffer, $27 \mu \mathrm{l}$ de In Vitro Trasncription Premix A y $4 \mu \mathrm{l}$ de DTT, y se incubó a $42{ }^{\circ} \mathrm{C}$ durante 4 horas. Para eliminar el cDNA se trató la muestra con RNase-Free DNase I durante 15 minutos a $37^{\circ} \mathrm{C}$. El RNA transcrito y libre de DNA se purificó utilizando el kit 'RNeasy® Mini Elute' (QIAGEN; Ref.: 74204), siguiendo el protocolo del fabricante.

\subsubsection{Segunda ronda de amplificación}

\section{a) Síntesis de la doble cadena de cDNA}

Se añadieron $2 \mu \mathrm{l}$ de Random Primers-SS a la muestra de RNA procedente de la primera ronda de amplificación y se concentró hasta un volumen de $3 \mu$ con la ayuda del SpeedVac ${ }^{\circledR}$ SPD111V (Thermo Savant). La mezcla se incubó a 5 minutos a $65{ }^{\circ} \mathrm{C}$ y 1 minuto en hielo. Tras esto, se añadió la mezcla de síntesis de la primera cadena, que contenía $0.25 \mu \mathrm{l}$ de SuperScript II Reverse Transcriptase, $1.5 \mu \mathrm{l}$ de Reverse Transcription PreMix-SS y $0.25 \mu \mathrm{l}$ de DTT, y se incubó 10 minutos a temperatura ambienten y 1 hora a $37^{\circ} \mathrm{C}$. Se añadieron $0.5 \mu \mathrm{l}$ de RNase H-SS y se incubó a $37{ }^{\circ} \mathrm{C}$ durante 20 minutos y a 95 ${ }^{\circ} \mathrm{C} 2$ minutos. Para la primera etapa de síntesis de la segunda cadena se añadió $1 \mu \mathrm{l}$ de T7- 
Oligo(dT) Primer C a la mezcla y se incubó 5 minutos a $70{ }^{\circ} \mathrm{C}$ y 10 minutos a $42{ }^{\circ} \mathrm{C}$. Seguidamente, se añadieron $0.5 \mu \mathrm{l}$ de DNA Polymerase-SS 2 y $13 \mu \mathrm{l}$ de DNA Polymerase PreMix-SS 2 , y se incubó a $37^{\circ} \mathrm{C}$ durante 10 minutos y a $80{ }^{\circ} \mathrm{C}$ durante 3 minutos.

\section{b) Transcripción in vitro con aminoalil-UTP}

El producto de la síntesis de la doble cadena de cDNA se combinó con $4 \mu \mathrm{l}$ de T7 RNA Polymerase, $9.6 \mu \mathrm{l}$ de $\mathrm{H}_{2} \mathrm{O}, 4 \mu \mathrm{l}$ de $\mathrm{T} 7$ Transcription Buffer, $16 \mu \mathrm{l}$ de In Vitro Transcription PreMix B, $2.4 \mu \mathrm{l}$ de Aminoallyl-UTP y $4 \mu \mathrm{l}$ de DTT, y se incubó durante 9 horas a $42{ }^{\circ} \mathrm{C}$. En esta reacción se emplea aminoalil-UTP porque su naturaleza química permite el posterior acople de los fluoróforos (Cy5 y Cy3). El posible cDNA remanente se eliminó añadiendo $2 \mu \mathrm{l}$ de RNase-Free DNase I e incubando la mezcla a $37^{\circ} \mathrm{C}$ durante 15 minutos. La purificación del aminoalil-RNA amplificado (AA-aRNA) se llevó a cabo con el kit 'RNeasy® Plant Mini' de QIAGEN. Finalmente, se cuantificó el RNA amplificado utilizando el espectrofotómetro NanoDrop® y se determinó el rango de tamaños mediante un gel de agarosa al $1 \%$ con bromuro de etidio, para lo que se cargaron $100 \mathrm{ng}$ de cada muestra. Las muestras de AA-aRNA se guardaron a $-80{ }^{\circ} \mathrm{C}$ hasta su posterior utilización.

\subsubsection{Acople de fluoróforos}

Para cada muestra de AA-aRNA se secó por completo un volumen equivalente a $5 \mu \mathrm{g}$ con la ayuda del SpeedVac®. El AA-aRNA desecado se resuspendió en $4 \mu \mathrm{l}$ de tampón $\mathrm{Na} 2 \mathrm{CO} 3$ 0.1 M pH 8.5. Seguidamente, se añadió a cada muestra $4 \mu$ l de solución NSH-Cy5 o NSH-Cy3 (Amersham ${ }^{\mathrm{TM}}$, UK, Ref.: PA25001 y PA23001, respectivamente), preparada según las indicaciones del fabricante, y se incubó durante 1 hora a temperatura ambiente y en oscuridad. Tras la reacción de acople del fluoróforo se purificó el aRNA utilizando el kit 'RNeasy®' de QIAGEN siguiendo el protocolo del fabricante. La concentración de fluoróforo incorporado se determinó mediante el módulo 'Microarray' del espectrofotómetro NanoDrop®. Las muestras se guardaron a $-80^{\circ} \mathrm{C}$ hasta el momento de la hibridación. 


\subsubsection{Hibridación de micromatrices}

\subsection{Preparación de las micromatrices (prehibridación)}

Las micromatrices se incubaron durante al menos 1 hora a $42{ }^{\circ} \mathrm{C}$ sumergidas en el tampón de prehibridación (SSC 5X, SDS 0.1\% y BSA 1\%) precalentado a esa temperatura. Tras la prehibridación se realizaron 3 lavados de 5 minutos cada uno en agitación con $\mathrm{H}_{2} \mathrm{O}$ DEPC a temperatura ambiente. Las micromatrices se secaron centrifugando 3 minutos a 300 r.p.m. y a temperatura ambiente.

\subsection{Preparación de las muestras}

De cada una de las muestras marcadas (Cy5 y Cy3) a hibridar se tomó el volumen equivalente a 150 pmoles de marcaje. La mezcla de ambas se concentró en el SpeedVac® hasta un volumen de $9 \mu \mathrm{l}$. A continuación, se añadió $1 \mu \mathrm{l}$ de 'Fragmentation Reagent' de Ambion (Austin, TX), con número de referencia AM8740, y se incubó a $70^{\circ} \mathrm{C}$ durante 15 minutos. Seguidamente, se añadió $1 \mu \mathrm{l}$ de 'Stop Solution' a la mezcla de reacción, se centrífugo brevemente y se mantuvo en hielo hasta la hibridación.

\subsection{Hibridación}

La micromatriz utilizada en este experimento fue descrita por Martínez-Godoy et al. (2008). La mezcla de muestras a hibridar se calentó a $80{ }^{\circ} \mathrm{C}$ durante 2 minutos. Se añadieron $50 \mu \mathrm{l}$ de tampón de hibridación (formamida 50\%, SSC 5X, SDS $0.1 \%$ y DNA de esperma de salmón $100 \mu \mathrm{g} / \mathrm{ml}$ ) precalentado a $80{ }^{\circ} \mathrm{C}$ y se centrifugó brevemente para eliminar burbujas. La solución de hibridación se depositó sobre el cubreobjetos 'Hybri-slip' (SIGMA-ALDRICH; Ref.: Z370274-100EA) formando una línea continua en uno de sus laterales largos. A continuación, la micromatriz se puso en contacto con el cubreobjetos por la línea formada por la solución de muestras y se dejó caer lentamente el lateral opuesto de modo que la solución difundiera por toda la parte impresa de la micromatriz. Inmediatamente, se invirtió la micromatriz hibridada y se colocó en la cámara de hibridación. La base de la cámara de hibridación se llenó con $100 \mathrm{ml}$ de SSC 2X para evitar la evaporación de la solución durante la hibridación. La cámara de hibridación con las 
micromatrices permaneció durante 20 horas en un horno de hibridación a $42{ }^{\circ} \mathrm{C}$ y protegida de la luz.

\subsection{Lavados}

Una vez transcurrido el tiempo de hibridación, se realizaron los lavados de las micromatrices. Para cada lavado se prepararon $200 \mathrm{ml}$ de la solución correspondiente. La secuencia de lavados se llevó a cabo como se describe a continuación:

1) 1 lavado con SSC $2 X$ y SDS $0.1 \%$. Cada micromatriz se introdujo en la solución precalentada a $42{ }^{\circ} \mathrm{C}$ en posición invertida e inclinada y se agitó suavemente hasta que el cubreobjetos se desprendió. Cada micromatriz se colocó entonces en el cestillo de tinción y se introdujo en la cubeta del segundo lavado. Los siguientes lavados se realizaron a temperatura ambiente y en agitación.

2) 1 lavado con SSC $2 X$ y SDS $0.1 \%$ durante 5 minutos.

3) 2 lavados con SSC 0.1X y SDS $0.1 \%$ durante 5 minutos cada uno.

4) 5 lavados con SSC 0.1X durante 1 minuto cada uno.

5) 1 lavado con SSC $0.01 \mathrm{X}$ durante 10 segundos.

Tras los lavados se secaron las micromatrices centrifugando a 300 r.p.m. durante 5 minutos y se guardaron protegidas de la luz hasta el momento de escasearlas.

\subsubsection{Escaneado de las micromatrices y adquisición de datos}

El escaneado de las micromatrices se llevó a cabo con el escáner ScanArray Gx (PerkinElmer), equipado con el software ScanArray Express. Las longitudes de onda utilizadas fueron $633 \mathrm{~nm}$ para el fluoróforo Cy5 y $543 \mathrm{~nm}$ para el fluoróforo Cy3. El software utilizado permite modificar la potencia del láser así como la ganancia de cada fluoróforo con el objetivo de optimizar para cada caso el proceso. La transformación de los datos de captura de imagen adquiridos con el escáner a datos numéricos se llevó a cabo con el programa GenePix Pro 6.0 (Axon Instruments), que es compatible con el software ScanArray Express. Se procedió al ajuste manual del fichero GAL (GenePix Array List) correspondiente a la micromatriz de cítricos (Martínez-Godoy et al., 2008), que consiste en una malla de puntos que acota el análisis de intensidades de hibridación a los spots de la 
micromatriz. Los datos de los spots designados por el software como 'not found' o 'bad', así como los spots cuya relación 'señal-background' era menor que 2, fueron descartados. Una vez ajustada la malla del fichero GAL y descartados los spots de intensidad débil, se grabaron los datos de hibridación para cada micromatriz.

\subsubsection{Normalización, control de calidad y análisis de las micromatrices}

La normalización, el control de calidad y el análisis de las micromatrices se realizó con el paquete LIMMA (Linear Models in Microarrays) del software Bioconductor (Gentleman et al., 2004; http://www.bioconductor.org). Los datos fueron normalizados para compensar las posibles diferencias en el marcaje de las muestras y otras fuentes de variabilidad no biológicas. Tras la normalización de los datos de las micromatrices, se seleccionaron como significativos los unigenes que presentaban un P-valor menor o igual que $5.0 \mathrm{E}^{-02}$ y un valor para $\mathrm{M}$ mayor o igual que 0.5 o menor o igual que -0.5 en los distintos contrastes. El parámetro $\mathrm{M}$ representa el nivel de expresión de un unigen en un determinado contraste. En este trabajo se llevó a cabo un estudio de 'time course' en dos tejidos diferentes (ZAC y $\mathrm{CF}$ ), de modo que el nivel de expresión venía dado por $\mathrm{M}=\log _{2}\left(\mathrm{ZAC}_{\mathrm{t}} / \mathrm{ZAC}_{0}\right)$ o $\mathrm{M}=\log _{2}\left(\mathrm{CF}_{\mathrm{t}} / \mathrm{CF}_{0}\right)$, o lo que es lo mismo: el logaritmo en base dos del cociente de la expresión entre el tiempo 't' de tratamiento (12 ó 24 h) y el tiempo ' 0 ' en cada tejido (ZAC y CF). Por tanto, los unigenes asociados a un valor de $\mathrm{M} \geq 0.5$ o $\mathrm{M} \leq-0.5$ se inducían o reprimían como mínimo 1.5 veces con respecto al tiempo '0’ en la ZAC o en la CF. Con el fin de eliminar las respuestas comunes de ambos tejidos al etileno, se compararon los análisis de 'time course' llevados a cabo en la ZAC y en la CF y se descartaron aquellos unigenes que aparecían en ambos análisis. Las tablas recogidas en los Anexos 1 y 2 muestran el nivel de expresión en el tiempo ' $t$ ' con respecto al tiempo ' 0 ' de los unigenes exclusivos de cada tejido.

\subsubsection{Agrupación en 'clusters' de los unigenes regulados por etileno en la ZAC}

Los unigenes regulados por etileno en la ZAC se agruparon en 'clusters' en función del perfil de expresión mostrado a lo largo del tratamiento $(0,12$ y 24 h en presencia de etileno). Se utilizó el algoritmo 'k-means' del programa GEPAS v4.0 (Vaquerizas et al., 2005; http://gepas3.bioinfo.cipf.es/). Los parámetros utilizados para el análisis fueron: 
distancia $=$ euclídea, número de clusters $=6$. El resto de parámetros fueron establecidos por defecto por el programa.

\subsubsection{Asignación de categorías funcionales a los unigenes regulados} diferencialmente

Para asignar una posible función a los unigenes regulados diferencialmente, se compararon sus secuencias (obtenidas de la base de datos del CGFP, http://bioinfo.ibmcp.upv.es/genomics/cfgpDB/) con el conjunto de unigenes de las bases de datos NCBI (National Center for Biotechnology Information, www.ncbi.nlm.nih.gov) y TAIR (The Arabidopsis Information Resource, www.arabidopsis.org) utilizando el algoritmo BLASTX (Altschul et al., 1990). Los homólogos con un valor esperado (E-value) inferior a $1.0 \mathrm{E}^{-03}$ fueron agrupados en categorías funcionales utilizando la herramienta FunCat de la base de datos MIPS (Munich Information Center for Protein Sequences, http://mips.gsf.de).

\subsubsection{Análisis de metabolitos mediante HPLC acoplada a espectrometría de} masas en tandem (HPLC-MS/MS)

Se recogieron tres muestras independientes de la ZAC a cada tiempo de tratamiento con $\operatorname{ACC}(0,12,24$ y 36 h) en $60 \mu \mathrm{l}$ de agua mediante microdisección asistida por láser (véase apartado 3.2.6.2). Cada una de las muestras contenía unas 40.000 células aproximadamente. Se añadieron a modo de estándares internos ácido indolacético deuterado $\left(\operatorname{IAAd}_{2}\right)$ y ácido salicílico deuterado $\left(\mathrm{SAd}_{4}\right)$ a las muestras. La suspensión resultante se incubó en un baño de ultrasonidos a temperatura ambiente durante 10 minutos para la extracción de los analitos. A continuación, el extracto se acidificó con ácido acético hasta una concentración final de $0.01 \%$ (v/v) y se realizarón dos particiones con $200 \mu \mathrm{l}$ de éter etílico. Se recuperó la fase etérea en un tubo nuevo y se evaporó a temperatura ambiente con ayuda del SpeedVac® SPD111V (Thermo Savant). El residuo seco resultante se resuspendió en $60 \mu \mathrm{l}$ de una solución de metanol grado HPLC al 30\%. Se inyectaron alícuotas de $20 \mu \mathrm{l}$ en un HPLC (Waters Alliance 2860, Waters Corp. Milford, MA, USA) y la separación se llevó a cabo en fase reversa sobre columna de C18 (Scharlau, Barcelona) utilizando como solventes metanol y agua suplementada con ácido acético a una 
concentración del $0.01 \%$ (v/v) a un flujo de $0.3 \mathrm{ml} / \mathrm{min}$ (Durgbanshi et al. 2005). La detección de los analitos se llevó a cabo mediante HPLC-MS/MS a través de una interfaz de 'electrospray' operada en modo negativo. La cuantificación de los metabolitos se realizó en base a una calibración externa con los compuestos comerciales (Tabla 2) utilizando el software Masslynx v. 4.1 (Micromass Ltd., Manchester, UK).

Tabla 2. Compuestos comerciales utilizados para el análisis de metabolitos en la zona de abscisión C mediante HPLC-MS/MS. Para cada metabolito, se muestra el estándar interno utilizado, el tipo de ionización realizada y la transición iónica experimentada.

\begin{tabular}{ccccc}
\hline Metabolito & Estándar interno & Polaridad & Transición & Fuente \\
\hline Ácido ferúlico & $\mathrm{IAAd}_{2}$ & Negativo & $193>134$ & Isotech \\
Ácido caféico & $\mathrm{SAd}_{4}$ & Negativo & $179>135$ & Sigma-Aldrich \\
Ácido cumárico & $\mathrm{IAAd}_{2}$ & Negativo & $163>119$ & Sigma-Aldrich \\
\hline
\end{tabular}

\subsubsection{RT-PCR semicuantitativa}

Los datos de la hibridación de micromatrices se confirmaron mediante análisis por RT-PCR semicuantitativa. La síntesis de la primera cadena de cDNA se llevó a cabo utilizando la retrotranscriptasa SuperScript II (Invitrogen; Ref.: 18064-014), siguiendo las indicaciones del fabricante. La reacción se preparó en un volumen total de $20 \mu$ y contenía $500 \mathrm{ng}$ de mRNA, $1 \mu \mathrm{l}$ de Oligo(dT) de Invitrogen (Ref.: 18418012), $1 \mu \mathrm{l}$ de dNTPs (10 $\mathrm{mM}$ ), $4 \mu \mathrm{l}$ de $5 X$ First-Strand Buffer, $2 \mu \mathrm{l}$ de DTT, $1 \mu \mathrm{l}$ de RNaseOUT (Invitrogen; Ref.: 10777-019), $1 \mu \mathrm{l}$ de SuperScript II RT y $12 \mu \mathrm{l}$ de $\mathrm{H}_{2} \mathrm{O}$. Las reacciones de PCR se llevaron a cabo utilizando la Taq DNA Polimerasa de BIOTOOLS (Ref.: 10.003). La mezcla de reacción contenía el volumen equivalente a $1 \mu \mathrm{g}$ de cDNA, $5 \mu \mathrm{l}$ de 10X Buffer, $1 \mu \mathrm{l}$ de dNTPs $(10 \mathrm{mM}), 2.5 \mu \mathrm{l}$ de cada cebador $(10 \mu \mathrm{M}), 1 \mu \mathrm{l}$ de Taq DNA Polimerasa y c.s.p de $\mathrm{H}_{2} \mathrm{O}$ hasta $50 \mu \mathrm{l}$. Las condiciones de amplificación por PCR fueron: 5 minutos a $95{ }^{\circ} \mathrm{C}$; 20 38 ciclos de $95{ }^{\circ} \mathrm{C}$ durante 30 segundos, $53-59^{\circ} \mathrm{C}$ (dependiendo de la pareja de cebadores) durante 30 segundos, $72{ }^{\circ} \mathrm{C}$ durante 30 segundos; 7 minutos a $72{ }^{\circ} \mathrm{C}$ y 5 minutos a $4{ }^{\circ} \mathrm{C}$. Finalmente, los productos de PCR se cargaron en un gel de agarosa al $1 \%$ para comprobar el tamaño y la intensidad de la banda esperada. El gen $U B C$ (ubiquitin-conjugating protein) se utilizó como referencia para evaluar las cantidades de mRNA en cada muestra (ZAC y CF tras 0,12 y $24 \mathrm{~h}$ de tratamiento con etileno). Los cebadores utilizados son los que se 
describen en la Tabla 3 y se diseñaron con el programa 'Primer3 version 0.4.0' (http://frodo.wi.mit.edu/primer3/).

Tabla 3. Cebadores utilizados para la RT-PCR semicuantitativa.

\begin{tabular}{|c|c|c|c|c|}
\hline Gen & Cebadores directo y reverso $\left(5^{\prime}-3^{\prime}\right)$ & $\begin{array}{c}\text { Producto } \\
(\mathbf{p b})\end{array}$ & $\begin{array}{l}\text { Temperatura } \\
\text { anillado }\left({ }^{\circ} \mathrm{C}\right)\end{array}$ & Ciclos \\
\hline CEL (C21007H10) & $\begin{array}{c}\text { GGGGTTCATCTCTACCGTCCA } \\
\text { GCTGATAATTATTACGATTATCG }\end{array}$ & 168 & $\begin{array}{l}53 \\
53\end{array}$ & 20 \\
\hline$P G$ (IC0AAA67DG09) & $\begin{array}{l}\text { AACTGCCGAAAGAACTCAGG } \\
\text { CTCCGAATTCCTCCAGTGAT }\end{array}$ & 164 & $\begin{array}{l}57 \\
57\end{array}$ & 23 \\
\hline$\beta-M A N(\mathrm{C} 03004 \mathrm{E} 07)$ & $\begin{array}{l}\text { TCATCACAGCCAAAGGAGTG } \\
\text { GGCTGTCACCACCATCACTA }\end{array}$ & 195 & $\begin{array}{l}57 \\
59\end{array}$ & 33 \\
\hline EXP (IC0AAA14BD04) & $\begin{array}{l}\text { TGTGCGAAGAAAGGAGGAAT } \\
\text { CACTGGCTGTCACTTGGAAA }\end{array}$ & 217 & $\begin{array}{l}55 \\
57\end{array}$ & 25 \\
\hline$P L(\mathrm{IC} 0 \mathrm{AAA} 15 \mathrm{AF} 11)$ & $\begin{array}{l}\text { AATGGCAATCCCTTCTCCTT } \\
\text { TGGAGCCACATAATTGGTCA }\end{array}$ & 161 & $\begin{array}{l}55 \\
55\end{array}$ & 38 \\
\hline XTH (C02023G10) & $\begin{array}{l}\text { TCATCAGACGGTCCAAATCA } \\
\text { CTGGTTCCAAAGGAGGGAAT }\end{array}$ & 180 & $\begin{array}{l}55 \\
57\end{array}$ & 28 \\
\hline$S K S(\mathrm{C} 02016 \mathrm{C} 05)$ & $\begin{array}{l}\text { CTTGGGCACGACAGTACCTT } \\
\text { TACCCAACGGTGGATCATTT }\end{array}$ & 174 & $\begin{array}{l}59 \\
55\end{array}$ & 30 \\
\hline PME (C01011H09) & $\begin{array}{l}\text { AATCAGAACACGGGCATCTC } \\
\text { TCCAGTGCAAAGTCTCCATTC }\end{array}$ & 197 & $\begin{array}{l}57 \\
57\end{array}$ & 30 \\
\hline PAE (C02003B05) & $\begin{array}{l}\text { TGAAGGCAGTGAGAGGCTTT } \\
\text { GCAAGGGTAGGGACAATCAA }\end{array}$ & 203 & $\begin{array}{l}57 \\
57\end{array}$ & 27 \\
\hline$A G P 1$ (IC0AAA56BH05) & $\begin{array}{l}\text { TTCACCCACATTAGCACCAA } \\
\text { AAATTGGTCAGAGCCACGAC }\end{array}$ & 213 & $\begin{array}{l}55 \\
57\end{array}$ & 30 \\
\hline$A G P 2(\mathrm{C} 31404 \mathrm{H} 07)$ & $\begin{array}{l}\text { CCACACGCAAACACAGATTC } \\
\text { GGGAACAACCAACAGGAAGA }\end{array}$ & 151 & $\begin{array}{l}57 \\
57\end{array}$ & 33 \\
\hline$C C R(\mathrm{C} 34205 \mathrm{C} 03)$ & $\begin{array}{l}\text { AGCCATCTGGAGAGAGGACA } \\
\text { GGCATTTATGGAAACCATGC }\end{array}$ & 175 & $\begin{array}{l}59 \\
55\end{array}$ & 33 \\
\hline$P A P(\mathrm{C} 02014 \mathrm{~A} 07)$ & $\begin{array}{l}\text { TTTATGTCCCCGCTGAGAAC } \\
\text { CCTTCCTGCCCATACCAATA }\end{array}$ & 226 & $\begin{array}{l}57 \\
57\end{array}$ & 25 \\
\hline HD-Zip (C31809D05) & $\begin{array}{l}\text { AAACATGCACAGAGCACTCG } \\
\text { GAGAATATTCGCCCCCATCT }\end{array}$ & 154 & $\begin{array}{l}59 \\
59\end{array}$ & 35 \\
\hline$U B C(\mathrm{C} 06015 \mathrm{C} 05)$ & $\begin{array}{l}\text { TGGACGCTTCAGTCTGTTTG } \\
\text { TCGTCAATCACCCCTTCTTT }\end{array}$ & 178 & $\begin{array}{l}59 \\
59\end{array}$ & 30 \\
\hline
\end{tabular}




\subsection{Resultados}

\subsubsection{Cinética de la abscisión de frutos}

Las Figuras 12.A y 12.B muestran el efecto del etileno y de su precursor, el ácido 1aminociclopropano-1-carboxílico (ACC), en el proceso de abscisión de frutos de naranjo 'Washington Navel' y 'Navel Ricalate', respectivamente.

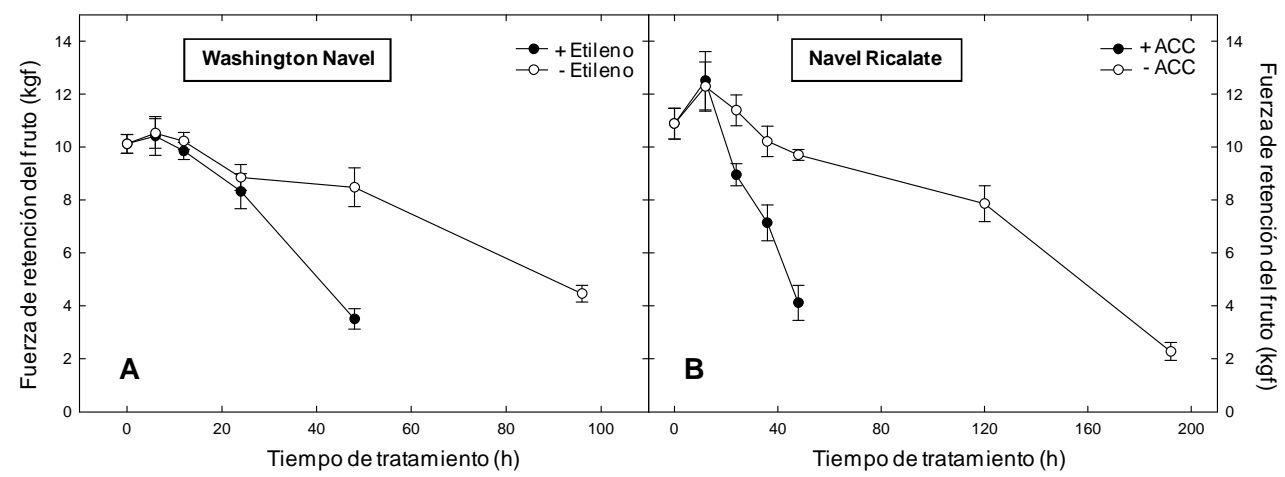

Figura 12. A. Cinética de abscisión de frutos de naranjo dulce cv. 'Washington Navel' incubados en atmósfera saturada de etileno $(\bullet)$ o en aire (०). B. Cinética de abscisión de frutos de naranjo dulce cv. 'Navel Ricalate' tratados con ACC $(\bullet)$ o sin tratar $(\circ)$. Los valores son la media \pm ES de al menos 10 frutos independientes.

La disminución en la fuerza de retención del fruto (FR) fue más rápida en los frutos tratados que en los no tratados, tanto en el experimento con etileno ('Washington Navel') como en el experimento con ACC ('Navel Ricalate'). Como se puede observar en las Figuras 12.A y 12.B, a partir de las 24 h se producía una caída más drástica de la FR en los frutos tratados. En ambos casos, a las $48 \mathrm{~h}$ se alcanzaron valores de FR en torno a 4 kgf, que se corresponden con un estado muy avanzado del proceso de abscisión. Sin embargo, en los frutos no tratados de 'Washington Navel' y 'Navel Ricalate' se alcanzaban valores de FR próximos a 4 kgf a las 96 h y a partir de las 120 h, respectivamente. Por tanto, el etileno y el ACC adelantan el inicio del proceso de abscisión de los frutos de ambas variedades y aceleran su cinética de manera prácticamente análoga. 


\subsubsection{Detección de lignina en la zona de abscisión C}

Con el fin de comprobar que, efectivamente, el proceso de abscisión transcurre de forma análoga en ambas variedades ('Washington Navel' y 'Navel Ricalate') bajo los tratamientos descritos y comprobar, además, el momento de activación del proceso, se llevó a cabo una tinción con phloroglucinol para detectar la deposición de lignina en secciones longitudinales de la zona de abscisión C (ZAC). Tras $24 \mathrm{~h}$ de tratamiento con etileno o ACC, se observó deposición de lignina en la parte central de la ZAC (Figuras 13.A y 13.B). Por tanto, la activación del programa de abscisión debe producirse antes de las $24 \mathrm{~h}$ de tratamiento en ambos experimentos. A las 48 h de tratamiento, la coloración se extendía a lo largo de la ZAC. Estos resultados, que ilustran el desarrollo del proceso de abscisión, correlacionan con los datos de la cinética de abscisión (Figuras 12.A y 12.B).
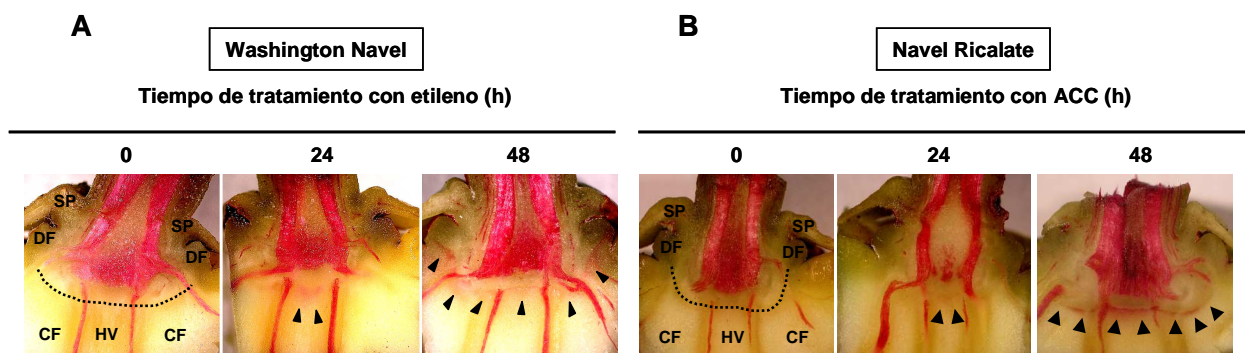

Figura 13. A. Tinción con phloroglucinol para la detección de lignina en la ZAC de frutos de 'Washington Navel' tras 0,24 y 48 h de tratamiento con etileno. B. Tinción con phloroglucinol para la detección de lignina en la ZAC de frutos de 'Navel Ricalate' tras 0, 24 y 48 h de tratamiento con ACC. ------ = zona de abscisión, $\boldsymbol{\Delta}=$ deposición de lignina (phloroglucinol) en la $\mathrm{ZAC}, \mathrm{SP}=$ sépalos, $\mathrm{DF}=$ disco floral, $\mathrm{CF}=$ corteza del fruto, $\mathrm{HV}=$ haces vasculares.

En base a estos resultados, se seleccionaron como puntos de muestreo para la hibridación de micromatrices 0,12 y 24 h de tratamiento con etileno. 


\subsubsection{Caracterización morfológica de la zona de abscisión C de los frutos}

\subsubsection{Caracterización morfológica de la ZAC mediante microscopía electrónica}

de barrido

Se utilizó la microscopía electrónica de barrido para examinar la morfología de las células de la ZAC de frutos de 'Washington Navel' tras 24, 48 y 96 h de tratamiento con etileno (Figura 14).

Tras 24 h de tratamiento con etileno, se observaba claramente la zona de abscisión C activada por el tratamiento (Figura 14.A). La imagen de más aumentos mostraba que las células de la ZAC contenían un material de naturaleza amorfa que no contenían las células parenquimáticas del cáliz y de la corteza del fruto que las rodean. La formación de esta materia amorfa podría ser el resultado del inicio de la acumulación de residuos procedentes de la disolución parcial de la lámina media en las capas de separación de la ZAC así como de la degradación de las paredes celulares. A las 48 h de tratamiento con etileno, se producía la separación efectiva entre las células de la parte central de la ZAC (Figura 14.B). En la imagen de más aumentos, se podía observar con mayor claridad la materia amorfa descrita a las 24 h debido al estado más avanzado de la degradación de las paredes celulares y se distinguía, además, una pérdida de consistencia de las células adyacentes a las capas de separación. Tras 96 h de tratamiento con etileno, la separación celular se extendía a lo largo de la ZAC y se observaba expansión celular en la parte proximal y distal de la ZAC (Figura 14.C). En la parte proximal, experimentaban expansión las células del tejido parenquimático (Figura 14.D), mientras que en la parte distal lo hacían las células de los haces vasculares (Figura 14.E). 
Tiempo de

tratamiento con

etileno

24h

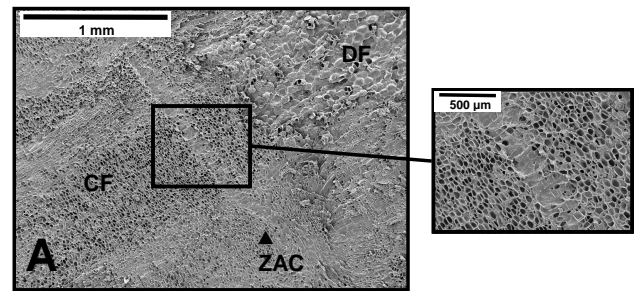

$48 \mathrm{~h}$

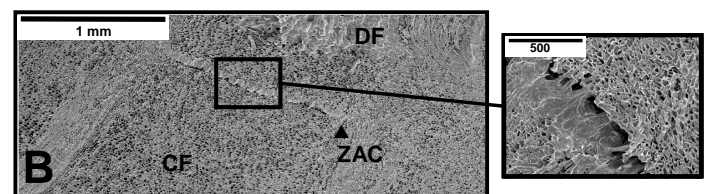

$96 \mathrm{~h}$
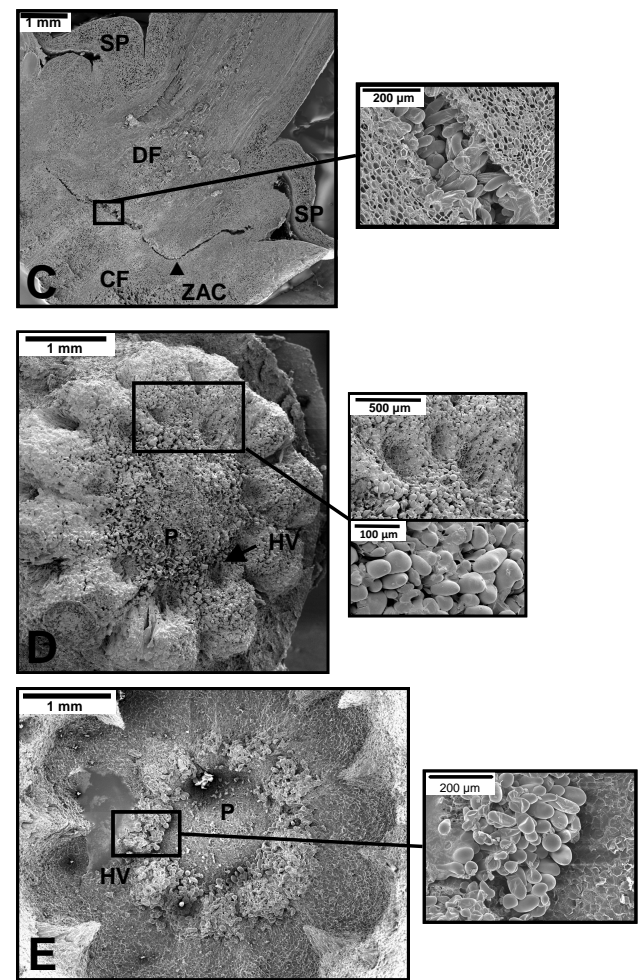

Figura 14. Morfología celular de la zona de abscisión C del fruto. Imágenes de microscopía electrónica de barrido de cortes longitudinales (A, B y C) de la ZAC de frutos maduros de naranjo 'Washington Navel' tras $24 \mathrm{~h}(\mathbf{A}), 48$ h (B) y 96 h (C) con etileno y del plano de fractura proximal (D; lado del disco floral) y distal (E; lado del fruto) tras $96 \mathrm{~h}$ con etileno. Las imágenes de mayor aumento muestran las células de la zona de separación. Barras: 1 $\mathrm{mm}, 100 \mu \mathrm{m}, 200 \mu \mathrm{m}$ y $500 \mu \mathrm{m}$. ZAC = zona de abscisión $\mathrm{C}, \mathrm{CF}=$ corteza del fruto, $\mathrm{DF}=$ disco floral, $\mathrm{SP}=$ sépalos, $\mathrm{HV}=$ haces vasculares, $\mathrm{P}=$ parénquima. 


\subsubsection{Caracterización anatómica de la ZAC mediante microscopía óptica}

Se realizaron tres tinciones diferentes a partir de cortes semifinos (alrededor de $1 \mu \mathrm{m}$ [PAS] y de 10/14 $\mu$ m [phloroglucinol y Sudán IV] de espesor) de tejido que contenía la ZAC con el objetivo de detectar los cambios anatómicos que tienen lugar en la ZAC durante el proceso de abscisión.

La Figura 15 muestra los resultados de la tinción con ácido periódico y reactivo de Schiff (PAS), que se utilizan para detectar carbohidratos insolubles. Esta tinción permitió distinguir las células de la ZAC gracias a que éstas acumulan gránulos de almidón en los plastos. En la Figura 15 se pueden ver los gránulos de almidón coloreados de rojo a las 0, 24 y 48 h de tratamiento con ACC. Tras 48 h de tratamiento, se observó la disolución de las paredes celulares así como expansión y degeneración de las células de la ZAC (Figura 15.I). Además, esta tinción permitió distinguir dos áreas celulares distintas dentro de las aproximadamente 10-15 capas celulares que componen la ZAC (Figura 15.G): un área formada por células con apariencia meristemática, localizada en la parte proximal de la ZAC (en contacto con las células de la médula del disco floral), y un área con células ricas en gránulos de almidón, localizada en la parte distal de la ZAC (en contacto con las células de la corteza del fruto). El análisis de las imágenes obtenidas sugiere que la línea de separación, donde se produce tanto la disolución de la lámina media como de las paredes primarias, se localiza fundamentalmente en las 2-3 capas de células ricas en almidón adyacentes a la zona de apariencia meristemática de la ZAC (Figura 15.I). Sin embargo, la expansión celular se observó en las 2-3 capas de células con apariencia meristemática en contacto con la zona de células ricas en almidón (Figura 15.I). 
Tiempo de tratamiento con ACC (h)

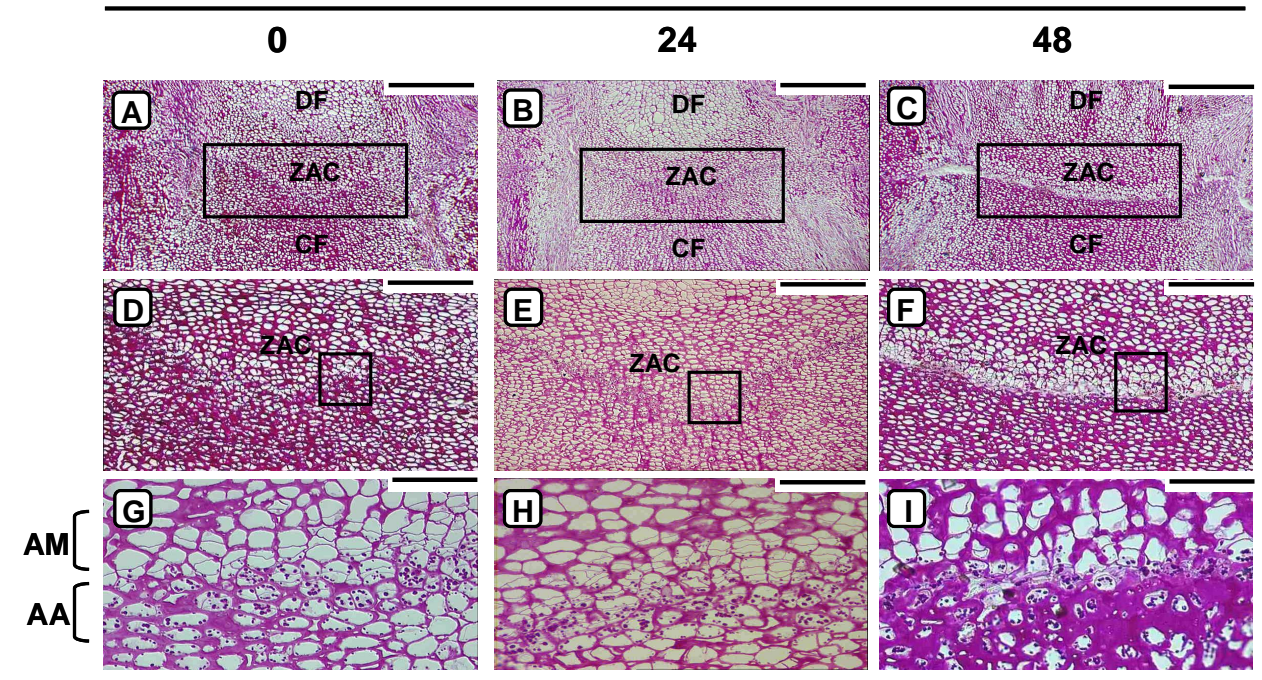

Figura 15. Tinción con PAS para carbohidratos insolubles de la ZAC de naranjo 'Navel Ricalate' a las 0 (A, D y G), 24 (B, E y H) y 48 h (C, F e I) de tratamiento con ACC. Las imágenes se tomaron con los objetivos 4X (A, B y C), 10X (D, E y F) y 40X (G, H e I). Barras: $500 \mu \mathrm{m}, 200 \mu \mathrm{m}$ y $50 \mu \mathrm{m}$. Los recuadros en $\mathbf{A}, \mathbf{B}$ y $\mathbf{C}$ y en $\mathbf{D}, \mathbf{E}$ y F marcan el área aumentada con los objetivos $10 \mathrm{X}$ y 40X, respectivamente. $\mathrm{ZAC}=$ zona de abscisión $\mathrm{C}, \mathrm{CF}=$ corteza del fruto, $\mathrm{DF}=$ disco floral, $\mathrm{AM}=$ área celular con apariencia meristemática, $\mathrm{AA}=$ área celular rica en almidón.

Por otra parte, se detectó deposición de cutina en la ZAC gracias a la tinción con Sudán IV (Figura 16). A las $24 \mathrm{~h}$ de tratamiento con etileno se comenzó a detectar una coloración rojiza confinada a las capas de separación de la ZAC (Figuras 16.B, 16.E y 16.H), que fue más intensa a las 48 h (Figuras 16.C, 16.F y 16.I). 
Tiempo de tratamiento con ACC (h)

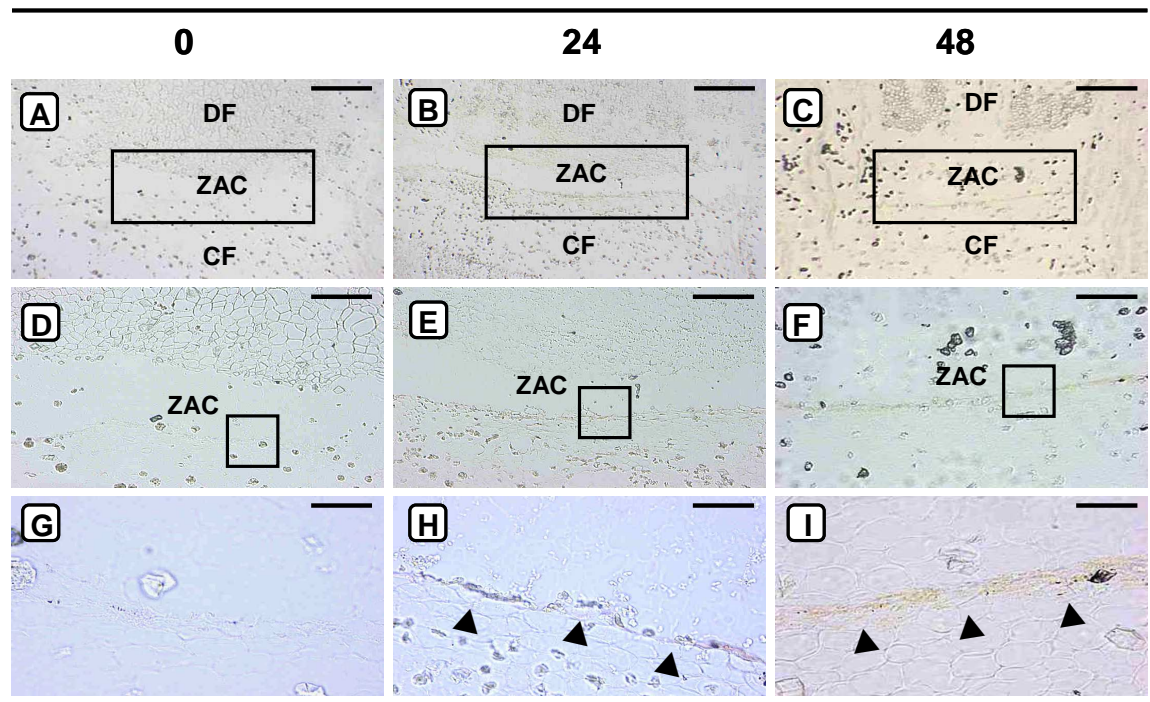

Figura 16. Tinción con Sudán IV para cutina de la ZAC de naranjo 'Washington Navel' a las 0 (A, D y G), 24 (B, $\mathbf{E}$ y $\mathbf{H})$ y 48 h (C, F e I) de tratamiento con etileno. Las imágenes se tomaron con los objetivos $4 \mathrm{X}(\mathbf{A}, \mathbf{B}$ y $\mathbf{C})$, 10X (D, E y F) y 40X (G, H e I). Barras: $500 \mu \mathrm{m}, 200 \mu \mathrm{m}$ y $50 \mu \mathrm{m}$. Los recuadros en $\mathbf{A}, \mathbf{B}$ y $\mathbf{C}$ y en $\mathbf{D}, \mathbf{E}$ y $\mathbf{F}$ marcan el área aumentada con los objetivos 10X y 40X, respectivamente. ZAC = zona de abscisión $\mathrm{C}, \mathrm{CF}=$ corteza del fruto, DF = disco floral, $\boldsymbol{\Delta}$ = deposición de cutina (Sudán IV) en la ZAC.

Se llevó a cabo una tinción con phloroglucinol de criocortes de alrededor de $10 \mu \mathrm{m}$ de espesor de la ZAC con el objetivo de observar a nivel celular, y de forma más precisa a la descrita en el apartado 3.3.2, la deposición de lignina en la ZAC (Figura 17). A las 24 h de tratamiento con etileno se observó una ligera coloración en la ZAC, mientras que a las $48 \mathrm{~h}$ la intensidad de la coloración aumentaba. Tal y como muestra la Figura 17.C, la deposición de lignina se producía exclusivamente en la parte de la corteza del fruto dentro de la ZAC. 
Tiempo de tratamiento con ACC (h)

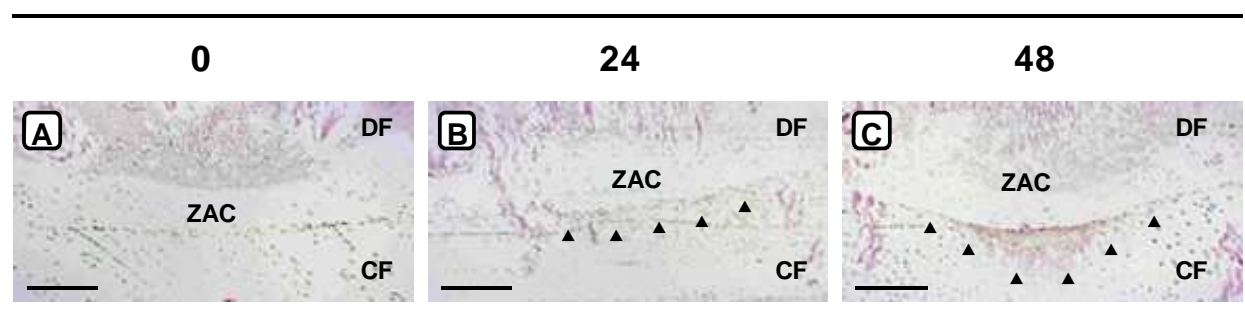

Figura 17. Tinción con phloroglucinol para lignina de la ZAC de naranjo 'Washington Navel' a las 0 (A), 24 (B) y $48 \mathrm{~h}(\mathbf{C})$ de tratamiento con etileno. Las imágenes se tomaron con el objetivo 4X. Barras: $500 \mu \mathrm{m}$. ZAC = zona de abscisión $\mathrm{C}, \mathrm{CF}=$ corteza del fruto, $\mathrm{DF}=$ disco floral, $\boldsymbol{\Delta}$ = deposición de lignina (phloroglucinol) en la ZAC.

\subsubsection{Expresión génica regulada por etileno en la zona de abscisión $\mathrm{C}$ y en la} corteza del fruto

Las micromatrices de cDNA de cítricos se hibridaron con RNA procedente de la zona de abscisión C y de la corteza del fruto con el fin de establecer los cambios secuenciales en la expresión génica que se producían en ambos tipos celulares durante las primeras $24 \mathrm{~h}$ de tratamiento con etileno. La comparación entre los análisis de 'time course' llevados a cabo en la ZAC y en la CF permitió descartar aquellos genes que aparecían en ambos análisis. Los resultados de esta comparación se muestran en la Figura 18. De los 21.081 unigenes que contiene la micromatriz de cDNA del Proyecto de Genómica Funcional de Cítricos (CFGP), el tratamiento con etileno reguló de forma significativa la expresión de 4.281 unigenes en la ZAC y 3.743 en la CF. La cantidad de genes cuya expresión estaba modulada por el etileno en ambos tejidos fue de 2.001 . 


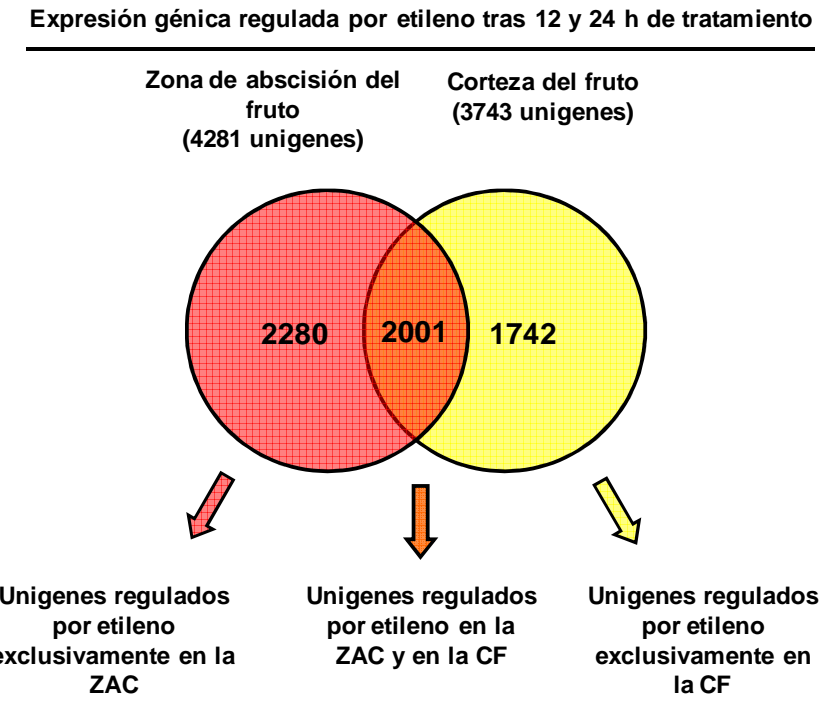

Figura 18. Diagrama de Venn de los unigenes regulados por etileno en la zona de abscisión C y en la corteza de frutos de naranjo 'Washington navel'.

Los Anexos 1 y 2 recogen el nivel de expresión en el tiempo 't' con respecto al tiempo '0' de los unigenes exclusivos de la ZAC y de la $\mathrm{CF}$, respectivamente. Los unigenes comunes a la ZAC y a la CF se recogen en el Anexo 3.

3.3.5. Perfiles de expresión de los genes regulados por etileno en la zona de abscisión C

Los 2.280 genes regulados por etileno en la ZAC se agruparon en diferentes 'clusters' en función de los perfiles de expresión génica observados. El algoritmo 'k-means' del programa estadístico GEPAS permitió organizar los transcritos con una distribución similar en seis clusters distintos. En la Figura 19, los clusters 1, 2 y 3 representan los genes que se inducían en la ZAC durante el tratamiento con etileno, mientras que los clusters 4,5 y 6 agrupan los genes que se reprimían. Concretamente, los clusters 1 y 4 agrupan genes cuya expresión aumentaba o disminuía, respectivamente, durante las primeras $12 \mathrm{~h}$ de tratamiento y luego se mantenía constante hasta las 24 h. Los clusters 2 y 5 representan genes cuya expresión se mantenía constante hasta las 12 h de tratamiento y, a partir de las $12 \mathrm{~h}$, aumentaba o disminuía, respectivamente. Por último, los clusters 3 y 6 agrupan genes que presentaban inducción o represión transitoria a las $12 \mathrm{~h}$ de tratamiento, 
respectivamente. La anotación de los genes de cada cluster se puede consultar en el Anexo 1, así como el valor de expresión a cada tiempo de tratamiento.

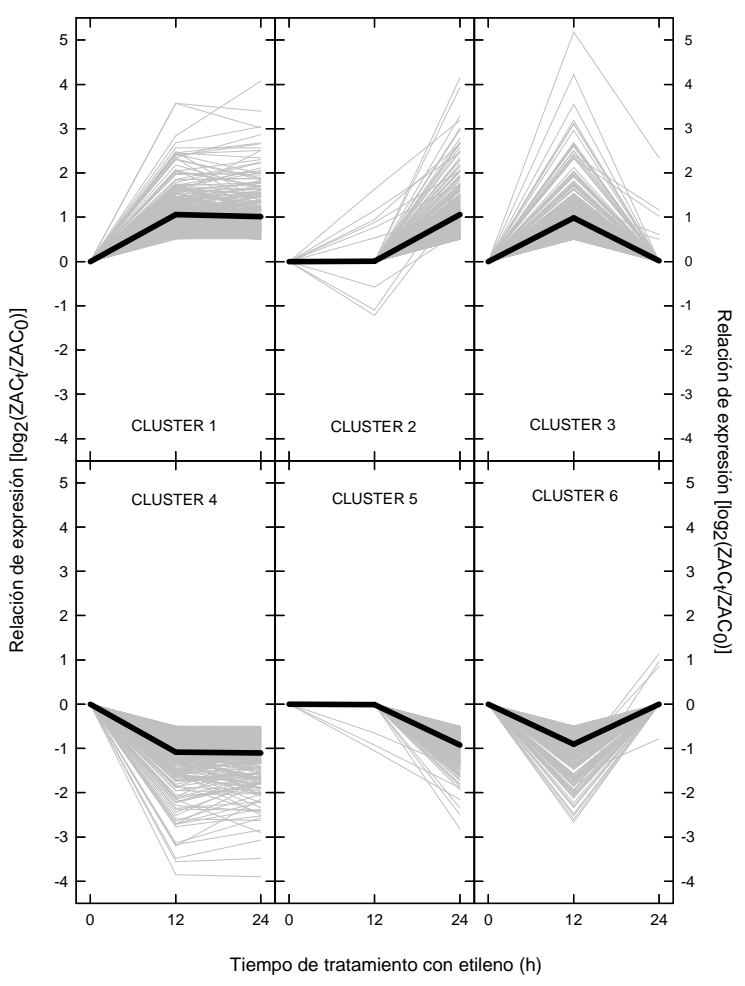

Figura 19. Clasificación en clusters de los genes regulados por etileno en la ZAC. El valor de la relación de expresión $\left[\log _{2}\left(\mathrm{ZAC}_{\mathrm{t}} / \mathrm{ZAC}_{0}\right)\right]$ que se asignó para el tiempo $0 \mathrm{~h}$ fue de '0' en todos los casos.

3.3.6. Clasificación funcional de los unigenes regulados por etileno en la zona de abscisión $\mathrm{C}$ y en la corteza del fruto

En la mayor parte de las categorías funcionales MIPS reguladas por el tratamiento con etileno, el porcentaje de unigenes fue superior en la ZAC que en la CF (ver listado completo de categorías MIPS de la ZAC y de la CF en los Anexos 4 y 5). Las categorías de 'energía', 'procesamiento del DNA y ciclo celular', 'transcripción', 'síntesis de proteínas', 'proteínas de unión', 'biogénesis de componentes celulares' y 'localización subcelular' fueron las que mostraron mayores diferencias entre ambos tejidos (Tabla 4). El porcentaje de unigenes asignados a la categoría de 'metabolismo' resultó ser muy similar en ambos 
tejidos, aunque, las subcategorías 'metabolismo de azúcares, glucósidos, polioles y carboxilatos' y 'metabolismo de polisacáridos' mostraron un porcentaje de regulación considerablemente mayor en la ZAC. Asimismo, la subcategoría 'transporte vesicular' presentó diferencias importantes en cuanto al número de unigenes regulados por el etileno en la ZAC (20 unigenes) y en la CF (12 unigenes). Atendiendo a la categoría de 'localización subcelular', las subcategorías de 'pared celular', 'vesículas de transporte intracelular' y 'proteínas de secreción/extracelulares' presentaron un porcentaje de regulación mayor en la ZAC que en la $\mathrm{CF}$.

El porcentaje y el número de unigenes de la ZAC y de la $\mathrm{CF}$ asignados al resto de categorías MIPS se puede consultar en el Anexo 6.

Tabla 4. Clasificación en categorías funcionales MIPS de los unigenes regulados por etileno en la ZAC y en la CF. Se muestra el porcentaje (calculado a partir del total de unigenes de la ZAC o de la CF asignados a las diferentes categorías MIPS) y el número de unigenes asignados a las categorías funcionales que presentaban diferencias relevantes entre la ZAC y la CF.

\begin{tabular}{|c|c|c|c|c|}
\hline \multirow[b]{2}{*}{ Categoría funcional MIPS } & \multicolumn{2}{|c|}{ Zona de abscisión $\mathrm{C}$} & \multicolumn{2}{|c|}{ Corteza del fruto } \\
\hline & $\begin{array}{c}\begin{array}{c}\text { Porcentaje de } \\
\text { unigenes }\end{array} \\
\end{array}$ & $\begin{array}{l}\text { Número de } \\
\text { unigenes }\end{array}$ & $\begin{array}{c}\begin{array}{c}\text { Porcentaje de } \\
\text { unigenes }\end{array} \\
\end{array}$ & $\begin{array}{c}\text { Número de } \\
\text { unigenes }\end{array}$ \\
\hline Metabolismo & 10.76 & 462 & 10.98 & 349 \\
\hline $\begin{array}{l}\text { - Metabolismo de carbohidratos y } \\
\text { compuestos de C }\end{array}$ & 4.10 & 176 & 4.06 & 129 \\
\hline $\begin{array}{l}\text { Metabolismo de azúcares, } \\
\text { glucósidos, polioles y carboxilatos }\end{array}$ & 2.47 & 106 & 1.95 & 62 \\
\hline - Metabolismo de polisacáridos & 0.68 & 29 & 0.35 & 11 \\
\hline Energía & 1.44 & 62 & 1.16 & 37 \\
\hline Procesamiento del DNA y ciclo celular & 2.35 & 101 & 1.86 & 59 \\
\hline Transcripción & 4.19 & 180 & 3.52 & 112 \\
\hline Síntesis de proteínas & 1.77 & 76 & 1.45 & 46 \\
\hline Proteínas de unión & 12.91 & 554 & 12.59 & 400 \\
\hline Transporte celular & 4.47 & 192 & 4.72 & 150 \\
\hline - Transporte vesicular (Golgi, etc.) & 0.47 & 20 & 0.38 & 12 \\
\hline Biogénesis de componentes celulares & 2.61 & 112 & 2.20 & 70 \\
\hline Localización subcelular & 19.45 & 835 & 18.47 & 587 \\
\hline - Pared celular & 0.77 & 33 & 0.53 & 17 \\
\hline - Vesículas de transporte intracelular & 0.26 & 11 & 0.13 & 4 \\
\hline - Proteínas de secreción/extracelulares & 0.19 & 8 & 0.13 & 4 \\
\hline
\end{tabular}




\subsubsection{Clasificación funcional de los unigenes regulados por etileno}

exclusivamente en la zona de abscisión C

Los genes que fueron regulados durante el tratamiento con etileno exclusivamente en la ZAC se agruparon en diferentes categorías funcionales MIPS (Figura 20). Las categorías que presentaron mayor número de genes, tanto inducidos como reprimidos, fueron: 'proteínas sin ortólogo en Arabidopsis', 'proteínas sin clasificar', 'localización subcelular', ‘proteínas de unión', 'plegamiento, modificación y destino de proteínas', 'transcripción', 'transporte' y 'metabolismo'.

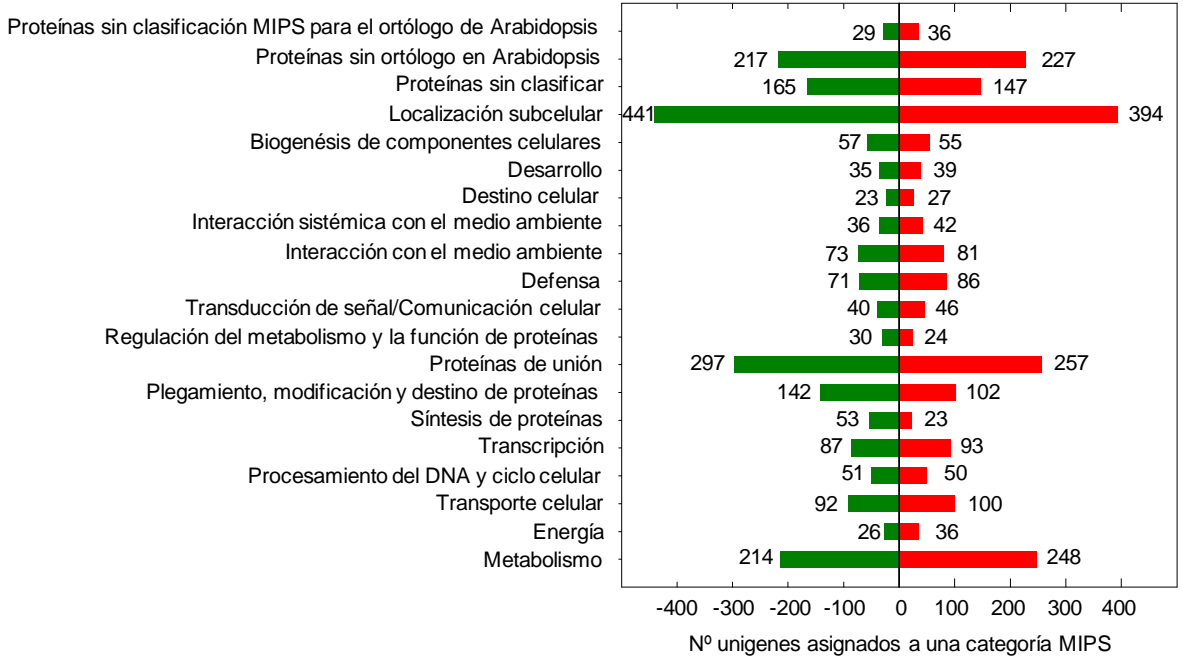

Figura 20. Distribución en categorías funcionales MIPS de los unigenes regulados por etileno en la ZAC de naranjo 'Washington Navel' tras $12 \mathrm{~h}$ y/o $24 \mathrm{~h}$ de tratamiento. Los valores positivos y negativos en la escala indican el número de unigenes inducidos (-) y reprimidos (-) en la ZAC, respectivamente.

Por otra parte, las categorías que mostraron mayores diferencias entre el número de genes inducidos y reprimidos fueron: 'metabolismo', 'energía', 'defensa', 'síntesis de proteínas', 'plegamiento, modificación y destino de proteínas' y 'proteínas de unión', siendo mayor la cantidad de genes inducidos en las tres primeras categorías y de genes reprimidos en las tres siguientes.

A continuación, se exponen los resultados de las categorías funcionales más representativas del análisis realizado en el presente capítulo. 
En relación a la categoría de 'metabolismo', el etileno indujo la expresión de 248 unigenes y reprimió la expresión de 214 unigenes. Tal y como se ha comentado en el apartado 3.3.6, las subcategorías 'metabolismo de azúcares, glucósidos, polioles y carboxilatos' y 'metabolismo de polisacáridos' mostraron un nivel de regulación superior en la ZAC en comparación con los resultados del análisis en la CF. La separación celular asociada a los últimos pasos del proceso de abscisión es consecuencia de la disolución de la lámina media y de la degradación de la pared primaria, e implica una reorganización de los polisacáridos que componen la pared.

Como se observa en la Tabla 5, el tratamiento con etileno reguló la expresión de varios genes que codifican proteínas relacionadas con la modificación de la pared celular. Una parte importante de estas familias de hidrolasas contenían tanto genes que se inducían como genes que se reprimían en la ZAC, sin embargo, otras familias estaban formadas sólo por genes inducidos o por genes reprimidos. La mayor parte de los genes inducidos se agrupaban en los clusters 1 y 2 , es decir, o bien aumentaba su expresión hasta las $12 \mathrm{~h}$ y se mantenía constante hasta las 24 h o bien aumentaba a partir de las 12 h. Sin embargo, la mayor parte de los genes reprimidos pertenecían al cluster 6 , es decir, mostraban represión transitoria a las $12 \mathrm{~h}$ de tratamiento con etileno. Así, dentro del cluster 1 se agruparon una $\beta$-galactosidasa ( $\beta$-GAL; $\mathrm{C} 31401 \mathrm{H} 10)$, una xiloglucano endotransglicosilasa (XTH; IC0AAA99CH05), una poligalacturonasa (PG; IC0AAA19CA02), una pectin metilesterasa (PME; IC0AAA40DF03) y una expansina (EXP; KN0AAQ1YG09). Por otra parte, dos PGs (IC0AAA85AB02 y IC0AAA67DG09), una pectato liasa (PL; IC0AAA15AF11), una PME (C32102B03), una celulasa (CEL; C21007H10), dos EXP (IC0AAA14BD04 y C02006G07) y una $\beta$-glucosidasa (IC0AAA1CB06) seguían el perfil de expresión del cluster 2. Dentro del cluster 3, se encontraban un PG (C01018A12) y una $\beta$-manano hidrolasa (C04002G09). En cuanto a los genes relacionados con la modificación de la pared celular que se reprimían durante el tratamiento con etileno, una XTH (C02023G10), una PL (C03011D06), dos PME (C05807A09 y C01011H09) y una $\beta$-glucosidasa (C31007D10) se anotaron en el cluster 4. El único gen agrupado en el cluster 5 (C01009B04) codificaba una XTH. En el cluster 6 quedaron agrupados los restantes genes reprimidos, que codificaban una $\beta$-GAL (C31805H10), una PG (C03009E03), dos pectin acetilesterasas (PAE; KN0AAP13YN19 y C02003B05), tres xilosidasas (C02024D10, C05075C11 y IC0AAA75AA10), una $\beta$-manano hidrolasa (C03004E07) y una PME (C08033H07). 
Tabla 5. Unigenes relacionados con el metabolismo de los polisacáridos de la pared celular regulados por el etileno exclusivamente en la ZAC. Junto a cada unigen se muestra el nivel de expresión a las 12 y $24 \mathrm{~h}$ de tratamiento con etileno con respecto a las $0 \mathrm{~h}\left[\mathrm{M}=\log _{2}\left(\mathrm{ZAC}_{\mathrm{t}} / \mathrm{ZAC}_{0}\right)\right]$. - = No se produjo cambio significativo en la expresión entre el tiempo ' $\mathrm{t}$ ' y el tiempo ' 0 ' en la ZAC.

\begin{tabular}{|c|c|c|c|c|c|}
\hline ID & Descripción & $\begin{array}{l}\text { Posible ortólogo } \\
\text { de } \text { A. thaliana }\end{array}$ & M 12h & M 24h & Cluster \\
\hline \multicolumn{6}{|l|}{$\beta$-galactosidasas } \\
\hline C $31401 \mathrm{H} 10$ & $\begin{array}{l}\text { Beta Galactosidase-like protein } \\
\text { [Ricinus communis }]\end{array}$ & AT3G54440 & 0.71 & 0.95 & 1 \\
\hline C $31805 \mathrm{H} 10$ & $\begin{array}{l}\text { Beta-D-galactosidase } \\
\text { [Prunus persica }]\end{array}$ & AT4G36360 & -1.59 & - & 6 \\
\hline \multicolumn{6}{|c|}{ Xiloglucano endotransglicosilasas } \\
\hline IC0AAA99CH05 & $\begin{array}{c}\text { Probable xyloglucan } \\
\text { endotransglucosylase/hydrolase } \\
\text { protein } 30 \text { precursor } \\
{[\text { Actinidia deliciosa }]}\end{array}$ & AT1G32170 & 1.07 & 1.03 & 1 \\
\hline C02023G10 & $\begin{array}{c}\text { Xyloglucan } \\
\text { endotransglucosylase/hydrolase } 4 \\
{[\text { Actinidia deliciosa }]}\end{array}$ & AT4G03210 & -1.55 & -2.33 & 4 \\
\hline C01009B04 & $\begin{array}{c}\text { Xyloglucan } \\
\text { endotransglucosylase/hydrolase } \\
\text { [Gossypium hirsutum] }\end{array}$ & AT5G65730 & - & -0.88 & 5 \\
\hline \multicolumn{6}{|l|}{ Poligalacturonasas } \\
\hline IC0AAA19CA02 & $\begin{array}{l}\text { Glycoside hydrolase family } 28 \\
\text { protein / polygalacturonase } \\
\text { (pectinase) family protein } \\
\text { [Arabidopsis thaliana] }\end{array}$ & AT3G57790 & 0.88 & 0.95 & 1 \\
\hline IC0AAA85AB02 & $\begin{array}{l}\text { Polygalacturonase-like protein } \\
\text { [Ricinus communis }]\end{array}$ & AT3G48950 & 0.58 & 0.63 & 2 \\
\hline IC0AAA67DG09 & $\begin{array}{l}\text { Polygalacturonase } \\
\text { [Pyrus communis }]\end{array}$ & AT2G43870 & 0.42 & 2.34 & 2 \\
\hline C01018A12 & $\begin{array}{l}\text { Polygalacturonase-like protein } \\
\text { [Ricinus communis }]\end{array}$ & AT3G61490 & 1.02 & - & 3 \\
\hline C03009E03 & $\begin{array}{l}\text { Putative polygalacturonase } \\
\text { [Ricinus communis] }\end{array}$ & AT4G23820 & -1.58 & - & 6 \\
\hline \multicolumn{6}{|l|}{ Pectato liasas } \\
\hline IC0AAA15AF11 & $\begin{array}{c}\text { Pectate lyase } \\
\text { [Gossypium hirsutum }]\end{array}$ & AT1G67750 & 0.81 & 2.66 & 2 \\
\hline C03011D06 & $\begin{array}{l}\text { Probable pectate lyase } 22 \text { precursor } \\
\text { [Ricinus communis }]\end{array}$ & AT5G63180 & -0.86 & -0.80 & 4 \\
\hline \multicolumn{6}{|c|}{ Pectin metilesterasas } \\
\hline IC0AAA40DF03 & $\begin{array}{c}\text { Pectin methylesterase-like protein } \\
{[\text { Arabidopsis thaliana }]}\end{array}$ & AT1G69940 & 0.71 & 0.71 & 1 \\
\hline С $32102 B 03$ & $\begin{array}{l}\text { Pectinesterase family protein } \\
{[\text { Arabidopsis thaliana }]}\end{array}$ & AT5G09760 & - & 1.41 & 2 \\
\hline C05807A09 & $\begin{array}{l}\text { Pectin methylesterase } \\
\text { [Ricinus communis }]\end{array}$ & AT4G33220 & -3.13 & -2.57 & 4 \\
\hline C01011H09 & $\begin{array}{l}\text { Pectin methylesterase } \\
\text { [Pyrus communis }]\end{array}$ & AT5G53370 & -2.15 & -2.90 & 4 \\
\hline С08033H07 & $\begin{array}{l}\text { Pectin methylesterase precursor } \\
\text { [Ricinus communis }]\end{array}$ & AT1G11580 & -2.30 & -0.88 & 6 \\
\hline
\end{tabular}


Tabla 5 (continuación de la página anterior).

\begin{tabular}{|c|c|c|c|c|c|}
\hline ID & Descripción & $\begin{array}{c}\text { Posible ortólogo } \\
\text { de } A \text {. thaliana }\end{array}$ & M 12h & M 24h & Cluster \\
\hline \multicolumn{6}{|c|}{ Pectin acetilesterasas } \\
\hline KN0AAP13YN19 & $\begin{array}{l}\text { Pectin acetylesterase } \\
\text { [Ricinus communis }]\end{array}$ & AT5G26670 & -0.72 & - & 6 \\
\hline С02003B05 & $\begin{array}{l}\text { Putative pectinacetylesterase } \\
{[\text { Arabidopsis thaliana }]}\end{array}$ & AT5G26670 & -1.57 & - & 6 \\
\hline \multicolumn{6}{|l|}{ Celulasas } \\
\hline $\mathrm{C} 21007 \mathrm{H} 10$ & Acidic cellulase [Citrus sinensis] & AT4G02290 & - & 4.15 & 2 \\
\hline \multicolumn{6}{|l|}{ Expansinas } \\
\hline KN0AAQ1YG09 & $\begin{array}{c}\text { Expansin-like protein B } \\
\text { [Oryza sativa Japonica Group }]\end{array}$ & AT4G17030 & 1.69 & 1.40 & 1 \\
\hline IC0AAA14BD04 & $\begin{array}{l}\text { Expansin precursor } \\
\text { [Citrus sinensis }]\end{array}$ & AT2G40610 & - & 3.01 & 2 \\
\hline C02006G07 & Expansin [Glycine max $]$ & AT1G20190 & - & 0.75 & 2 \\
\hline \multicolumn{6}{|l|}{$\beta$-glucosidasas } \\
\hline IC0AAA1CB06 & $\begin{array}{l}\text { Putative beta-glycosidase } \\
\text { [Solanum lycopersicum] }\end{array}$ & AT2G44480 & - & 0.62 & 2 \\
\hline C31007D10 & $\begin{array}{l}\text { Putative beta-glucosidase } \\
\text { [Ricinus communis }]\end{array}$ & AT5G20950 & -0.59 & -0.55 & 4 \\
\hline \multicolumn{6}{|l|}{ Xylosidasas } \\
\hline C02024D10 & $\begin{array}{c}\text { Beta-xylosidase } \\
{[\text { Arabidopsis thaliana }]}\end{array}$ & AT1G78060 & -0.63 & - & 6 \\
\hline $\mathrm{C} 05075 \mathrm{C} 11$ & $\begin{array}{c}\text { Alpha-xylosidase } \\
{[\text { Arabidopsis thaliana }]}\end{array}$ & AT1G68560 & -0.98 & - & 6 \\
\hline IC0AAA75AA10 & $\begin{array}{l}\text { Beta-xylosidase } \\
\text { [Arabidopsis thaliana] }\end{array}$ & AT5G20950 & -0.99 & - & 6 \\
\hline \multicolumn{6}{|c|}{ Endo-1,4- $\beta$-manosidasa } \\
\hline C04002G09 & $\begin{array}{l}\text { (1-4)-beta-mannan endohydrolase } \\
\text { precursor [Coffea arabica] }\end{array}$ & AT1G68560 & 1.41 & - & 3 \\
\hline C03004E07 & $\begin{array}{l}\text { Mannan endo-1,4-beta-mannosidase } \\
\text { [Cucumis melo }]\end{array}$ & AT5G66460 & -1.44 & - & 6 \\
\hline
\end{tabular}

Además de regular genes que codifican enzimas implicadas en la hidrólisis de la pared celular, el etileno reguló la expresión de genes relacionados con la biosíntesis de la pared celular (Tabla 6). Excepto una celulosa sintasa (IC0AAA5DG11) y una ramnosa sintasa (KNOAAI3AD11), que se reprimieron transitoriamente a las $12 \mathrm{~h}$ de tratamiento, el resto de genes de este tipo se indujeron en la ZAC. Así, se indujeron dos celulosas sintasas, una de forma transitoria a las $12 \mathrm{~h}$ de tratamiento (C16012C03) y otra a las $24 \mathrm{~h}$ (C05070F01), y una UDP-glucosa-4-epimerasa (C31108G08) y dos manano sintasas (IC0AAA16BH03 y IC0AAA99AD02) también a las $24 \mathrm{~h}$. 
Tabla 6. Unigenes relacionados con la biosíntesis de polisacáridos de la pared celular regulados por el etileno exclusivamente en la ZAC. Junto a cada unigen se muestra el nivel de expresión a las 12 y 24 h de tratamiento con etileno con respecto a las $0 \mathrm{~h}\left[\mathrm{M}=\log _{2}\left(\mathrm{ZAC}_{\mathrm{t}} / \mathrm{ZAC}_{0}\right)\right]$. - = No se produjo cambio significativo en la expresión entre el tiempo ' $t$ ' y el tiempo '0' en la ZAC.

\begin{tabular}{|c|c|c|c|c|c|}
\hline ID & Descripción & $\begin{array}{l}\text { Posible ortólogo } \\
\text { de A. thaliana }\end{array}$ & M 12h & M 24h & Cluster \\
\hline C05070F01 & $\begin{array}{c}\text { Cellulose synthase-like protein D4 } \\
\text { [Populus tremuloides }]\end{array}$ & AT3G03050 & - & 0.68 & 2 \\
\hline C31108G08 & $\begin{array}{l}\text { UDP-glucose 4-epimerase } \\
\text { [Solanum tuberosum }]\end{array}$ & AT4G10960 & - & 0.95 & 2 \\
\hline IC0AAA16BH03 & $\begin{array}{c}\text { ATCSLA02; mannan synthase/ transferase } \\
{[\text { [Arabidopsis thaliana }]}\end{array}$ & AT5G22740 & - & 1.47 & 2 \\
\hline IC0AAA99AD02 & $\begin{array}{c}\text { ATCSLA02; mannan synthase/ transferase } \\
{[\text { Arabidopsis thaliana }]}\end{array}$ & AT5G22740 & - & 1.36 & 2 \\
\hline $\mathrm{C} 16012 \mathrm{C} 03$ & $\begin{array}{l}\text { Putative cellulose synthase } \\
\text { [Ricinus communis }]\end{array}$ & AT4G24010 & 1.82 & - & 3 \\
\hline IC0AAA5DG11 & $\begin{array}{c}\text { Cellulose synthase A catalytic subunit } 6 \\
\text { [Ricinus communis] }\end{array}$ & AT5G05170 & -1.74 & - & 6 \\
\hline KN0AAI3AD11 & $\begin{array}{c}\text { RHM1 (RHAMNOSE BIOSYNTHESIS } \\
\text { 1); UDP-L-rhamnose synthase } \\
\text { [Arabidopsis thaliana] }\end{array}$ & AT1G78570 & -0.52 & - & 6 \\
\hline
\end{tabular}

En relación al metabolismo de la lignina, el etileno reguló la expresión de 6 genes integrados en la ruta de biosíntesis (Tabla 7). Una fenilalanina amonio liasa (PAL; C02002A11) y una cinamoil-CoA reductasa (CCR; C34205C03) se inducían durante las primeras $12 \mathrm{~h}$ de tratamiento y mantenían el nivel de expresión hasta las 24 h, una 4cumarato-CoA ligasa (4CL; C31504D07) se inducía a las $24 \mathrm{~h}$ y una lacasa (IC0AAA50DG04) se inducía de forma transitoria a las $12 \mathrm{~h}$. Mientras que 2 genes de la familia de las O-metiltransferasas del ácido cafeico (COMT) se reprimían, uno a las 24 h de tratamiento (C05133H01) y otro de forma transitoria a las $12 \mathrm{~h}$ (C03007H04).

Por otra parte, dos unigenes relacionados con la biosíntesis de cutina, una esterol desaturasa (C02002B06) y una glicerol-3-fostato aciltransferasa (C31604E03), se inducían en la ZAC a las 12 y a las $24 \mathrm{~h}$ de tratamiento con etileno, respectivamente (Tabla 7). Sin embargo, un unigen correspondiente a otra esterol desaturasa (IC0AAA51DG12) se reprimía a las $12 \mathrm{~h}$ de tratamiento con etileno en la ZAC. La inducción de dos genes relacionados con la biosíntesis de cutina correlacionaba con la deposición de cutina observada en cortes de la ZAC a las 24 y $48 \mathrm{~h}$ de tratamiento (Figura 16). 
Tabla 7. Unigenes relacionados con la biosíntesis de lignina y de cutina regulados por el etileno exclusivamente en la ZAC. Junto a cada unigen se muestra el nivel de expresión a las 12 y $24 \mathrm{~h}$ de tratamiento con etileno con respecto a las $0 \mathrm{~h}\left[\mathrm{M}=\log _{2}\left(\mathrm{ZAC}_{\mathrm{t}} / \mathrm{ZAC}_{0}\right)\right]$. - = No se produjo cambio significativo en la expresión entre el tiempo ' $\mathrm{t}$ ' y el tiempo '0' en la ZAC.

\begin{tabular}{|c|c|c|c|c|c|}
\hline ID & Descripción & $\begin{array}{l}\text { Posible ortólogo } \\
\text { de } \text { A. thaliana }\end{array}$ & M 12h & M 24h & Cluster \\
\hline \multicolumn{6}{|c|}{ Biosíntesis de lignina } \\
\hline C02002A11 & $\begin{array}{l}\text { Phenylalanine ammonia-lyase } \\
\text { [Canarium album] }\end{array}$ & AT3G10340 & 2.33 & 1.22 & 1 \\
\hline C $34205 \mathrm{C} 03$ & $\begin{array}{l}\text { Cinnamoyl-CoA reductase-like protein } \\
\text { [Ricinus communis }]\end{array}$ & AT4G30470 & 0.94 & 1.39 & 1 \\
\hline C31504D07 & $\begin{array}{l}\text { 4-coumarate-CoA ligase-like } \\
\text { [Populus trichocarpa }]\end{array}$ & AT4G19010 & - & 1.00 & 2 \\
\hline IC0AAA50DG04 & Laccase II [Hortaea acidophila] & AT4G39830 & 0.87 & - & 3 \\
\hline C05133H01 & $\begin{array}{c}\text { Caffeic acid 3-O-methyltransferase } \\
\text { [Citrus aurantium] }\end{array}$ & AT5G54160 & - & -0.87 & 5 \\
\hline C03007H04 & $\begin{array}{c}\text { Caffeic acid 3-O-methyltransferase } \\
\text { [Coffea canephora }]\end{array}$ & AT5G54160 & -0.75 & - & 6 \\
\hline \multicolumn{6}{|c|}{ Biosíntesis de cutina } \\
\hline C31604E03 & $\begin{array}{c}\text { Glycerol-3-phosphate acyltransferase } 4 \\
\text { [Vernicia fordii] }\end{array}$ & AT4G00400 & - & 2.50 & 2 \\
\hline C02002B06 & $\begin{array}{l}\text { Sterol desaturase; CER3 } \\
\text { (ECERIFERUM 3) } \\
\text { [Arabisopsis thaliana] }\end{array}$ & AT5G57800 & 1.40 & - & 3 \\
\hline IC0AAA51DG12 & $\begin{array}{l}\text { Sterol desaturase; CER1 } \\
\text { (ECERIFERUM 1) } \\
\text { [Arabisopsis thaliana] }\end{array}$ & AT1G02205 & -0.58 & - & 6 \\
\hline
\end{tabular}

Utilizando HPLC acoplada a espectrometría de masas se detectó un aumento en los niveles de algunos componentes de la ruta de síntesis de lignina en células de la ZAC tras el tratamiento con etileno (Figura 21). Como se observa en la Figura 21.A, se produjo un incremento significativo de ácido cumárico en la ZAC tras $12 \mathrm{~h}$ de tratamiento con etileno. Este aumento en la cantidad de ácido cumárico fue acompañado por un aumento en la cantidad de ácido cafeico y ferúlico, compuestos que se sintetizan a partir del ácido cumárico. Los niveles altos de ácido cafeico y ferúlico se mantuvieron desde las $12 \mathrm{~h}$ hasta las $36 \mathrm{~h}$ de tratamiento (Figuras 21.B y 21.C). La detección de estos analitos en la ZAC activada por etileno correlaciona con los datos de expresión asociados a la biosíntesis de lignina (Tabla 7) y con la deposición de lignina observada tras 24 y $48 \mathrm{~h}$ de tratamiento (Figuras 13 y 17). 


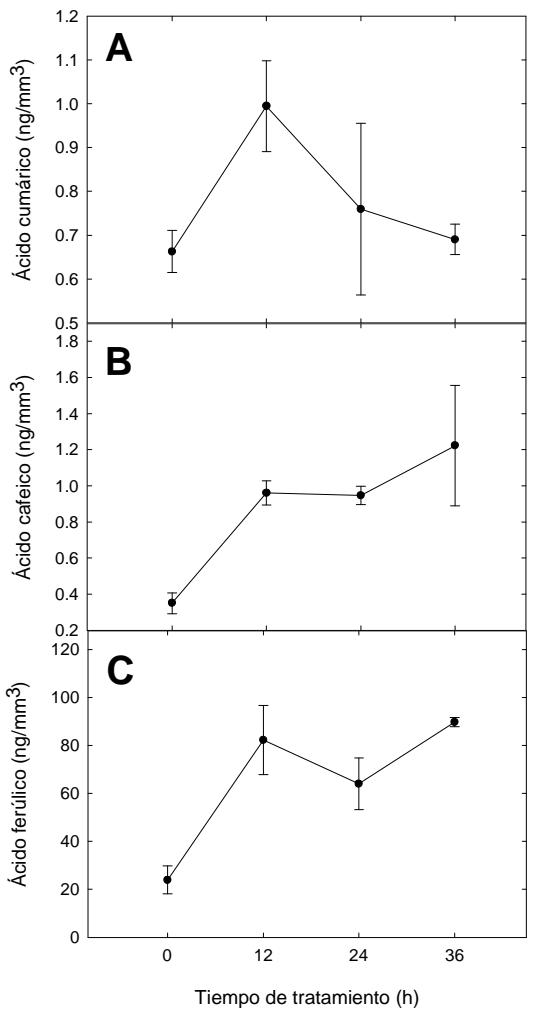

Figura 21. Cuantificación de compuestos de la ruta de biosíntesis de la lignina mediante HPLC acoplada a espectrometría de masas (HPLC-MS/MS) en tejido microdiseccionado de la ZAC tras 0, 12, 24 y 36 h de tratamiento con ACC. A. Medida de la cantidad de ácido cumárico expresada en ng por $\mathrm{mm}^{3}$ de tejido microdiseccionado. B. Medida de la cantidad de ácido cafeico expresada en ng por $\mathrm{mm}^{3}$ de tejido microdiseccionado. C. Medida de la cantidad de ácido ferúlico expresada en ng por $\mathrm{mm}^{3}$ de tejido microdiseccionado.

Un número importante de los unigenes asignados a la categoría 'proteínas de unión' fueron agrupados en la subcategoría 'preoteínas de unión a proteína'. La Tabla 8 recoge algunos de estos unigenes, que codifican, principalmente, proteínas de ubiquitinación y degradación de proteínas vía proteasoma. Concretamente, estos unigenes codificaban 17 proteínas que conjugan ubiquitina (proteínas E1, E2 y E3), 4 poliubiquitinas y 9 proteínas del proteasoma. 
Tabla 8. Unigenes relacionados con la ubiquitinación y la degradación de proteínas vía proteasoma regulados por el etileno exclusivamente en la ZAC. Junto a cada unigen se muestra el nivel de expresión a las 12 y 24 h de tratamiento con etileno con respecto a las $0 \mathrm{~h}\left[\mathrm{M}=\log _{2}\left(\mathrm{ZAC}_{\mathrm{t}} / \mathrm{ZAC}_{0}\right)\right]$. - = No se produjo cambio significativo en la expresión entre el tiempo ' $\mathrm{t}$ ' y el tiempo ' 0 ' en la ZAC.

\begin{tabular}{|c|c|c|c|c|c|}
\hline ID & Descripción & $\begin{array}{l}\text { Posible ortólogo } \\
\text { de } \text { A. thaliana }\end{array}$ & M 12h & M 24h & Cluster \\
\hline \multicolumn{6}{|l|}{ Proteínas E1 } \\
\hline C32106B08 & $\begin{array}{l}\text { Ubiquitin activating enzyme E1 } \\
\text { [Nicotiana tabacum }]\end{array}$ & AT2G30110 & - & -0.82 & 5 \\
\hline \multicolumn{6}{|l|}{ Proteínas E2 } \\
\hline C04035F10 & $\begin{array}{l}\text { Ubiquitin carrier protein } 4 \\
\text { [Ricinus communis }]\end{array}$ & AT5G41340 & 1.14 & 0.82 & 1 \\
\hline C34110B03 & $\begin{array}{l}\text { Ubiquitin-conjugating enzyme E2-17 } \\
\text { kDa 10/12 [Arabidopsis thaliana] }\end{array}$ & AT1G64230 & 0.85 & - & 3 \\
\hline KN0AAA1DE04 & $\begin{array}{l}\text { Putative ubiquitin carrier protein } \\
\text { [Ricinus communis }]\end{array}$ & AT1G50490 & -1.96 & -1.64 & 4 \\
\hline C20006C06 & $\begin{array}{l}\text { Ubiquitin conjugating enzyme } \\
\text { [Ricinus communis }]\end{array}$ & AT5G50870 & - & -0.76 & 5 \\
\hline \multicolumn{6}{|l|}{ Proteínas E3 } \\
\hline C06022A03 & U-box protein [Capsicum annuum] & AT3G52450 & 0.60 & 0.74 & 1 \\
\hline IC0AAA47CF03 & $\begin{array}{l}\text { RING-H2 finger protein } \\
\text { [Arabidopsis thaliana] }\end{array}$ & АT3G60220 & 1.16 & 0.93 & 1 \\
\hline С08033H03 & $\begin{array}{l}\text { RING-H2 finger protein ATL4M } \\
\text { [Ricinus communis }]\end{array}$ & AT4G35840 & 0.75 & 0.73 & 1 \\
\hline IC0AAA11BB03 & $\begin{array}{l}\text { RING/C3HC4/PHD zinc finger-like } \\
\text { protein [Cucumis melo] }\end{array}$ & AT5G27420 & 0.74 & 0.68 & 1 \\
\hline KN0AAQ4YD04 & $\begin{array}{l}\text { RING/U-box superfamily protein } \\
\text { [Arabidopsis thaliana] }\end{array}$ & AT3G09760 & - & 0.72 & 2 \\
\hline IC0AAA65CC10 & $\begin{array}{c}\text { OSJNBa0076N16.22 protein } \\
\text { [ARIADNE } 8 \text { (ARI8)] [Oryza sativa] }\end{array}$ & AT1G65430 & - & 0.64 & 2 \\
\hline IC0AAA16DB01 & $\begin{array}{l}\text { RING-H2 subgroup RHE protein } \\
{[\text { Populus tremula x Populus alba }]}\end{array}$ & AT3G16720 & 0.90 & - & 3 \\
\hline C08015H05 & $\begin{array}{l}\text { Zinc finger (C3HC4-type RING finger) } \\
\text { protein-like [Vitis vinifera] }\end{array}$ & AT1G11020 & - & -0.69 & 5 \\
\hline C07006D03 & $\begin{array}{l}\text { RING-H2 zinc finger protein RHA2a } \\
{[\text { Arabidopsis thaliana }]}\end{array}$ & AT1G15100 & - & -1.57 & 5 \\
\hline C34009C07 & $\begin{array}{l}\text { Zinc finger (C3HC4-type RING finger) } \\
\text { family protein [Arabidopsis thaliana] }\end{array}$ & AT3G55530 & - & -1.19 & 5 \\
\hline C05069A02 & $\begin{array}{l}\text { Zinc finger (C3HC4-type RING finger) } \\
\text { family protein [Arabidopsis thaliana] }\end{array}$ & AT1G23980 & -0.65 & - & 6 \\
\hline C02003A07 & $\begin{array}{l}\text { RING-H2 finger protein ATL2C } \\
\text { [Zea mays }]\end{array}$ & AT4G30400 & -1.02 & - & 6 \\
\hline \multicolumn{6}{|l|}{ Poliubiquitinas } \\
\hline C08010E08 & Polyubiquitin [Naegleria gruberi] & AT5G20620 & - & 0.74 & 2 \\
\hline $\mathrm{C} 31302 \mathrm{~F} 04$ & Polyubiquitin [Ricinus communis] & AT1G31340 & -1.12 & -1.41 & 4 \\
\hline C08008E05 & Polyubiquitin [Hevea brasiliensis] & AT4G05320 & -0.68 & -0.71 & 4 \\
\hline $\mathrm{C} 08012 \mathrm{~F} 03$ & Polyubiquitin [Naegleria gruberi] & AT5G20620 & -0.64 & - & 6 \\
\hline
\end{tabular}


Tabla 8 (continuación de la página anterior).

\begin{tabular}{|c|c|c|c|c|c|}
\hline ID & Descripción & $\begin{array}{l}\text { Posible ortólogo } \\
\text { de A. thaliana }\end{array}$ & M 12h & M 24h & Cluster \\
\hline \multicolumn{6}{|c|}{ Proteínas del proteasoma } \\
\hline C32003H11 & $\begin{array}{c}\text { 26S protease regulatory subunit } 7 \\
\text { [Lactuca sativa }]\end{array}$ & AT1G53750 & 0.71 & 0.70 & 1 \\
\hline C31204B08 & $\begin{array}{c}\text { Putative } 26 \mathrm{~S} \text { proteasome regulatory } \\
\text { subunit S2 [Oryza sativa] }\end{array}$ & AT2G20580 & 0.62 & - & 3 \\
\hline C02019C08 & $\begin{array}{c}\text { Probable } 26 \text { S proteasome non- } \\
\text { ATPase regulatory subunit } 3 \\
\text { [Ricinus communis }]\end{array}$ & AT1G20200 & -0.83 & -0.84 & 4 \\
\hline $\mathrm{C} 34202 \mathrm{H} 02$ & $\begin{array}{l}\text { Proteasome beta subunit PBG1 } \\
\text { [Arabidopsis thaliana] }\end{array}$ & AT1G56450 & -1.22 & -1.26 & 4 \\
\hline C08026E11 & $\begin{array}{l}\text { Proteasome subunit beta type } 6 \\
\text { precursor [Ricinus communis] }\end{array}$ & AT4G31300 & -1.04 & -1.33 & 4 \\
\hline $\mathrm{C} 32005 \mathrm{C} 04$ & $\begin{array}{l}\text { Proteasome subunit beta type 7-B } \\
\text { precursor [Ricinus communis] }\end{array}$ & AT5G40580 & -0.66 & -0.72 & 4 \\
\hline C04019C04 & $\begin{array}{c}\text { 26S proteasome subunit } \mathrm{P} 45 \\
{[\text { Medicago truncatula }]}\end{array}$ & AT4G29040 & -0.79 & - & 6 \\
\hline IC0AAA32AF06 & $\begin{array}{l}\text { Putative } 26 \mathrm{~S} \text { proteosome regulatory } \\
\text { subunit [Arabidopsis thaliana] }\end{array}$ & AT5G16930 & -0.54 & - & 6 \\
\hline $\mathrm{C} 04013 \mathrm{H} 02$ & $\begin{array}{c}26 \mathrm{~S} \text { proteasome non-ATPase } \\
\text { regulatory subunit } \\
{[\text { Ricinus communis }]}\end{array}$ & AT5G23540 & -0.59 & - & 6 \\
\hline
\end{tabular}

El etileno, además de regular genes relacionados con la degradación de proteínas, provocó cambios en la expresión de genes implicados en la síntesis de proteínas. La Tabla 9 muestra unigenes relacionados con proteínas ribosomales (45), aminoacil-tRNA sintasas (6), factores de iniciación (9), factores de elongación (3) y factores de terminación de la traducción (1), que aparecieron alternativamente inducidos o reprimidos en la ZAC.

Tabla 9. Unigenes relacionados con la síntesis de proteínas regulados por el etileno exclusivamente en la ZAC. Junto a cada unigen se muestra el nivel de expresión a las 12 y 24 h de tratamiento con etileno con respecto a las 0 $\mathrm{h}\left[\mathrm{M}=\log _{2}\left(\mathrm{ZAC}_{\mathrm{t}} / \mathrm{ZAC}_{0}\right)\right]$. - = No se produjo cambio significativo en la expresión entre el tiempo 't' y el tiempo '0' en la ZAC.

\begin{tabular}{lccccc}
\hline ID & Descripción & $\begin{array}{c}\text { Posible ortólogo } \\
\text { de } \text { A. thaliana }\end{array}$ & M 12h & M 24h & Cluster \\
\hline Proteínas ribosomales & & & & & \\
C08023B04 & L19 [Zea mays] & AT1G02780 & 1.5 & 2.51 & 1 \\
C31206D06 & L3 Ribosomal protein [Ricinus communis] & AT1G61580 & 0.90 & 0.93 & 1 \\
KN0AAQ6YM10 & Ribosomal protein L4 [Heliothis virescens] & AT3G09630 & 1.85 & 1.87 & 1 \\
C06016D11 & $\begin{array}{c}\text { 60S ribosomal protein L37 } \\
{[\text { Penicillium marneffei] }}\end{array}$ & AT3G16080 & 0.74 & 1.03 & 1 \\
\hline
\end{tabular}


Tabla 9 (continuación de la página anterior).

\begin{tabular}{|c|c|c|c|c|c|}
\hline ID & Descripción & $\begin{array}{c}\text { Posible ortólogo } \\
\text { de A.thaliana }\end{array}$ & M 12h & M 24h & Cluster \\
\hline \multicolumn{6}{|c|}{ Proteínas ribosomales } \\
\hline C08005B06 & $\begin{array}{l}\text { 60S ribosomal protein } \mathrm{L} 13 \mathrm{a} \\
{[\text { Cyanophora paradoxa }]}\end{array}$ & AT3G24830 & 1.36 & 0.93 & 1 \\
\hline IC0AAA65CG07 & $\begin{array}{l}\text { 40S ribosomal protein } \mathrm{S} 13 \\
\text { [Georissus sp. APV-2005] }\end{array}$ & AT4G00100 & 0.84 & 0.87 & 1 \\
\hline C31201D09 & Ribosomal protein L21 [Triticum aestivum] & AT1G09590 & - & 0.58 & 2 \\
\hline IC0AAA72AC08 & $\begin{array}{c}\text { Ribosomal protein P0 } \\
\text { [Sclerotinia sclerotiorum 1980] }\end{array}$ & AT3G09200 & - & 0.55 & 2 \\
\hline C34209C12 & $\begin{array}{c}\text { Putative ribosomal protein } \mathrm{S} 17 \\
\text { [Arabidopsis lyrata] }\end{array}$ & AT1G49400 & 0.75 & - & 3 \\
\hline C08001G12 & $\begin{array}{l}\text { Putative } 60 \mathrm{~S} \text { ribosomal protein } \\
\quad[\text { Arabidopsis thaliana }]\end{array}$ & AT3G24830 & 1.11 & - & 3 \\
\hline C31205C06 & $\begin{array}{c}\text { 40S ribosomal protein S2 } \\
\text { [Phytophthora infestans } \mathrm{T} 30-4]\end{array}$ & AT3G57490 & 0.62 & - & 3 \\
\hline IC0AAA37AG08 & 60 S ribosomal protein L12 [Ricinus communis] & AT5G60670 & 0.76 & - & 3 \\
\hline C02026H07 & $60 \mathrm{~S}$ ribosomal protein L34 [Vitis vinifera] & AT1G26880 & -0.88 & -0.77 & 4 \\
\hline C31403A06 & $\begin{array}{l}\text { 40S ribosomal protein } \mathrm{S} 13-1 \\
\text { [Solanum tuberosum }]\end{array}$ & AT4G00100 & -0.92 & -0.54 & 4 \\
\hline C06018F06 & 40S ribosomal protein S16 [Ricinus communis] & AT5G18380 & -0.92 & -0.85 & 4 \\
\hline $\mathrm{C} 31200 \mathrm{C} 02$ & 60 S ribosomal protein L5 [Ricinus communis] & AT5G39740 & -1.18 & -1.22 & 4 \\
\hline С $34005 \mathrm{H} 02$ & $\begin{array}{l}\text { 40S ribosomal protein S10-like } \\
\text { [Ricinus communis }]\end{array}$ & AT5G52650 & -0.72 & -0.75 & 4 \\
\hline C20007B11 & 40S ribosomal protein S19-1 [Ricinus communis] & AT5G61170 & -0.68 & -0.56 & 4 \\
\hline C31602A12 & 60 S ribosomal protein L34 [Nicotiana tabacum] & AT1G26880 & - & -1.49 & 5 \\
\hline C06012D09 & 60 S ribosomal protein L23 [Triticum aestivum] & AT3G04400 & - & -0.98 & 5 \\
\hline C06020E05 & $\begin{array}{l}\text { Putative ribosomal-protein S6 kinase-like protein } \\
\text { [Solanum lycopersicum] }\end{array}$ & AT3G08720 & - & -0.85 & 5 \\
\hline $\mathrm{C} 05801 \mathrm{H} 12$ & $60 \mathrm{~S}$ ribosomal protein L37a [Capsicum chinense] & AT3G10950 & - & -1.29 & 5 \\
\hline C32202E05 & $60 \mathrm{~S}$ acidic ribosomal protein [Prunus dulcis] & AT3G44590 & - & -0.71 & 5 \\
\hline C08004D06 & $40 \mathrm{~S}$ ribosomal protein S13 [Naegleria gruberi] & AT4G09800 & - & -0.77 & 5 \\
\hline IC0AAA16AH04 & 40S ribosomal protein $\mathrm{S} 15 \mathrm{~A}$ [Arabidopsis lyrata] & AT4G29430 & - & -0.5 & 5 \\
\hline C06018E09 & Ribosomal protein S29 [Zea mays] & AT4G33865 & - & -0.79 & 5 \\
\hline C16013G06 & 40S ribosomal protein S16 [Ricinus communis] & AT5G18380 & - & -0.70 & 5 \\
\hline C31806G03 & $\begin{array}{c}\text { Putative } 50 \text { S ribosomal protein L33 } \\
\text { [Arabidopsis thaliana] }\end{array}$ & AT5G18790 & - & -1 & 5 \\
\hline C04033G07 & Ribosomal protein L7Ae-like [Ricinus communis] & AT5G20160 & - & -1.11 & 5 \\
\hline C32202G10 & $\begin{array}{c}\text { Ribosomal protein L36 family protein } \\
\text { [Arabidopsis lyrata] }\end{array}$ & AT5G20180 & - & -0.51 & 5 \\
\hline IC0AAA5BD08 & $60 \mathrm{~S}$ ribosomal protein $\mathrm{L} 9[$ Cucumis melo] & AT1G33140 & -0.55 & - & 6 \\
\hline C31208A12 & Ribosomal protein L3 [Ricinus communis] & AT1G43170 & -1.04 & - & 6 \\
\hline IC0AAA7BC12 & $60 S$ ribosomal protein L21 [Zea mays] & AT1G57660 & -0.50 & - & 6 \\
\hline
\end{tabular}


Tabla 9 (continuación de la página anterior).

\begin{tabular}{|c|c|c|c|c|c|}
\hline ID & Descripción & $\begin{array}{l}\text { Posible ortólogo } \\
\text { de A. thaliana }\end{array}$ & M 12h & M 24h & Cluster \\
\hline \multicolumn{6}{|c|}{ Proteínas ribosomales } \\
\hline C02013D08 & $\begin{array}{l}\text { 60S ribosomal protein } \mathrm{L} 27 \mathrm{a}-2 \\
\text { [Ricinus communis }]\end{array}$ & AT1G70600 & -0.91 & - & 6 \\
\hline C02021E06 & $\begin{array}{l}\text { 60S ribosomal protein L6 } \\
\text { [Ricinus communis }]\end{array}$ & AT1G74050 & -0.81 & - & 6 \\
\hline C34101G08 & $\begin{array}{l}\text { 60S ribosomal protein } \mathrm{L} 7 \\
\text { [Ricinus communis }]\end{array}$ & AT2G01250 & -1.13 & - & 6 \\
\hline IC0AAA39AA05 & $\begin{array}{l}\text { 40S ribosomal protein } \mathrm{S} 14-3 \\
\text { [Ricinus communis] }\end{array}$ & AT3G52580 & -0.62 & - & 6 \\
\hline IC0AAA15BH10 & $\begin{array}{l}\text { 60S ribosomal protein } \mathrm{L} 24 \\
\text { [Ricinus communis }]\end{array}$ & AT3G53020 & -0.76 & - & 6 \\
\hline C32201G11 & $\begin{array}{l}\text { 60S ribosomal protein L38 } \\
\text { [Ricinus communis }]\end{array}$ & AT3G59540 & -0.98 & - & 6 \\
\hline $\mathrm{C} 06022 \mathrm{C} 03$ & Ribosomal protein L32 [Ricinus communis] & AT4G18100 & -0.75 & - & 6 \\
\hline C31102B12 & $\begin{array}{l}\text { 40S ribosomal protein S1-like protein } \\
\text { [Glomerella graminicola } \mathrm{M} 1.001]\end{array}$ & AT4G34670 & -0.76 & - & 6 \\
\hline C32201D12 & $\begin{array}{l}\text { 40S ribosomal protein } \mathrm{S} 17 \\
\quad \text { [Ricinus communis }]\end{array}$ & AT5G04800 & -0.76 & - & 6 \\
\hline $\mathrm{C} 31107 \mathrm{C} 05$ & $\begin{array}{l}\text { 40S ribosomal protein S6-1 } \\
\text { [Ricinus communis }]\end{array}$ & AT5G10360 & -1.01 & - & 6 \\
\hline C08031B08 & $\begin{array}{l}\text { 60S ribosomal protein } \mathrm{L} 10 \mathrm{~A} \\
\text { [Arabidopsis thaliana] }\end{array}$ & AT5G22440 & -0.83 & - & 6 \\
\hline C08010F11 & $\begin{array}{l}\text { 60S acidic ribosomal protein P1 (RPP1C) } \\
\text { [Arabidopsis thaliana] }\end{array}$ & AT5G47700 & -0.62 & - & 6 \\
\hline \multicolumn{6}{|c|}{ Aminoacil-tRNA sintetasas } \\
\hline IC0AAA83DG03 & $\begin{array}{l}\text { Threonyl-tRNA synthetase [Ricinus } \\
\text { communis] }\end{array}$ & AT5G26830 & 0.61 & 0.76 & 1 \\
\hline C06005F06 & $\begin{array}{l}\text { Tyrosyl-tRNA synthetase [Nicotiana } \\
\text { tabacum] }\end{array}$ & AT2G33840 & 1.12 & - & 3 \\
\hline C31001F04 & $\begin{array}{l}\text { Asparaginyl-tRNA synthetase } \\
\text { [Arabidopsis thaliana }]\end{array}$ & AT5G56680 & 0.69 & - & 3 \\
\hline C02004C11 & $\begin{array}{c}\text { Glycyl-tRNA synthetase } 1 \text { [Ricinus } \\
\text { communis] }\end{array}$ & AT1G29880 & -0.97 & - & 6 \\
\hline $\mathrm{C} 05057 \mathrm{C} 04$ & $\begin{array}{c}\text { Putative tyrosyl-tRNA synthetase } \\
\text { [Ricinus communis }]\end{array}$ & AT3G02660 & -0.63 & - & 6 \\
\hline С03011H07 & $\begin{array}{l}\text { Aspartate--tRNA ligase-like protein } \\
\text { [Ricinus communis }]\end{array}$ & AT4G31180 & -0.56 & - & 6 \\
\hline \multicolumn{6}{|c|}{ Factores de iniciación } \\
\hline IC0AAA50DE05 & $\begin{array}{l}\text { Putative translation initiation factor eIF-2B } \\
\text { epsilon subunit [Cucumis melo] }\end{array}$ & AT2G34970 & - & 1.18 & 2 \\
\hline C01020H11 & $\begin{array}{l}\text { Eukaryotic initiation factor subunit } \\
\text { [Ricinus communis }]\end{array}$ & AT5G25780 & - & 0.62 & 2 \\
\hline $\mathrm{C} 08028 \mathrm{C} 09$ & $\begin{array}{c}\text { Eukaryotic translation initiation factor } 3 \\
\text { subunit } 8 \text { [Arabidopsis thaliana] }\end{array}$ & AT3G56150 & 0.95 & - & 3 \\
\hline
\end{tabular}


Tabla 9 (continuación de la página anterior).

\begin{tabular}{|c|c|c|c|c|c|}
\hline ID & Descripción & $\begin{array}{l}\text { Posible ortólogo } \\
\text { de A. thaliana }\end{array}$ & M 12h & M 24h & Cluster \\
\hline \multicolumn{6}{|c|}{ Factores de iniciación } \\
\hline C08010C12 & $\begin{array}{l}\text { Eukaryotic translation initiation factor 5A- } \\
\qquad 2[\text { Ricinus communis }]\end{array}$ & AT1G13950 & -0.71 & -0.71 & 4 \\
\hline C02020A09 & $\begin{array}{l}\text { Probable eukaryotic translation initiation } \\
\text { factor 5-2 [Ricinus communis }]\end{array}$ & AT1G77840 & - & -0.65 & 5 \\
\hline $\mathrm{C} 20002 \mathrm{~F} 11$ & eif-1a [Ricinus communis $]$ & AT2G04520 & - & -0.77 & 5 \\
\hline C05146B05 & $\begin{array}{l}\text { Putative translation initiation factor eIF-2B } \\
\text { alpha subunit [Arabidopsis thaliana] }\end{array}$ & AT2G05830 & - & -0.77 & 5 \\
\hline $\mathrm{C} 07002 \mathrm{C} 11$ & $\begin{array}{l}\text { Protein translation factor SUI1 homolog } \\
\text { [Salix bakko] }\end{array}$ & AT4G27130 & - & -0.95 & 5 \\
\hline C05801D12 & Initiation factor $3 \mathrm{~g}$ [Arabidopsis thaliana] & AT3G11400 & -0.8 & - & 6 \\
\hline \multicolumn{6}{|c|}{ Factores de elongación } \\
\hline C01018H10 & $\begin{array}{l}\text { EF-1-alpha-related GTP-binding protein, } \\
\text { putative [Arabidopsis thaliana] }\end{array}$ & AT1G18070 & -1.56 & -1.23 & 4 \\
\hline C34106A03 & Putative elongation factor $\mathrm{P}$ [Zea mays] & AT3G08740 & -0.61 & - & 6 \\
\hline KNOAAA3BH04 & Elongation factor 1-alpha [Zea mays] & AT5G60390 & -0.91 & - & 6 \\
\hline \multicolumn{6}{|c|}{ Factor de terminación } \\
\hline C32102G01 & $\begin{array}{l}\text { Peptide chain release factor } \\
\text { [Ricinus communis }]\end{array}$ & AT1G33330 & -0.53 & -0.52 & 4 \\
\hline
\end{tabular}

La Tabla 10 agrupa proteínas de unión a proteína relacionadas con la modulación de la actividad enzimática y la señalización. Se pueden observar 30 unigenes asociados a proteínas de tipo quinasa, 20 unigenes que codifican receptores de tipo quinasa, 4 unigenes asociados a proteínas con repeticiones ricas en leucina (proteínas LRR) y 14 unigenes que codifican proteínas de tipo fosfatasa. Como se observa en la Tabla 10, el etileno provocó tanto inducción como represión en relación a este tipo de proteínas.

Tabla 10. Unigenes relacionados con la señalización regulados por el etileno exclusivamente en la ZAC. Junto a cada unigen se muestra el nivel de expresión a las 12 y $24 \mathrm{~h}$ de tratamiento con etileno con respecto a las $0 \mathrm{~h}$ $\left[\mathrm{M}=\log _{2}\left(\mathrm{ZAC}_{\mathrm{t}} / \mathrm{ZAC}_{0}\right)\right]$. - = No se produjo cambio significativo en la expresión entre el tiempo ' $\mathrm{t}$ ' y el tiempo ' 0 ' en la ZAC.

\begin{tabular}{|c|c|c|c|c|c|}
\hline ID & Descripción & $\begin{array}{c}\text { Posible ortólogo } \\
\text { de A.thaliana }\end{array}$ & M 12h & M 24h & Cluster \\
\hline \multicolumn{6}{|l|}{ Quinasas } \\
\hline KN0AAP4YO15 & $\begin{array}{l}\text { CBL-interacting serine/threonine-protein } \\
\text { kinase } 1 \text { [Ricinus communis }]\end{array}$ & AT3G17510 & 0.60 & 0.83 & 1 \\
\hline C06016D07 & $\begin{array}{l}\text { Mitogen-activated protein kinase } \\
\text { [Ricinus communis] }\end{array}$ & AT5G58350 & 2.45 & 2.68 & 1 \\
\hline
\end{tabular}


Tabla 10 (continuación de la página anterior).

\begin{tabular}{|c|c|c|c|c|c|}
\hline ID & Descripción & $\begin{array}{l}\text { Posible ortólogo } \\
\text { de } \text { A.thaliana }\end{array}$ & M 12h & M 24h & Cluster \\
\hline \multicolumn{6}{|l|}{ Quinasas } \\
\hline $\mathrm{C} 01005 \mathrm{C} 12$ & $\begin{array}{l}\text { Mitogen-activated protein kinase } \\
\text { [Ricinus communis }]\end{array}$ & AT5G58350 & 1.60 & 1.55 & 1 \\
\hline C04022A06 & $\begin{array}{l}\text { Serine/threonine-protein kinase AtPK19 } \\
\text { [Arabidopsis lyrata }]\end{array}$ & AT3G08720 & 1.02 & 0.93 & 1 \\
\hline IC0AAA43BH09 & $\begin{array}{l}\text { Calcium-dependent protein kinase CDPK1444 } \\
\text { [Ricinus communis }]\end{array}$ & AT2G17890 & 0.51 & 0.51 & 1 \\
\hline $\mathrm{C} 07006 \mathrm{H} 03$ & $\begin{array}{l}\text { Auxin-regulated dual specificity cytosolic } \\
\text { kinase [Solanum lycopersicum] }\end{array}$ & AT1G72540 & 0.57 & 0.63 & 1 \\
\hline C03006G07 & MAP kinase 9 [Brassica napus] & AT3G18040 & - & 1.00 & 2 \\
\hline IC0AAA94AD09 & Protein kinase-like protein [Glycine $\max ]$ & AT5G02070 & - & 1.15 & 2 \\
\hline IC0AAA15AF04 & Protein kinase-like protein [Glycine $\max ]$ & AT5G02070 & - & 1.35 & 2 \\
\hline IC0AAA11BC11 & $\begin{array}{l}\text { Putative mitogen-activated protein kinase } 1 \\
\text { [Ricinus communis] }\end{array}$ & AT4G08500 & 0.67 & - & 3 \\
\hline IC0AAA2CD12 & Serine/threonine kinase [Ricinus communis] & AT5G01810 & 1.13 & - & 3 \\
\hline $\mathrm{C} 20001 \mathrm{~A} 08$ & $\begin{array}{l}\text { Putative serine/threonine protein kinase } \\
\text { [Ricinus communis }]\end{array}$ & AT5G01020 & 1.23 & - & 3 \\
\hline IC0AAA11BC11 & $\begin{array}{l}\text { Putative mitogen-activated protein kinase } 1 \\
\text { [Ricinus communis] }\end{array}$ & AT4G08500 & 0.67 & - & 3 \\
\hline IC0AAA66CB04 & MAP kinase [Ricinus communis] & AT3G18040 & 0.60 & - & 3 \\
\hline C08006D01 & $\begin{array}{l}\text { Serine/threonine-protein kinase MHK } \\
\text { [Ricinus communis }]\end{array}$ & AT4G13020 & 1.45 & - & 3 \\
\hline C $31502 \mathrm{~A} 04$ & $\begin{array}{l}\text { Similarity to protein kinase } \\
\text { [Arabidopsis thaliana }]\end{array}$ & AT5G63940 & 0.69 & - & 3 \\
\hline C31208F02 & $\begin{array}{l}\text { Serine/threonine-protein kinase NrkA } \\
\text { [Trypanosoma brucei gambiense DAL972] }\end{array}$ & AT3G63280 & 0.84 & - & 3 \\
\hline IC0AAA57DA10 & $\begin{array}{l}\text { Shaggy-related protein kinase dzeta } \\
{[\text { Arabidopsis thaliana }]}\end{array}$ & AT2G30980 & -0.99 & -0.78 & 4 \\
\hline C06023D06 & Histidine kinase [Ricinus communis] & AT1G27320 & -0.97 & -0.87 & 4 \\
\hline C18019F11 & Wall-associated kinase 4 [Ricinus communis] & AT1G21210 & -1.17 & -1.07 & 4 \\
\hline $\mathrm{C} 31505 \mathrm{G} 04$ & $\begin{array}{c}\text { Protein kinase } \mathrm{Ck} 2 \text { regulatory subunit } 2 \\
\text { [Nicotiana tabacum] }\end{array}$ & AT5G47080 & - & -0.58 & 5 \\
\hline C31102E06 & $\begin{array}{l}\text { Protein-serine/threonine kinase } \\
\text { [Nicotiana tabacum }]\end{array}$ & AT5G15730 & - & -0.53 & 5 \\
\hline C08021H09 & Protein kinase [Nicotiana tabacum] & AT4G21940 & - & -0.74 & 5 \\
\hline C32101D04 & $\begin{array}{l}\text { Serine/threonine-protein kinase AFC2 } \\
\text { [Ricinus communis }]\end{array}$ & AT4G24740 & - & -0.80 & 5 \\
\hline C34003A11 & $\begin{array}{l}\text { Calcium-dependent protein kinase } \\
\text { [Populus trichocarpa] }\end{array}$ & AT3G51850 & - & -0.66 & 5 \\
\hline C34108D10 & $\begin{array}{l}\text { Serine/threonine/tyrosine kinase } \\
\text { [Ricinus communis }]\end{array}$ & AT2G24360 & - & -0.70 & 5 \\
\hline IC0AAA89BG04 & $\begin{array}{l}\text { Putative kinase binding protein } \\
\text { [Ricinus communis }]\end{array}$ & AT4G31120 & - & -0.60 & 5 \\
\hline
\end{tabular}


Tabla 10 (continuación de la página anterior).

\begin{tabular}{|c|c|c|c|c|c|}
\hline ID & Descripción & $\begin{array}{l}\text { Posible ortólogo } \\
\text { de A.thaliana }\end{array}$ & M 12h & M 24h & Cluster \\
\hline \multicolumn{6}{|l|}{ Quinasas } \\
\hline IC0AAA56CC11 & $\begin{array}{l}\text { Putative serine/threonine kinase } 38 \\
\text { [Ricinus communis }]\end{array}$ & AT4G33080 & -0.65 & - & 6 \\
\hline C05069B11 & $\begin{array}{c}\text { Osmosensor histidine-aspartate kinase } \\
\text { [Ricinus communis }]\end{array}$ & AT2G17820 & -0.58 & - & 6 \\
\hline C16018E05 & Protein kinase-like protein [Ricinus communis] & AT4G28880 & -0.65 & - & 6 \\
\hline \multicolumn{6}{|c|}{ Quinasas tipo receptor } \\
\hline IC0AAA20DC09 & $\begin{array}{l}\text { Receptor protein kinase-like protein } \\
{[\text { Arabidopsis thaliana }]}\end{array}$ & AT4G34215 & 0.84 & 0.69 & 1 \\
\hline C20008D03 & $\begin{array}{l}\text { Putative leucine-rich repeat receptor kinase } \\
\text { [Ricinus communis] }\end{array}$ & AT2G16250 & 1.18 & 0.75 & 1 \\
\hline IC0AAA2AF03 & $\begin{array}{l}\text { Senescence-induced receptor-like } \\
\text { serine/threonine kinase-like } \\
\text { [Ricinus communis }]\end{array}$ & AT1G25570 & - & 1.02 & 2 \\
\hline С $34003 \mathrm{H} 08$ & $\begin{array}{l}\text { Putative receptor-like protein kinase } 2 \\
\text { [Glycine } \max ]\end{array}$ & AT3G14840 & 0.98 & - & 3 \\
\hline C20007G06 & Receptor-kinase, putative [Ricinus communis] & AT1G60630 & -0.90 & -0.81 & 4 \\
\hline KN0AAB2DF06 & $\begin{array}{l}\text { Receptor kinase-like protein } \\
\text { [Ricinus communis] }\end{array}$ & AT3G47570 & -0.85 & -0.73 & 4 \\
\hline C31207A10 & $\begin{array}{c}\text { Similarity to receptor-like kinase } \\
{[\text { Arabidopsis thaliana }]}\end{array}$ & AT5G65500 & -0.92 & -0.81 & 4 \\
\hline C18023G09 & $\begin{array}{l}\text { Putative receptor-like protein kinase } \\
\text { [Citrus limon] }\end{array}$ & AT2G19130 & -0.71 & -0.76 & 4 \\
\hline C20007G06 & Receptor-kinase [Ricinus communis] & AT1G60630 & -0.90 & -0.81 & 4 \\
\hline C02026D02 & $\begin{array}{l}\text { Receptor-like protein kinase } \\
\text { [Nicotiana tabacum] }\end{array}$ & AT2G31880 & - & -0.87 & 5 \\
\hline C32104B12 & Putative receptor kinase [Arabidopsis thaliana] & AT4G03230 & - & -0.62 & 5 \\
\hline С $31702 \mathrm{H} 06$ & $\begin{array}{l}\text { Putative rust resistance kinase } \operatorname{Lr} 10 \\
{[\text { Oryza sativa Indica Group }]}\end{array}$ & AT1G66910 & - & -0.86 & 5 \\
\hline $\mathrm{C} 03006 \mathrm{C} 04$ & $\begin{array}{l}\text { Putative receptor-like protein kinase } \\
\quad[\text { Arabidopsis thaliana }]\end{array}$ & AT2G01210 & -0.87 & - & 6 \\
\hline C06022B05 & $\begin{array}{l}\text { Putative receptor-like protein kinase } \\
\text { [Ricinus communis] }\end{array}$ & AT3G02130 & -0.89 & - & 6 \\
\hline IC0AAA21DD11 & $\begin{array}{l}\text { Leucine rich repeat receptor kinase-like protein } \\
\text { [Ricinus communis }]\end{array}$ & AT4G22730 & -0.88 & - & 6 \\
\hline $\mathrm{C} 16013 \mathrm{H} 02$ & $\begin{array}{l}\text { S-receptor kinase-like protein } 1 \\
\text { [Ricinus communis] }\end{array}$ & AT1G65800 & -1.04 & - & 6 \\
\hline C08028D08 & $\begin{array}{l}\text { Senescence-induced receptor-like } \\
\text { serine/threonine kinase-like } \\
\text { [Arabidopsis thaliana] }\end{array}$ & AT1G25570 & -1.10 & - & 6 \\
\hline C32104H06 & $\begin{array}{l}\text { Senescence-induced receptor-like } \\
\text { serine/threonine kinase-like } \\
\text { [Ricinus communis }]\end{array}$ & AT1G25570 & -1.25 & - & 6 \\
\hline C02021G02 & $\begin{array}{l}\text { Receptor protein kinase-like } \\
\text { [Arabidopsis thaliana }]\end{array}$ & AT3G46290 & -0.81 & - & 6 \\
\hline
\end{tabular}


Tabla 10 (continuación de la página anterior).

\begin{tabular}{|c|c|c|c|c|c|}
\hline ID & Descripción & $\begin{array}{l}\text { Posible ortólogo } \\
\text { de A.thaliana }\end{array}$ & M 12h & M 24h & Cluster \\
\hline \multicolumn{6}{|c|}{ Quinasas tipo receptor } \\
\hline $\mathrm{C} 04027 \mathrm{C} 11$ & $\begin{array}{l}\text { Putative receptor protein kinase } \\
\text { [Ricinus communis }]\end{array}$ & AT2G33580 & -0.61 & - & 6 \\
\hline \multicolumn{6}{|c|}{ Proteínas con repeticiones de leucina } \\
\hline IC0AAA42DG01 & $\begin{array}{l}\text { Putative leucine-rich repeat protein } \\
\text { [Arabidopsis thaliana] }\end{array}$ & AT4G03010 & 0.80 & 0.76 & 1 \\
\hline C08038F02 & $\begin{array}{l}\text { Putative leucine-rich-repeat protein } \\
\text { [Ricinus communis] }\end{array}$ & AT2G19330 & 0.79 & 1.01 & 2 \\
\hline C04030G06 & $\begin{array}{l}\text { Leucine rich repeat protein precursor } \\
\qquad \text { [Glycine } \max ]\end{array}$ & AT3G20820 & - & 3.29 & 2 \\
\hline $\mathrm{C} 05072 \mathrm{H} 03$ & $\begin{array}{l}\text { Putative leucine rich repeat protein } \\
\text { [Oryza sativa Japonica Group }]\end{array}$ & AT2G34680 & - & -1.08 & 5 \\
\hline \multicolumn{6}{|l|}{ Fosfatasas } \\
\hline IC0AAA22BA01 & $\begin{array}{l}\text { Protein phosphatase } \mathrm{PP} 2 \mathrm{~A} \text { regulatory subunit } \\
\text { A [Pyrenophora tritici-repentis Pt-1C-BFP] }\end{array}$ & AT1G25490 & 1.03 & 0.99 & 1 \\
\hline IC0AAA1DA05 & $\begin{array}{c}\text { Type } 5 \text { protein serine/threonine phosphatase } 62 \\
\mathrm{kDa} \text { isoform [Solanum lycopersicum] }\end{array}$ & AT2G42810 & 1.04 & 1.05 & 1 \\
\hline IC0AAA31CB11 & Tyrosine phosphatase [Arabidopsis thaliana] & AT3G19420 & 0.52 & 0.92 & 1 \\
\hline C02014A07 & $\begin{array}{l}\text { Putative purple acid phosphatase } \\
{[\text { Arabidopsis thaliana }]}\end{array}$ & AT5G50400 & - & 2.04 & 2 \\
\hline IC0AAA33СB06 & Putative acid phosphatase [Ricinus communis] & AT4G29260 & - & 0.50 & 2 \\
\hline KN0AAP12YJ01 & Protein phosphatase-2C [Ricinus communis] & AT3G62260 & 1.10 & - & 3 \\
\hline C01006B09 & Protein phosphatase $2 \mathrm{C}$ [Ricinus communis] & AT3G55050 & 1.04 & - & 3 \\
\hline C08004A05 & $\begin{array}{c}\text { Phosphatase-like protein Mtc923 } \\
\text { [Medicago truncatula] }\end{array}$ & AT4G15410 & 0.71 & - & 3 \\
\hline IC0AAA24AA02 & Protein phosphatase-2C [Ricinus communis] & AT4G26080 & - & -0.63 & 5 \\
\hline C01008F01 & Protein phosphatase $2 \mathrm{C}$ [Ricinus communis] & AT4G31750 & - & -0.68 & 5 \\
\hline C34005D06 & PP1A protein [Catharanthus roseus] & AT2G39840 & - & -0.77 & 5 \\
\hline $\mathrm{C} 03007 \mathrm{C} 09$ & Acid phosphatase [Glycine max] & AT4G25150 & -1.21 & -1.10 & 4 \\
\hline C16018B03 & Putative phosphatase [Ricinus communis] & AT4G29530 & -1.13 & -0.89 & 4 \\
\hline C32004F06 & $\begin{array}{c}\text { Serine/threonine-protein phosphatase PP1 } \\
\text { [Ricinus communis] }\end{array}$ & AT4G11240 & - & -0.78 & 5 \\
\hline
\end{tabular}

La Tabla 11 muestra algunos de los factores transcripcionales más interesantes regulados por el etileno en la ZAC. Entre ellos se encuentran varios factores de transcripción de respuesta a etileno (ERF; 5 inducidos y uno reprimido), factores relacionados con las auxinas (ARF y Aux/IAA; 5 inducidos y uno reprimido), factores relacionados con el ácido abscísico (VP1/ABI3; 2 inducidos), factores de transcripción de las familias bHLH (4 inducidos y 3 reprimidos), MADS box (uno inducido y 2 reprimidos) y un factor de transcripción de tipo DOF reprimido. Además, otros factores con dominios 
NAC (4 inducidos), factores de la familia 'homeobox leucine zipper' (HD-Zip; 3 inducidos y uno reprimido), factores TCP (2 inducidos) y factores MYB (uno inducido y 3 reprimidos) fueron regulados por el etileno exclusivamente en la ZAC.

Tabla 11. Unigenes relacionados con el control de la transcripción regulados por el etileno exclusivamente en la ZAC. Junto a cada unigen se muestra el nivel de expresión a las 12 y $24 \mathrm{~h}$ de tratamiento con etileno con respecto a las $0 \mathrm{~h}\left[\mathrm{M}=\log _{2}\left(\mathrm{ZAC}_{\mathrm{t}} / \mathrm{ZAC}_{0}\right)\right]$. - = No se produjo cambio significativo en la expresión entre el tiempo ' $\mathrm{t}$ ' y el tiempo '0' en la ZAC.

\begin{tabular}{|c|c|c|c|c|c|}
\hline ID & Descripción & $\begin{array}{l}\text { Posible ortólogo } \\
\text { de A.thaliana }\end{array}$ & M 12h & M 24h & Cluster \\
\hline \multicolumn{6}{|l|}{ ERF } \\
\hline C31604B06 & $\begin{array}{l}\text { Putative ethylene response factor } \\
\text { ERF3b [Malus x domestica }]\end{array}$ & AT3G15210 & 1.42 & 1.83 & 1 \\
\hline IC0AAA52AF07 & $\begin{array}{c}\text { AP2/EREBP transcription factor ERF- } \\
2 \text { [Gossypium hirsutum }]\end{array}$ & AT3G16770 & 1.35 & 0.81 & 1 \\
\hline C31303G04 & $\begin{array}{l}\text { Ethylene-responsive element binding } \\
\text { protein ERF4 [Gossypium hirsutum] }\end{array}$ & AT5G44210 & 2.45 & 2.34 & 1 \\
\hline C08037B08 & EIN3-like protein [Citrus sinensis] & AT3G20770 & 1.36 & - & 3 \\
\hline C31405C10 & $\begin{array}{l}\text { Putative AP2/EREBP transcription } \\
\text { factor [Populus trichocarpa] }\end{array}$ & AT5G11590 & 0.70 & - & 3 \\
\hline C31305E08 & $\begin{array}{c}\text { Ethylene-responsive transcription factor } \\
13 \text { [Ricinus communis] }\end{array}$ & AT2G44840 & -0.55 & - & 6 \\
\hline \multicolumn{6}{|l|}{ ARF } \\
\hline KN0AAP8YN01 & $\begin{array}{l}\text { Auxin response factor } 17 \\
\text { [Ricinus communis }]\end{array}$ & AT1G77850 & 1.1 & 0.77 & 1 \\
\hline C04015B03 & $\begin{array}{c}\text { Auxin response factor-like protein } \\
\text { [Mangifera indica }]\end{array}$ & AT5G62000 & 1.23 & - & 3 \\
\hline C16018D07 & $\begin{array}{l}\text { Auxin response factor } 9 \\
\text { [Ricinus communis }]\end{array}$ & AT4G23980 & 0.55 & - & 3 \\
\hline \multicolumn{6}{|l|}{ Aux/IAA } \\
\hline IC0AAA19AG08 & Aux/IAA protein [Ricinus communis] & AT4G28640 & 0.86 & 0.85 & 1 \\
\hline C05131B01 & $\begin{array}{c}\text { Auxin-responsive protein IAA27 } \\
\text { [Ricinus communis }]\end{array}$ & AT2G22670 & - & 1.21 & 2 \\
\hline KN0AAI2DB11 & $\begin{array}{c}\text { Auxin-responsive protein IAA27 } \\
\text { [Ricinus communis] }\end{array}$ & AT2G22670 & -1.07 & -1.35 & 4 \\
\hline \multicolumn{6}{|l|}{ VP1/ABI3 } \\
\hline IC0AAA43CA11 & $\begin{array}{c}\text { VP1/ABI3 family regulatory protein- } \\
\text { like protein } \\
\text { [Oryza sativa Japonica Group }]\end{array}$ & AT4G32010 & - & 0.59 & 2 \\
\hline С08022H08 & $\begin{array}{l}\text { Transcription factor HY5 } \\
\text { [Ricinus communis }]\end{array}$ & AT5G11260 & 1.05 & - & 3 \\
\hline
\end{tabular}


Tabla 11 (continuación de la página anterior).

\begin{tabular}{|c|c|c|c|c|c|}
\hline ID & Descripción & $\begin{array}{l}\text { Posible ortólogo } \\
\text { de A.thaliana }\end{array}$ & M 12h & M 24h & Cluster \\
\hline \multicolumn{6}{|l|}{ NAC } \\
\hline C08037H04 & Nam-like protein 3 [Citrus sinensis] & AT1G01720 & 2.39 & 2.66 & 1 \\
\hline C04033H06 & $\begin{array}{l}\text { NAC domain protein NAC4 } \\
\text { [Gossypium hirsutum }]\end{array}$ & AT4G27410 & 2.3 & 1.85 & 1 \\
\hline IC0AAA84AA06 & $\begin{array}{l}\text { NAC domain protein } \\
\text { [Citrus sinensis }]\end{array}$ & AT5G63790 & - & 0.56 & 2 \\
\hline IC0AAA88DA08 & $\begin{array}{l}\text { NAC domain-containing protein } \\
\text { [Ricinus communis }]\end{array}$ & AT4G27410 & 0.57 & - & 3 \\
\hline \multicolumn{6}{|l|}{ bHLH } \\
\hline C34001D01 & $\begin{array}{c}\text { BHLH transcription factor PTF1-like } \\
\text { protein } \\
\text { [Oryza sativa Japonica Group }]\end{array}$ & AT2G24260 & 0.69 & 0.9 & 1 \\
\hline C08014B07 & $\begin{array}{c}\text { Putative bHLH transcription factor } \\
\text { [Lotus japonicus }]\end{array}$ & AT4G29100 & 0.92 & 0.95 & 1 \\
\hline IC0AAA5CB08 & $\begin{array}{c}\text { Auxin-induced basic helix-loop-helix } \\
\text { transcription factor } \\
\text { [Gossypium hirsutum }]\end{array}$ & AT3G47620 & - & 1.09 & 2 \\
\hline C04015F06 & $\begin{array}{l}\text { Putative bHLH transcription factor } \\
\text { [Lotus japonicus] }\end{array}$ & AT4G29100 & 1.29 & - & 3 \\
\hline IC0AAA71CF08 & $\begin{array}{l}\text { BHLH transcription factor } \\
\text { [Gossypium hirsutum }]\end{array}$ & AT5G62610 & -1.19 & -1.73 & 4 \\
\hline C06003G03 & $\begin{array}{l}\text { BHLH transcription factor } \\
\quad[\text { Ricinus communis }]\end{array}$ & AT1G05710 & - & -1.31 & 5 \\
\hline IC0AAA6BC03 & $\begin{array}{c}\text { BHLH transcription factor PTF1 } \\
\text { [Zea mays }]\end{array}$ & AT5G58010 & -0.5 & - & 6 \\
\hline \multicolumn{6}{|l|}{ MADS-box } \\
\hline C02017D01 & $\begin{array}{l}\text { MADS-box protein } 26 \\
\text { [Cucumis sativus] }\end{array}$ & AT5G20240 & 0.74 & 0.62 & 1 \\
\hline C16016Е08 & $\begin{array}{l}\text { MADS- box transcription factor } \\
\quad[\text { Populus tomentosa }]\end{array}$ & AT4G22950 & -1.04 & -1.31 & 4 \\
\hline С $34106 \mathrm{~B} 08$ & $\begin{array}{l}\text { MADS box protein GHMADS-2 } \\
\text { [Gossypium hirsutum }]\end{array}$ & AT4G09960 & -0.64 & - & 6 \\
\hline \multicolumn{6}{|l|}{ MYB } \\
\hline C34004C09 & MYBR2 [Malus x domestica] & AT3G16350 & 0.76 & 0.54 & 1 \\
\hline C02008E10 & MYB92 [Malus $x$ domestica] & AT2G37630 & -2.59 & -2.63 & 4 \\
\hline С08035B03 & $\begin{array}{l}\text { MYB domain class transcription } \\
\text { factor [Malus } x \text { domestica }]\end{array}$ & AT5G67300 & - & -1.26 & 5 \\
\hline $\mathrm{C} 18005 \mathrm{C} 01$ & $\begin{array}{l}\text { MYB domain class transcription } \\
\text { factor [Malus x domestica] }\end{array}$ & AT4G21440 & -0.85 & - & 6 \\
\hline \multicolumn{6}{|l|}{ TCP } \\
\hline IC0AAA34DF02 & $\begin{array}{l}\text { TCP family transcription factor } \\
\text { [Arabidopsis thaliana }]\end{array}$ & AT1G72010 & 0.88 & 0.57 & 1 \\
\hline IC0AAA55DG09 & $\begin{array}{l}\text { TCP domain class transcription factor } \\
\text { [Malus } x \text { domestica }]\end{array}$ & AT5G51910 & 0.95 & 1.39 & 1 \\
\hline
\end{tabular}


Tabla 11 (continuación de la página anterior).

\begin{tabular}{lccccc}
\hline ID & Descripción & $\begin{array}{c}\text { Posible ortólogo } \\
\text { de } \text { A.thaliana }\end{array}$ & M 12h & M 24h & Cluster \\
\hline HD-Zip (ATHB) & & & & & \\
C02021F02 & $\begin{array}{c}\text { Class III HD-Zip protein } 8 \\
\text { [Citrus trifoliata] }\end{array}$ & AT1G52150 & 1.27 & 1.00 & 1 \\
IC0AAA56DD03 & $\begin{array}{c}\text { PHAVOLUTA-like HD-ZIPIII } \\
\text { protein [Nicotiana sylvestris] }\end{array}$ & AT1G30490 & 0.51 & - & 3 \\
C31809D05 & $\begin{array}{c}\text { Homeobox-leucine zipper protein } \\
\text { ATHB-7 [Arabidopsis thaliana] }\end{array}$ & AT2G46680 & 2.42 & - & 3 \\
C32011E02 & $\begin{array}{c}\text { Homeobox-leucine zipper protein } \\
\text { HOX32 [Oryza sativa Indica Group] }\end{array}$ & AT2G34710 & - & -0.64 & 5 \\
DOF & $\begin{array}{c}\text { AT5G60850 } \\
\text { IC0AAA75CF12 }\end{array}$ & $\begin{array}{c}\text { Dof zinc finger protein DOF5.4 } \\
{[\text { Arabidopsis thaliana] }}\end{array}$ & -0.829 & - & 6 \\
\hline
\end{tabular}

Además de los factores de transcripción relacionados con la regulación de la respuesta a hormonas, el etileno reguló genes implicados en la biosíntesis de hormonas (Tabla 12). El unigen C02019D04, que codifica una ACC oxidasa (ACO), enzima implicada en la síntesis de etileno, se inducía transitoriamente a las $12 \mathrm{~h}$ de tratamiento, y el gen C16011H01, que codifica una zeaxantina epoxidasa (ZEP), enzima implicada en la síntesis de ácido abscísico, se inducía a las 24 h de tratamiento.

Tabla 12. Unigenes relacionados con la biosíntesis de hormonas regulados por el etileno exclusivamente en la ZAC. Junto a cada unigen se muestra el nivel de expresión a las 12 y $24 \mathrm{~h}$ de tratamiento con etileno con respecto a las $0 \mathrm{~h}\left[\mathrm{M}=\log _{2}\left(\mathrm{ZAC}_{\mathrm{t}} / \mathrm{ZAC} \mathrm{C}_{0}\right)\right]$. - = No se produjo cambio significativo en la expresión entre el tiempo ' $\mathrm{t}$ ' y el tiempo '0' en la ZAC.

\begin{tabular}{lccccc}
\hline ID & \multicolumn{1}{c}{ Descripción } & $\begin{array}{c}\text { Posible ortólogo } \\
\text { de } \text { A. thaliana }\end{array}$ & M 12h & M 24h & Cluster \\
\hline Biosíntesis de etileno & & & & & \\
C02019D04 & ACC oxidase 1 [Gossypium hirsutum] & AT1G05010 & 1.22 & 1.03 & 3 \\
$\begin{array}{l}\text { Biosíntesis de ácido abscísico } \\
\text { C16011H01 Zeaxanthin epoxidase [Citrus maxima }]\end{array}$ & AT5G67030 & - & 1.36 & 2 \\
\hline
\end{tabular}


El etileno reguló la expresión de un número elevado de unigenes relacionados con el estrés oxidativo (Tabla 13). Se indujeron 7 glutatión-S-transferasas (C06022B06, C19005A01, C01008G07, C31303F07, IC0AAA71BF05, C32101A12, C08034B04 y C05811E06), 5 tiorredoxinas (IC0AAA10DH07, C01009G02, C34100G10, C08008G07 y C16017H03), 2 glutarredoxinas (IC0AAA71BF05 y C31708D11), una catalasa (IC0AAA97BF03) y 2 proteínas de tipo metalotioneína (C31402C06 y IC0AAA97AG12). Por otra parte, se reprimieron 6 peroxidasas (C31010D03, C31101F04, KN0AAP11YP14, KN0AAB3CB05, C31503H10 y C32004B11), una glutarredoxina (C04016F07), una glutatión-S-transferasa (C31401B08), una superóxido dismutasa (C02001B06) y una peroxirredoxina (C01020H10). Estos genes relacionados con la destoxificación de especies reactivas del oxígeno quedaron distribuidos en los diferentes clusters que se muestran en la

Tabla 13.

Tabla 13. Unigenes relacionados con el estrés oxidativo regulados por el etileno exclusivamente en la ZAC. Junto a cada unigen se muestra el nivel de expresión a las 12 y $24 \mathrm{~h}$ de tratamiento con etileno con respecto a las $0 \mathrm{~h}$ $\left[\mathrm{M}=\log _{2}\left(\mathrm{ZAC}_{\mathrm{t}} / \mathrm{ZAC} \mathrm{C}_{0}\right)\right]$. - = No se produjo cambio significativo en la expresión entre el tiempo ' $\mathrm{t}$ ' y el tiempo ' 0 ' en la ZAC.

\begin{tabular}{|c|c|c|c|c|c|}
\hline ID & Descripción & $\begin{array}{c}\text { Posible ortólogo } \\
\text { de } \text { A. thaliana }\end{array}$ & M 12h & M 24h & Cluster \\
\hline \multicolumn{6}{|c|}{ Glutatión-S-transferasas } \\
\hline С06022B06 & $\begin{array}{l}\text { Glutathione S-transferase } \\
\text { [Ricinus communis] }\end{array}$ & AT1G10360 & 1.71 & 1.13 & 1 \\
\hline C19005A01 & $\begin{array}{l}\text { Glutathione S-transferase } \\
\text { [Ricinus communis }]\end{array}$ & AT1G10370 & 1.78 & 2.23 & 1 \\
\hline C01008G07 & $\begin{array}{l}\text { Glutathione S-transferase GST } 14 \\
\text { [Glycine } \max ]\end{array}$ & AT2G29420 & 1.74 & 0.90 & 1 \\
\hline C31303F07 & $\begin{array}{c}\text { Glutathione S-transferase GST } 22 \\
{[\text { Ricinus communis }]}\end{array}$ & AT2G30860 & 1.44 & 1.17 & 1 \\
\hline C32101A12 & $\begin{array}{c}\text { Putative glutathione S-transferase T3 } \\
\text { [Solanum lycopersicum }]\end{array}$ & AT2G29420 & - & 1.28 & 2 \\
\hline C08034B04 & $\begin{array}{c}\text { Glutathione S-transferase GST } 22 \\
{[\text { Ricinus communis }]}\end{array}$ & AT2G30860 & - & 0.87 & 2 \\
\hline C05811E06 & $\begin{array}{l}\text { Glutathione S-transferase } \\
\text { [Ricinus communis }]\end{array}$ & AT5G62480 & 1.39 & - & 3 \\
\hline C31401B08 & Glutathione S-transferase [Citrus sinensis] & AT1G78380 & - & -0.81 & 5 \\
\hline \multicolumn{6}{|l|}{ Tiorredoxinas } \\
\hline IC0AAA10DH07 & $\begin{array}{c}\text { Thioredoxin-like } 1 \\
\text { [Oryza sativa Japonica Group] }\end{array}$ & AT1G08570 & 1.29 & 0.76 & 1 \\
\hline C01009G02 & $\begin{array}{l}\text { Chloroplast drought-induced stress protein/ } \\
\text { Thioredoxin [Arabidopsis thaliana] }\end{array}$ & AT1G76080 & 0.72 & 0.82 & 1 \\
\hline C34100G10 & Thioredoxin H [Citrus $x$ paradisi] & AT3G51030 & 1.35 & 0.87 & 1 \\
\hline
\end{tabular}


Tabla 13 (continuación de la página anterior).

\begin{tabular}{|c|c|c|c|c|c|}
\hline ID & Descripción & $\begin{array}{l}\text { Posible ortólogo } \\
\text { de A. thaliana }\end{array}$ & M 12h & M 24h & Cluster \\
\hline \multicolumn{6}{|l|}{ Tiorredoxinas } \\
\hline C08008G07 & Thioredoxin H [Citrus $x$ paradisi] & AT3G51030 & 1.13 & - & 3 \\
\hline C16017H03 & Thioredoxin H [Ricinus communis] & AT5G39950 & 0.74 & - & 3 \\
\hline \multicolumn{6}{|l|}{ Glutarredoxinas } \\
\hline IC0AAA71BF05 & $\begin{array}{l}\text { Glutaredoxin family protein } \\
\text { [Arabidopsis thaliana }]\end{array}$ & AT5G58530 & 0.61 & 0.76 & 1 \\
\hline C31708D11 & Glutaredoxin [Arabidopsis thaliana] & AT1G64500 & 1.23 & & 3 \\
\hline $\mathrm{C} 04016 \mathrm{~F} 07$ & Glutaredoxin [Citrus hybrid cultivar] & AT5G40370 & -1.05 & -2.16 & 5 \\
\hline \multicolumn{6}{|l|}{ Peroxidasas } \\
\hline C31010D03 & $\begin{array}{c}\text { Peroxidase precursor } \\
\text { [Cucumis melo subsp. melo] }\end{array}$ & AT4G21960 & -1.65 & -1.9 & 4 \\
\hline C31101F04 & Peroxidase [Populus trichocarpa $]$ & AT2G37130 & - & -1.11 & 5 \\
\hline KN0AAP11YP14 & $\begin{array}{l}\text { Glutathione peroxidase } \\
\text { [Arabidopsis thaliana] }\end{array}$ & AT4G11600 & - & -0.52 & 5 \\
\hline KN0AAB3CB05 & $\begin{array}{l}\text { Putative L-ascorbate peroxidase } \\
\text { [Arabidopsis thaliana }]\end{array}$ & AT4G09010 & -1.24 & - & 6 \\
\hline C $31503 \mathrm{H} 10$ & Class III peroxidase [Gossypium hirsutum] & AT5G05340 & -1.48 & - & 6 \\
\hline C32004B11 & Peroxidase [Citrus maxima] & AT5G06730 & -1.42 & - & 6 \\
\hline \multicolumn{6}{|l|}{ Catalasas } \\
\hline IC0AAA97BF03 & CAT1 catalase [Passalora fulva] & AT1G20630 & 0.64 & - & 3 \\
\hline \multicolumn{6}{|c|}{ Superóxido dismutasas } \\
\hline C02001B06 & $\begin{array}{l}\mathrm{Cu}-\mathrm{Zn} \text { superoxide dismutase } \\
{[\text { Avicennia marina }]}\end{array}$ & AT1G08830 & -0.93 & -0.9 & 4 \\
\hline \multicolumn{6}{|l|}{ Peroxirredoxinas } \\
\hline $\mathrm{C} 01020 \mathrm{H} 10$ & $\begin{array}{l}\text { Putative peroxiredoxin protein } \\
\text { [Ricinus communis }]\end{array}$ & AT3G52960 & -1.3 & -1.46 & 4 \\
\hline \multicolumn{6}{|l|}{ Metalotioneínas } \\
\hline C31402C06 & $\begin{array}{l}\text { Metallothionein-like protein } \\
\text { [Citrus hybrid cultivar] }\end{array}$ & AT3G15353 & 1.70 & - & 3 \\
\hline IC0AAA97AG12 & $\begin{array}{l}\text { Metallothionein-like protein } \\
\text { [Citrus hybrid cultivar] }\end{array}$ & AT3G15353 & 1.02 & - & 3 \\
\hline
\end{tabular}

La Tabla 14 muestra los unigenes relacionados con la defensa frente a patógenos que fueron regulados significativamente en la ZAC. El etileno indujo cuatro genes que codifican quitinasas (C31005C03, C31100B11, C34101G09 y C32009D05), uno que codifica una proteína PR (Pathogen-Related protein; C31208A08), dos genes (IC0AAA29DG03 y C31303E07) que codifican inhibidores de proteasas y un gen (C18025F01) con homología a una proteína de resistencia a enfermedades de tipo NBS- 
LRR (nucleotide-binding site leucine-rich repeat protein). Por otra parte, se reprimieron siete genes que codifican proteínas relacionadas con defensa: una proteína inducible por herida y patógenos (C18001F07), una proteína inhibidora de proteinasa (C31708B05), dos proteínas de resistencia a enfermedades de tipo NBS-LRR (IC0AAA69CB12 y C34106C07), una proteína de resistencia a hongos (C05807D08) y dos proteínas asociadas a resistencia (C31709D09 y C05136A10).

Tabla 14. Unigenes relacionados con la defensa regulados por el etileno exclusivamente en la ZAC. Junto a cada unigen se muestra el nivel de expresión a las 12 y $24 \mathrm{~h}$ de tratamiento con etileno con respecto a las $0 \mathrm{~h}$ $\left[\mathrm{M}=\log _{2}\left(\mathrm{ZAC} / \mathrm{ZAC} \mathrm{C}_{0}\right)\right]$. - = No se produjo cambio significativo en la expresión entre el tiempo ' $\mathrm{t}$ ' y el tiempo ' 0 ' en la ZAC.

\begin{tabular}{|c|c|c|c|c|c|}
\hline ID & Descripción & $\begin{array}{l}\text { Posible ortólogo } \\
\text { de } A \text {. thaliana }\end{array}$ & M 12h & M 24h & Cluster \\
\hline $\mathrm{C} 31005 \mathrm{C} 03$ & Chitinase CHI1 [Citrus sinensis] & AT3G54420 & 1.03 & 1.61 & 1 \\
\hline C31100B11 & Chitinase CHI1 [Citrus sinensis] & AT3G54420 & - & 2.58 & 2 \\
\hline C34101G09 & Acidic chitinase III [Nicotiana tabacum] & AT5G24090 & - & 2.07 & 2 \\
\hline C32009D05 & Acidic class I chitinase [Citrus jambhiri] & AT3G12500 & 2.34 & - & 3 \\
\hline C31208A08 & $\begin{array}{l}\text { Pathogenesis-related protein } 4 \mathrm{~b} \\
\text { [Capsicum chinense }]\end{array}$ & AT3G04720 & 0.85 & 1.17 & 1 \\
\hline $\mathrm{C} 18001 \mathrm{~F} 07$ & $\begin{array}{l}\text { Pathogen-and wound-inducible antifungal } \\
\text { protein CBP20 [Nicotiana tabacum] }\end{array}$ & AT3G04720 & -1.70 & -1.57 & 4 \\
\hline IC0AAA29DG03 & $\begin{array}{l}\text { Proteinase inhibitor se60-like protein } \\
\text { [Citrus } x \text { paradisi }]\end{array}$ & AT5G63660 & 0.92 & 0.99 & 1 \\
\hline C31303E07 & $\begin{array}{l}\text { Type I proteinase inhibitor-like protein } \\
\text { [Citrus } x \text { paradisi }]\end{array}$ & AT2G38870 & -1.22 & 1.29 & 2 \\
\hline C31708B05 & $\begin{array}{l}\text { Type I proteinase inhibitor-like protein } \\
\text { [Citrus } x \text { paradisi }]\end{array}$ & AT2G38870 & -3.85 & -3.9 & 4 \\
\hline $\mathrm{C} 18025 \mathrm{~F} 01$ & $\begin{array}{l}\text { NBS-LRR type disease resistance protein } \\
{[\text { Citrus trifoliata }]}\end{array}$ & AT1G12280 & - & 0.813 & 2 \\
\hline IC0AAA69CB12 & $\begin{array}{c}\text { Putative NBS-LRR type resistance protein } \\
{[\text { Populus trichocarpa }]}\end{array}$ & AT3G14460 & -0.67 & -0.631 & 4 \\
\hline $\mathrm{C} 34106 \mathrm{C} 07$ & $\begin{array}{l}\text { NBS-LRR type disease resistance protein } \\
\text { Rps1-k-2 [Quercus suber] }\end{array}$ & AT3G14470 & -0.955 & -1.13 & 4 \\
\hline C31709D09 & CC-NBS-LRR protein [Quercus suber] & AT3G14460 & - & -1.01 & 5 \\
\hline C05136A10 & CC-NBS-LRR protein [Quercus suber] & AT3G14470 & - & -1.13 & 5 \\
\hline C05807D08 & $\begin{array}{l}\text { Verticillium wilt disease resistance protein } \\
\text { Ve2 [Solanum lycopersicum] }\end{array}$ & AT1G45616 & -1.36 & - & 6 \\
\hline
\end{tabular}


El etileno reguló también un número elevado de unigenes relacionados con el transporte, tal y como se puede observar en la Figura 19. Concretamente, el transporte de vesículas experimentó una regulación importante en la ZAC que, como se comentaba en el apartado 3.3.6, agrupaba un número mayor de unigenes que en la CF. La Tabla 15 recoge la expresión de los unigenes correspondientes a proteínas relacionadas con el tráfico de vesículas desde el retículo endoplasmático hasta el aparato de Golgi y viceversa, con el transporte a través del aparato de Golgi, con el transporte hacia la vacuola, con la formación de endosomas y con la secreción. Entre ellas se encuentran: dos proteínas COPI (Coat protein complex I; C05001C06 y C31109C04), una proteína COPII (Coat protein complex II; IC0AAA5AD04), 4 proteínas adaptadoras de clatrina o adaptinas (C34010E12, KN0AAP1YP16, C02026H10 y KN0AAP10YD02), una clatrina (IC0AAA71AF06), 8 GTPasas (C31004D09, C34104C09, KN0AAH1AH10， C31202D08， C16015D09, C34201D03, KN0AAI2BD07 y IC0AAA73CC12), cinco proteínas SNARE (Soluble Nethylmaleimide-sensitive factor activating protein receptor; C16016D06, IC0AAA44CF06, C31501E12, C31401C06 y C31107H07), una proteína implicada en la endocitosis mediada por clatrina (Epsin; C01005F12) y otras 6 proteínas diferentes relacionadas con el tráfico de proteínas intracelular (IC0AAA55AH05, C08034G10, C03006C12, C16013E04, C32103A03 y C02026D02).

Tabla 15. Unigenes relacionados con el transporte de vesículas regulados por el etileno exclusivamente en la ZAC. Junto a cada unigen se muestra el nivel de expresión a las 12 y 24 h de tratamiento con etileno con respecto a las $0 \mathrm{~h}\left[\mathrm{M}=\log _{2}\left(\mathrm{ZAC}_{\mathrm{t}} / \mathrm{ZAC}_{0}\right)\right]$. - = No se produjo cambio significativo en la expresión entre el tiempo 't' y el tiempo '0' en la ZAC.

\begin{tabular}{|c|c|c|c|c|c|}
\hline ID & Descripción & $\begin{array}{l}\text { Posible ortólogo } \\
\text { de } \text { A. thaliana }\end{array}$ & M 12h & M 24h & Cluster \\
\hline \multicolumn{6}{|l|}{ Proteínas COP I } \\
\hline C05001C06 & $\begin{array}{l}\text { Putative coatomer complex subunit } \\
\text { [Ricinus communis }]\end{array}$ & AT1G52360 & 0.53 & - & 3 \\
\hline C $31109 \mathrm{C} 04$ & $\begin{array}{l}\text { Putative coatomer gamma-2 subunit } \\
\text { [Ricinus communis] }\end{array}$ & AT4G34450 & -1.08 & - & 6 \\
\hline \multicolumn{6}{|l|}{ Proteínas COP II } \\
\hline IC0AAA5AD04 & $\begin{array}{l}\text { Putative protein transport factor } \operatorname{Sec} 23 \\
\text { [Ricinus communis] }\end{array}$ & AT4G01810 & - & 0.50 & 2 \\
\hline \multicolumn{6}{|c|}{ Proteínas adaptadoras de clatrina/Adaptinas } \\
\hline C34010E12 & $\begin{array}{l}\text { Putative clathrin coat assembly protein } \\
\text { [Arabidopsis thaliana] }\end{array}$ & AT1G60780 & - & 0.65 & 2 \\
\hline KN0AAP1YP16 & Putative beta-adaptin [Arabidopsis thaliana] & AT4G23460 & - & 0.61 & 2 \\
\hline
\end{tabular}


Tabla 15 (continuación de la página anterior).

\begin{tabular}{|c|c|c|c|c|c|}
\hline ID & Descripción & $\begin{array}{c}\text { Posible ortólogo } \\
\text { de A. thaliana }\end{array}$ & M 12h & M 24h & Cluster \\
\hline \multicolumn{6}{|c|}{ Proteínas adaptadoras de clatrina/Adaptinas } \\
\hline KN0AAP10YD02 & $\begin{array}{l}\text { Clathrin adaptor complex small chain family } \\
\text { protein [Ricinus communis] }\end{array}$ & AT3G50860 & - & -0.64 & 5 \\
\hline $\mathrm{C} 02026 \mathrm{H} 10$ & $\begin{array}{l}\text { Putative clathrin coat assembly protein } \\
\text { [Ricinus communis }]\end{array}$ & AT1G47830 & -0.79 & - & 6 \\
\hline \multicolumn{6}{|l|}{ Clatrina } \\
\hline IC0AAA71AF06 & $\begin{array}{l}\text { Putative clathrin heavy chain } \\
\text { [Pediculus humanus corporis] }\end{array}$ & AT3G11130 & - & 0.98 & 2 \\
\hline \multicolumn{6}{|l|}{ GTPasas } \\
\hline C31004D09 & $\begin{array}{l}\text { ADP-ribosylation factor } \\
\text { [Populus tremuloides }]\end{array}$ & AT1G10630 & 0.87 & 0.88 & 1 \\
\hline C34104C09 & $\begin{array}{l}\text { Ras-related GTP-binding protein } \\
\text { [Arabidopsis thaliana }]\end{array}$ & AT2G43130 & - & 0.80 & 2 \\
\hline KN0AAH1AH10 & $\begin{array}{l}\text { Putative Ras-related GTP-binding protein } \\
\text { [Lotus japonicus }]\end{array}$ & AT1G02130 & - & 0.82 & 2 \\
\hline C31202D08 & $\begin{array}{l}\text { Ras-related protein GTP-binding protein } \\
\text { ARA5 [Arabidopsis thaliana] }\end{array}$ & AT1G02130 & - & 0.97 & 2 \\
\hline C16015D09 & $\begin{array}{l}\text { Rac-like GTP-binding protein } \\
\text { [Ricinus communis }]\end{array}$ & AT5G62880 & -0.99 & -0.95 & 4 \\
\hline C34201D03 & $\begin{array}{l}\text { Rac-like GTP-binding protein } \\
\text { [Ricinus communis }]\end{array}$ & AT1G75840 & -0.89 & -1.27 & 4 \\
\hline KN0AAI2BD07 & $\begin{array}{l}\text { ADP-ribosylation factor } \\
{[\text { Glycine max }]}\end{array}$ & AT5G37680 & - & -0.65 & 5 \\
\hline IC0AAA73CC12 & GTP-binding protein [Pisum sativum] & AT3G46060 & - & -0.56 & 5 \\
\hline \multicolumn{6}{|l|}{ Proteínas SNARE } \\
\hline C16016D06 & $\begin{array}{l}\text { Putative syntaxin protein } \\
\text { [Ricinus communis }]\end{array}$ & AT5G08080 & - & 1.51 & 2 \\
\hline IC0AAA44CF06 & $\begin{array}{l}\text { Putative syntaxin protein } \\
\text { [Nicotiana tabacum }]\end{array}$ & AT3G05710 & - & 0.51 & 2 \\
\hline C31107H07 & $\begin{array}{l}\text { Vesicle-associated membrane family protein } \\
\text { [Arabidopsis lyrata] }\end{array}$ & AT4G21450 & 0.67 & - & 3 \\
\hline C31501E12 & $\begin{array}{l}\text { USE1 domain-containing protein } \\
\text { [Arabidopsis thaliana }]\end{array}$ & AT3G55600 & - & -1.14 & 5 \\
\hline C31401C06 & $\begin{array}{l}\text { Snare protein ykt6, putative } \\
\text { [Ricinus communis }]\end{array}$ & AT5G58060 & - & -0.96 & 5 \\
\hline \multicolumn{6}{|c|}{ Proteína de endocitosis } \\
\hline $\mathrm{C} 01005 \mathrm{~F} 12$ & $\begin{array}{c}\text { Epsin N-terminal homology (ENTH) } \\
\text { domain-containing protein / clathrin } \\
\text { assembly protein-related } \\
\text { [Arabidopsis thaliana }]\end{array}$ & AT5G11710 & -0.98 & - & 6 \\
\hline \multicolumn{6}{|l|}{ Otras proteínas } \\
\hline IC0AAA55AH05 & $\begin{array}{l}\text { Exocyst complex subunit Sec15-like family } \\
\text { protein [Ricinus communis] }\end{array}$ & AT3G56640 & 0.92 & 0.97 & 1 \\
\hline C08034G10 & $\begin{array}{l}\text { VHS domain-containing protein / GAT } \\
\text { domain-containing protein [Glycine max] }\end{array}$ & AT4G32760 & - & 0.92 & 2 \\
\hline
\end{tabular}


Tabla 15 (continuación de la página anterior).

\begin{tabular}{|c|c|c|c|c|c|}
\hline ID & Descripción & $\begin{array}{l}\text { Posible ortólogo } \\
\text { de A. thaliana }\end{array}$ & M 12h & M 24h & Cluster \\
\hline \multicolumn{6}{|c|}{ Otras proteínas } \\
\hline C32103A03 & $\begin{array}{c}\text { Signal recognition particle receptor alpha } \\
\text { subunit [Arabidopsis thaliana] }\end{array}$ & AT4G30600 & -0.53 & -0.61 & 4 \\
\hline C02026D02 & $\begin{array}{c}\text { Leucine-rich repeat receptor-like protein } \\
\text { kinase (EVERSHED) } \\
\text { [Arabidopsis thaliana }]\end{array}$ & AT2G31880 & - & -0.87 & 5 \\
\hline $\mathrm{C} 03006 \mathrm{C} 12$ & $\begin{array}{l}\text { Signal recognition particle receptor alpha } \\
\text { subunit [Ricinus communis] }\end{array}$ & AT1G73430 & -1.01 & - & 6 \\
\hline C16013E04 & $\begin{array}{l}\text { Putative protein transport protein SEC61 } \\
\text { alpha subunit [Populus trichocarpa] }\end{array}$ & AT2G34250 & -0.74 & - & 6 \\
\hline
\end{tabular}




\subsubsection{Validación del análisis de expresión mediante micromatrices por RT-PCR}

semicuantitativa

Los resultados del análisis de expresión global mediante micromatrices se validaron a través del análisis de expresión particular de 14 genes por medio de la técnica de RT-PCR semicuantitativa. Las Figuras 20 y 21 muestran que las tendencias de expresión de los genes comprobados con ambas técnicas son equivalentes. También se evaluó por RT-PCR la expresión de estos genes en la corteza del fruto con el objetivo de comprobar que solamente se producían cambios de expresión significativos durante el tratamiento con etileno en la ZAC.

\section{A}

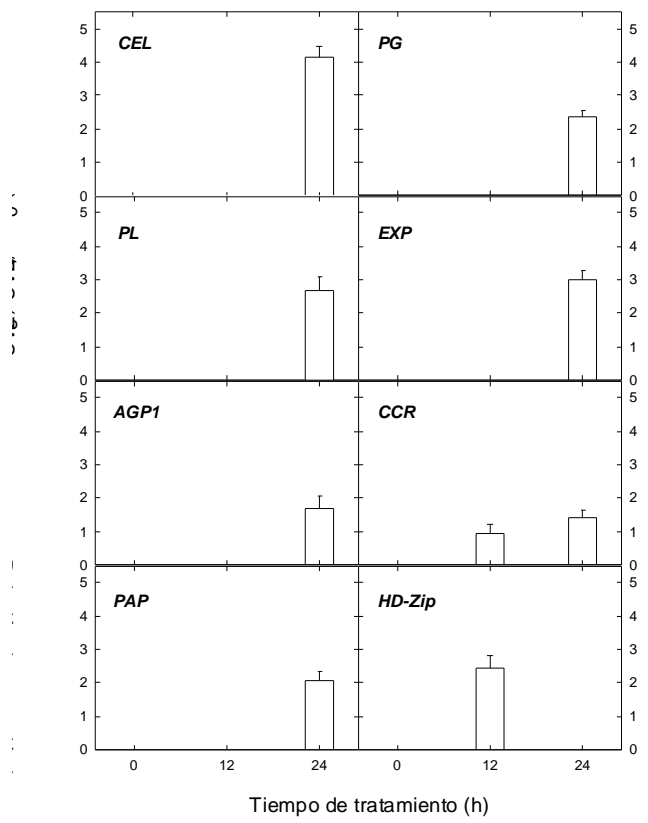

$\frac{\circ}{\frac{0}{0}}$ B

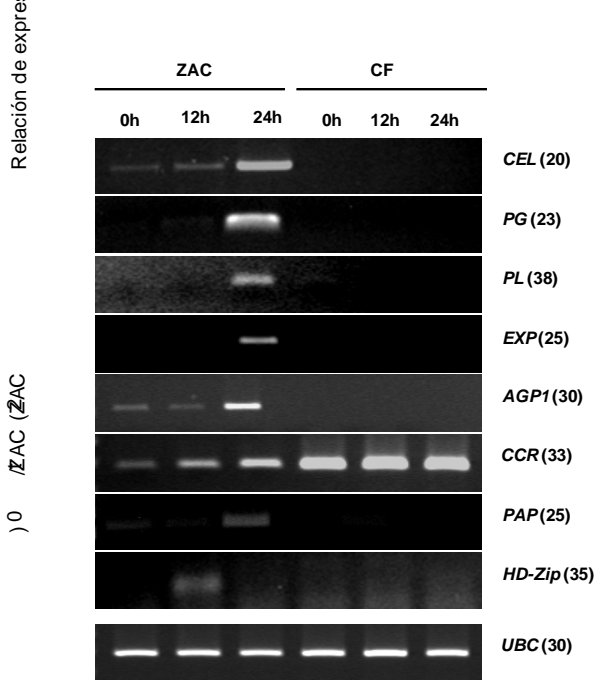

Figura 22. Contraste entre el análisis de expresión mediante micromatrices (A) y mediante RT-PCR semicuantitativa (B) de los genes CEL/Celulasa ácida/C21007H10, PG/Poligalacturonasa 1/IC0AAA67DG09, $P L /$ Pectato liasa/IC0AAA15AF11, EXP/Expansina/IC0AAA14BD04, AGP1/Arabinogalactan-protein 1/IC0AAA56BH05, CCR/Cinamoil-CoA reductasa/C34205C03, PAP/Purple acid phosphatase/C02014A07, HDZip/Homeobox-leucine zipper protein/C31809D05 y UBC/Ubiquitin-conjugating enzyme/C06015C05 (gen de referencia). Valores representados como $0.00=$ no significativos en la comparación. Entre paréntesis aparece el número de ciclos de amplificación para cada gen validado por RT-PCR. 
A

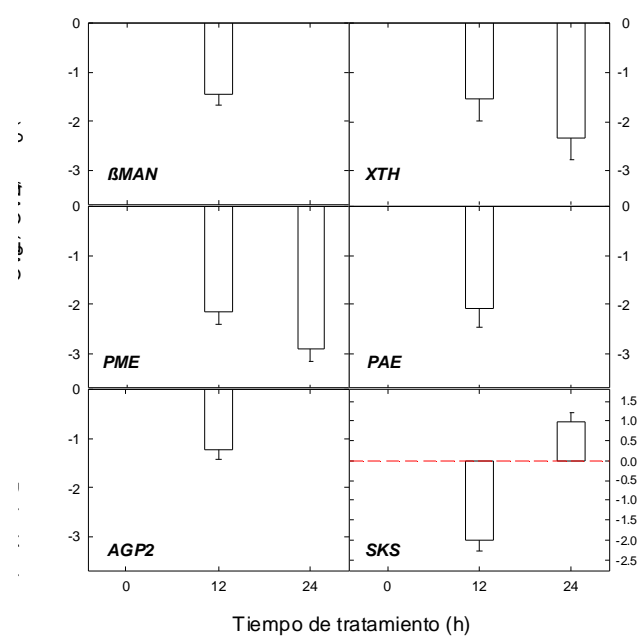

亳B

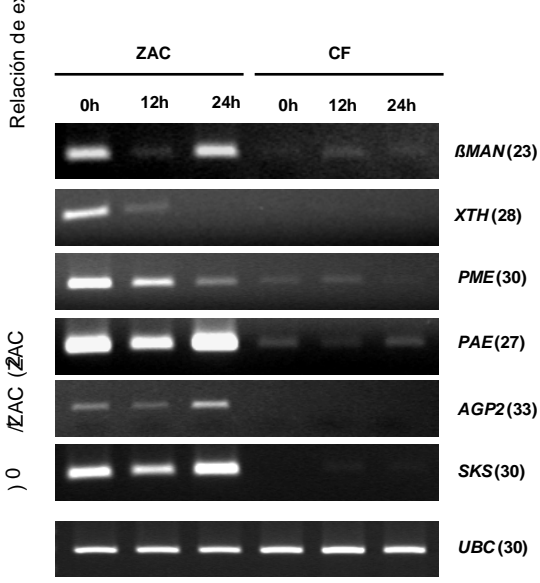

Figura 23. Contraste entre el análisis de expresión mediante micromatrices (A) y mediante RT-PCR semicuantitativa $\quad(\mathbf{B}) \quad$ de $\quad$ los genes $\beta$-MAN/ $\beta$-manosidasa/C03004E07, XTH/Xiloglucano endotransglicosilasa/C02023G10, PME/Pectin metilesterasa/C01011H09, PAE/Pectin acetilesterasa/C02003B05, AGP2/Arabinogalactan-protein 1/C31404H07, SKS/Multicopper oxidase/C02016C05 y UBC/Ubiquitinconjugating enzyme/C06015C05 (gen de referencia). Valores representados como 0.00 = no significativos en la comparación. Entre paréntesis aparece el número de ciclos de amplificación para cada gen validado por RT-PCR. 


\subsection{Discusión}

Los tratamientos con etileno y ácido 1-aminociclopropano-1-carboxílico (ACC) aceleraban la abscisión de frutos maduros separados del árbol de las variedades 'Washington Navel' y 'Navel Ricalate', respectivamente (Figuras 12.A y 12.B). Los frutos tratados con etileno o ACC experimentaron un rápido descenso de la fuerza de retención (FR) a partir de las $24 \mathrm{~h}$ y a las $48 \mathrm{~h}$ de tratamiento alcanzaron valores de FR en torno a 4 kgf, mientras que los frutos no tratados alcanzaron valores próximos a 4 kgf a las 96 h y a partir de las 120 h ('Washington Navel' y 'Navel Ricalate', respectivamente). Por tanto, los resultados de la cinética de abscisión fueron comparables independientemente del tratamiento (etileno o ACC) y de la variedad ('Washington Navel' o 'Navel Ricalate') utilizada. Ambos tratamientos permitieron disponer de muestras homogéneas en relación a la activación de la abscisión ya que posibilitaron tanto la sincronización como la aceleración del proceso.

La caracterización morfológica de la ZAC aportó datos interesantes sobre el desarrollo del proceso a nivel celular. Tras $24 \mathrm{~h}$ de tratamiento con etileno, utilizando la microscopía electrónica de barrido, se podía observar una materia amorfa en la ZAC resultado, posiblemente, del inicio de la degradación de la lámina media y de las paredes de las células de las capas de separación (Figura 14.A). A las 48 h de tratamiento esta materia amorfa era más abundante y se produjo la separación celular en la parte central de la ZAC. Además, la pérdida de consistencia celular se extendió a un mayor número de capas dentro de la ZAC (Figura 14.B). Tras 96 h de tratamiento con etileno, se había producido la separación celular completa de la ZAC (Figura 14.C) y se observó expansión celular diferencial entre la parte proximal y distal de la ZAC. En la parte proximal, se expandían las células del tejido parenquimático (Figura 14.D), mientras que en la parte distal lo hacían las células de los haces vasculares (Figura 14.E). El modelo de abscisión propuesto por Patterson (2001) en Arabidopsis thaliana considera dos alternativas para la etapa de activación (etapa C; Figura 3): una en la que la expansión celular observada tras la separación celular no sería un componente del programa de abscisión sino una consecuencia y otra en la que la expansión celular formaría parte del programa de activación del proceso y tendría lugar en la parte proximal de la zona de abscisión. Por tanto, en los frutos de naranjo bajo las condiciones estudiadas, la expansión celular 
observada tras la separación efectiva supondría una nueva alternativa al modelo de abscisión propuesto hasta el momento, ya que ocurre tanto en la parte proximal como distal de la ZAC y, además, en zonas complementarias.

El trabajo realizado en relación a la anatomía de la ZAC utilizando la tinción PAS permitió diferenciar dos áreas celulares dentro de la ZAC: una con apariencia meristemática localizada hacia el disco floral y otra rica en gránulos de almidón en contacto con las células de la corteza del fruto (Figura 15.G). Ambas áreas celulares eran fácilmente distinguibles desde las $0 \mathrm{~h}$ hasta las $48 \mathrm{~h}$ de tratamiento (Figuras 15.G, H e I). Existen algunos trabajos relacionados con el proceso de abscisión en diferentes especies vegetales (Bornman et al., 1966; Huberman et al., 1983; Goren, 1993; Shiraishi y Yanagisawa, 1988) en los que, previamente a la separación celular, observan acumulación de almidón en las células de la ZA, y en las últimas etapas del proceso de abscisión, el número de gránulos de almidón disminuye. Sin embargo, tal y como se observa en las Figuras 15.G, 15.H y 15.I, la cantidad de gránulos de almidón parece que se mantiene constante en la ZAC desde las 0 h hasta las 48 h de tratamiento. En la presente tesis, esta caracterización morfológica y anatómica permitió identificar y delimitar las capas que conforman la ZAC para el posterior aislamiento mediante microdisección asistida por láser de células de la ZAC así como para realizar una descripción precisa de los cambios que experimentan las células de la ZAC durante la activación y el desenlace del proceso de abscisión.

La deposición de lignina observada en la zona de abscisión C (ZAC) de ambas variedades tras 24 y $48 \mathrm{~h}$ de tratamiento (Figuras 13.A y 13.B) sirvió como indicador de la activación del proceso de abscisión y confirmó los resultados de la cinética de abscisión. A las $24 \mathrm{~h}$ de tratamiento con etileno o ACC se detectó deposición de lignina en la parte central de la ZAC, por tanto, el proceso ya se había desencadenado. A las $48 \mathrm{~h}$ de tratamiento el proceso se encontraba en un estado más avanzado ya que la deposición de lignina se extendía a lo largo de la ZAC. Estos resultados correlacionaban con los valores de FR alcanzados a las $48 \mathrm{~h}$ de tratamiento en ambas variedades (Figuras 12.A y 12.B). Existe una controversia en la literatura en relación al significado biológico de la lignificación que experimentan algunos tejidos durante el proceso de abscisión. Por una parte, parece evidente que los tejidos que van a quedar expuestos tras la abscisión pueden experimentar un programa de transdiferenciación que implicaría la deposición de lignina en 
las paredes de las células de las nuevas capas protectoras (Addicott, 1982; Agustí et al., 2008; van Nocker, 2009). Sin embargo, otros trabajos han incidido también en la importancia de la lignificación para generar una tensión en la zona de separación que posibilite la rotura mecánica de las paredes celulares como parte de los procesos de abscisión y dehiscencia (Liljegren et al., 2000; Sexton, 1979). En el caso de la ZAC activada por el etileno, la lignificación solamente afecta a la porción distal de la zona de abscisión y, además, este proceso de deposición de lignina parece extenderse a las células de la corteza del fruto (Figura 17.C). Por tanto, la deposición de lignina que se detecta durante la abscisión de los frutos maduros de cítricos parece estar única y exclusivamente relacionada con la generación de una tensión en la zona de separación que posibilite la rotura mecánica de las paredes celulares y la abscisión.

Conforme avanzaba el proceso de abscisión ( 24 y 48 h de tratamiento), se detectó también deposición de cutina en el plano de fractura de la ZAC, siendo más abundante este polímero a las $48 \mathrm{~h}$ (Figura 16.I). La cutina es un poliéster extracelular que constituye una barrera frente a patógenos, confiere resistencia a estrés, regula el flujo de nutrientes entre células y órganos e impermeabiliza las hojas y los frutos de las plantas superiores (Heredia, 2002; Yang et al., 2010). Por tanto, la deposición de cutina observada a las 24 y 48 h de tratamiento en el plano de fractura de la ZAC podría estar relacionada con la impermeabilización y el sellado de la herida resultante de la abscisión como medida de protección frente a la pérdida de agua y el ataque de patógenos.

En el presente capítulo se discute el análisis de expresión a gran escala de la ZAC activada por etileno mediante el empleo de micromatrices de cDNA. Tanto la microdisección asistida por láser, que permitió aislar células exclusivas de la ZAC, como la comparación con el análisis de expresión en la CF (tejido utilizado como control) proporcionaron datos muy específicos del proceso de abscisión a nivel molecular. Los resultados muestran que el etileno regulaba la expresión de 4.281 genes en la ZAC y 3.743 genes en la $\mathrm{CF}$, mientras que 2.001 genes fueron regulados por el etileno tanto en la ZAC como en la CF (Figura 18).

Los genes regulados por el etileno exclusivamente en la ZAC y exclusivamente en la CF fueron agrupados en categorías funcionales MIPS (Anexos 4 y 5). Todas las categorías 
funcionales reguladas mostraron representantes tanto en la ZAC como en la $\mathrm{CF}$, lo que sugiere una regulación de la expresión génica por el tratamiento con etileno muy similar en ambos tejidos a nivel de categorías funcionales. Sin embargo, en la mayor parte de las categorías funcionales el porcentaje de genes regulado por el etileno era superior en la ZAC (Anexo 6). Teniendo en cuenta que en la plataforma del CFGP utilizada en este estudio el nivel de representación del proceso de abscisión es considerablemente inferior al nivel de representación de procesos fisiológicos asociados a la corteza del fruto (la micromatriz contiene ESTs procedentes de 5 genotecas de abscisión y de 12 genotecas asociadas a la corteza de fruto), estos resultados sugieren que la ZAC responde de manera más activa que la $\mathrm{CF}$ al tratamiento con etileno y que los procesos relacionados con la separación celular comunes a otros aspectos del desarrollo y crecimiento vegetal, como la maduración, la senescencia o la expansión celular, están bien representados en la micromatriz de cDNA utilizada en el experimento. Las categorías funcionales que mostraron mayor porcentaje de regulación en la ZAC que en la CF fueron 'energía', 'procesamiento del DNA y ciclo celular', 'transcripción', 'síntesis de proteínas', ‘proteínas de unión', ‘biogénesis de componentes celulares' y 'localización subcelular' (Tabla 4). Por otra parte, un aspecto relevante que cabe destacar dentro de la categoría de 'metabolismo' es que las subcategorías de 'metabolismo de azúcares, glucósidos, polioles y carboxilatos' y 'metabolismo de polisacáridos' presentaban un porcentaje de regulación considerablemente mayor en la ZAC. La subcategoría de 'transporte vesicular' mostraba también un porcentaje mayor de regulación en la ZAC y lo mismo ocurría con las subcategorías de 'pared celular', 'vesículas de transporte intracelular' y 'proteínas de secreción/extracelulares', relacionadas con la localización subcelular. Estos resultados sugieren que a las 12 y 24 h de tratamiento con etileno se había activado a nivel transcripcional la maquinaria responsable de la degradación de la lámina media y de la pared celular y el transporte intracelular asociado a sistemas de membrana, que proporcionaría las proteínas necesarias para tales modificaciones de la lámina media y la pared celular en la ZAC.

Los 2.280 unigenes regulados por el etileno únicamente en la ZAC fueron agrupados en seis clusters distintos en función del perfil de expresión que mostraban durante la activación del proceso de abscisión (Figura 19). Los unigenes agrupados en el cluster 1 aumentaban su expresión durante las primeras $12 \mathrm{~h}$ de tratamiento y mantenían el nivel de expresión hasta las 24 h. El cluster 2 recogía los unigenes cuya expresión aumentaba a 
partir de las $12 \mathrm{~h}$ y el cluster 3 agrupaba unigenes cuya expresión aumentaba de forma transitoria a las $12 \mathrm{~h}$ de tratamiento. Por otra parte, la expresión de los unigenes del cluster 4 disminuía durante las primeras 12 h y luego se mantenía el nivel de expresión hasta las 24 h. Los unigenes del cluster 4 disminuían su expresión a partir de las 12 h y los unigenes del cluster 6 disminuían su expresión de forma transitoria a las 12 h de tratamiento con etileno.

La clasificación en categorías funcionales se estudió con más detalle en el caso de los unigenes regulados por el etileno exclusivamente en las ZAC. Las categorías funcionales que presentaban mayor número de genes regulados por el etileno, tanto inducidos como reprimidos, eran 'proteínas sin ortólogo en Arabidopsis, 'proteínas sin clasificar', 'localización subcelular', 'proteínas de unión', 'plegamiento, modificación y destino de proteínas', 'transcripción', 'transporte' y 'metabolismo' (Figura 20). El hecho de que las categorías 'proteínas sin ortólogo en Arabidopsis' y 'proteínas sin clasificar' se encuentren altamente representadas indica que, posiblemente, existen proteínas o familias de proteínas nuevas y de función todavía desconocida que podrían desempeñar una función importante en el proceso de abscisión.

El etileno reguló un número importante de unigenes relacionados con el metabolismo de la pared celular, algunos de los cuales se inducían tras el tratamiento con etileno, mientras que otros se reprimían. Como se observa en la Tabla 5, la mayor parte de los unigenes inducidos asignados a esta categoría seguían el patrón de expresión de los clusters 1 y 2 , es decir, su expresión aumentaba a las 12 h de tratamiento y se mantenía hasta las 24 $\mathrm{h}$ o aumentaba a las $24 \mathrm{~h}$ de tratamiento. A las $24 \mathrm{~h}$ de tratamiento se indujo la celulasa ácida (C21007H10) y dos poligalacturonasas (IC0AAA85AB02 y IC0AAA67DG09). Otra poligalacturonasa (IC0AAA19CA02) se inducía a las 12 y $24 \mathrm{~h}$ de tratamiento, y otra (C01018A12) se inducía de forma transitoria a las $12 \mathrm{~h}$. Por otra parte, una pectin metilesterasa (IC0AAA40DF03) se inducía a las 12 y $24 \mathrm{~h}$ de tratamiento con etileno y otra (C32102B03) a las $24 \mathrm{~h}$ de tratamiento. Del resto de genes que codifican enzimas capaces de hidrolizar polisacáridos de la pared celular destacaron: una $\beta$-manano hidrolasa (C04002G09) inducida a las $12 \mathrm{~h}$, una pectato liasa (IC0AAA15AF11) inducida a las $24 \mathrm{~h}$ y una $\beta$-galactosidasa $(\mathrm{C} 31401 \mathrm{H} 10)$, una xiloglucano endotransglicosilasa (IC0AAA99CH05) y una $\beta$-glucosidasa (IC0AAA1CB06) inducidas a las 12 y $24 \mathrm{~h}$ de tratamiento. En relación a la familia de las expansinas, se indujeron tres unigenes, uno de 
ellos (KN0AAQ1YG09) a las 12 y $24 \mathrm{~h}$ de tratamiento y otros dos (IC0AAA14BD04 y C02006G07) a las $24 \mathrm{~h}$.

Lo comentado hasta ahora en relación a las hidrolasas corrobora que en la ZAC se produce una amplia modificación del metabolismo de los polisacáridos estructurales de la lámina media y la pared celular, que es necesaria para la separación efectiva del órgano, en este caso el fruto.

El etileno también reprimió la expresión de algunos componentes de estas familias de hidrolasas (Tabla 5). Se reprimieron una poligalacturonasa (C03009E03), una $\beta$ galactosidasas (C31805H10), dos xiloglucano endotransglicosilasas (C02023G10 y C01009B04), una pectato liasa (C03011D06), 5 pectinesterasas (C05807A09, C01011H09, C08033H07, KN0AAP13YN19 y C02003B05), una $\beta$-manano hidrolasa (C03004E07) y una $\beta$-glucosidasa (C31007D10) y tres xilosidasas (C02024D10, C05075C11 y IC0AAA75AA10). Esto pone de manifiesto que, dentro de cada una de las familias de proteínas relacionadas con la modificación de la pared celular, sólo algunos miembros son específicos del proceso de abscisión. Los genes que aquí se reprimen probablemente estén implicados en otros procesos en los que también se produce remodelación de la pared celular, como la maduración del fruto, la senescencia o el crecimiento. Estas familias de proteínas se discuten con mayor profundidad en el Capítulo V.

El etileno reguló la expresión de varios genes relacionados con la biosíntesis de polímeros de pared celular (Tabla 6). Excepto una celulosa sintasa (IC0AAA5DG11) y una ramnosa sintasa (KN0AAI3AD11), el resto de genes de este tipo estaban inducidos en la ZAC. Se indujeron dos celulosas sintasas, una de forma transitoria a las $12 \mathrm{~h}$ de tratamiento (C16012C03) y otra a las 24 h (C05070F01). El etileno indujo tras 24 h de tratamiento una UDP-glucosa-4-epimerasa (C31108G08), familia que participa en la regulación de la biosíntesis de polisacáridos de la pared celular (Rösti et al., 2007), y dos manano sintasas (IC0AAA16BH03 y IC0AAA99AD02), enzimas que pertenecen a la familia de las proteínas CSL (Cellulose synthase-like) implicadas en la síntesis de los $\beta$-1,4-mananos que se encuentran en la pared celular de muchas especies de plantas (Davis et al., 2010). 
Los resultados de expresión expuestos demuestran que el etileno reguló el metabolismo de la pared celular tanto a nivel de degradación como de biosíntesis. La actuación conjunta de estos dos mecanismos de regulación de la pared está ampliamente documentada en procesos de desarrollo y crecimiento. En relación a la abscisión, existen evidencias que muestran expansión de las células de la zona de separación durante la última etapa del proceso de abscisión (Addicott, 1982; Patterson, 2001). En el plano de fractura de la ZAC del fruto de los cítricos (Figura 14) se observó esta expansión celular, mayoritariamente en el plano proximal de fractura. Este crecimiento debe estar relacionado con la creación de capas protectoras en las partes que van a quedar expuestas tras la abscisión, y debe ir acompañado de la síntesis de polímeros de la pared celular. Además, el hecho de que las células de tipo meristemático de la ZAC no muestren síntomas de degeneración durante la abscisión sugiere que estas células son las que están previamente preparadas para experimentar la expansión celular durante las últimas etapas del proceso de abscisión. Por tanto, los genes asociados a la biosíntesis de estos polímeros que se indujeron en la ZAC estarían relacionados con la última etapa del proceso de separación celular.

Como se comentaba al comienzo de este apartado, son varias las alternativas propuestas acerca del papel de la lignificación durante el proceso de abscisión (Addicott, 1982; Liljegren et al., 2000; Sexton, 1979). Excepto dos O-metil transferasas de ácido cafeico que se reprimieron en la ZAC, una a las $12 \mathrm{~h}$ de forma transitoria (C03007H04) y otra a las $24 \mathrm{~h}$ de tratamiento $(\mathrm{C} 05133 \mathrm{H} 01)$, el resto de genes relacionados con la biosíntesis de lignina se indujeron (Tabla 7). Una fenilalanina amonio liasa (C02002A11) y una cinamoil-CoA reductasa $(\mathrm{C} 34205 \mathrm{C} 03)$ se indujeron a las $12 \mathrm{~h}$ de tratamiento y mantuvieron su nivel de expresión hasta las 24 h, una 4-cumarato-CoA ligasa (C31504D07) se indujo a las $24 \mathrm{~h}$ (C31504D07) y una lacasa (IC0AAA50DG04) a las $12 \mathrm{~h}$ de tratamiento. Además, mediante HPLC acoplada a espectrometría de masas, se detectó en la ZAC un incremento de varios intermediarios de la ruta de biosíntesis de lignina. Así, se observó un aumento en el nivel de ácido cumárico tras $12 \mathrm{~h}$ de tratamiento con etileno y un aumento en el nivel de ácido cafeico y ferúlico tras 12, 24 y 36 h de tratamiento (Figura 21). La inducción de genes de biosíntesis de lignina en la ZAC junto con los resultados de la tinción con phloroglucinol (Figuras 13 y 17) y del análisis de analitos (Figura 21) demuestran que, efectivamente, se sintetiza lignina en la ZAC y seguidamente se deposita 
en el plano de fractura. Estos resultados, junto con la inducción de dos genes relacionados con la síntesis de cutina, una glicerol-3-fostato aciltransferasa y una esterol desaturasa (C31604E03 y C02002B06), y la deposición de cutina observada en la zona de separación (Figura 16) sugieren una posible acción conjunta de ambos polímeros extracelulares en el proceso de abscisión, tal y como se ha comentado con anterioridad.

El etileno reguló un número importante de genes relacionados con el metabolismo y la modificación de proteínas (Tablas 8 y 9), que fueron agrupados en las categorías funcionales MIPS 'síntesis de proteínas', 'plegamiento, modificación y destino de proteínas' y 'proteínas de unión' (subcategoría 'proteínas de unión a proteína'). La abundancia de este tipo de genes implica que el etileno estimula un importante recambio de proteínas durante el proceso de abscisión, que concuerda con el cambio de actividad y metabolismo que van a experimentar las células de la zona de abscisión. De hecho, trabajos previos mostraron un aumento significativo en la cantidad de proteínas y en la actividad enzimática en la zona de abscisión durante el desarrollo del proceso (Addicott, 1982; Sexton y Roberts, 1982). El etileno provocó tanto inducción como represión de genes relacionados con el recambio de proteínas. Esto implica que debe existir especificidad de tejido, es decir, los genes que se inducen son candidatos a estar regulando este proceso de manera específica durante la activación de la abscisión por etileno. Además, esto resulta interesante teniendo en cuenta que trabajos recientes indican que el etileno reprime la síntesis de proteínas (Nemhauser et al., 2006). Sin embargo, la ZAC responde de manera particular a la hormona en relación al metabolismo de proteínas ya que debe llevar a cabo un proceso altamente específico, activo y degradativo como es la separación celular.

En relación a la síntesis de proteínas, aumentó la expresión de 12 genes que codifican proteínas estructurales de los ribosomas, como las proteínas L3 y L19 de la subunidad $60 \mathrm{~S}$ o las proteínas S2 y S13 de la subunidad 40 S (Tabla 9). La inducción de estos genes en la ZAC concuerda con estudios ultraestructurales previos que describen un incremento del retículo endoplasmático rugoso durante la abscisión, que está relacionado a su vez con la síntesis de novo de proteínas (Lieberman et al., 1983; Valdovinos et al., 1972). También se indujeron genes que codifican aminoacil-tRNA sintasas (3) y factores de iniciación de la traducción (3). Sin embargo, el número de genes reprimidos relacionados con la síntesis de proteínas fue superior al de inducidos. Este hecho puede deberse a que la ZAC es un tejido 
que va a ser degradado y, por tanto, es posible que sólo mantenga activa la maquinaria enzimática necesaria para tal degradación celular, que llevará en última instancia al desprendimiento del órgano. La reducción de la expresión de los genes englobados en esta categoría puede interpretarse como un cambio en el patrón de síntesis de proteínas.

El etileno también indujo la maquinaria proteolítica en la ZAC (Tabla 8). La ruta de degradación de proteínas mediada por ubiquitina se encontraba altamente representada en este análisis. Este sistema es muy específico y selectivo, y permite degradar proteínas mal formadas, dañadas o innecesarias en un proceso fisiológico particular (Santos et al., 2006; Sullivan et al., 2003; Vierstra, 2003). La cascada de conjugación de ubiquitina requiere la actuación de tres familias de proteínas: E1 (enzimas de activación de ubiquitina), E2 (enzimas de conjugación de ubquitina) y E3 (ubiquitina ligasas). Las proteínas E1 y E2 son poco específicas. En Arabidopsis thaliana existen dos proteínas E1 y 37 proteínas E2, de las cuales sólo se han caracterizado algunas (Kraft et al., 2005). Sin embargo, existen más de 1200 proteínas de tipo E3, que son las que confieren especificidad de sustrato del sistema de degradación (Vierstra, 2003). Una vez se han marcado con ubiquitina las proteínas actúa el proteasoma, un complejo proteico que identifica las proteínas unidas a ubiquitina y las degrada (Kraut et al., 2007). En este trabajo, se indujeron dos proteínas pertenecientes a la familia E2 (C04035F10 y C34110B03), 7 proteínas de la familia E3 (C06022A03， IC0AAA47CF03， C08033H03， IC0AAA11BB03， KN0AAQ4YD04, IC0AAA65CC10 y IC0AAA16DB01), una poliubiquitina (C08010E08) y dos proteínas del proteasoma (C32003H11 y C31204B08). En el caso de la abscisión, la degradación de proteínas mediada por ubiquitina podría estar relacionada no sólo con la eliminación de proteínas dañadas o innecesarias sino también con la eliminación de proteínas represoras del proceso. Este tipo de activación de respuestas a través de la desrepresión mediada por proteólisis dependiente de ubiquitina ha sido previamente descrita en otros procesos, como en la percepción de la señal de auxinas (Kepinski y Leyser, 2005).

Este estudio permitió identificar diferentes proteínas de tipo quinasa y fosfatasa. Este tipo de enzimas fosforilan o desfosforilan proteínas causando cambios en la actividad enzimática, la localización celular o la asociación con otras proteínas, y son muy importantes en procesos de señalización (Hunter, 1995). El etileno indujo 17 unigenes que codifican proteínas de tipo quinasa, de los cuales un número importante pertenecían al 
grupo 'serine/threonine kinase' (Tabla 10). Esta clase de proteínas amplifican las señales extracelulares por medio de cascadas de fosforilación, por lo que podrían estar implicadas en la transducción de señales mediada por etileno en la ZAC. Las proteínas quinasa de tipo receptor (RLK; IC0AAA20DC09, C20008D03, IC0AAA2AF03 y C34003H08) y las proteínas con repeticiones de leucina (LRR; IC0AAA42DG01, C08038F02 y C04030G06), que pueden unirse a quinasas y adquirir actividad de tipo receptor, son especialmente interesantes. La abscisión de órganos florales en Arabidopsis thaliana parece estar regulada por una receptor-quinasa rica en leucina denominada $H A E S A$, ya que las plantas transgénicas que expresan este gen en antisentido presentan retraso en la abscisión (Jinn et al., 2000). Un estudio reciente (Cho et al., 2008) propone que la acción secuencial de los receptores de tipo quinasa denominados HAESA y HAESA-like 2 y las MAP quinasas MKK4 y MKK5 (Mitogen-Activated Protein Kinase Kinase) y MPK3 y MPK6 (MitogenActivated Protein Kinase) regula la separación celular en la zona de abscisión de órganos florales de Arabidopsis thaliana. En relación a las fosfatasas inducidas durante la activación del proceso con etileno, cabe destacar el gen C02014A07, que codifica una proteína de tipo 'purple acid phosphatase'. En un trabajo reciente llevado a cabo en Nicotiana tabacum, los autores sugieren que la sobreexpresión de una fosfatasa de este grupo (NtPAP12) promueve la actividad celulosa y calosa sintasa en el apoplasto (Kaida et al., 2010). La NtPAP12 reduce la actividad de $\beta$-xilosidasas y $\beta$-glucosidasas, lo que provoca una acumulación de oligosacáridos en el apoplasto, y son estos oligosacáridos los que actúan como efectores de la celulosa y calosa sintasas (Hayashi et al., 1987). La inducción de este tipo de fosfatasa en la ZAC concuerda con la inducción de las dos celulosa sintasas (C16012C03 y C05070F01) que, como ya se ha comentado, podrían estar implicadas en la expansión celular observada en la ZAC en la última etapa de la abscisión.

En relación al control de la transcripción, el etileno reguló un número importante de factores de transcripción pertenecientes a diferentes familias, algunas de las cuales han sido relacionadas previamente con el proceso de abscisión (Tabla 11). Se indujeron de forma significativa genes con homología a factores de las familias bHLH (C34001D01, C08014B07, IC0AAA5CB08 y C04015F06) y MADS-box (C02017D01). Los factores transcripcionales bHLH son muy importantes en el control de la identidad de los distintos tejidos que forman la zona de dehiscencia del fruto de Arabidopsis, así como en la lignificación de la misma (Lewis et al., 2006). INDEHISCENT (IND) es un bHLH 
necesario para la separación de las valvas del fruto de Arabidopsis y que, además, controla la diferenciación de zonas de separación lignificadas en los márgenes de la valva (Liljegren et al., 2004). Análisis genéticos han demostrado que IND, junto con los MADS-box redundantes SHATTERPROOF 1 (SHP1) y SHP2 y ALCATRAZ y SPATULA, otros dos factores bHLH, forman una red que controla la identidad y la dehiscencia de los márgenes de la valva (Heisler et al., 2001; Liljegren et al., 2000; 2004; Rajani y Sundaresan, 2001). Un factor de transcripción MYB (C34004C09) también apareció inducido en la ZAC. Algunos miembros de esta familia han sido relacionados con la lignificación durante la dehiscencia de las anteras (Steiner-Lange et al., 2003; Zhu et al., 2004). En base a estos resultados, es posible que estos tipos de factores (bHLH, MADS-box y MYB) pudieran controlar alguno de los procesos que se desarrollan en la ZAC, ya que existe una alta similitud entre los procesos de abscisión y dehiscencia (Ferrándiz, 2002).

Otras familias transcripcionales que fueron reguladas por el etileno en la ZAC son: factores con dominio 'HD-Zip' (C02021F02, IC0AAA56DD03 y C31809D05), factores con dominio 'TCP' (IC0AAA34DF02, IC0AAA55DG09) y factores de la familia NAC (NAM/ATAF/CUC; C08037H04; C04033H06; IC0AAA84AA06 y IC0AAA88DA08). No se conocen precedentes de estas familias en relación a procesos de separación celular, lo que sugiere la posible existencia de factores de transcripción no identificados hasta el momento que podrían ser importantes en el control del proceso de abscisión.

Por otra parte, el etileno reprimió la expresión de un factor de transcripción de la familia 'DNA binding with one finger' (DOF; IC0AAA75CF12) cuyo ortólogo de Arabidopsis presenta una alta homología con el factor de transcripción AtDOF4.7. En un trabajo previo, Wei et al. (2010) demostraron que en las plantas transgénicas que sobreexpresaban AtDOF4.7 no se producía disolución de la lámina media en la zona de abscisión de los órganos florales y, como consecuencia, no se producía la abscisión. Los autores comprobaron que AtDOF4.7 se unía al promotor de la poligalacturonasa PGAZAT, relacionada previamente con el proceso de abscisión (González-Carranza et al., 2002), y reprimía su expresión. Este factor, además, interactuaba con el factor de transcripción AtZFP2 implicado en la abscisión de los estambres de Arabidopsis (Cai y Lashbrook, 2008). Estos resultados sugieren que AtDOF4.7 participa en el control de la abscisión como parte de un complejo transcripcional que regula directamente la expresión 
de enzimas que participan en la remodelación de la pared celular. Por tanto, la represión de IC0AAA75CF12 podría estar relacionada con la inducción de poligalacturonasas observada en la ZAC (IC0AAA85AB02, IC0AAA67DG09, IC0AAA19CA02 y C01018A12).

La Tabla 11 incluye factores de transcripción relacionados con la respuesta a diferentes hormonas. Algunos trabajos hacen referencia a la existencia de interacciones entre diferentes hormonas dentro de la compleja red de factores que puede estar controlando el proceso de abscisión (Binder y Patterson, 2009; Nemhauser et al., 2006; Taylor y Whitelaw, 2001). La abscisión es un proceso en el que el etileno actúa como elemento inductor o acelerador y las auxinas como elemento represor o ralentizador (Roberts et al., 2002; Taylor y Whitelaw, 2001). En concordancia con este balance hormonal entre el etileno y las auxinas, se detectó regulación de la expresión de genes relacionados con la respuesta o señalización de ambas hormonas. Así, destaca la inducción en la ZAC de cinco factores de transcripción de repuesta a etileno (ERF), de los cuales tres se inducían a las 12 y $24 \mathrm{~h}$ de tratamiento (C31604B06, IC0AAA52AF07 y C31303G04) y dos solamente a las 12 h (C08037B08 y C31405C10). En relación a la respuesta a auxinas, se indujeron en la ZAC tanto factores de transcripción activadores de la respuesta a auxinas (ARF) como represores de la expresión de proteínas ARF (Aux/IAA). La inducción de dos represores Aux/IAA (IC0AAA19AG08 y C05131B01) junto con la represión de un transportador de auxinas PIN (IC0AAA7CC10) es esperable teniendo en cuenta el papel antagónico del etileno y las auxinas en la zona de abscisión durante el proceso. Sin embargo, un factor Aux/IAA se reprimió (KNOAAI2DB11) y se indujeron tres genes que codifican factores ARF (KN0AAP8YN01, C04015B03 y C16018D07). Trabajos previos (Gaspar et al., 1978; Jaffe y Goren, 1979) demostraron un incremento transitorio en el nivel de auxinas que se asoció a la expansión celular durante el proceso de separación. Otros trabajos (Rayle y Cleland, 1992; Vanderhoef y Dute, 1981; Vissenberg et al., 2001) sugieren la participación de las auxinas en la elongación celular durante otros procesos fisiológicos. Por tanto, es posible que la represión de determinados factores Aux/IAA y la inducción de factores ARF específicos estén relacionadas con la regulación de proteínas implicadas en el proceso de elongación durante la abscisión de frutos. Además, algunos trabajos recientes (Ellis et al., 2005; Okushima et al., 2005a, b) sugieren que diferentes factores ARF (ARF1, ARF2, ARF7 y ARF19) actúan con redundancia parcial como promotores de la abscisión. 
Por último, se detectó inducción en la ZAC de dos factores de transcripción relacionados con la señalización por ácido abscísico (ABA). A las 12 h de tratamiento se inducía el gen C08022H08, cuyo ortólogo de Arabidopsis thaliana codifica el factor de transcripción HY5 (LONG HYPOCOTYL 5), que promueve la expresión de $A B I 5$, un factor de transcripción relacionado con la señalización por ABA durante el desarrollo de las semillas (Chen et al., 2008). El factor de transcripción HY5 también promueve la expresión de proteínas Aux/IAA (Cluis et al., 2004), lo que concuerda con la inducción antes comentada de este tipo de factores de transcripción. También se indujo un factor de transcripción VP1/ABI3 (IC0AAA43CA11) que, al igual que ABI5, actúa como intermediario en la regulación de la expresión de genes inducibles por ABA durante el desarrollo de la semilla (Lazarova et al., 2002).

Además, de estos factores de transcripción relacionados con la regulación de la señalización hormonal, se indujeron genes implicados en la biosíntesis de hormonas (Tabla 12). Es el caso de C02019D04, que codifica una ACC oxidasa, enzima implicada en la síntesis de etileno, y C16011H01 que codifica una zeaxantina epoxidasa (ZEP), enzima relacionada con la síntesis de ABA. Existen diversos estudios que implican al ácido abscísico, junto al etileno, en el proceso de abscisión foliar en cítricos (Goren, 1993). Gómez-Cadenas et al. (1996) demostraron que la biosíntesis de ABA en las raíces de plantas de mandarino Cleopatara bajo condiciones de estrés hídrico severo es necesaria para que se desencadene el proceso de abscisión foliar, modulando la síntesis y acumulación de ACC en las raíces. Un estudio reciente (Ogawa et al., 2009) sugiere que el ABA junto con el etileno y el ácido jasmónico desempeña un papel importante en la abscisión de órganos florales de Arabidopsis thaliana.

El etileno reguló la expresión de una serie de genes relacionados con la destoxificación de especies reactivas del oxígeno (ROS) en la ZAC (Tabla 13). Dentro de este grupo se encontraban inducidos genes que codifican glutation S-transferasas, catalasas, tiorredoxinas, glutarredoxinas o proteínas tipo metalotioneína. Las especies reactivas del oxígeno están implicadas en diferentes procesos, incluyendo la respuesta a estreses bióticos y abióticos, la muerte celular programada, el desarrollo o la señalización hormonal (Kwak et al., 2006; Sakamoto et al., 2008). Durante el proceso de abscisión se producen especies reactivas del oxígeno (Michaeli et al., 2001; Sakamoto et al., 2008) y, además, algunos 
trabajos han demostrado el aumento de peroxidasas en la zona de abscisión (Gahagan et al., 1968; Henry, 1975). Otros estudios han relacionado directamente el etileno con la señalización ROS (D’Haeze et al., 2003; Desikan et al., 2005). Sakamoto et al. (2008) proponen que las especies reactivas del oxígeno pueden actuar como intermediarios entre el etileno y la expresión de genes relacionados con la degradación de la pared celular durante el proceso de abscisón. Por tanto, la inducción observada en la ZAC de genes relacionados con proteínas que destruyen estas especies puede ocurrir como consecuencia de su sobreproducción.

La abscisión es un proceso que produce una herida tras el desprendimiento del órgano. Esta herida es un lugar propicio para el ataque de patógenos, por lo que la planta activa una serie de rutas defensivas como medida preventiva (Roberts et al., 2002). En relación a este aspecto, encontramos varios genes inducibles por estrés biótico que aumentaron su expresión durante el tratamiento con etileno en la ZAC (Tabla 14). Se indujeron cuatro genes que codifican quitinasas (C31005C03; C31100B11; C34101G09 y C32009D05) y una proteína PR (Pathogen-Related protein; C31208A08), enzimas que se han relacionado con la abscisión en Phaseolus vulgaris (Lim et al., 1987; del Campillo y Lewis, 1992). También se indujeron dos genes (IC0AAA29DG03 y C31303E07) que codifican inhibidores de proteasas y un gen $(\mathrm{C} 18025 \mathrm{~F} 01)$ con homología a una proteína de resistencia a enfermedades de tipo NBS-LRR (nucleotide-binding site leucine-rich repeat protein).

Atendiendo a la categoría de transporte, la subcategoría de transporte intracelular de vesículas presentó un elevado número de representantes regulados por el etileno en la ZAC. La Tabla 15 recoge genes que codifican proteínas relacionadas con el tráfico intracelular, como las proteínas COPI y COPII (Coat protein complex I y II), las adaptinas, la clatrina, las GTPasas o las proteínas SNARE (Soluble N-ethylmaleimide-sensitive factor activating protein receptor). Este tipo de proteínas podrían estar implicadas en el transporte extracelular de proteínas necesarias para la remodelación de la pared celular y la lámina media, tal y como se ha comentado anteriormente, y con el aporte de monómeros de lignina y cutina al plano de fractura. La posible función de estas proteínas en el proceso de abscisión de los frutos cítricos se discute con mayor detalle en el Capítulo IV. 
En resumen, el análisis de expresión génica global expuesto en el presente capítulo proporciona una amplia visión de los principales procesos biológicos y moleculares que podrían estar relacionados con la abscisión de frutos cítricos. Además, la utilización de la microdisección asistida por láser para aislar únicamente células de un tejido muy especializado, como es la zona de abscisión, confiere gran especificidad a los resultados obtenidos. A este respecto, cabe destacar también que es la primera vez que se aplica esta técnica al estudio de la abscisión en frutos de una especie con importante valor agronómico.

Este trabajo ha permitido identificar nuevos genes pertenecientes a familias descritas previamente como importantes en relación a la abscisión o a los procesos de separación celular en general. Se han identificado nuevos genes pertenecientes a las familias más estudiadas en relación al metabolismo de la pared celular y algunos genes relacionados con la respuesta a hormonas implicadas en el proceso. También se han identificado nuevos factores de transcripción de familias previamente asociadas a los procesos de separación, así como nuevos genes relacionados con procesos menos estudiados en relación a la abscisión, como la transducción de la señal o el transporte intracelular de vesículas. Por tanto, aunque muchas de las familias génicas estudiadas ya habían sido asociadas a la abscisión o a los procesos de separación celular, la mayoría de los genes identificados no se habían relacionado con la abscisión en cítricos. 


\subsection{Conclusiones}

Los resultados presentados en este capítulo han permitido obtener las siguientes conclusiones:

1) El desarrollo del proceso de abscisión es comparable en variedades diferentes de naranjo dulce [Citrus sinensis (L.) Osb. cv. 'Washington Navel' y cv. 'Navel Ricalate'] bajo tratamientos promotores distintos [etileno $(10 \mu \mathrm{l} / \mathrm{l})$ y ACC $(0.1 \mathrm{mM})]$. La cinética de abscisión y la deposición de lignina concomitante al avance del proceso de abscisión son análogas en ambos casos.

2) El estudio morfológico y anatómico de la zona de abscisión C (ZAC) ha permitido delimitar los cambios específicos que se producen a nivel celular durante el proceso de abscisión en frutos. La ZAC de frutos cítricos está compuesta por 10-15 capas celulares organizadas en dos áreas celulares fácilmente distinguibles: una con apariencia meristemática en la parte proximal de la ZAC y otra rica en gránulos de almidón en la parte distal de la ZAC. En la ZAC de los frutos cítricos se produce expansión celular en la parte proximal (tejido parenquimático) y distal (haces vasculares).

3) El tratamiento con etileno induce en la ZAC la expresión de un gran número de genes que codifican enzimas hidrolíticas de la pared celular y proteínas implicadas en la biosíntesis de polisacáridos de pared que participan en la disolución y en la expansión de la pared celular, respectivamente.

4) Los resultados referentes a la síntesis de lignina y cutina sugieren que estos polímeros se sintetizan y depositan en la ZAC durante la activación del proceso de abscisión para facilitar la rotura mecánica de la ZAC y sellar la herida que se produce tras la abscisión, respectivamente.

5) La activación de la abscisión implica un recambio de proteínas en la ZAC que es producto de la inducción tanto de genes de biogénesis de proteínas como de proteólisis. 
6) Paralelamente a la síntesis de proteínas y a la síntesis de polímeros extracelulares, se activa el transporte intracelular de vesículas. Este transporte podría estar relacionado con el aumento de sistemas membranosos asociado a la abscisión, con el aporte extracelular de enzimas necesarias para la separación celular y con el aporte de monómeros de lignina y cutina al plano de fractura.

7) Otros procesos destacados durante la activación de la abscisión son el control de la transcripción, que incluye tanto a familias génicas ya descritas (MADS-box, bHLH o MYB) como a varias familias nuevas (HD-Zip, TCP o NAC), o la transducción de señales, que incluye genes que codifican proteínas de tipo quinasa o LRR-RLK. Otros procesos activados durante la abscisión son la biosíntesis y señalización hormonal, la destoxificación de especies reactivas del oxígeno (ROS) y la defensa frente al ataque de patógenos. 
IV. Identificación de genes relacionados con el tráfico intracelular de vesículas en la zona de abscisión $\mathrm{C}$ 


\subsection{Introducción}

El tráfico intracelular de proteínas se encuentra estrechamente relacionado con diversos procesos biológicos, como el desarrollo de la planta, la respuesta a estreses bióticos y abióticos o la señalización mediada por fitohormonas. Esto es debido a que tales procesos biológicos requieren cambios en la distribución espacial y temporal de proteínas en las células (Geldner, 2004; Hwang, 2008; Robatzek, 2007).

La transferencia de material entre orgánulos está mediada por vesículas que, continuamente, se forman en una membrana y se fusionan en otra. Cada evento de transporte de vesículas se divide en cuatro fases esenciales que incluyen: la formación de la vesícula en el orgánulo donador, el transporte hacia el orgánulo receptor, el anclaje en la membrana y, finalmente, la fusión (Bonifacino y Glick, 2004; Mellman y Warren, 2000). Estas etapas se encuentran altamente reguladas con el objetivo de asegurar que cada vesícula generada alcanza el compartimento receptor correcto.

El tráfico intracelular de vesículas comprende dos rutas principales: la secreción y la endocitosis. La ruta secretora representa la principal vía de biosíntesis donde las proteínas recién sintetizadas son etiquetadas con un péptido-señal en el retículo endoplasmático (RE) y transportadas al aparato de Golgi y, posteriormente, a la membrana plasmática (MP) o a la matriz extracelular (MEC). Contrariamente, la ruta endocítica representa un flujo de material desde la MP/MEC hasta la vacuola a través de los endosomas. Alternativamente a estas dos rutas principales, existen varias rutas de transporte retrógrado mediadas por señales que constituyen un mecanismo de reciclaje de proteínas desde las últimas etapas de la ruta secretora y endocítica. Además, estas rutas alternativas sirven para dirigir el tráfico de proteínas nuevas desde la ruta secretora hasta la vacuola (Bassham et al., 2008).

En la formación de las vesículas de transporte participan las proteínas de cubierta (Bonifacino y Lippincott-Schwartz, 2003; Kirchhausen, 2000; McMahon y Mills, 2004). Las cubiertas proteicas son estructuras dinámicas que deforman la membrana en sitios específicos del orgánulo donador y permiten la liberación de la vesícula recubierta. Estas proteínas de cubierta son reclutadas desde el citosol hacia la membrana donadora por pequeñas GTPasas de las familias Arf1 y Sar1, que regulan el ensamblaje de las mismas (Springer et al., 1999). La primera proteína de cubierta identificada fue la clatrina (Pearse, 
1975). Las vesículas de clatrina derivan, fundamentalmente, de la membrana plasmática o de la red trans-Golgi (TGN; trans-Golgi network), una red extensa de membrana situada en la cara trans de Golgi, y son transportadas hasta los endosomas (Owen et al., 2004). Estudios posteriores identificaron diferentes complejos proteicos, COPI (coat protein complex I) y COPII (coat protein complex II), que intervienen en la primera etapa de la ruta secretora. COPI actúa, principalmente, en el transporte desde el aparato de Golgi hasta el RE o entre las propias cisternas de Golgi, mientras que COPII interviene en el tráfico desde el RE hasta el aparato de Golgi (Barlowe et al., 1994; Letourneur et al., 1994; Waters et al., 1991).

Las vesículas generadas son transportadas a su destino final por difusión o a través del citoesqueleto. La interacción inicial de la vesícula con la membrana receptora está mediada por complejos proteicos denominados factores de anclaje y por pequeñas GTPasas de la familia Rab, y determinan, conjuntamente, el reconocimiento específico entre la vesícula de transporte y la membrana diana (Sztul y Lupashin, 2006; Whyte y Munro, 2002). Finalmente, la fusión de la vesícula a su membrana diana se produce gracias a la intervención de las proteínas transmembrana SNARE (soluble N-ethylmaleimide-sensitive factor attachment protein receptor) (Söllner et al., 1993).

Algunos trabajos sobre el proceso de abscisión, basados en observaciones ultraestructurales de la zona de abscisión (Addicott, 1982; Sexton et al., 1977; Valdovinos et al., 1972), han revelado que a medida que avanza la separación celular se produce un incremento en la cantidad de retículo endoplasmático rugoso (RER), de vesículas y de áreas de Golgi en las proximidades de la pared celular. Estos cambios celulares sugieren que la abscisión requiere un aumento de la demanda de la maquinaria secretora del sistema de endomembranas. Los autores sugieren que esta ruta secretora podría aportar las enzimas específicas de la abscisión en la zona de separación.

En un trabajo reciente llevado a cabo en Arabidopsis thaliana, Liljegren et al. (2009) observaron que una mutación recesiva, que bloqueaba la abscisión de órganos florales, afectaba la función de una proteína Arf-GAP (ADP-ribosylation factor GTPase activating protein), familia proteica que regula la actividad de las Arf-GTPasas (ADP-ribosylation factor GTPases) de cubierta. La proteína, llamada NEVERSHED (NEV), se localizaba en la 
red trans-Golgi y en los endosomas. Además, las células de la ZA de los mutantes nev presentaban defectos en el aparato de Golgi y una acumulación de vesículas junto a la pared celular. En base a los resultados obtenidos, los autores sugieren que la actividad de NEV es necesaria para el tráfico de moléculas implicadas en la separación celular. Posteriormente, Leslie et al. (2010) observaron que la mutación denominada evershed restauraba la abscisión en las flores nev, lo que implica que EVERSHED, que codifica una quinasa de tipo receptor LRR (LRR-RLK), actuaría como inhibidor de la abscisión y participaría en la regulación del tráfico de membrana durante el proceso.

En el presente capítulo se han analizado los perfiles de expresión en la zona de abscisión C (ZAC) y en la corteza del fruto (CF) de un amplio grupo de genes relacionados con el tráfico intracelular de vesículas y se ha profundizado en el estudio de su posible participación en el proceso de abscisión ya que, hasta el momento, el conocimiento a nivel molecular que existe al respecto es limitado. 


\subsection{Materiales y métodos}

\subsubsection{Material vegetal $y$ tratamientos}

El material vegetal y los tratamientos in vitro a los que se hace referencia en este capítulo son los descritos en el apartado 3.2.1.

\subsubsection{Clasificación y análisis de perfiles de expresión de genes relacionados con el} transporte intracelular de vesículas

Los genes relacionados con el tráfico de vesículas representados en la micromatriz de $20 \mathrm{~K}$ de cítricos (Martínez-Godoy et al., 2008) utilizada en este estudio se seleccionaron utilizando los datos de homología con los genes de Arabidopsis thaliana asociados a este proceso biológico. Mediante el módulo BLASTN del programa BLAST (Altschul et al., 1990) se recuperaron sistemáticamente los ESTs de cítricos depositados en la base de ESTs (dbEST) del GenBank que mostraban una homología $\geq 95 \%$ y una cobertura de secuencia $\geq$ $10 \%$ para cada gen, los cuales se ensamblaron utilizando el programa CAP3 (Huang y Madan, 1999), bajo los parámetros establecidos por el programa. De esta manera, se obtuvieron las secuencias CDS (CoDing Sequence) completas o parciales para cada uno de los genes asociados al tráfico intracelular de vesículas representados en la micromatriz utilizada en el estudio. Por último, se compararon las secuencias de estos genes con la base de datos del NCBI (National Center for Biotechnology Information, www.ncbi.nlm.nih.gov) utilizando el módulo BLASTX y se clasificaron los genes en familias según el ortólogo de Arabidopsis thaliana. Con el objetivo de determinar la posible especificidad de estos genes durante el proceso de abscisión, se compararon los perfiles de expresión en la zona de abscisión C y en la corteza del fruto. 


\subsection{Resultados}

4.3.1. Estudio de los perfiles de expresión de genes relacionados con el tráfico intracelular de vesículas en la ZAC y en la CF

Una parte importante de los cambios asociados a la abscisión activada por etileno están relacionados con el transporte intracelular de vesículas (ver Tabla 4, Capítulo III). A continuación, se exponen los perfiles de expresión de genes relacionados con dicho transporte en la ZAC y en la CF.

\subsubsection{Proteínas implicadas en la formación de vesículas en los orgánulos} donadores

El etileno reguló la expresión de genes relacionados con los complejos proteicos que constituyen la cubierta de las vesículas durante su formación en los orgánulos donadores así como la expresión de genes que codifican pequeñas GTPasas que regulan la actividad de dichas proteínas de cubierta. Dentro de este grupo de proteínas, cabe resaltar también los cambios de expresión que experimentaron algunas proteínas reguladoras de la actividad de las GTPasas de cubierta. La Tabla 16 agrupa estos genes y muestra la homología génica más elevada con Arabidopsis thaliana.

Tabla 16. Listado de genes relacionados con la formación de vesículas de tráfico intracelular regulados significativamente por el etileno durante la abscisión de frutos.

\begin{tabular}{|c|c|c|c|c|}
\hline ID $^{\mathbf{a}}$ & CFGP singleton/contig ${ }^{\mathrm{b}}$ & Nombre & $\begin{array}{c}\text { Homología génica A.thaliana } \\
\text { (AGI locus) }\end{array}$ & BLASTX score \\
\hline \multicolumn{5}{|c|}{ Complejos de cubierta } \\
\hline KN0AAP1YP16 & aKN0AAP1YP16FM1_c & Cit $\beta$-Adaptin & $\begin{array}{l}\text { Putative beta-adaptin } \\
\text { (AT4G23460) }\end{array}$ & $8,0 \mathrm{E}-82$ \\
\hline C34010E12 & aCL4031Contig1 & Citu1-Adaptin & $\begin{array}{l}\text { Putative clathrin coat assembly } \\
\text { protein (AT1G60780) }\end{array}$ & $5,0 \mathrm{E}-153$ \\
\hline IC0AAA2AB04 & aIC0AAA2AB04RM1_c & Cit $\gamma 1$-Adaptin & $\begin{array}{l}\text { Clathrin assembly protein } \\
\text { complex } 1 \text { gamma-2 large chain } \\
\text { (AT1G60070) }\end{array}$ & $0,0 \mathrm{E}+00$ \\
\hline
\end{tabular}

${ }^{a}$ EST impreso en la micromatriz

${ }^{\text {b }}$ CFGP: Spanish Citrus Functional Genomics Project 
Tabla 16 (continuación de la página anterior).

\begin{tabular}{|c|c|c|c|c|}
\hline ID $^{\mathbf{a}}$ & CFGP singleton/contig ${ }^{\mathrm{b}}$ & Nombre & $\begin{array}{c}\text { Homología génica } \text { A.thaliana } \\
\text { (AGI locus) }\end{array}$ & BLASTX score \\
\hline \multicolumn{5}{|c|}{ Complejos de cubierta } \\
\hline $\mathrm{C} 02026 \mathrm{H} 10$ & aCL8923Contig1 & Cito2-Adaptin & $\begin{array}{l}\text { Putative clathrin coat } \\
\text { assembly protein } \\
\text { (AT1G47830) }\end{array}$ & $5.0 \mathrm{E}-72$ \\
\hline KN0AAP10YD02 & aKN0AAP10YD02FM1_c & Cito3-Adaptin & $\begin{array}{l}\text { Clathrin adaptor complex } \\
\text { small chain family protein } \\
\text { (AT3G50860) }\end{array}$ & $3.0 \mathrm{E}-63$ \\
\hline $\mathrm{C} 04019 \mathrm{C} 02$ & aCL8883Contig 1 & Cito4-Adaptin & $\begin{array}{l}\text { Clathrin adaptor complex } \\
\text { small chain family protein } \\
\text { (AT2G19790) }\end{array}$ & $2.0 \mathrm{E}-72$ \\
\hline IC0AAA71AF06 & aCL1690Contig1 & CitTriskelion & $\begin{array}{l}\text { Putative clathrin heavy chain } \\
\text { (AT3G11130) }\end{array}$ & $0.0 \mathrm{E}+00$ \\
\hline IC0AAA5AD04 & aCL7834Contig 1 & CitSec 23 & $\begin{array}{l}\text { Putative protein transport } \\
\text { factor (AT4G01810) }\end{array}$ & $0.0 \mathrm{E}+00$ \\
\hline $\mathrm{C} 02011 \mathrm{G} 02$ & aCL7242Contig1 & Cit $\alpha-C O P I$ & $\begin{array}{l}\text { Putative coatomer protein } \\
\text { complex, subunit alpha } \\
\text { (AT1G62020) }\end{array}$ & $1.0 \mathrm{E}-170$ \\
\hline $\mathrm{C} 05001 \mathrm{C} 06$ & aC05001C06SK_c & Cit $\beta^{\prime}-C O P I$ & $\begin{array}{l}\text { Putative coatomer complex } \\
\text { subunit (AT1G52360) }\end{array}$ & $6.0 \mathrm{E}-126$ \\
\hline C31109C04 & aC31109C04EF_c & Cit $\gamma 2-C O P I$ & $\begin{array}{l}\text { Putative coatomer gamma-2 } \\
\text { subunit (AT4G34450) }\end{array}$ & $0.0 \mathrm{E}+00$ \\
\hline \multicolumn{5}{|c|}{ GTPasas de cubierta (Arf-GTPases; ADP-ribosylation factor GTPases) } \\
\hline C31004D09 & aC31004D09EF_c & CitArfAlf & $\begin{array}{l}\text { ADP-ribosylation factor } \\
\text { (AT1G10630) }\end{array}$ & $5.0 \mathrm{E}-84$ \\
\hline \multicolumn{5}{|c|}{ Arf-GEFs (ADP-ribosylation factor GTP-exchange factors) } \\
\hline C31806H05 & aCL5288Contig1 & CitBIG2 & $\begin{array}{l}\text { Guanine nucleotide } \\
\text { exchange factor-like protein } \\
\text { (AT3G60860) }\end{array}$ & $0.0 \mathrm{E}+00$ \\
\hline \multicolumn{5}{|c|}{ Arf-GAPs (ADP-ribosylation factor GTPase-activating proteins) } \\
\hline C31505F05 & aCL2674Contig1 & CitAGD5/NEV & $\begin{array}{l}\text { ADP-ribosylation factor } \\
\text { GTPase-activating protein } \\
\text { (AT5G54310, } \\
\text { NEVERSHED) }\end{array}$ & $8.0 \mathrm{E}-117$ \\
\hline $\mathrm{C} 04035 \mathrm{C} 01$ & aC04035C01SK_c & CitAGD8 & $\begin{array}{l}\text { ADP-ribosylation factor } \\
\text { GTPase-activating protein } \\
\text { (AT4G17890) }\end{array}$ & $1.0 \mathrm{E}-147$ \\
\hline
\end{tabular}

${ }^{\text {a }}$ EST impreso en la micromatriz

${ }^{\text {b }}$ CFGP: Spanish Citrus Functional Genomics Project

El tratamiento con etileno indujo la expresión exclusivamente en la ZAC de dos genes que codifican proteínas adaptadoras de clatrina o adaptinas (APs; Citu1-Adaptin y Cit $\beta$ Adaptin) y un gen que codifica la subunidad 'triskelion' de los complejos de clatrina (CitTriskelion) (Figura 24). Otros dos genes correspondientes a APs (Cito2-Adaptin y Cito3-Adaptin) se reprimían exclusivamente en la ZAC, mientras que Cito4-Adaptin y Cit $\gamma 1$-Adaptin se reprimían tanto en la ZAC como en la CF. En relación a los complejos 
COP-I (Coat Protein Complex I) y COP-II, los genes CitSec23 y Cit $\beta$ '-COPI se inducían exclusivamente en la ZAC, Cit $\alpha$-COPI se inducía en la ZAC y en la CF y Cit $\gamma 2-C O P I$ se reprimía exclusivamente en la ZAC. Por otra parte, el gen CitArfA1, que codifica una ArfGTPasa, se inducía exclusivamente en la ZAC. Finalmente, un gen correspondiente a una Arf-GEF (CitBIG2) se inducía en la ZAC y en la CF y los genes CitAGD5 (CitNEV) y CitAGD8, que codifican Arf-GAPs, se inducían o reprimían, respectivamente, en la ZAC y en la CF.

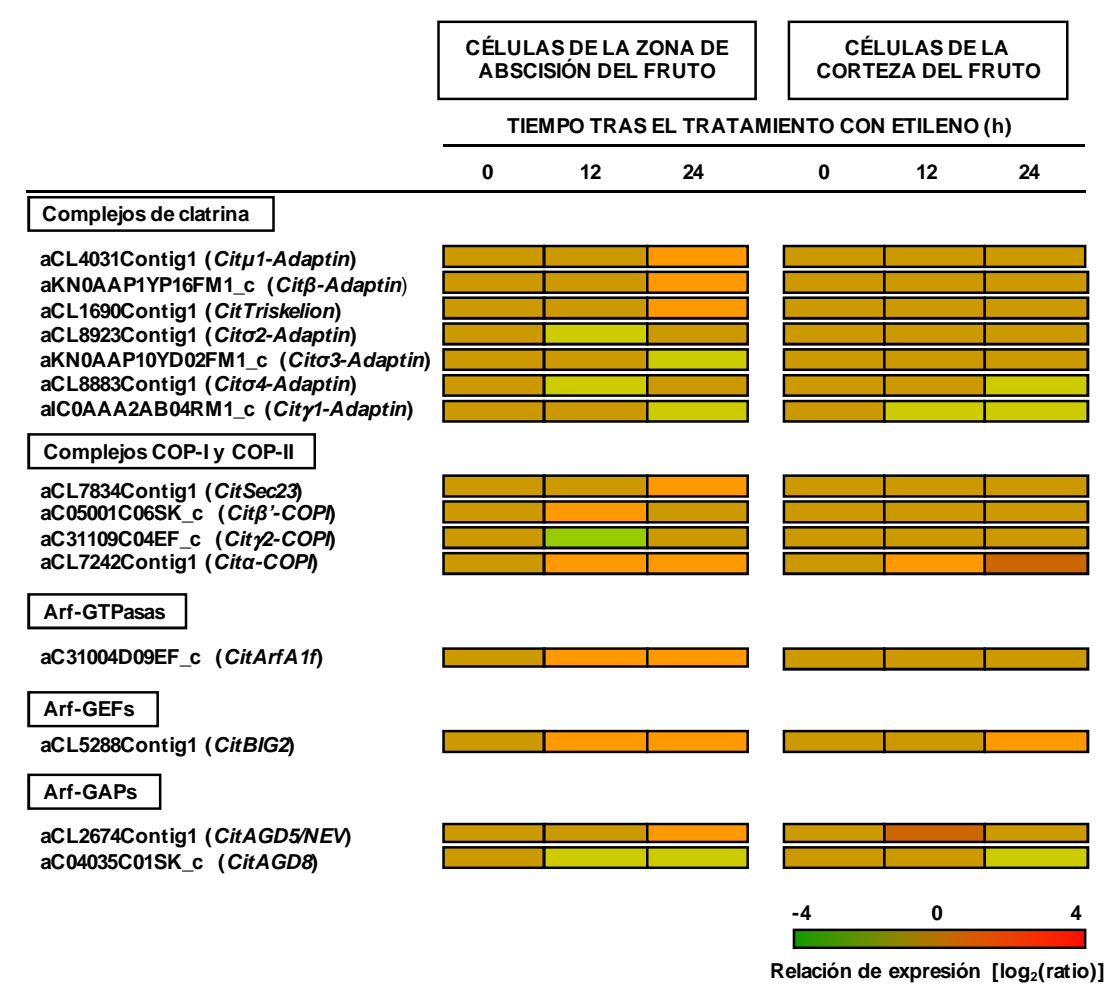

Figura 24. Perfiles de expresión de genes relacionados con la formación de vesículas de tráfico intracelular regulados significativamente en las células de la ZAC y/o de la CF. La escala de colores representa el nivel de expresión a las 12 y $24 \mathrm{~h}$ de tratamiento con etileno respecto a las $0 \mathrm{~h}$ en la $\mathrm{ZAC}$ o en la $\mathrm{CF}$ [M= $\log _{2}\left(\mathrm{ZAC}_{\mathrm{t}} / \mathrm{ZAC}_{0}\right)$ o $\left.\mathrm{M}=\log _{2}\left(\mathrm{CF}_{\mathrm{t}} / \mathrm{CF}_{0}\right)\right]$. 


\subsubsection{Proteínas implicadas en la fusión de membranas}

La Tabla 17 agrupa diferentes genes regulados significativamente por el etileno que codifican proteínas implicadas en la fusión de vesículas en los sistemas de endomembranas de destino. Esta tabla recoge, además, los genes ortólogos de Arabidopsis thaliana con mayor significación (BLASTX score).

Tabla 17. Listado de genes relacionados con la fusión de vesículas en el sistema de endomembranas regulados significativamente por el etileno durante la abscisión de frutos.

\begin{tabular}{|c|c|c|c|c|}
\hline ID $^{\mathbf{a}}$ & CFGP singleton/contig ${ }^{\mathbf{b}}$ & Nombre & $\begin{array}{c}\text { Homología génica A.thaliana } \\
\text { (AGI locus) }\end{array}$ & BLASTX score \\
\hline \multicolumn{5}{|l|}{ Rab-GTPasas } \\
\hline KNOAAH1AH10 & aCL1125Contig1 & CitRabA2a & $\begin{array}{l}\text { Putative Ras-related GTP-binding } \\
\text { protein (AT1G02130) }\end{array}$ & $2.0 \mathrm{E}-95$ \\
\hline C34104C09 & aCL3098Contig2 & CitRabA5c & $\begin{array}{l}\text { Putative Ras-related GTP-binding } \\
\text { protein (AT2G43130) }\end{array}$ & $6.0 \mathrm{E}-94$ \\
\hline KN0AAL1AD04 & aCL9458Contig1 & CitRabA6a & $\begin{array}{l}\text { Putative Ras-related GTP-binding } \\
\text { protein (AT1G73640) }\end{array}$ & $1.0 \mathrm{E}-79$ \\
\hline C05075E05 & aCL4527Contig1 & CitRabAld & $\begin{array}{l}\text { Putative ras-related GTP binding } \\
\text { protein (AT4G18800) }\end{array}$ & $1.0 \mathrm{E}-104$ \\
\hline $\mathrm{C} 08001 \mathrm{C} 01$ & aC08001C01SK_c & CitRabCl & $\begin{array}{l}\text { Putative GTP-binding protein } \\
\text { (AT1G43890) }\end{array}$ & $2.0 \mathrm{E}-96$ \\
\hline C31202D08 & aCL3353Contig1 & CitRabD2a & $\begin{array}{l}\text { GTP-binding protein } \\
\text { (AT1G02130) }\end{array}$ & $5.0 \mathrm{E}-104$ \\
\hline IC0AAA73CC12 & aCL1584Contig3 & CitRabE1c & $\begin{array}{l}\text { Small GTP-binding protein } \\
\text { (AT3G46060) }\end{array}$ & $1.0 \mathrm{E}-83$ \\
\hline C34104A03 & aC34104A03EF_c & CitRabHIb & $\begin{array}{l}\text { GTP-binding protein } \\
\text { (AT2G44610) }\end{array}$ & $1.0 \mathrm{E}-99$ \\
\hline C31101G01 & aC31101G01EF_c & CitRabHle & $\begin{array}{l}\text { GTP-binding protein } \\
\text { (AT5G10260) }\end{array}$ & $6.0 \mathrm{E}-104$ \\
\hline \multicolumn{5}{|c|}{ Proteínas de la familia SM (Sec1-Munc) } \\
\hline $\mathrm{C} 01006 \mathrm{~F} 12$ & aCL8448Contig 1 & CitKEULE & $\begin{array}{l}\text { SNARE-interacting protein } \\
\text { KEULE (AT1G12360) }\end{array}$ & $0.0 \mathrm{E}+00$ \\
\hline \multicolumn{5}{|c|}{ SNAREs (soluble $N$-ethylmaleimide-sensitive fusion protein attachment protein receptors) y proteínas asociadas } \\
\hline IC0AAA44CF06 & aCL2Contig 16 & CitSYP43 & $\begin{array}{l}\text { Putative syntaxin protein } \\
\text { (AT3G05710) }\end{array}$ & $2.0 \mathrm{E}-131$ \\
\hline C16016D06 & aCL8428Contig1 & CitSYP132 & $\begin{array}{l}\text { Putative syntaxin protein } \\
\text { (AT5G08080) }\end{array}$ & $4.0 \mathrm{E}-84$ \\
\hline C34208H12 & aCL2799Contig1 & CitSYP51 & $\begin{array}{l}\text { Putative syntaxin protein } \\
\text { (AT1G16240) }\end{array}$ & $2.0 \mathrm{E}-85$ \\
\hline
\end{tabular}

${ }^{\text {a }}$ EST impreso en la micromatriz

${ }^{\text {b }}$ CFGP: Spanish Citrus Functional Genomics Project 
Tabla 17 (continuación de la página anterior).

\begin{tabular}{lllll}
\hline ID & CFGP singleton/contig & Nombre & \multicolumn{1}{c}{$\begin{array}{c}\text { Homología génica } \text { A.thaliana } \\
\text { (AGI locus) }\end{array}$} & BLASTX score \\
\hline \multicolumn{2}{l}{ SNAREs (soluble $N$-ethylmaleimide-sensitive fusion protein attachment protein receptors) y proteínas asociadas } \\
C31501E12 & aC31501E12EF_c & CitUSE12 & $\begin{array}{l}\text { USE1 domain-containing protein } \\
\text { (AT3G55600) }\end{array}$ & $3.0 \mathrm{E}-66$ \\
C08038F09 & aC08038F09SK_c & CitVTI12 & $\begin{array}{l}\text { Vesicle soluble NSF attachment } \\
\text { protein receptor (AT1G26670) }\end{array}$ & $1.0 \mathrm{E}-79$ \\
C31404C08 & aCL3580Contig1 & CitSec22 & $\begin{array}{l}\text { Putative protein transporter } \\
\text { (AT1G11890) }\end{array}$ & $3.0 \mathrm{E}-110$ \\
C31401C06 & aCL2744Contig1 & CitYKT61 & $\begin{array}{l}\text { VAMP-like protein YKT61 } \\
\text { (AT5G58060) }\end{array}$ & $4.0 \mathrm{E}-99$ \\
C31107H07 & aCL5686Contig1 & CitPva42 & $\begin{array}{l}\text { Putative membrane associated } \\
\text { protein (AT4G21450) }\end{array}$ & $6.0 \mathrm{E}-90$ \\
\hline
\end{tabular}

${ }^{\text {a }}$ EST impreso en la micromatriz

${ }^{\mathrm{b}}$ CFGP: Spanish Citrus Functional Genomics Project

Dentro del grupo de las GTPasas de la familia Rab, los genes CitRabA5c, CitRabA2a y CitRabD2a se inducían exclusivamente en la ZAC, mientras que el gen CitRabElc se reprimía en la ZAC (Figura 25). Por otra parte, tres Rab-GTPasas (CitRabHle, CitRabHIb y CitRabA6a) se inducían tanto en la ZAC como en la CF, mientras que los genes CitRabAld y CitRabCl se reprimían en ambos tejidos. El gen CitKEULE, perteneciente a la familia SM, se indujo exclusivamente en la ZAC. Finalmente, en relación a las proteínas de tipo SNARE, tres genes (CitSYP132, CitSYP43 y CitPva42) se inducían exclusivamente en la ZAC, otros tres genes (CitUSE12, CitYKT61 y CitSec22) se reprimían exclusivamente en la ZAC y dos genes (CitSYP51 y CitVTI12) se reprimían tanto en la ZAC como en la CF. 


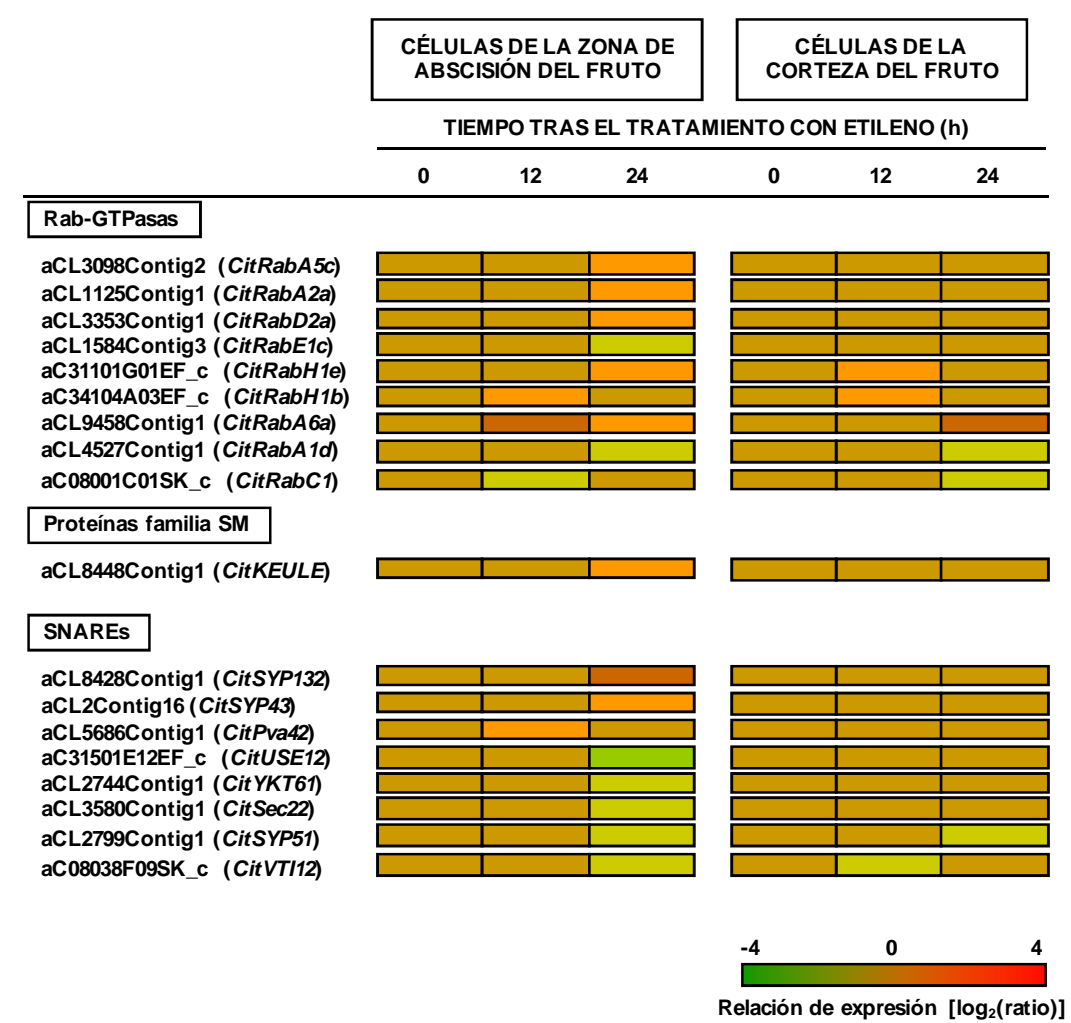

Figura 25. Perfiles de expresión de genes relacionados con la fusión de vesículas regulados significativamente en las células de la ZAC y/o de la CF. La escala de colores representa el nivel de expresión a las 12 y $24 \mathrm{~h}$ de tratamiento con etileno respecto a las $0 \mathrm{~h}$ en la $\mathrm{ZAC}$ o en la $\mathrm{CF}\left[\mathrm{M}=\log _{2}\left(\mathrm{ZAC}_{\mathrm{t}} / \mathrm{ZAC}_{0}\right)\right.$ o $\left.\mathrm{M}=\log _{2}\left(\mathrm{CF}_{\mathrm{t}} / \mathrm{CF}_{0}\right)\right]$. 


\subsubsection{Otras proteínas implicadas en el tráfico intracelular de vesículas}

La Tabla 18 recoge diferentes genes que codifican pequeñas GTPasas (proteínas 'Arflike' y Rho GTPasas), proteínas asociadas a APs ('epsin'), proteínas relacionadas con la formación de vesículas en los endosomas (ATPasa SKD1), quinasas de tipo receptor LRR y otras proteínas relacionadas con la endocitosis y la secreción. Junto a cada gen de cítricos aparece el correspondiente ortólogo de Arabidopsis thaliana.

Tabla 18. Listado de genes relacionados con el tráfico intracelular de vesículas regulados significativamente por el etileno durante la abscisión de frutos.

\begin{tabular}{|c|c|c|c|c|}
\hline $\mathbf{I D}^{\mathbf{a}}$ & CFGP singleton/contig ${ }^{\mathrm{b}}$ & Nombre & $\begin{array}{l}\text { Homología génica A.thaliana } \\
\text { (AGI locus) }\end{array}$ & BLASTX score \\
\hline \multicolumn{5}{|c|}{ ARLs (Arf-like proteins) } \\
\hline KN0AAI2BD07 & aKN0AAI2BD07FM1_c & CitArlAla & $\begin{array}{l}\text { ADP-ribosylation factor-like } \\
\text { protein (AT5G37680) }\end{array}$ & $2.0 \mathrm{E}-93$ \\
\hline C08018D11 & aCL9385Contig 1 & CitArlBl & $\begin{array}{l}\text { GTP-binding protein } \\
\text { (AT5G52210) }\end{array}$ & $3.0 \mathrm{E}-90$ \\
\hline KN0AAL3AF03 & aCL8603Contig1 & CitArfEl & $\begin{array}{l}\text { Putative ADP-ribosylation factor } \\
\text { (AT2G24765) }\end{array}$ & $5.0 \mathrm{E}-86$ \\
\hline C32012E11 & aC32012E11EF_c & CitArlCl & $\begin{array}{l}\text { Putative ADP-ribosylation factor } \\
\text { (AT2G18390) }\end{array}$ & $3.0 \mathrm{E}-86$ \\
\hline \multicolumn{5}{|l|}{ Rho GTPasas } \\
\hline C16015D09 & aC16015D09SK_c & CitROPI1 & $\begin{array}{l}\text { Rac-like GTP-binding protein } \\
\text { (AT5G62880) }\end{array}$ & $2.0 \mathrm{E}-93$ \\
\hline C34201D03 & aCL1882Contig1 & CitROP4 & $\begin{array}{l}\text { Rac-like GTP-binding protein } \\
\text { (AT1G75840) }\end{array}$ & $1.0 \mathrm{E}-90$ \\
\hline \multicolumn{5}{|l|}{ Otras proteínas } \\
\hline $\mathrm{C} 01005 \mathrm{~F} 12$ & aCL3017Contig 1 & CitEPSIN1 & $\begin{array}{l}\text { Epsin N-terminal homology } \\
\text { (ENTH) domain-containing } \\
\text { protein / clathrin assembly } \\
\text { protein-related(AT5G11710) }\end{array}$ & $2.0 \mathrm{E}-144$ \\
\hline C31805C09 & aCL2413Contig1 & CitSC3 & $\begin{array}{l}\text { Secretory carrier membrane } \\
\text { protein/ SCAMP (SECRETORY } \\
\text { CARRIER 3) (AT1G61250) }\end{array}$ & 7.0E-118 \\
\hline C06020E10 & aC06020E10SK_c & CitSKD1 & $\begin{array}{l}\text { Putative ATPase/ ESCRT-related } \\
\text { protein (AT2G27600) }\end{array}$ & $0.0 \mathrm{E}+00$ \\
\hline C08034G10 & aCL2078Contig1 & CitVHS-GAT & $\begin{array}{l}\text { VHS domain-containing protein / } \\
\text { GAT domain-containing protein } \\
\text { (AT4G32760) }\end{array}$ & $0.0 \mathrm{E}+00$ \\
\hline IC0AAA55AH05 & aIC0AAA55AH05RM1_c & CitSec15a & $\begin{array}{l}\text { Exocyst complex subunit Sec15- } \\
\text { like family protein (AT3G56640) }\end{array}$ & $0.0 \mathrm{E}+00$ \\
\hline
\end{tabular}


Tabla 18 (continuación de la página anterior).

\begin{tabular}{|c|c|c|c|c|}
\hline ID $^{\mathbf{a}}$ & CFGP singleton/contig ${ }^{\mathrm{b}}$ & Nombre & $\begin{array}{l}\text { Homología génica A.thaliana } \\
\text { (AGI locus) }\end{array}$ & BLASTX score \\
\hline \multicolumn{5}{|c|}{ Otras proteínas } \\
\hline $\mathrm{C} 03006 \mathrm{C} 12$ & aC03006C12SK_c & CitSec34 & $\begin{array}{l}\text { Sec34-like family protein } \\
\text { (AT1G73430) }\end{array}$ & $0.0 \mathrm{E}+00$ \\
\hline C16013E04 & aCL2081Contig2 & CitSec61 & $\begin{array}{l}\text { putative protein transport protein } \\
\text { SEC61 alpha subunit (AT2G34250) }\end{array}$ & $0.0 \mathrm{E}+00$ \\
\hline C02026D02 & aC02026D02SK_c & CitEVR & $\begin{array}{l}\text { leucine-rich repeat receptor-like } \\
\text { protein kinase (EVERSHED) } \\
\text { (AT2G31880) }\end{array}$ & $6.0 \mathrm{E}-89$ \\
\hline
\end{tabular}

${ }^{a}$ EST impreso en la micromatriz

${ }^{\mathrm{b}}$ CFGP: Spanish Citrus Functional Genomics Project

Como se observa en la Figura 26, el tratamiento con etileno causó mayoritariamente represión de la expresión génica. Así, excepto los genes CitVHS-GAT y CitSec15a, que se inducían exclusivamente en la ZAC y que codifican una proteína con un dominio VHS/GAT y una proteína del complejo 'exocyst', respectivamente, el resto de genes se reprimían en la ZAC y/o en la CF. Atendiendo a la familia de GTPasas Arl, el gen CitArlAla se reprimía exclusivamente en la ZAC, mientras que los genes CitArlB1, CitArfE 1 y CitArlC1 se reprimían en la ZAC y en la CF. Los genes CitROP11 y CitROP4, que codifican Rho GTPasas, se reprimían exclusivamente en la ZAC. Los genes CitEPSIN1, CitSec34, CitSec61 y CitEVR se reprimían también exclusivamente en la ZAC y codifican una proteína asociada a APs ('epsin'), un factor de anclaje, una proteína transmembrana y una quinasa de tipo receptor LRR, respectivamente. Por último, un gen correspondiente a una proteína SCAMP (secretory carrier membrane protein; CitSC3) y un gen que codifica una ATPasa (CitSKDl) asociada al complejo ESCRT (endosomal sorting complexes required for transport) se reprimían tanto en la ZAC como en la CF. 


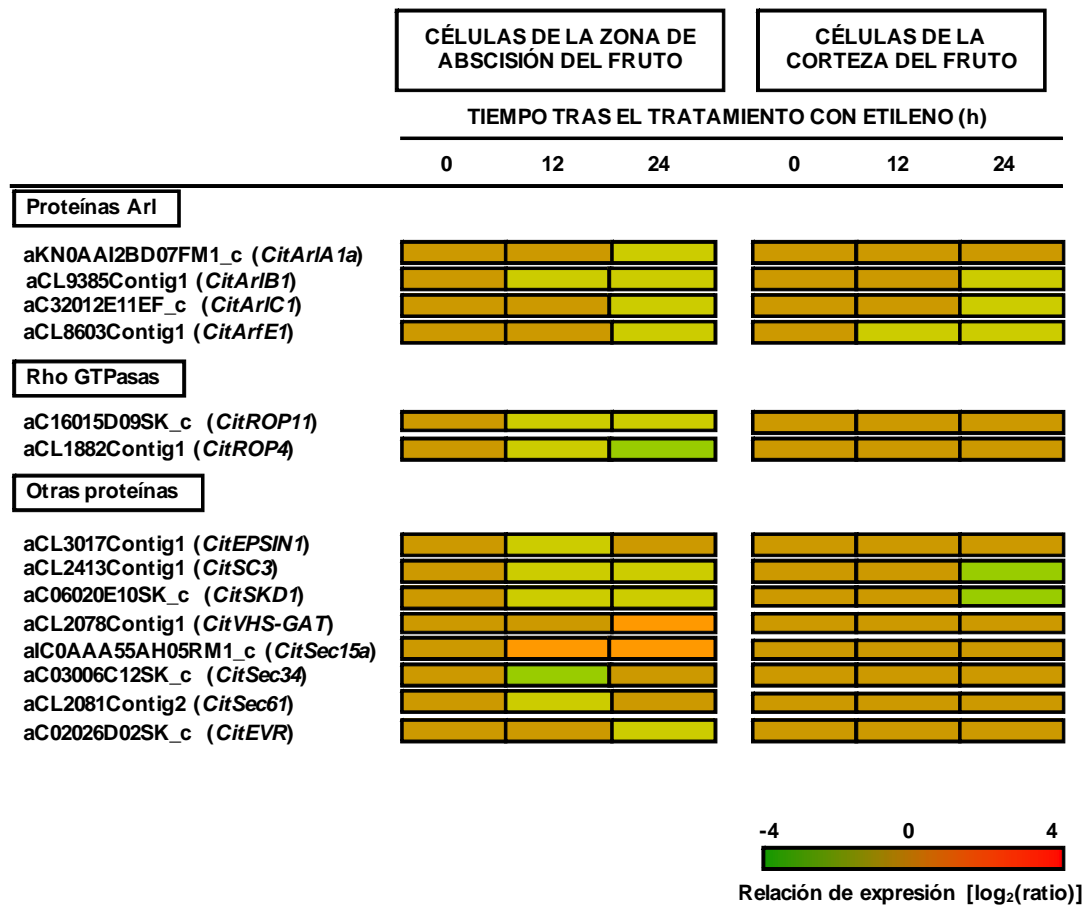

Figura 26. Perfiles de expresión de genes relacionados con el tráfico de vesículas regulados significativamente en las células de la ZAC y/o de la CF. La escala de colores representa el nivel de expresión a las 12 y 24 h de tratamiento con etileno respecto a las $0 \mathrm{~h}$ en la $\mathrm{ZAC}$ o en la $\mathrm{CF}\left[\mathrm{M}=\log _{2}(\mathrm{ZAC} / \mathrm{ZAC})_{0}\right.$ o $\left.\mathrm{M}=\log _{2}\left(\mathrm{CF}_{t} / \mathrm{CF}_{0}\right)\right]$. 


\subsection{Discusión}

Los resultados expuestos en este capítulo en relación al tráfico intracelular de vesículas revelan una notable participación de este proceso en la abscisión de frutos cítricos (ver también Tabla 4, Capítulo III). En la literatura referente a la abscisión únicamente se encuentran dos estudios a nivel molecular que han implicado el transporte de proteínas a través del sistema de endomembranas en la regulación de la separación celular. Liljegren et al. (2009) y Leslie et al. (2010) aislaron y caracterizaron los genes NEVERSHED (NEV) y EVERSHED $(E V R)$, que codifican una proteína Arf-GAP y un receptor LRR-RLK, respectivamente, implicados en la ruta secretora de proteínas necesarias para la abscisión.

El análisis de expresión diferencial a gran escala entre la zona de abscisión (ZAC) y la corteza del fruto (CF) mediante el empleo de micromatrices de cDNA ha permitido sumar a los dos posibles ortólogos de NEV y EVR (CitNEV y CitEVR) un total de 46 genes significativos asociados a la ruta secretora y endocítica así como a las diferentes rutas de transporte retrógrado que constituyen, principalmente, la vía de reposición de proteínas empleadas en la secreción y endocitosis. La Figura 27 recoge la localización de estos genes en los distintos eventos de transporte que tienen lugar a lo largo del sistema de endomembranas.

Los genes que forman parte de la ruta secretora (ruta de transporte biosintética), que comprende el transporte desde el RE hasta el aparato de Golgi y el subsiguiente transporte hasta la MP o la pared celular (PC), se encontraban mayoritariamente inducidos en la ZAC (ver Figura 27). Es el caso del gen $C i t S e c 23$, que codifica una proteína del complejo COPII que forma el revestimiento de las vesículas de transporte entre el RE y Golgi (Russell y Stagg, 2010). En esta misma etapa se encontraba inducida una pequeña GTPasa del grupo RabD (CitRabD2a). Este grupo de Rab-GTPasas, proteínas que determinan la especificidad entre la vesícula de transporte y la membrana receptora (Cai et al., 2007), han sido relacionadas con el tráfico biosintético, concretamente, con el transporte desde el RE hasta Golgi (Batoko et al., 2000). 


\section{Vacuola}

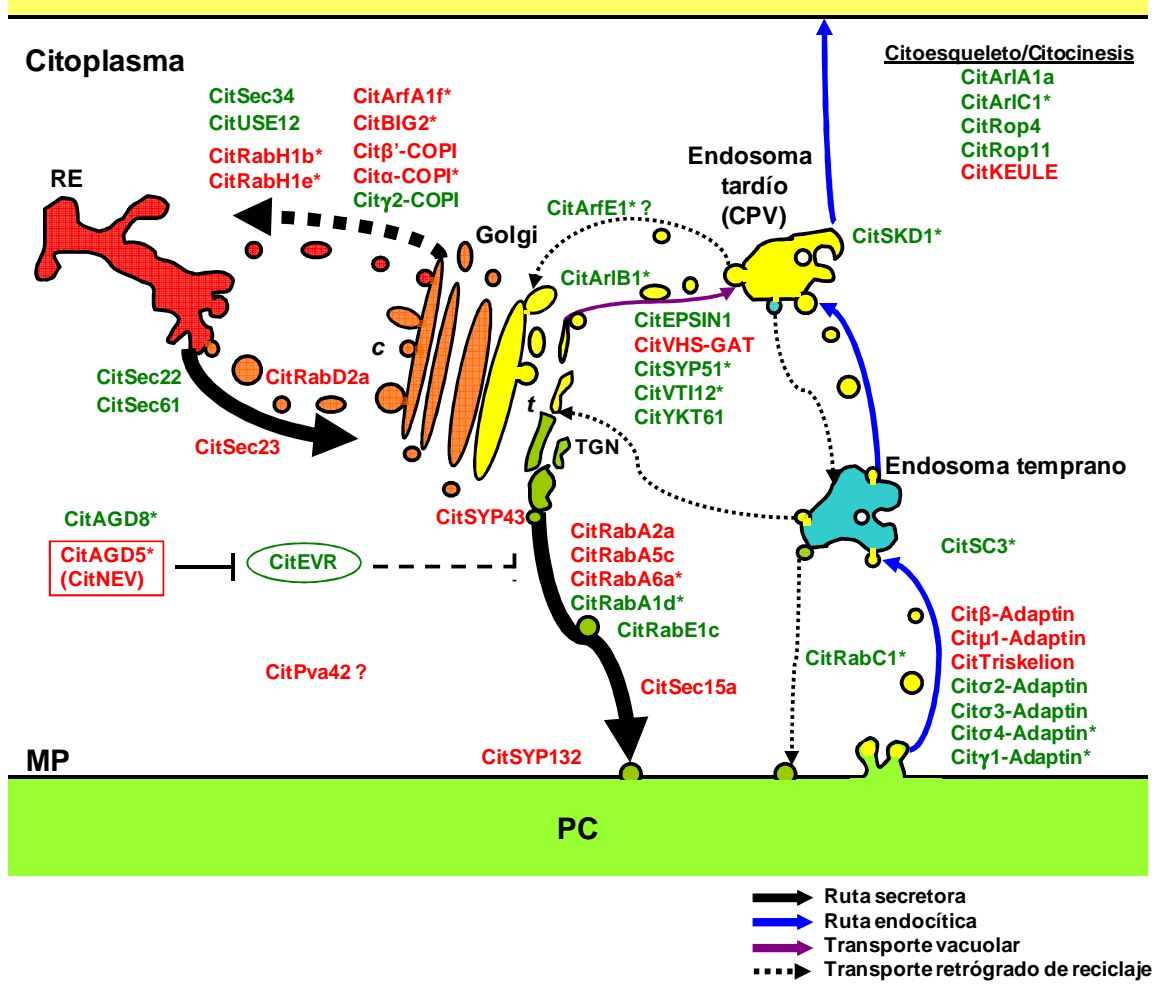

Figura 27. Genes relacionados con la ruta secretora, la ruta endocítica y las rutas retrógradas regulados significativamente durante la abscisión activada por etileno en frutos cítricos (figura adaptada de Bassham et al., 2008). Los genes en rojo se inducen en la ZAC y/o CF, los genes en verde se reprimen en la ZAC y/o CF, la presencia de un asterisco implica inducción o represión en ambos tejidos y la ausencia de asterisco implica inducción o represión exclusivamente en la ZAC. $\mathrm{RE}=$ retículo endoplasmático; $\mathrm{MP}=$ membrana plasmática; $\mathrm{PC}$ $=$ pared celular; $\mathrm{c}=$ cara cis de Golgi; $\mathrm{t}=$ cara trans de Golgi; TGN $=$ red trans Golgi; $\mathrm{CPV}=$ compartimento prevacuolar.

En la interfaz entre el RE y Golgi se localizaría el gen $\operatorname{CitSec} 22$ que, a diferencia de los genes descritos anteriormente, se reprimía en la ZAC. El homólogo de A. thaliana que codifica una proteína SNARE, familia proteica implicada en la fusión de vesículas a su membrana diana, ha sido implicado en el transporte desde el RE hasta Golgi (Chatre et al., 2005). 
El gen CitSYP43, correspondiente a una proteína de la familia SNARE, se inducía exclusivamente en la ZAC. La proteína SYP43 de A. thaliana, perteneciente al grupo QaSNAREs (syntaxins), se localiza en la red trans-Golgi (TGN) (Bassham et al., 2008), de modo que podría actuar en la fusión específica de vesículas de transporte a la membrana de la red trans-Golgi. Por tanto, CitSYP43 podría participar en el siguiente paso de la ruta secretora. Cuatro genes correspondientes a GTPasas del grupo RabA, localizadas también en la red trans-Golgi e implicadas en el transporte hacia la MP (Vernoud et al., 2003; Rehman et al., 2008), fueron regulados significativamente durante la abscisión. CitRabA2a y CitRabA5c se inducían exclusivamente en la ZAC, mientras que CitRabA6a y CitRabAld se inducían y reprimían, respectivamente, en la ZAC y en la CF. Por tanto, dentro de este grupo de proteínas, CitRabA2a y CitRabAld estarían actuando de forma específica en el proceso de abscisión, mientras que CitRabA6a participaría, posiblemente, en procesos regulados por el etileno que son comunes a ambos tejidos. Algunos trabajos previos (de Graaf et al., 2005; Inaba et al., 2002; Lycett et al., 2008; Nagano et al., 1995; Preuss et al., 2006) han implicado a este grupo de Rab-GTPasas en la secreción de enzimas y componentes de pared celular a la membrana plasmática. Por tanto, los genes CitRabA2a, CitRabAld y CitRabA6a podrían estar implicados en la secreción de enzimas de modificación de la pared celular necesarios para la abscisión y CitRAbA6a, además, en la secreción de enzimas o componentes de la pared celular necesarios para la maduración del fruto. Esto concuerda con los resultados del estudio llevado a cabo por Lu et al. (2001) en Solanum lycopersicon, en el que la inhibición antisentido de genes RabA causa retraso en la maduración del fruto. En concreto, el bloqueo de los genes RabA afectaba el proceso normal de ablandamiento del fruto, hecho que los autores atribuyen a defectos en la secreción de enzimas de modificación de la pared celular. Además, en un trabajo posterior llevado a cabo en Prunus persica (Falchi et al., 2010), los autores sugieren que la inducción de genes RabA y RabD durante el desarrollo del fruto está relacionada con la liberación de enzimas de modificación de la pared celular al apoplasto.

En esta misma etapa de la ruta secretora se localizaría una GTPasa del grupo RabE (CitRabE1c), reprimida exclusivamente en la ZAC. En plantas, las proteínas RabE se han relacionado con el transporte de vesículas desde el aparato de Golgi hasta la membrana plasmática (Speth et al., 2009; Zheng et al., 2005). De modo que, la represión génica tanto de CitRabElc como de CitRabAld indicaría que dentro de una misma familia es posible 
que determinados genes presenten especificidad de tejido o bien que actúen en procesos de tráfico intracelular diferentes.

Por último, los genes CitSec15a y CitSYP132, inducidos exclusivamente en la ZAC, podrían actuar en la última fase de la ruta secretora, ya que la proteína Sec15a de $A$. thaliana forma parte del complejo 'exocyst' implicado en el anclaje de vesículas a la membrana plasmática durante la secreción (Chong et al., 2009). La proteína SYP132 de la familia SNARE se localiza en la membrana plasmática (Bassham et al., 2008) y ha sido implicada en la secreción de proteínas PR durante el ataque patogénico en Nicotiana benthamiana (Kalde et al., 2007).

El transporte retrógrado desde el aparato de Golgi hasta el RE está mediado por vesículas COPI y requiere la participación de Arf-GTPasas (ADP rybosilation factorGTPases), Arf-GEFs (ADP ribosylation factor GTP-exchange factors) y Arf-GAPs (ADP ribosylation factor GTPase-activating proteins), que regulan el ensamblaje del complejo COPI (Foresti et al., 2008). Como muestra la Figura 27, varios genes de este grupo de proteínas se encontraban regulados significativamente durante la abscisión. Los genes Cit $\beta$ '-COPI y Cit $\alpha$-COPI, correspondientes a proteínas del complejo de revestimiento COPI (Hwang y Robinson, 2009), se inducían en la ZAC, pero sólo Cit $\beta$ '-COPI era exclusivo de la ZAC. Por otra parte, Cit 2 2-COPI se reprimía exclusivamente en la ZAC. El gen CitArfA1, que codifica una ARF-GTPasa de la familia ArfA/Arf1, se inducía en la ZAC y en la CF. Esta familia de Arf-GTPasas participa en diferentes procesos de revestimiento de vesículas (Bassham et al., 2008), así pues, ha sido implicada en el tráfico retrógrado entre Golgi y el RE, en el transporte entre la red trans-Golgi y la membrana plasmática y en la endocitosis (Xu y Scheres, 2005; Stefano et al., 2006; Matheson et al., 2008). Los genes CitBIG2 y CitAGD5 (CitNEV) se inducían también en la ZAC y en la CF, y codifican una Arf-GEF y una Arf-GAP, respectivamente, proteínas implicadas en la regulación de la actividad de las Arf-GTPasas (Bassham et al., 2008). Como se ha comentado anteriormente, $N E V$, el gen homólogo a CitNEV, ha sido relacionado con la secreción de proteínas necesarias durante el proceso de abscisión en A. thaliana (Liljegren et al., 2009), de modo que, parece lógica la inducción de CitNEV en la ZAC. Además este hecho correlaciona con la represión de CitEVR en la ZAC, homólogo al gen EVR de A. thaliana, un inhibidor de la abscisión relacionado con $N E V$ (Leslie et al., 2010). Otra Arf-GAP 
(CitAGD8) se reprimía en la ZAC y en la CF, lo que indicaría, de nuevo, que dentro de una misma familia génica algunos miembros pueden ser específicos de un tejido o momento del desarrollo concretos.

Algunos trabajos llevados a cabo en plantas (Langhans et al., 2008; Pimpl et al., 2003; Stefano et al., 2006) muestran que el transporte retrógrado COPI derivado del aparato de Golgi es necesario para mantener un mecanismo de reciclaje de membrana y, en definitiva, un funcionamiento eficiente del transporte COPII derivado del RE. En células epidérmicas de tabaco (Stefano et al., 2006), observan que la inhibición de la actividad de la proteína Arf1, además de bloquear el transporte retrógrado entre el aparato de Golgi y el RE, provoca alteraciones en el ensamblaje de la cubierta de las vesículas COPII. Sin embargo, la liberación de la inhibición de la actividad Arf1 reestablece el ensamblaje de COPII. Por tanto, los resultados obtenidos del análisis de expresión sugieren que, en conjunto, Cit $\beta$ 'COPI, Cito-COPI, CitArfA1, CitBIG2 y CitNEV podrían participar en el mantenimiento del flujo de vesículas entre el aparato de Golgi y el RE e, indirectamente, en el transporte REGolgi que, como se comentaba anteriormente, se encuentra activado en la ZAC.

Las Rab-GTPasas del grupo RabH, CitRabHlb y CitRabHle, se inducían en la ZAC y en la CF. En plantas, este grupo de GTPasas se localiza en el aparato de Golgi (Bednarek et al., 1994; Latijnhouwers et al., 2007) y muestra elevada homología con los grupos Ypt6 y Rab6 de levadura y animales, respectivamente, que se han relacionado con el tráfico de vesículas desde el aparato de Golgi al RE (Pereira-Leal, 2007). Por tanto, estos genes podrían estar regulando también el transporte retrógrado hacia el RE en ambos tejidos (ZAC y CF).

El gen CitUSE12 se encontraba reprimido exclusivamente en la ZAC. La proteína USE12 de A.thaliana, perteneciente a la familia Qc-SNARE, muestra homología con la proteína USE1-like de levadura, que ha sido implicada en el transporte retrógrado desde el aparato de Golgi al RE (Dilcher et al., 2003). El gen CitSec34, que también se encuentra reprimido en la ZAC, codifica un factor de anclaje que interacciona con el complejo proteico COPI y, por tanto, participa en el transporte entre el aparato de Golgi y el RE (Suvorova et al., 2002). Tales genes podrían ser, por tanto, específicos de otro tejido o proceso fisiológico y la inducción de Cit $\beta$ '-COPI, Cita-COPI, CitArfA1, CitBIG2 y CitNEV 
podría mantener un nivel basal de transporte retrógrado suficiente para reponer las proteínas del RE e, indirectamente, mantener el transporte RE-Golgi en la ruta secretora.

El gen CitPva42, que codifica una proteína VAMP (vesicle-associated membrane protein) de la familia SNARE, se inducía exclusivamente en la ZAC. El homólogo de $A$. thaliana no ha sido caracterizado, de modo que no se puede concretar su localización exacta dentro del sistema de endomembranas. Además, se trata de una familia muy numerosa en la que incluso los miembros de una misma subfamilia se localizan en distintas membranas (Bassham et al., 2008; Sanderfoot et al., 2007). Como otras proteínas SNARE, podría participar en la fusión de membranas en la membrana plasmática, en el aparato de Golgi, en los endosomas o en la vacuola.

Como se puede observar en la Figura 27, la ruta de endocitosis, el transporte retrógrado (excepto entre el aparato de Golgi y el RE) y el transporte hacia la vacuola derivado de la red trans-Golgi se encontraban representados, mayoritariamente, por genes reprimidos.

La endocitosis comienza en la membrana plasmática con la formación de vesículas cubiertas de clatrina que son transportadas hasta los endosomas tempranos (Bassham et al., 2008). Un total de siete genes que codifican proteínas relacionadas con la formación de las vesículas de clatrina fueron regulados durante la abscisión. Los genes Cit $\beta$-Adaptin y Citu1-Adaptin se inducían exclusivamente en la ZAC y codifican proteínas de los complejos AP (adaptor protein), necesarios para la selección de las proteínas que van a ser transportadas en las vesículas (proteínas 'cargo'). El gen CitTriskelion se inducía también en la ZAC y codifica una proteína de la cubierta de clatrina. Por otra parte, cuatro genes que codifican proteínas de los complejos AP se reprimían en la ZAC (Cito2-Adaptin y Cito3-

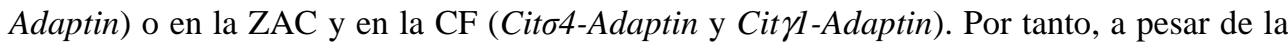
represión de estos genes, Citß-Adaptin, Citul-Adaptin y CitTriskelion podrían mantener un nivel basal de tráfico endocítico de proteínas desde la membrana plasmática.

Las proteínas de la familia SCAMP (secretory carrier membrane proteins) son proteínas de membrana localizadas en la membrana plasmática y en los endosomas y participan en la endocitosis mediada por clatrina (Fernández-Chacón et al., 2000; Wang et 
al., 2010). Además, las SCAMPs han sido recientemente asociadas a la abscisión de órganos florales en A. thaliana (Patterson et al., 2010). En concreto, la línea mutante delayed abscission 5 (dab5), que muestra retraso en la abscisión de órganos florales, presentaba una inserción de T-DNA en el promotor del gen SCAMP5 (AT1G32050). En el caso de la abscisión de frutos cítricos promovida por el etileno, el gen CitSC3, perteneciente a esta familia, se reprime en la ZAC.

Las vesículas de clatrina se localizan también en la red trans-Golgi y son transportadas a los endosomas (Bassham et al., 2008). Por tanto, los genes descritos relacionados con la formación de este tipo de vesículas podrían participar también en este transporte. El gen CitEPSIN1, que se reprimía en la ZAC, codifica una proteína con dominio ENTH (epsin N-terminal homology) que ha sido relacionada con el ensamblaje de clatrina y participa en el tráfico vacuolar en la red trans-Golgi (Lee et al., 2007). El gen CitYKT61 se reprimía exclusivamente en la ZAC y, considerando su homología con YKT6 de A. thaliana, se podría localizar en la red trans-Golgi y en la vacuola (Bassham et al., 2008; Chen et al., 2005). Por otra parte, el unigen CitVHS-GAT se inducía exclusivamente en la ZAC. Este tipo de proteínas con dominios VHS y GAT han sido relacionadas con el tráfico entre la red trans-Golgi y la vacuola (Hirst et al., 2000). Por tanto, este gen podría participar en el transporte a la vacuola de determinadas proteínas que ya han desempeñado su función durante la abscisión y van a ser degradadas o bien de proteínas vacuolares recién sintetizadas.

Los genes CitSYP51 y CitVTI12, que se reprimían en la ZAC y en la CF, codifican dos proteínas de la familia SNARE que, en A. thaliana, actúan conjuntamente en el transporte entre la red trans-Golgi y el endosoma tardío/ compartimento prevacuolar (CPV) (Sanderfoot et al., 2001; Sanmartín et al., 2007). En el CPV se localizaría también el gen CitSKD1, que se encuentra reprimido en la ZAC y en la CF. El gen SKD1 de A. thaliana codifica una ATPasa que interacciona con el complejo proteico ESCRT (endosomal sorting complex required for transport) durante la invaginación de la membrana del CPV (Bassham et al., 2008; Haas et al., 2007; Ritcher et al., 2009).

El gen CitSec61, homólogo a AtSec61 $\alpha$, se reprimía exclusivamente en la ZAC. Este gen codifica una proteína de membrana del RE y, en Triticum aestivum, se induce 
notablemente junto con un receptor de señalización vacuolar (BP-80) localizado en Golgi y en el CPV (Shy et al., 2001). Los resultados sugieren que ambos genes son cruciales para el transporte vacuolar de proteínas de reserva en la semilla, por tanto, CitSec61 podría localizarse en el mismo compartimento del sistema de endomembranas afectando el tráfico vacuolar.

Los genes CitArfE1 y CitArlB1, que codifican GTPasas de la familia Arf-like implicadas en el anclaje de vesículas en la red trans-Golgi (Bassham et al., 2008), se encontraban reprimidos en la ZAC y en la CF. En un trabajo llevado a cabo en Prunus persica (Falchi et al., 2010), observan que la inducción del gen PpArlB1, homólogo al gen ArlB1 de A. thaliana, coincide con el momento de máxima acumulación de azúcares y crecimiento del fruto. En base a estos resultados, los autores proponen que PpArlB1 podría participar en la acumulación de azúcares en la vacuola. Por tanto, la represión de CitArlB1 podría estar afectando el transporte hacia la vacuola. En cuanto a CitArfE1, no existen estudios que aporten datos sobre la función concreta de este grupo de GTPasas en la célula, aparte de su localización en la red trans-Golgi, de modo que su represión podría estar afectando el transporte entre el aparato de Golgi y diferentes compartimentos post-Golgi.

En los endosomas se localizaría por homología con los genes de A. thaliana (Bassham et al., 2008) una GTPasa del grupo RabC (CitRabC1) reprimida en la ZAC y en la CF. Se ha sugerido que la proteína RabC1 podría participar en el reciclaje de proteínas entre el endosoma y la membrana plasmática (Segev, 2001). Por tanto, la represión de CitRabCl podría reducir el tráfico de vesículas en esta etapa.

Otros genes pertenecientes a las familias de GTPasas Arf-like y ROP (hho-related proteins of plants), que han sido relacionados con la regulación del citoesqueleto (Boureux et al., 2007; Brembu et al., 2006; Kahn et al., 2006), se reprimían durante el proceso de abscisión. Es el caso de los genes CitArlA1a, CitROP4 y CitROP11, cuya expresión se reprimía exclusivamente en la ZAC, y CitArlCl, que se reprimía en la ZAC y en la CF.

El gen CitKEULE, perteneciente a la familia SM (Sec1-Munc), se inducía exclusivamente en la ZAC. Estas proteínas interaccionan con proteínas SNARE en la fusión 
de vesículas que da lugar a la formación de la placa celular durante la citocinesis (Assaad et al., 2001).

A la vista de los resultados de expresión descritos, parece ser que durante la abscisión de los frutos se produce una activación de la ruta secretora de proteínas, mientras que el transporte hacia la vacuola, la ruta endocítica y el transporte retrógrado desde los endosomas a la MP se encuentran limitados. Por tanto, las células de la ZAC promoverían mayoritariamente el transporte extracelular de proteínas. Este comportamiento es esperable ya que, en definitiva, las modificaciones en la pared celular y la lámina media son las que van a posibilitar la separación celular y, en última instancia, el desprendimiento del fruto.

El tráfico intracelular de membranas desempeña una función crucial en la biología de las células eucariotas aunque, de la multitud de componentes proteicos de este sistema de transporte que se conocen en plantas, solamente un grupo reducido ha sido caracterizado con respecto a su función biológica en procesos del desarrollo y del crecimiento vegetal así como en procesos de respuesta a diferentes estreses. En este capítulo, se ha identificado un amplio número de genes relacionados con el tráfico intracelular de proteínas que podrían estar implicados en la regulación del proceso de abscisión de frutos cítricos. Concretamente, podrían participar en la secreción de enzimas de modificación de la pared celular ya que, como se ha descrito en el Capítulo III, una cantidad importante de genes relacionados con tales modificaciones se inducían en la ZAC durante la activación de la abscisión. Además, durante la activación del proceso de abscisión se observó un incremento del número de genes relacionados con la síntesis y modificación de proteínas (Capítulo III). Otros trabajos han relacionado el aumento en la síntesis de proteínas con la activación de la ruta secretora durante el proceso de abscisión, en base a observaciones ultraestructurales en las que se detectaba un desarrollo considerable de los sistemas endomembranosos, especialmente del retículo endoplasmático rugoso y las áreas de Golgi (Sexton et al., 1974; 1977; Iwahori et al., 1976). Por tanto, ambos procesos (síntesis y tráfico extracelular de proteínas) podrían aportar las enzimas de remodelación de pared celular al plano de fractura para facilitar la separación celular.

Por otra parte, cabe pensar también que estas proteínas de transporte podrían estar implicadas en la secreción de monómeros de cutina y lignina a la zona de separación ya 
que, como se comentó en el Capítulo III, se detectó inducción de genes de las rutas biosintéticas así como deposición de ambos polímeros en la ZAC activada. Sin embargo, los estudios existentes en relación al mecanismo de transporte de ambos polímeros no aportan evidencias claras de que su deposición extracelular sea a través de la exocitosis, y ello es debido, principalmente, a que se trata de compuestos muy hidrofóbicos (Kunst y Samuels, 2002; Achyuthan et al., 2010). En el caso de la cutina, se postulan dos hipótesis acerca de su transporte extracelular: por transferencia directa desde el RE hasta la membrana plasmática o mediante exocitosis mediada por el aparato de Golgi (Kunst y Samuels, 2002). Mientras que, en el caso de la lignina, Kaneda et al. (2008) sugieren que los monómeros serían exportados a través de transportadores, aún por caracterizar, más que mediante vesículas de Golgi. Sin embargo, no se podría descartar en principio la posibilidad de un transporte mediado por vesículas debido a la escasa información que existe al respecto en la literatura. Por tanto, este es un aspecto que requiere una investigación más profunda. 


\subsection{Conclusiones}

Los resultados presentados en este capítulo han permitido obtener las siguientes conclusiones:

1) El tratamiento con etileno activa la ruta de secreción de proteínas en la ZAC. Sin embargo, la ruta endocítica, el transporte vacuolar y el transporte de reciclaje de membranas se encuentran afectados negativamente. Por tanto, las células de la ZAC promueven mayoritariamente el transporte extracelular de proteínas, lo que podría estar relacionado con el aporte de enzimas de remodelación de la pared celular al plano de fractura.

2) Se han aislado un total de quince genes que podrían estar implicados en el aporte extracelular de proteínas necesarias para la abscisión. Entre estos genes se han identificado:

- Miembros de los complejos proteicos que forma la cubierta de las vesículas COPII (CitSec23) y COPI (Cit $\beta$ '-COPI y Cito-COPI).

- Genes relacionados con la regulación del ensamblaje de las cubiertas proteicas (CitArfA1) y con la regulación de la actividad de las GTPasas de cubierta (CitBIG2 y CitAGD5/CitNEV).

- Genes de la familia Rab de GTPasas implicadas en el reconocimiento específico entre la vesícula de transporte y la membrana diana (CitRabD2a, CitRabA5c, CitRabA2a, CitRabA6a, CitRabH1b y CitRabHle).

- Genes de la familia SNARE, implicada en la fusión de vesículas a su membrana diana (CitSYP43 y CitSYP132).

- Proteínas de complejos de exocitosis (CitSec15a).

De estos genes, ocho podrían ser exclusivos del proceso de abscisión (CitSec23, Cit $\beta$ 'COPI, CitRabD2a, CitRabA5c, CitRabA2a, CitSYP43, CitSYP132 y CitSec15a), mientras que el resto participarían en procesos comunes a la ZAC y a la $\mathrm{CF}$. 
V. Identificación de genes relacionados con la remodelación de la pared celular durante la abscisión de frutos cítricos 


\subsection{Introducción}

La adhesión entre las células vegetales es una característica fundamental del desarrollo y el crecimiento de las plantas, y constituye una parte esencial de la estrategia a través de la cual las plantas en crecimiento adquieren fuerza mecánica (Jarvis et al., 2003). Las paredes celulares vegetales son estructuras muy complejas que posibilitan esta cohesión entre las células vegetales vecinas y están formadas por polisacáridos de naturaleza diversa, por proteínas estructurales y, dependiendo del tipo celular, por otros componentes como lignina o cutina (Revilla y Zarra, 2008). La celulosa es uno de los polisacáridos más importantes de las paredes celulares pues confiere las características de fortaleza y rigidez a la pared. La celulosa es un polímero lineal compuesto por unidades de $\beta$-D-glucosa unidas entre sí por enlaces $(1 \rightarrow 4)$ formando microfibrillas que están embebidas en una matriz compuesta por pectinas, hemicelulosa y proteínas (Fry, 2004). Las pectinas son los componentes más importantes de la lámina media y de las paredes celulares primarias en las plantas dicotiledóneas y representan el 30-35\% del peso seco de las paredes celulares. Las pectinas son polisacáridos muy complejos, ricos en ácido galacturónico, que pueden contener hasta diecisiete monosacáridos diferentes (Vincken et al., 2003). En las pectinas pueden distiguirse cuatro dominios polisacáridos: homogalacturonano (HGA), ramnogalacturonano I (RGI), ramnogalacturonano II (RGII) y xilogalacturonano (XGA). El HGA es un homopolímero lineal compuesto por unidades de ácido $\alpha$-D-galacturónico que se unen entre sí por enlaces $(1 \rightarrow 4)$ y puede estar metilesterificado en el grupo carboxilo en C6 o llevar grupos acetilo en $\mathrm{O} 2$ y O3. El XGA es un homogalacturonano con cadenas laterales de $\beta$-D-xilopiranósido unidas por enlaces $(1 \rightarrow 3)$ que pueden estar también metilesterificadas. El RGII es un polisacárido de estructura muy compleja que se une al esqueleto del HGA y está compuesto por cadenas laterales de naturaleza diversa, tanto por los residuos glicosilo como por la manera en que están enlazados para formar la estructura. El RGI está formado por un gran número de unidades de disacáridos repetidas hasta cien veces $([(1 \rightarrow 2)-\alpha$-L-ramnosa- $(1 \rightarrow 2)-\alpha$-D-galacturonato $] n)$. Los residuos galacturonilo pueden llevar grupos acetilo en $\mathrm{O} 2$ y $\mathrm{O} 3$ y residuos ramnosilo sustituidos en $\mathrm{O} 4$ por azúcares neutros como $\beta$-D-galactanos unidos por enlaces $(1 \rightarrow 4)$ o $\alpha$-L-arabinanos unidos por enlaces $(1 \rightarrow 5)$. Por otra parte, las hemicelulosas están formadas, principalmente, por xiloglucanos y xilanos y, en menores cantidades, por diferentes polisacáridos ricos en manosa (Bewley et al., 1997; Handford et al., 2003). Los polisacáridos hemicelulósicos 
pueden unirse a la celulosa mediante puentes de hidrógeno y entrelazar las microfibrillas (Revilla y Zarra, 2008). Los xiloglucanos están constituidos por un eje central de residuos D-glucosilo unidos mediante un enlace $\beta$ - $(1 \rightarrow 4)$, que pueden ser sustituidos por residuos xilosilo, galactosilo y L-fucosilo (Renard et al., 1992). Los xilanos están constituidos por una cadena lineal de residuos D-xilosilo unidos por un enlace $\beta-(1 \rightarrow 4)$ con sustituciones de grupos acetilo, L-arabinofuranosilo, galactosilo, glucuronilo y 4-O-metilglucuronilo (Coughlan y Hazlewood, 1993; Kulkarni et al., 1999; Prade, 1996). La estructura química de los polisacáridos celulósicos, pécticos y hemicelulósicos se puede observar en la Figura 28.

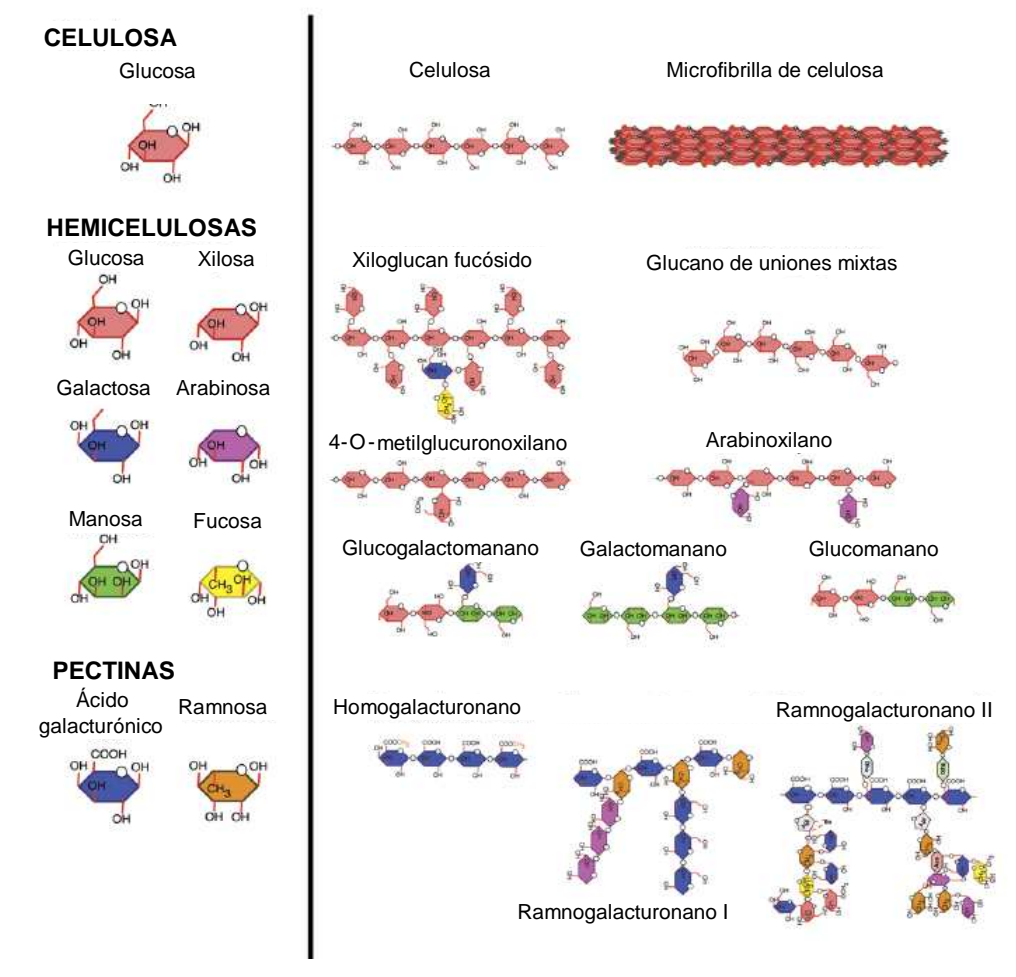

Figura 28. Estructura química de los polisacáridos predominantes en las paredes celulares vegetales. Panel izquierdo: monómeros. Panel derecho: subunidades de los polímeros respectivos. Figura adaptada de Sarkar et al. (2009). 
En determinados momentos del desarrollo de la planta, la red de polisacáridos que constituye la pared celular es desmantelada con gran precisión y de manera localizada. Esto ocurre durante el desarrollo de espacios intercelulares, durante la dispersión del polen y las semillas, durante la emergencia de raíces primarias y secundarias, durante la maduración de los frutos y durante la dehiscencia de la vaina del fruto o la abscisión de órganos (Roberts et al., 2002). Cada uno de estos procesos de separación celular tiene unas características únicas inherentes, aunque es de esperar que conserven ciertas características, especialmente aquellas relacionadas con los tipos de enzimas de remodelación de la pared celular que intervienen (Lewis et al., 2006). La separación celular implica la disolución de la lámina media que mantiene unidas las células y/o la degradación de su pared celular. En el caso de la abscisión de órganos, multitud de proteínas que actúan sobre las pectinas, la celulosa y las hemicelulosas se acumulan en las paredes celulares de la zona de abscisión (ZA) modulando la estructura de la pared primaria y reduciendo la adhesión entre las células contiguas con el fin de permitir el desprendimiento del órgano (Lashbrook, 2009).

La primera enzima relacionada con la degradación de la pared celular durante la abscisión fue una celulasa (CEL). Horton y Osborne (1967) encontraron una correlación entre el aumento en la actividad celulasa y el desarrollo de la abscisión en explantes de judía tratados con etileno in vitro y, posteriormente, se clonó el gen que codifica tal enzima (Tucker et al., 1988). En otros trabajos llevados a cabo en diferentes especies, como saúco (Sambucus nigra; Taylor et al., 1994), tomate (Lashbrook et al., 1994), pimiento (Ferrarese et al., 1995), cítricos (Burns et al., 1998), manzano (Li y Yuan, 2008), algodón (Mishra et al., 2008) o melocotón (Trainotti et al., 2008), también se detectó un incremento en la expresión de CELs en la ZA durante el desarrollo del proceso de abscisión. Las CELs pertenecen a una gran familia génica; en tomate, por ejemplo, se han clonado siete isoformas diferentes (Cel1-Cel7; Brummell et al., 1999; Catala et al., 1997; del Campillo y Bennett, 1996; Lashbrook et al., 1994). De estas siete celulasas, solamente Cel1, Cel2 y Cel5 experimentaban un aumento de expresión en la ZA del pedicelo de la flor durante la abscisión (del Campillo y Bennett, 1996; González-Bosch et al., 1997; Kalaitzis et al., 1999). En trabajos posteriores (Brummell et al., 1999; Lashbrook et al., 1998) se comprobó, mediante la estrategia de RNA en antisentido, que la expresión de Cell y Cel2 disminuía en la ZA, al mismo tiempo que aumentaba la fuerza necesaria para separar el pedicelo de la flor. Sin embargo, tales plantas transgénicas no exhibían ningún retraso o 
alteración en el ablandamiento del fruto, a pesar de que la expresión de ambos genes aumentaba durante la maduración del fruto en las plantas silvestres. Estos resultados sugieren que la separación celular durante la abscisión y la maduración debe implicar eventos de degradación de pared diferentes (Roberts et al., 2002).

Recientemente, se han aislado y caracterizado diferentes genes que codifican poligalacturonasas (PGs) que participan en el proceso de abscisión (González-Carranza et al., 2002, 2007; Ogawa et al., 2009). La correlación entre el incremento de la actividad poligalacturonasa y la separación celular se detectó por primera vez durante la maduración del fruto en tomate (Huber, 1983). En esta misma especie se han aislado tres PGs implicadas en la abscisión (TAPG1, TAPG2 y TAPG4). Estos tres genes presentan una homología entre sí a nivel de nucleótidos cercana al 90\%. Sin embargo, la homología con la PG caracterizada durante el ablandamiento del fruto es inferior al 50\%, y los transcritos que codifican son de menor tamaño (Kalaitzis et al., 1997). Por tanto, aunque la separación celular es un evento común a diversos procesos del desarrollo, tal y como se ha comentado, muchas de estas enzimas deben ser isoformas específicas de las ZAs (Jarvis et al., 2003).

La identificación de genes específicos implicados en el proceso de abscisión resulta de gran interés, aunque en el caso de las proteínas relacionadas con la modificación de la pared celular es muy complicado debido a que forman parte de familias génicas muy extensas (Patterson, 2001). Actualmente, se han realizado estudios de expresión a gran escala en diferentes especies (Agustí et al., 2008, 2009; Cai y Lashbrook, 2008; Lashbrook y Cai, 2008; Meir et al., 2010) que han permitido identificar un número importante de genes pertenecientes a familias relacionadas con la remodelación de la pared celular que podrían ser específicos del proceso de abscisión. Los análisis de expresión génica a gran escala mediante la utilización de micromatrices así como los análisis in silico de colecciones de ESTs (expressed sequence tags) permiten evaluar un número elevado de secuencias al mismo tiempo y obtener resultados de forma relativamente rápida (Lashbrook, 2009). En este trabajo, con el propósito de identificar genes responsables de la modificación de la pared celular con una elevada especificidad funcional durante la abscisión, se han comparado los perfiles de expresión de genes relacionados con la pared celular en células de la zona de abscisión C (ZAC) y de la corteza del fruto (CF) durante el tratamiento con etileno de frutos maduros de 'Washington Navel' (resultados de expresión procedentes del 
experimento descrito en el Capítulo III). Adicionalmente, se han establecido relaciones filogenéticas entre las posibles proteínas relacionadas con la remodelación de la pared celular localizadas en la versión v0.9 (6,5 equivalentes genómicos) del ensamblaje del genoma haploide de Citrus clementina, las reguladas por etileno en las células de la ZAC y/o de la CF y las descritas en la literatura como asociadas a la abscisión en otras especies vegetales. Además, se ha estudiado la estructura proteica de las secuencias de aminoácidos deducidas de los genes de estas familias en cítricos y se ha comparado con la de los genes relacionados con la abscisión en otras especies vegetales. Por otra parte, se ha analizado in silico la expresión diferencial de los genes de cítricos pertenecientes a este tipo de familias en diferentes ZAs así como la región promotora de algunas proteínas relacionadas con la modificación de la pared potencialmente implicadas en la abscisión de frutos cítricos activada por etileno. Finalmente, este estudio ha sido complementado con el análisis mediante cromatografía gas-líquido (GLC) e inmunolocalización de azúcares estructurales de las paredes de las células de la ZAC durante el proceso de abscisión. 


\subsection{Materiales y métodos}

\subsubsection{Material vegetal $y$ tratamientos}

El material vegetal y los tratamientos in vitro a los que se hace referencia en este capítulo son los descritos en el apartado 3.2.1.

\subsubsection{Muestreo de material vegetal}

En función de la cinética de abscisión de frutos de 'Washington Navel' tratados con etileno determinada en el Capítulo III, se recogieron muestras que contenían la zona de abscisión C (ZAC) a las 0,24 y $48 \mathrm{~h}$ de tratamiento con etileno. Estas muestras se incluyeron en OCT de forma análoga a la descrita en el apartado 3.2.6.1 y se almacenaron a $-80{ }^{\circ} \mathrm{C}$ para el posterior análisis por cromatografía gas-líquido (GLC) de la composición en monosacáridos de las paredes celulares de la ZAC (apartado 5.2.6). Por otra parte, una vez evaluada la cinética de abscisión de frutos de 'Navel Ricalate' tratados con ACC (Capítulo III), se seleccionaron $0,24,36$ y $48 \mathrm{~h}$ como puntos de muestreo para el experimento de inmunolocalización de polisacáridos de la pared celular en la ZAC. En este caso, las muestras se prepararon como se describe en el apartado 3.2.5.2.1.

\subsubsection{Análisis filogenético y estudio de la estructura proteica de familias génicas} relacionadas con la modificación de la pared celular

Para cada una de las familias de proteínas relacionadas con la modificación de la pared celular (según la clasificación de la base de datos CAZy; Carbohydrate-Active Enzymes; Cantarel et al., 2009; http://www.cazy.org/), que se encontraban altamente representadas en los resultados de la hibridación de micromatrices (Capítulo III), se llevaron a cabos dos análisis filogenéticos. Por una parte, se establecieron relaciones filogenéticas entre las secuencias proteicas deducidas de los genes de Arabidopsis thaliana y las localizadas en el genoma haploide de Citrus clementina (ver Anexo 7). Los miembros que componían cada una de las familias de genes asociados a la remodelación de la pared celular se recuperaron mediante búsqueda TBLASTN utilizando secuencias consenso de los dominios funcionales característicos de cada familia en el web browser de la base de datos 
(versión v0.9) del genoma haploide de Citrus clementina (http://www.phytozome.net/search.php). Por otra parte, se establecieron relaciones filogenéticas entre las proteínas deducidas localizadas en el genoma haploide de Citrus clementina, las reguladas por etileno en las células de la ZAC y/o en las células de la corteza del fruto del naranjo 'Washington Navel' y las descritas en la literatura como asociadas a la abscisión en otras especies vegetales (ver apartado 5.3.1). En ambos casos, los árboles filogenéticos están basados en alineamientos múltiples (ClustalW; http://www.ch.embnet.org/software/ClustalW-XXL.html) y se generaron utilizando el programa MEGA 4.0 (Tamura et al., 2007) mediante el método Neighbor-Joining (complete deletion, Poisson correction). Se utilizó el soporte Bootstrap para 1000 réplicas y solamente se consideraron los valores superiores al $50 \%$.

Para el estudio de la estructura de las secuencias de aminoácidos deducidas de los diferentes genes pertenecientes a cada familia, se llevó a cabo la predicción de dominios y motivos conservados mediante los servidores SMART (http://smart.embl-heidelberg.de/; Schultz et al., 1998, Letunic et al., 2008), PSORT (http://psort.hgc.jp/form.html), InterProScan (http://www.ebi.ac.uk/Tools/pfa/iprscan/) y big-PI Plant Predictor (http://mendel.imp.ac.at/gpi/plant_server.html). Los alineamientos con los dominios característicos de cada familia, editados con el programa GeneDoc (http://www.nrbsc.org/gfx/genedoc/), se pueden ver en el apartado 5.3.1.

\subsubsection{Análisis de expresión génica según la frecuencia de ESTs}

La identificación de genes relacionados con la remodelación de la pared celular expresados diferencialmente durante la abscisión en cítricos se realizó con el programa IDEG6 (Romualdi et al., 2003), utilizando el análisis estadístico de Audic y Claverie (1997). Para cada uno de los unigenes relacionados con la modificación de la pared celular, se empleó la frecuencia de ESTs procedentes de genotecas generadas a partir de distintas zonas de abscisión de cítricos (ZAA y ZAC de ovarios en desarrollo, ZAC de frutos maduros, ZAL de hojas y ZAC de frutos maduros tratados con CMNP) así como la frecuencia de ESTs de cítricos (de los géneros Citrus y Poncirus) depositados en la dbEST del GenBank agrupados en 14 genotecas sintéticas basadas en el órgano/tejido utilizado para la construcción de cada genoteca de cDNA (ver Anexo 18). El número total de ESTs 
que contienen las diferentes genotecas sintéticas y la frecuencia de ESTs de los diferentes unigenes relacionados con la pared celular para cada tipo de tejido se pueden consultar en el Anexo 18.

\subsubsection{Aislamiento y análisis de promotores}

Se aislaron los promotores de dos genes supuestamente específicos de la zona de abscisión (la celulasa ácida aCL1347Contig1 y la poligalacturonasa aCL675Contig4) siguiendo el procedimiento del kit 'GenomeWalkerTM Universal' (Clontech, Ref.: 638904). El kit proporciona todos los reactivos necesarios excepto la Taq DNA polimerasa 'Advantage ${ }^{\circledR} 2$ DNA Polymerase' (Clontech, Ref.: 639202). Esta técnica permite aislar secuencias desconocidas de DNA a partir de secuencias conocidas adyacentes, como el cDNA (Siebert et al., 1995).

\subsubsection{Extracción de DNA genómico}

Se utilizaron hojas adultas procedentes de la brotación del año anterior de la variedad de mandarino 'Clemenules' (Citrus clementina Hort. Ex Tan.), injertada sobre el patrón mandarino Cleopatra (Citrus reshni Hort. Ex Tan.). El material vegetal se pulverizó con nitrógeno líquido y con ayuda de un mortero hasta obtener un polvo fino. La extracción se realizó siguiendo el protocolo del kit 'DNeasy® Plant Mini' de QIAGEN, con número de referencia 69104. Se utilizó una cantidad de material vegetal de partida de $100 \mathrm{mg}$ y el volumen final de elución en agua fue de $100 \mu$ l. Finalmente, se cuantificó la concentración de DNA en el espectrofotómetro NanoDrop ${ }^{\circledR}$ y se comprobó la integridad del mismo mediante electroforesis en gel de agarosa al $1 \%$.

\subsubsection{Construcción de genotecas de DNA genómico}

\section{a) Digestión de DNA genómico}

Se llevaron a cabo seis reacciones de digestión de DNA independientes, cada una con una enzima de restricción diferente ( $D r a \mathrm{I}, P v u \mathrm{II}, E c o$ RV, StuI, SmaI y AluI) que dejaba extremos romos. La mezcla de reacción contenía $25 \mu \mathrm{l}$ de DNA $(0.1 \mu \mathrm{g} / \mu \mathrm{l}), 8 \mu \mathrm{l}$ de 
Restriction Enzyme (10 U/ $\mu \mathrm{l}), 10 \mu \mathrm{l}$ Restriction Enzyme Buffer (10X) y $57 \mu \mathrm{lde} \mathrm{H}_{2} \mathrm{O}$, y se incubó durante $18-20$ horas a $37^{\circ} \mathrm{C}$. Una vez finalizada la reacción, se purificó el DNA digerido mediante la técnica fenol-cloroformo.

\section{b) Ligación del adaptador (AP)}

El DNA digerido se ligó por ambos extremos al adaptador suministrado por el kit, que contiene las secuencias complementarias a los cebadores utilizados en las subsiguientes PCRs. La reacción de ligación contenía $4 \mu \mathrm{l}$ de DNA digerido, $1.9 \mu \mathrm{l}$ de GenomeWalker Adaptor $(25 \mu \mathrm{M}), 1.6 \mu \mathrm{l}$ de $10 \mathrm{X}$ Ligation Buffer y $0.5 \mu \mathrm{l}$ de $\mathrm{H}_{2} \mathrm{O}$. La mezcla de reacción se incubó a $16{ }^{\circ} \mathrm{C} \mathrm{d} / \mathrm{n}$ y, tras esto, a $70{ }^{\circ} \mathrm{C}$ durante 5 minutos para detener la reacción. Finalmente, se añadieron $72 \mu \mathrm{l}$ de TE (10/1, pH 7.5).

\subsubsection{3. 'DNA Walking'}

A partir de cada una de las genotecas, se llevaron a cabo dos PCRs sucesivas que permitieron amplificar la secuencia desconocida (región promotora) aguas arriba del cDNA de los genes CitCEL (aCL1347Contig1) y CitPG (aCL675Contig4), tal y como se representa en la Figura 29.

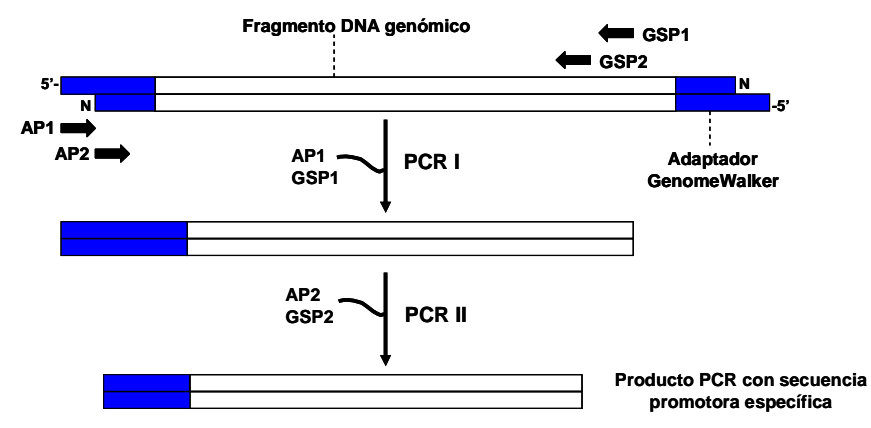

Figura 29. Estrategia 'DNA Walking' utilizada para obtener la región promotora de los genes CitCEL y CitPG. 
La primera reacción de PCR (PCR I) se realizó con el cebador AP1 (adaptor primer) del adaptador y con el cebador GSP1 (gene-specific primer) del gen específico (CitCEL o CitPG). Para la segunda reacción de PCR (PCR II) se emplearon los cebadores AP2 y GSP2, ambos internos a AP1 y GSP1, respectivamente.

\section{a) Diseño de cebadores específicos (GSP1 y GSP2)}

Los cebadores de los genes de interés se diseñaron a partir de las secuencias de cDNA y en la región 5', siguiendo las indicaciones del kit. Las secuencias de los cebadores GSP y AP se pueden ver en el Anexo 19.

\section{b) PCR I}

Se preparó la reacción de PCR I para cada genoteca en un tubo que contenía $1 \mu \mathrm{l}$ de DNA ligado al adaptador, $5 \mu \mathrm{l}$ de Advantage 2 PCR Buffer (10X), $1 \mu \mathrm{l}$ de dNTPs (10 mM), $1 \mu \mathrm{l}$ de AP1 $(10 \mu \mathrm{M}), 1 \mu \mathrm{l}$ de GSP1 $(10 \mu \mathrm{M}), 1 \mu \mathrm{l}$ de Advantage 2 Polymerase Mix (50X) y $40 \mu \mathrm{l}$ de $\mathrm{H}_{2} \mathrm{O}$. Las condiciones de amplificación por PCR fueron: 5 minutos a $94{ }^{\circ} \mathrm{C} ; 10$ ciclos de $94{ }^{\circ} \mathrm{C}$ durante 30 segundos, 1 minuto con temperatura en descenso $\left(1{ }^{\circ} \mathrm{C} /\right.$ ciclo $)$ hasta alcanzar la temperatura de anillado de GSP 1 y $72^{\circ} \mathrm{C}$ durante 3 minutos; 35 ciclos de $94{ }^{\circ} \mathrm{C}$ durante 30 segundos, 1 minuto a la temperatura de anillado de GSP 1 y $72{ }^{\circ} \mathrm{C}$ durante 3 minutos; 7 minutos a $72{ }^{\circ} \mathrm{C}$ y 5 minutos a $4{ }^{\circ} \mathrm{C}$. A continuación, se comprobaron los productos de PCR mediante visualización en un gel de agarosa al 1.5\% (Anexo 19).

\section{c) PCR II}

La mezcla de reacción se preparó a partir de $1 \mu \mathrm{l}$ del producto de la PCR I diluido 1/50. La reacción se preparó de forma análoga a la descrita para la PCR I pero utilizando los cebadores AP2 y GSP2. Las condiciones de la reacción de PCR fueron las mismas que las empleadas para la PCR I pero aplicando las temperaturas de anillado correspondientes a los cebadores AP2 y GSP2. Los productos de PCR se comprobaron en un gel de agarosa al $1.5 \%$. Finalmente, se seleccionaron las reacciones que mostraban una sola banda (Anexo 19) y se purificó el producto de PCR utilizando el kit 'QIAquick® Gel Extraction' (QIAGEN, Ref.: 28704), siguiendo las instrucciones del fabricante. 
5.2.5.4. Ligación de productos de PCR, clonación en Escherichia coli y purificación de plásmidos

Las reacciones de ligación de los productos de PCR se llevaron a cabo utilizando el kit 'CloneJET ${ }^{\mathrm{TM}}$ PCR Cloning' (Fermentas, Ref.: K1232). El vector 'pJET 1.2/blunt' que proporciona el kit es un vector con extremos romos de modo que, previamente a la ligación, se llevó a cabo una reacción de corrección de los extremos protuberantes del fragmento de PCR, ya que las Taq polimerasas convencionales añaden, generalmente, una base A en los extremos. Este vector contiene un sitio $\mathrm{Amp}^{\mathrm{R}}$, que confiere resistencia a la ampicilina, y el gen letal eco47IR, que facilita la selección de bacterias transformantes con inserto. La cantidad de inserto se calculó en función de su tamaño y de la relación molar deseada de inserto/vector (3:1). La mezcla de la reacción de corrección contenía $10 \mu$ de tampón de reacción (2X), $1 \mu \mathrm{l}$ de DNA Blunting Enzyme, x $\mu$ de inserto y x $\mu \mathrm{l}$ de $\mathrm{H}_{2} \mathrm{O}$ hasta un volumen final de $18 \mu \mathrm{l}$. Una vez preparada, se incubó a $70^{\circ} \mathrm{C}$ durante 5 minutos y, tras esto, se enfrío en hielo para detener la reacción. Seguidamente, se añadió $1 \mu l$ de vector de ligación $(50 \mathrm{ng} / \mu \mathrm{l})$ y $1 \mu \mathrm{l}$ de T4 DNA ligasa y se incubó a temperatura ambiente durante 30 minutos. Para la transformación de las bacterias 'One Shot' (Invitrogen, Ref.: 12297016), se descongeló una alícuota de $50 \mu \mathrm{l}$ en hielo y se añadió un volumen de $5 \mu \mathrm{l}$ de ligación. La mezcla permaneció en hielo durante 30 minutos, tras lo que se incubó en un termobloque a $42{ }^{\circ} \mathrm{C}$ durante 30 segundos y se volvió a dejar en hielo durante 5 minutos más. Se añadió un volumen de $300 \mu \mathrm{l}$ de medio LB líquido (triptona $1 \%$, extracto de levadura $0.5 \%$ y $\mathrm{NaCl}$ $1 \%$ ) a la mezcla y se incubó a $37^{\circ} \mathrm{C}$ durante 1 hora en un agitador orbital (180 r.p.m.). Tras esto, las bacterias se cultivaron a $37^{\circ} \mathrm{C} \mathrm{d} / \mathrm{n}$ en placas petri con LB agar (triptona $1 \%$, extracto de levadura $0.5 \%, \mathrm{NaCl} 1 \%$ y agar bacteriológico $1 \%$ ) suplementado con ampicilina $(50 \mu \mathrm{g} / \mathrm{ml})$.

Las colonias transformantes se cultivaron en LB-ampicilina $(50 \mu \mathrm{g} / \mathrm{ml})$ a $37^{\circ} \mathrm{C}$ en agitación (180 r.p.m.) d/n. Se purificó el DNA plasmídico utilizando el kit 'GeneJET ${ }^{\mathrm{TM}}$ Plasmid Miniprep' de Fermentas, con número de referencia K0503, siguiendo las indicaciones del fabricante. Se comprobó la presencia de inserto mediante digestión con enzimas que cortaban el plásmido a ambos lados del inserto (XhoI y XbaI de Promega; R4164 y R4184, respectivamente) y mediante visualización en un gel de agarosa al 1\%. Los 
plásmidos que habían incorporado el inserto del tamaño esperado se secuenciaron en la empresa Secugen (Madrid).

\subsubsection{Análisis in silico de promotores}

Una vez obtenidas las secuencias de los promotores de los genes CitCEL y CitPG, se llevó a cabo un análisis in silico de las mismas utilizando el programa ConSite (Sandelin et al., 2004; http://asp.ii.uib.no:8090/cgi-bin/CONSITE/consite/) con el objetivo de localizar posibles elementos reguladores en cis. Se consideraron los factores de transcripción de plantas del programa y un intervalo de confianza del $85 \%$.

\subsubsection{Análisis de la composición de monosacáridos de las paredes celulares de la}

\section{ZAC mediante cromatografía gas-líquido (GLC)}

Para cada uno de los puntos de muestreo comentados en el apartado 5.2.2, se aislaron mediante microdisección asistida por láser (MAL; apartado 3.2.6.2) tres muestras independientes de la ZAC previamente preparadas como se explica en el apartado 3.2.6.1. En este caso, cada muestra contenía alrededor de 50000 células, que fueron recogidas directamente en un microtubo $(0.5 \mathrm{ml})$ sin ningún tipo de tampón y congeladas a $-80{ }^{\circ} \mathrm{C}$ hasta su utilización.

Las muestras fueron sometidas a una metanólisis de $16 \mathrm{~h}$ a $80^{\circ} \mathrm{C}$ con $500 \mu \mathrm{L}$ de $\mathrm{HCl}$ metanólico $1 \mathrm{M}$ (Supelco). Tras la evaporación del metanol, los metil glucósidos resultantes fueron transformados en sus derivados trimetilsililos durante 20 minutos a $80^{\circ} \mathrm{C}$ con 200 $\mu \mathrm{L}$ de reactivo de sililación (HMDS:TMCS:Piridina, 3:1:9; Supelco). A continuación, se llevó a cabo el análisis por GLC utilizando un cromatógrafo de gases Varian CP-3800 (Varian) equipado con un detector de ionización de llama, una columna capilar WCOT de sílice fundida (longitud: $25 \mathrm{~m}$, i.d.: $0.25 \mathrm{~mm}$ ) con CP-Sil $5 \mathrm{CP}$ como fase estacionaria y helio como vector. El programa de temperaturas del horno fue: 2 minutos a $120{ }^{\circ} \mathrm{C}, 10$ minutos a $160{ }^{\circ} \mathrm{C}, 1.5{ }^{\circ} \mathrm{C} /$ minuto hasta $220{ }^{\circ} \mathrm{C}$ y $20{ }^{\circ} \mathrm{C} /$ minuto hasta $280{ }^{\circ} \mathrm{C}$. La cuantificación de azúcares se realizó a través de la integración de los picos y la determinación de los correspondientes valores molares utilizando los factores de respuesta establecidos con los monosacáridos estándar. 


\subsubsection{Inmunolocalización de polímeros pécticos en la ZAC}

Los anticuerpos monoclonales primarios (mAbs) utilizados en este estudio fueron LM5, LM6 y JIM5. Como anticuerpo secundario se utilizó isotiocianato de fluoresceína (FITC) conjugado al anticuerpo Anti-Rat IgG (Sigma-Aldrich, Ref.: F6258). En la Tabla 19 aparecen los polímeros de la pared celular que son reconocidos por estos mAbs así como las respectivas referencias bibliográficas.

Tabla 19. Anticuerpos monoclonales (mAbs) dirigidos a polisacáridos de la pared celular utilizados en este estudio.

\begin{tabular}{ccc}
\hline mAb & $\begin{array}{c}\text { Polímero/epítopo de pared celular } \\
\text { reconocido }\end{array}$ & $\begin{array}{c}\text { Referencia } \\
\text { bibliográfica }\end{array}$ \\
\hline LM5 & $(1 \rightarrow 4)-\beta$-D-galactano & Jones et al. $(1997)$ \\
LM6 & $(1 \rightarrow 5)-\alpha-L$-arabinano & Willats et al. $(1998)$ \\
JIM5 & $\begin{array}{c}\text { homogalacturonanos parcialmente metil- } \\
\text { esterificados/desesterificados }\end{array}$ & Knox et al. $(1990)$ \\
\hline
\end{tabular}

Las secciones de tejido, cuyo montaje se describe en el apartado 3.2.5.2.1, fueron delimitadas con un rotulador lipofílico 'Pap pen' (Sigma-Aldrich, Ref.: Z672548-1EA) e incubadas durante 10 minutos en la solución de bloqueo (5 g leche en polvo en $100 \mathrm{ml}$ de tampón PBS). Seguidamente, se lavaron con PBS y se incubaron con el anticuerpo primario (dilución 1:5 en solución de bloqueo) en una cámara húmeda durante 2-3 horas a temperatura ambiente y 8-12 horas a $4{ }^{\circ} \mathrm{C}$. Las secciones utilizadas como control se incubaron siguiendo el mismo procedimiento pero solamente con la solución de bloqueo. Una vez finalizada la incubación, se realizaron dos lavados de 10 minutos con PBS y un lavado de 5-10 minutos con agua destilada, y se incubaron las secciones con el anticuerpo secundario (dilución 1:100 en solución de bloqueo) durante 3-4 horas en una cámara húmeda y en oscuridad. A continuación, se repitieron los lavados con PBS y agua destilada durante los tiempos descritos, se tiñeron las secciones con 'Calcofluor White' (Fluorescent brightener, Sigma-Aldrich, Ref.: F3543) y se montaron los portaobjetos con 'Vectashield' (Vector Laboratories, Ref.: H-1000) para la detección de fluorescencia. La observación de las muestras se llevó a cabo en un microscopio invertido de epifluorescencia 'Zeiss Axio Imager Z1' utilizando los objetivos 'Zeiss Plan Apochromatic 63X/1.40' o 'Zeiss Neofluor 20X/0.50', y los filtros de 365/445 nm para la tinción con calcofluor y 470/525 nm para la 
tinción con fluoresceína. La adquisición de las imágenes se realizó con una cámara 'Axiocam MR' en modo de exposición automático y se procesaron con el software 'Axiovision 4.4'. 


\subsection{Resultados}

5.3.1. Análisis filogenético y estudio de la estructura proteica de familias de proteínas relacionadas con la modificación de la pared celular

A continuación, se exponen los resultados del análisis filogenético de las familias de proteínas relacionadas con la degradación o la modificación de la estructura de la pared celular y la lámina media (glicósido hidrolasas, polisacárido liasas, carbohidrato esterasas y expansinas), así como los resultados de los alineamientos de las secuencias proteicas deducidas y de la predicción de dominios proteicos específicos de cada familia génica.

\subsubsection{Endo- $\beta$ - $(1 \rightarrow 4)$-glucanasas o Celulasas (EGasas o CELs; familia GH9 de} glicósido hidrolasas)

Las microfibrillas de celulosa son los elementos estructurales centrales de la pared celular vegetal, estructura que proporciona la fuerza y la flexibilidad a los tejidos vegetales. Las unidades poliméricas de la celulosa son $\beta$-1,4-glucanos sin cadenas laterales que se asocian entre sí mediante puentes de hidrógeno formando largas microfibrillas cristalinas que contienen 36 o más glucanos en sección transversal. Las endo- $\beta$ - $(1 \rightarrow 4)$-glucanasas (EGasas) o celulasas (CELs; EC 3.2.1.4), enzimas pertenecientes a la familia 9 de las glicósido hidrolasas (GH9; CAZy; http://www.cazy.org/fam/CE8.html; Henrissat, 1991), despolimerizan polisacáridos que contienen enlaces $(1 \rightarrow 4)-\beta$-D-glucano. Las EGasas no presentan actividad o su actividad es muy baja sobre la celulosa cristalina pero su actividad es fácilmente medible sobre los derivados solubles de la celulosa como la carboximetilcelulosa, la celulosa no cristalina y ciertos polisacáridos como los xilanos, los $(1 \rightarrow 3)$ $(1 \rightarrow 4)-\beta$-glucanos y los glucomananos (Master et al., 2004; Yoshida y Komae, 2006; Urbanowicz et al., 2007).

Las CELs se clasifican en tres grupos en función de los dominios que contiene su secuencia: CELs del grupo A, con un dominio citosólico, un dominio transmembrana y un dominio catalítico Glyco_hydro_9 (PF00759), CELs del grupo B, con un péptido señal y el dominio Glyco_hydro_9, y CELs del grupo C, con un péptido señal, el dominio Glyco_hydro_9, una región 'linker’ y un dominio CBM49 (Carbohydrate Binding Module 
49; PF09478), que no presenta actividad catalítica pero tiene la capacidad de unirse a polisacáridos durante la hidrólisis de la pared celular (Urbanowicz et al., 2007). El grupo A de CELs comprende proteínas de anclaje a la membrana plasmática, que pueden o no tener el dominio citosólico, mientras que los grupos $\mathrm{B}$ y $\mathrm{C}$ comprenden proteínas que van a ser secretadas (Libertini et al., 2004; Urbanowicz et al., 2007) ya que contienen un péptido señal en su extremo amino-terminal que las etiqueta para ser procesadas por los sistemas endomembranosos celulares (retículo endoplasmático y áreas de Golgi) y exportadas a la pared celular o al espacio extracelular.

La familia CEL de Arabidopsis thaliana está formada por 25 genes (ver Figura S1 del Anexo 7; Urbanowicz et al., 2007). En la versión v0.9 (6,5 equivalentes genómicos) del ensamblaje del genoma haploide de Citrus clementina se han localizado 24 ORFs (22 completas y 2 parciales) que potencialmente codifican proteínas CEL ya que presentan un dominio Glyco-hydro_9 en su secuencia deducida de aminoácidos (ver Anexo 8). El número de proteínas CEL pertenecientes a los grupos A y B en A. thaliana y C. clementina fue el mismo, 4 proteínas y 18 proteínas, respectivamente, mientras que el grupo C mostraba 3 proteínas en $A$. thaliana y 2 proteínas en $C$. clementina (ver Figura $\mathbf{S 1}$ del Anexo 7 y Anexo 9). Excepto el locus clementine0.9_033095m.g, cuya secuencia era incompleta, todas las CELs de $C$. clementina englobadas en el grupo A presentaban el dominio transmembrana (ver Figura S10 del Anexo 8 y Anexo 9). En relación a las CELs del grupo B, todas las proteínas deducidas de $C$. clementina presentaban en su secuencia un péptido señal en el extremo amino-terminal, excepto las proteínas deducidas de los locus clementine0.9_009141m.g, clementine0.9_028557m.g y clementine0.9_030982m.g (y la proteína parcial deducida del locus clementine0.9_028193m.g).

La micromatriz de cDNA empleada en el presente trabajo contiene sondas de 6 CELs de cítricos (Figura 30), de las cuales 2 sondas pertenecen al grupo A de CELs, 3 al grupo B y una al grupo C (ver Figuras S10, S11 y S12 del Anexo 8). Por tanto, esta micromatriz de cDNA únicamente cubre un $25 \%$ de las posibles CELs presentes en el genoma de los cítricos. La Figura 30 muestra el análisis filogenético de las proteínas de la familia CEL de C. clementina y de las CELs deducidas de A. thaliana (Lashbrook y Cai, 2008), aguacate (Tonutti et al., 1995), tomate (Brumell et al., 1999; del Campillo et al., 1996; Lashbrook et al., 1994), pimiento (Ferrarese et al., 1995), soja (Tucker et al., 2007), manzano (Li y 
Yuan, 2008), algodón (Mishra et al., 2008), melocotón (Trainotti et al., 2006) y Dendrobium (Rungruchkanont et al., 2007) relacionadas con el proceso de abscisión. El análisis filogenético de la familia CEL mostró que el gen aCL1347Contig1 (clementine0.9_008028m.g), inducido exclusivamente en la ZAC tras $24 \mathrm{~h}$ de tratamiento con etileno, estaba estrechamente relacionado con otras CELs inducidas durante el proceso de abscisión en aguacate (PaCEL1; Tonutti et al., 1995), tomate (SLGH9B4; Brumell et al., 1999), pimiento (CaCEL2; Ferrarese et al., 1995) y soja (GmCEL09; Tucker et al., 2007). El resto de genes de cítricos con homología a CELs y representados en la micromatriz de cDNA que, a diferencia de aCL1347Contig1, no mostraron cambios de expresión significativos en la ZAC durante la activación del proceso, quedaron agrupados con CELs de otras especies vegetales implicadas en el proceso de abscisión. Así, el gen aKN0AAK1AB05FM2_c (clementine0.9_008549m.g), homólogo al gen CsCEL-b1 inducido en la ZA de hojas y frutos de cítricos según un estudio anterior (Burns et al., 1998), estaba estrechamente relacionado con CELs inducidas durante la abscisión en soja (GmCEL06; Tucker et al., 2007), manzano (MdEG1; Li y Yuan, 2008) y A. thaliana (AtGH9B3 y AtGH9B4; Lashbrook y Cai, 2008). El gen aCL1594Contig1 (clementine0.9_008291m.g) se encontraba en la misma rama que SLGH9B2, inducido durante la abscisión de flores y frutos en tomate (del Campillo et al., 1996; Lashbrook et al., 1994). El gen aCL5093Contig1 (clementine0.9_004972m.g) estaba estrechamente relacionado con las CELs GhCel1 y PpEG4, inducidas durante la abscisión en algodón y melocotón, respectivamente (Mishra et al., 2008; Trainotti et al., 2006). Por último, los genes aIC0AAA3AB03RM1_c (clementine0.9_004824m.g) y aCL5359Contig1 (clementine0.9_005121m.g), mostraron proximidad a las CELs DenCel1 del género Dendrobium y SLGH9B5 de tomate, respectivamente. La CEL DenCel1 se induce durante la abscisión floral (Rungruchkanont et al., 2007), mientras que el gen SLGHB5 se reprime durante la abscisión floral (del Campillo et al., 1996). Los ortólogos en A. thaliana de aIC0AAA3AB03RM1_c y aCL5359Contig1 (AT1G65610 y AT5G49720, respectivamente) pertenecen a una clase de endoglucanasas (KORRIGAN; Robert et al., 2005) implicadas en la biosíntesis de celulosa que no han sido relacionadas hasta ahora con el proceso de abscisión. 


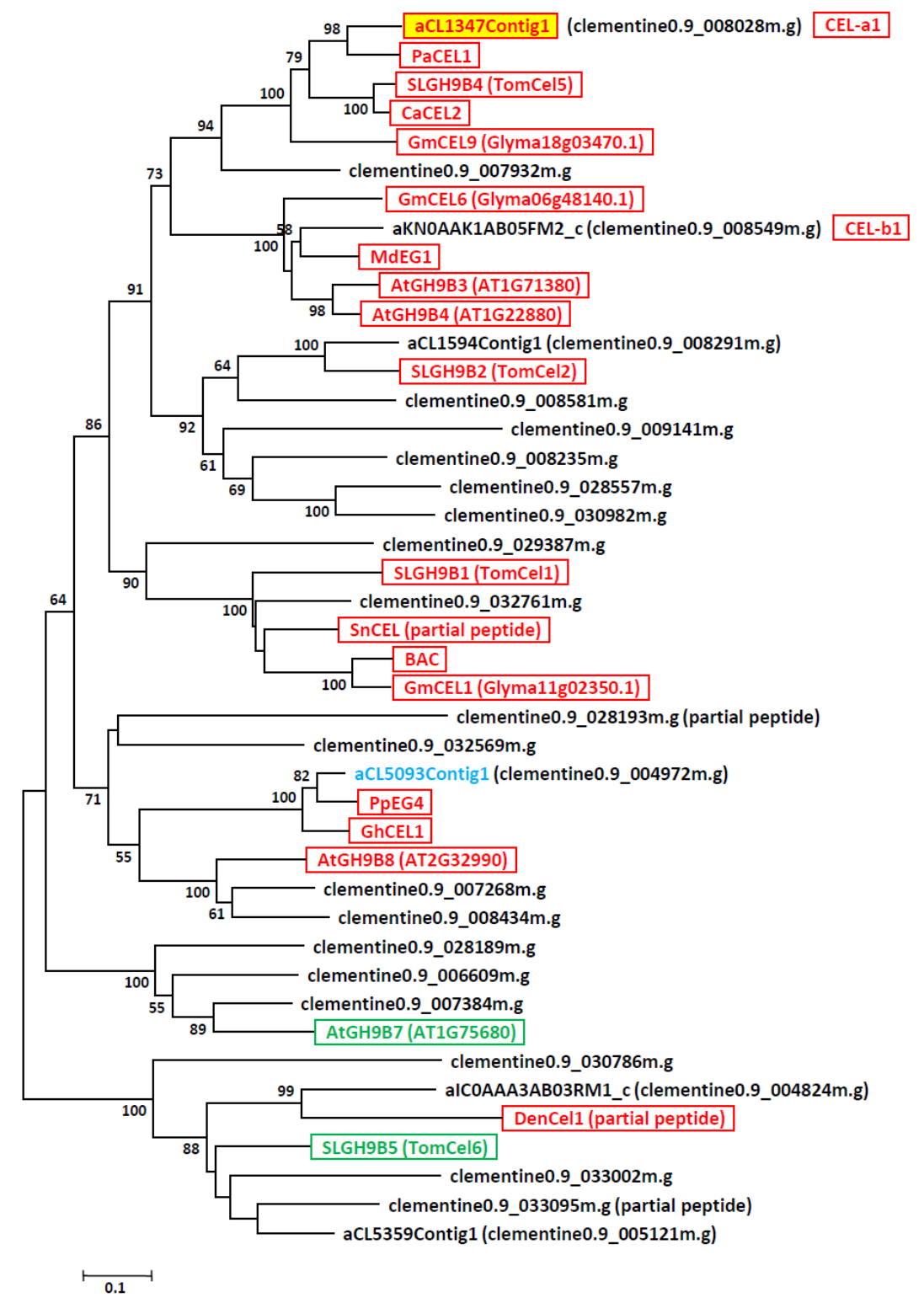

Figura 30. Relaciones filogenéticas entre las celulasas (GH9s) localizadas en el genoma haploide de Citrus clementina, las reguladas por etileno en las células de la ZAC y/o en las células parenquimáticas de la corteza del fruto maduro del naranjo 'Washington Navel' y las descritas en la literatura como asociadas a la abscisión en otras especies vegetales (ver Anexo 9). El árbol filogenético está basado en alineamientos múltiples (ClustalW http://www.ch.embnet.org/software/ClustalW-XXL.html) y se generó utilizando el programa MEGA 4.0 mediante el método Neighbor-Joining (complete deletion, Poisson correction). El soporte Bootstrap para 1000 réplicas se muestra en las ramificaciones del árbol (solamente se muestran los valores superiores al 50\%). Clave de colores de los identificadores de las proteínas alineadas: (Citrus), inducción de la expresión por etileno exclusivamente en las células de la ZAC; (Citrus), presente en la micromatriz de cítricos de $20 \mathrm{~K}$ (Martínez-Godoy et al., 2008) pero sin resultados de la hibridación; (XXXX), inducido durante la activación de las ZAs en diferentes órganos de otras especies vegetales; (XXXX), reprimido durante la activación de las ZAs en diferentes órganos de otras especies vegetales. 


\subsubsection{Poligalacturonasas (PGs; familia GH28 de glicósido hidrolasas)}

La pectina es el principal constituyente de la lámina de las paredes celulares primarias de las plantas dicotiledóneas y está compuesta de homogalacturonano y ramnogalacturonano alternativamente (Williamson et al., 1998; Van der Vlugt-Bergmans $e t$ al., 2000). Este heteropolisacárido confiere rigidez a la pared celular cementando la red de celulosa, aunque en determinados momentos del desarrollo es necesario modificar la rigidez de la pared celular, como ocurre en los procesos de abscisión de órganos, dehiscencia de las anteras y del fruto, maduración de los frutos o crecimiento del tubo polínico (Haldfield et al., 1998; Kim et al., 2006). Las poligalacturonasas (PGs; EC 3.2.1.15) pertenecen a la familia 28 de las glicósido hidrolasas (GH28; CAZy; http://www.cazy.org/fam/GH28.html; Henrissat, 1991) y degradan las pectinas; concretamente, catalizan la hidrólisis de enlaces $\alpha-(1 \rightarrow 4)$ glicosídicos en pectato y otros galacturonanos (Markovic y Janecek, 2001) y, de esta manera, modifican la rigidez de las paredes celulares.

En base al análisis filogenético de sus secuencias de aminoácidos, las PGs de plantas se clasifican en 3 grupos diferentes (grupos A, B y C, Kim et al., 2006). La familia PG de A. thaliana está formada por 66 proteínas, de las cuales, 53 proteínas pertenecen al grupo A, 12 proteínas al grupo B y una proteína al grupo C (Figura S2 del Anexo 7). En la versión v0.9 (6,5 equivalentes genómicos) del ensamblaje del genoma haploide de $C$. clementina se han localizado 55 ORFs (43 completas y 12 parciales) que potencialmente codifican proteínas PG ya que presentan el dominio Glyco-hydro_28 (PF00295) en su secuencia deducida de aminoácidos (ver Anexo 10 y Figuras S13, S14 y S15 del Anexo 8). De las 55 potenciales proteínas PG de C. clementina, 46 proteínas pertenecen al grupo A, 8 proteínas al grupo B y una proteína al grupo C (Figura S2 del Anexo 7).

Se han identificado cuatro motivos funcionales altamente conservados en el dominio Glyco-hydro_28 (motivos I, II, III y IV; Park et al., 2008). Las secuencias SPNTDGI, GDDC, CGPGHGISIGSLG y RIK que constituyen los motivos I, II, III y IV, respectivamente, se encontraban muy conservadas en las proteínas PG del grupo A; sin embargo, el motivo III de las proteínas del grupo B presentaba mayores diferencias con 
respecto a la secuencia consenso, tanto en las PGs de C. clementina como en las PGs asociadas a la abscisión en otras especies vegetales (Figuras S13, S14 y S15 del Anexo 8).

Las PGs se localizan en el apoplasto y, excepto las proteínas correspondientes a los locus clementine0.9_018713m.g, clementine0.9_030237m.g, clementine0.9_014542m.g, clementine0.9_034844m.g y clementine0.9_008372m.g (y las proteínas parciales correspondientes a los locus clementine0.9_018713m.g, clementine0.9_029085m.g, clementine0.9_027866m.g, clementine0.9_029944m.g, clementine0.9_028836m.g, clementine0.9_033174m.g, clementine0.9_011796m.g y clementine0.9_028610m.g), 41 proteínas de $C$. clementina presentaban un péptido señal en su extremo amino-terminal (ver Figuras S13, S14 y S15 del Anexo 8 y Anexo 10) que dirige su secreción al espacio extracelular (Yokoyama y Nishitani, 2001). La proteína deducida del locus clementine0.9_028610m.g no tiene péptido señal, como se ha indicado, pero presenta un dominio transmembrana (Anexo 10).

La micromatriz de cDNA empleada en este trabajo contiene sondas correspondientes a 17 PGs de cítricos (ver Figura 31 y Anexo 10), por tanto, únicamente cubre un $31 \%$ de las posibles PGs presentes en el genoma de los cítricos. La Figura 31 muestra el análisis filogenético de las proteínas de la familia PG de C. clementina y de las proteínas deducidas de genes de A. thaliana (González-Carranza et al. 2002, 2007; Kim et al., 2006; Lashbrook y Cai, 2008; Ogawa et al., 2009), soja (Tucker et al., 2007), colza (Brassica napus; González-Carranza et al., 2002; Petersen et al., 1996), manzano (Atkinson et al., 2002) y plátano (Mbéguié-A-Mbéguié et al., 2009) asociados a la abscisión. En relación al grupo A de PGs, el gen aCL675Contig4 (clementine0.9_012194m.g), que se inducía exclusivamente en la ZAC tras $24 \mathrm{~h}$ de tratamiento con etileno, y el gen aKN0AAK1DH04FM2_c (clementine0.9_012391m.g), que se inducía exclusivamente en la CF tras $24 \mathrm{~h}$ de tratamiento, quedaron agrupados en la misma rama, aunque alejados, que TAPG1, TAPG2 y TAPG4, tres genes inducidos durante la abscisión de hojas y flores en tomate (Kalaitzis et al., 1997). Dentro del grupo A de la familia PG, cabe destacar, además, que en una misma rama se encontraban un gran número de PGs inducidas durante los procesos de abscisión y dehiscencia en diferentes especies vegetales. Se trata de los genes ADPG2 y QRT2, asociados a la dehiscencia de la silicua y a la abscisión de órganos florales en A. thaliana, respectivamente (González-Carranza et al., 2002, 2007; Ogawa et al., 2009), PGAZBRAN 
y RDPG1, relacionados con la abscisión y la dehiscencia en la colza (Brassica napus), respectivamente (González-Carranza et al., 2002; Petersen et al., 1996), GDPG1 y GmPG11, relacionados con la abscisión foliar en manzano y soja, respectivamente (Atkinson et al., 2002; Tucker et al., 2007), y MaPG2, relacionado con la separación del fruto en plátano (Mbéguié-A-Mbéguié et al., 2009). Sin embargo, el único gen de cítricos (aC01018C01SK_c; clementine0.9_014542m.g) representado en la micromatriz que se encontraba próximo a estos genes no mostró datos de hibridación. En relación al grupo B de la familia PG, los genes aCL5261Contig1 (clementine0.9_006745m.g) y aIC0AAA85AB02RM1_c (clementine0.9_008916m.g) se inducían exclusivamente en la ZAC tras 12 y $24 \mathrm{~h}$ de tratamiento con etileno, respectivamente. Estos genes se situaban próximos a una rama que incluía el gen aCL3497Contig1 (clementine0.9_009866m.g), inducido en la ZAC tras $24 \mathrm{~h}$ de tratamiento con etileno y en la CF tras 12 y $24 \mathrm{~h}$ de tratamiento, el gen aIC0AAA15BF03RM1_c (clementine0.9_009484m.g), reprimido exclusivamente en la CF tras $12 \mathrm{~h}$ de tratamiento con etileno, y el gen AT3G16850, reprimido en la ZA de los estambres de A. thaliana (Lashbrook y Cai, 2008). Por otra parte, en una rama diferente quedaban agrupados aCL2029Contig1 (clementine0.9_010307m.g), reprimido exclusivamente en la ZAC tras $12 \mathrm{~h}$ de tratamiento con etileno, AT4G23820, reprimido en la ZA de los estambres de A. thaliana (Lashbrook y Cai, 2008) y GmPG16, reprimido en la ZA de la hoja en soja (Tucker et al., 2007). Por último, el único gen correspondiente a una PG del grupo $\mathrm{C}$ relacionado con el proceso de abscisión era aCL1063Contig1 (clementine0.9_008942m.g), que se inducía exclusivamente en la ZAC tras 12 y $24 \mathrm{~h}$ de tratamiento con etileno. 


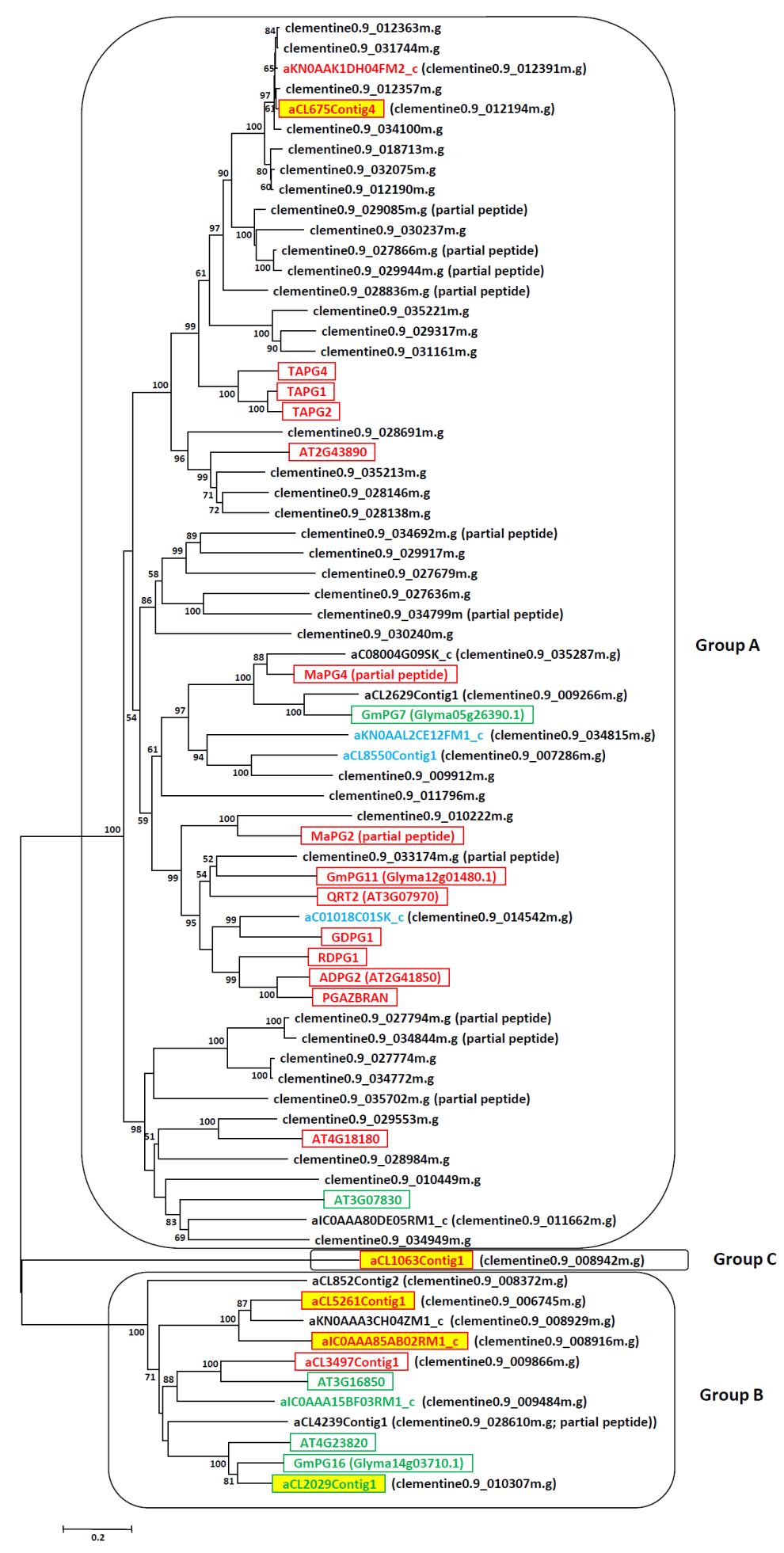


Figura 31 (página anterior). Relaciones filogenéticas entre las poligalacturonasas (GH28s) localizadas en el genoma haploide de Citrus clementina, las reguladas por etileno en las células de la ZAC y/o en las células parenquimáticas de la corteza del fruto maduro del naranjo 'Washington Navel' y las descritas en la literatura como asociadas a la abscisión en otras especies vegetales (ver Anexo 10). El árbol filogenético está basado en alineamientos múltiples (ClustalW; http://www.ch.embnet.org/software/ClustalW-XXL.html) y se generó utilizando el programa MEGA 4.0 mediante el método Neighbor-Joining (complete deletion, Poisson correction) El soporte Bootstrap para 1000 réplicas se muestra en las ramificaciones del árbol (solamente se muestran los valores superiores al 50\%). Clave de colores de los identificadores de las proteínas alineadas: (Citrus), inducción de la expresión por etileno exclusivamente en las células de la ZAC; (Citrus), inducción de la expresión por etileno en las células de la ZAC y en las células parenquimáticas de la corteza del fruto; (Citrus), inducción de la expresión por etileno en las células parenquimáticas de la corteza del fruto; (Citrus), represión de la expresión por etileno en las células parenquimáticas de la corteza del fruto; (Citrus), presente en la micromatriz de cítricos de 20 K (Martínez-Godoy et al., 2008) pero sin resultados de la hibridación; (XXXX), inducido durante la activación de las ZAs en diferentes órganos de otras especies vegetales; (XXXX), reprimido durante la activación de las ZAs en diferentes órganos de otras especies vegetales. 
5.3.1.3. $\beta$-xilosidasas ( $\beta$-XYLs; familia 3 de glicósido hidrolasas), $\alpha$-xilosidasas ( $\alpha$ XYLs; familia 31 de glicósido hidrolasas) y $\alpha$-L-arabinofuranosidasas (ASDs; familia 51 de glicósido hidrolasas)

Las hemicelulosas constituyen el 30-35 \% del peso seco de la pared celular y están formadas principalmente por xiloglucano y xilano con menores cantidades de polisacáridos que contienen manosa (Bewley et al., 1997; Handford et al., 2003). Los xiloglucanos presentan una cadena principal de residuos D-glucosilo unidos mediante un enlace $\beta$ $(1 \rightarrow 4)$, que pueden ser sustituidos por residuos xilosilo, galactosilo y L-fucosilo (Renard et al., 1992). El xilano presenta una estructura compleja basada en una cadena principal de residuos D-xilosilo unidos por un enlace $\beta$-( $1 \rightarrow 4)$, que pueden ser sustituidos por grupos acetilo, L-arabinofuranosilo, galactosilo, glucuronilo y 4-O-metilglucuronilo (Coughlan y Hazlewood, 1993; Kulkarni et al., 1999; Prade, 1996). El xilano es el principal componente de las hemicelulosas y, debido a su heterogeneidad, su hidrólisis requiere la acción de diferentes enzimas (Rahman et al., 2003; Tuncer y Ball, 2003), entre las que se encuentran $\beta$-xilosidasas ( $\beta$-XYLs; EC 3.2.1.37), $\alpha$-xilosidasas ( $\alpha$-XYLs; EC 3.2.1.-) y $\alpha$-Larabinofuranosidasas (ASDs; EC 3.2.1.55) (Sunna y Antranikian, 1997). Las $\beta$-XYLs y $\alpha$ XYLs pertenecen a las familias 3 y 31, respectivamente, de las glicósido hidrolasas (GH3; GH31; CAZy; http://www.cazy.org/fam/GH3.html) y catalizan la hidrólisis de los $(1 \rightarrow 4)$ $\beta$-D-xilanos para eliminar residuos sucesivos de D-xilosa del extremo no reducido. Las $\alpha$ L-arabinofuranosidasas pertenecen a la familia 51 de las glicósido hidrolasas (GH51; CAZy; http://www.cazy.org/fam/GH51.html) y catalizan la hidrólisis de residuos terminales $\alpha$-L-arabinofuranósido no reducidos en $\alpha$-L-arabinósidos. Algunos miembros de las familia GH3 ( $\beta$-XYLs) presentan actividad dual $\beta$-xilosidasa y arabinofuranosidasa (Arsovski et al., 2009; Minic et al., 2006).

Las $\beta$-XYLs se caracterizan por tener en su secuencia de aminoácidos un péptido señal, el dominio Glyco_hydro_3 (PF00933) en su extremo amino-terminal y el dominio Glyco_hydro_3_C (PF01915) en su extremo carboxilo-terminal. Las $\alpha$-XYLs presentan un péptido señal y el dominio Glyco_hydro_31 (PF01055) en su secuencia de aminoácidos. Por otra parte, las ASDs contienen un péptido señal, el dominio CBM_4_9 (Carbohydrate binding domain; PF02018) de unión a carbohidratos situado en el extremo amino-terminal 
y el dominio catalítico Alpha-L-AF_C (Alpha-L-arabinofuranosidase C-terminus; PF06964) localizado en el extremo carboxilo-terminal.

Las familias GH3, GH31 y GH51 de A. thaliana están formadas por 15, 5 y 2 proteínas, respectivamente (ver Figura S3 del Anexo 7). En la versión v0.9 (6,5 equivalentes genómicos) del ensamblaje del genoma haploide de $C$. clementina se han localizado 19 ORFs (16 completas y 3 parciales) correspondientes a posibles proteínas de la familia GH3, 9 ORFs correspondientes a posibles proteínas de la familia GH31 (7 completas y 2 parciales) y una ORF correspondiente a una posible proteína de la familia GH51 (ver Figura S3 del Anexo 7). Las XYLs y ASDs se localizan en el apoplasto, aunque algunas de las proteínas de cítricos no presentaban el péptido señal (ver Figuras S16, S17 y $\mathbf{S 1 8}$ del Anexo 8 y Anexo 11). Este es el caso de las $\beta$-XYLs codificadas por los locus clementine0.9_003281m.g, clementine0.9_004518m.g, clementine0.9_005004m.g, clementine0.9_005391m.g, clementine0.9_027655m.g, clementine0.9_028200m.g (y las $\beta$ XYLs parciales codificadas por los locus clementine0.9_031179m.g y clementine0.9_033751m.g), y las $\alpha$-XYLs codificadas por los locus clementine0.9_004774m.g, clementine0.9_002132m.g, clementine0.9_001417m.g, clementine0.9_002886m.g (y las $\alpha$-XYLs parciales codificadas por los locus clementine0.9_034854m.g y clementine0.9_034951m.g).

La micromatriz de cDNA empleada en este trabajo contenía sondas correspondientes a $10 \beta$-XYLs, $5 \alpha$-XYL y una ASD de cítricos (ver Figura 32 y Anexo 11). Por tanto, esta micromatriz de cDNA únicamente cubre un $53 \%$ y un $56 \%$, respectivamente, de las posibles $\beta$ - y $\alpha$-XYLs presentes en el genoma de los cítricos. La única ASD localizada en el genoma de $C$. clementina se encuentra representada en la micromatriz de cítricos. La Figura 32 muestra el análisis filogenético de las proteínas de las familias GH3, GH31 y GH51 de C. clementina y de las proteínas deducidas de genes de A. thaliana cuyos promotores dirigen la actividad $\beta$-glucuronidasa hacia las ZAs de los órganos florales (AtBXL1, AT5G49360; AtASD1, AT3G10740; AtASD2, AT5G26120; AtXYL1, AT1G68560) y de genes de A. thaliana inducidos en la ZA de los órganos florales (AT5G20950) (Fulton y Cobbett, 2003; Goujon et al., 2003; Lashbrook y Cai, 2008; Sampedro et al., 2010). En relación a la familia $\beta$-XYL, el gen aCL271Contig1 (clementine0.9_002914m.g), que se inducía en la ZAC y en la CF tras 12 y 24 h de 
tratamiento, y el gen aCL2321Contig1 (clementine0.9_002988m.g), que se inducía en la ZAC tras $12 \mathrm{~h}$ de tratamiento con etileno y en la CF tras $24 \mathrm{~h}$ de tratamiento, se encontraban estrechamente relacionados con la proteína AtBXL1 de A. thaliana, con actividad $\beta$-glucuronidasa dirigida a las ZAs de los órganos florales por su secuencia promotora específica (Goujon et al., 2003). Por otra parte, los genes de cítricos aCL3345Contig1 (clementine0.9_002926m.g) y aCL8110Contig1 (clementine0.9_004996m.g) se reprimían exclusivamente en la ZAC tras $12 \mathrm{~h}$ de tratamiento con etileno. El gen aCL3345Contig1 no mostraba homología a ninguna $\beta$-XYL con actividad en las zonas de abscisión, mientras que el gen aCL8110Contig1 mostraba homología a AT5G20950, una $\beta$-XYL inducida durante la abscisión de los estambres (Lashbrook y Cai, 2008). En relación a la familia ASD, los genes AtASD1 y AtASD2, con actividad $\beta$-glucuronidasa dirigida a las ZAs de los órganos florales de A. thaliana por su secuencia promotora específica (Fulton y Cobett, 2003), quedaban agrupados junto con un gen de cítricos (aKN0AAP8YC15FM1_c; clementine0.9_004189m.g) que no mostraba cambios significativos de expresión durante la abscisión. Por último, dentro de la familia $\alpha$ XYL, el gen aCL6235Contig1 (clementine0.9_002017m.g), que se reprimía exclusivamente en la ZAC a las $12 \mathrm{~h}$ de tratamiento con etileno, presentaba homología a la proteína AtXYL1 de A. thaliana, cuya expresión se localiza en la ZA de órganos florales (Sampedro et al., 2010), mientras que el gen aC08018A05SK_c (clementine0.9_034951m.g), reprimido en la ZAC y en la CF tras 24 h de tratamiento con etileno, se localizaba en una rama diferente a aCL6235Contig1 y AtXYL1. 


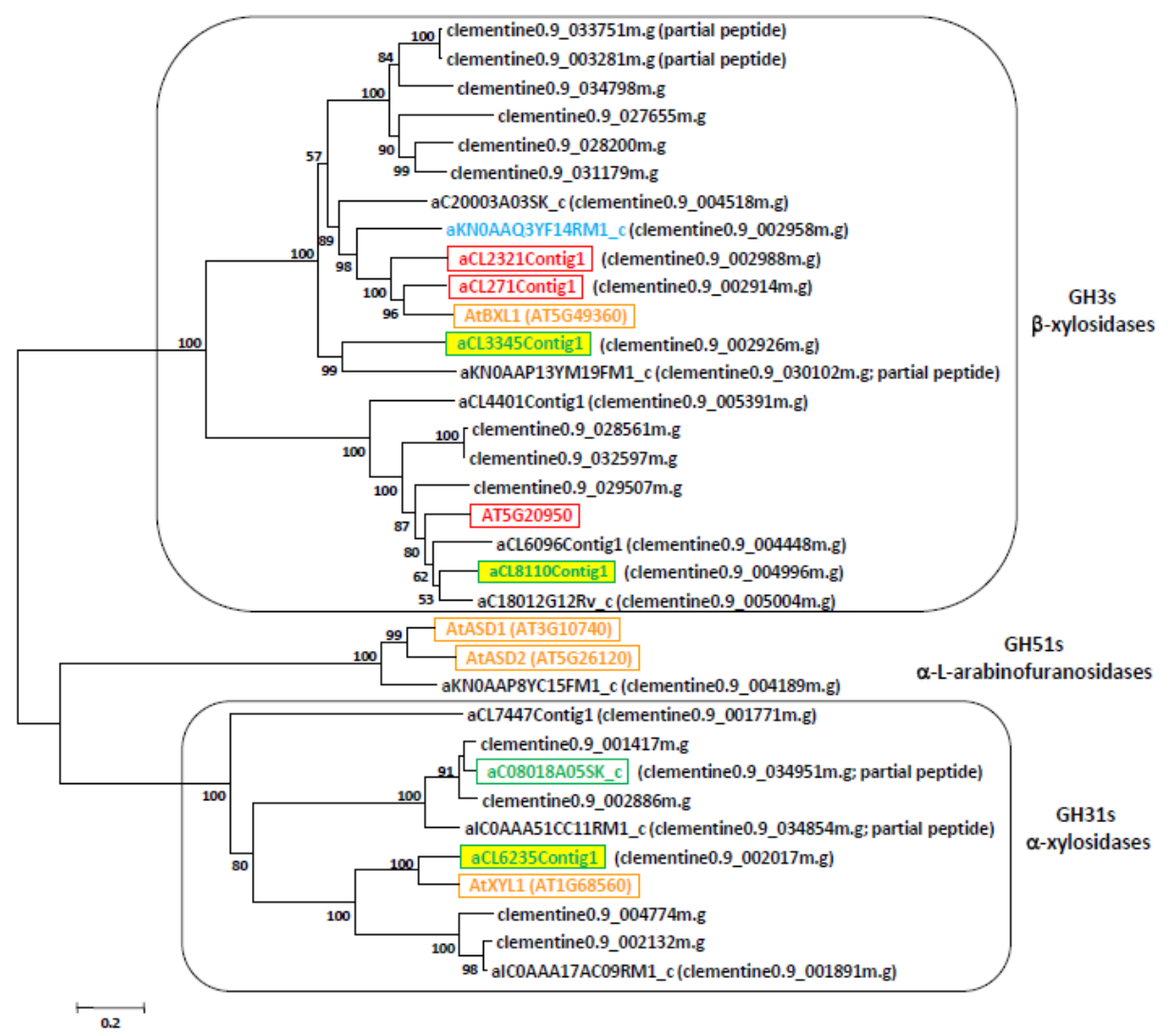

Figura 32. Relaciones filogenéticas entre las $\beta$-xilosidasas (GH3s), las $\alpha$-L-arabinofuranosidasas (GH51s) y las $\alpha$ xilosidasas (GH31s) localizadas en el genoma haploide de Citrus clementina, las reguladas por etileno en las células de la ZAC y/o en las células parenquimáticas de la corteza del fruto maduro del naranjo 'Washington Navel' y las descritas en la literatura como asociadas a la abscisión y con actividad $\beta$-glucuronidasa dirigida a las ZAs por su secuencia promotora específica en otras especies vegetales (ver Anexo 11). El árbol filogenético está basado en alineamientos múltiples (ClustalW; http://www.ch.embnet.org/software/ClustalW-XXL.html) y se generó utilizando el programa MEGA 4.0 mediante el método Neighbor-Joining (complete deletion, Poisson correction). El soporte Bootstrap para 1000 réplicas se muestra en las ramificaciones del árbol. Clave de colores de los identificadores de las proteínas alineadas: (Citrus), represión de la expresión por etileno exclusivamente en las células de la ZAC; (Citrus), inducción de la expresión por etileno en las células de la ZAC y en las células parenquimáticas de la corteza del fruto maduro del naranjo 'Washington Navel'; (XXXX), inducidas durante la activación de las ZAs en diferentes órganos de otras especies vegetales; (XXXX), con actividad $\beta$-glucuronidasa dirigida a las ZAs de los órganos florales por su secuencia promotora específica. 


\subsubsection{Xiloglucano transglicosilasas/hidrolasas (XTHs; familia 16 de glicósido}

hidrolasas)

La hemicelulosa xiloglucano se une a las microfibrillas paracristalinas de celulosa y, de esta manera, participa en la modulación de las propiedades mecánicas y en la morfología de la pared celular vegetal (Carpita y McCann, 2000). Una vez depositada en la pared celular, la estructura del xiloglucano puede ser modificada para generar cadenas de polisacáridos más largas o más cortas gracias a la acción de las xiloglucano transglicosilasas/hidrolasas (XTHs), enzimas pertenecientes a la familia 16 de las glicósido hidrolasas (CAZy; GH16; http://www.cazy.org/GH16.html; Rose et al. 2002). Las XTHs pueden presentar actividad xiloglucano endo-transglicosilasa (XET; EC 2.4.1.207) y/o xiloglucano endo-hidrolasa (XEH; EC 3.2.1.151).

La familia XTH de A. thaliana está compuesta por 33 genes cuyas proteínas han sido clasificadas en tres grupos o subfamilias, los Grupos I, II y III, en función de su estructura y organización genómica (Rose et al. 2002). En la versión v0.9 (6,5 equivalentes genómicos) del ensamblaje del genoma haploide de C. clementina se han localizado 36 ORFs (31 completas y 5 parciales) que potencialmente codifican proteínas XTH pues presentan un dominio Glyco-hydro_16 (PF00722) en su secuencia deducida de aminoácidos (ver Figura $\mathbf{S 1 9}$ del Anexo 8 y Anexo 12). El análisis filogenético de las familias XTH de $C$. clementina y A. thaliana (Figura $\mathbf{S 4}$ del Anexo 7) mostraba 9 proteínas de C. clementina y 11 proteínas de $A$. thaliana en el Grupo I, 18 proteínas de $C$. clementina y 14 proteínas de A. thaliana en el Grupo II y 9 proteínas de C. clementina y 7 proteínas de A. thaliana en el Grupo III. La estructura 3D de las XTHs es de tipo hoja plegada con dos asas (loop 1 y loop 2) flanqueando el sitio catalítico (Baumann et al., 2007). Las proteínas deducidas de los locus clementine0.9_017259m.g y clementine0.9_017408m.g, pertenecientes al Grupo III, mostraban una extensión en el número de aminoácidos que conforman los loops 1 y 2 en comparación con los otros miembros de la familia XTH de C. clementina (Figura S19 del Anexo 8). La enzima Tm-NXG1, aislada a partir de semillas de Tropaeolum majus, presenta casi exclusivamente actividad endo-hidrolasa (Fanutti et al., 1993) y muestra estas mismas características estructurales diferenciales. La eliminación de ciertos aminoácidos del loop 2 de Tm-NXG1 modifica la actividad catalítica aumentando enormemente la razón entre las actividades transglicosilasa/hidrolasa de la enzima (Baumann et al., 2007). Por 
tanto, es muy probable que las proteínas deducidas de los locus clementine0.9_017259m.g y clementine0.9_017408m.g catalicen mayoritariamente la hidrólisis de xiloglucanos. Excepto los locus clementine0.9_021549m.g y clementine0.9_031401m.g, todas las proteínas XTH deducidas presentaban también un dominio XET_C (PF06955) en su extremo carboxilo-terminal (ver Figura S19 del Anexo 8 y Anexo 12). El dominio XET_C participa en la relajación de la estructura de la pared celular ya que cataliza la rotura de las cadenas de xiloglucano y la unión de los extremos generados a los extremos de otras cadenas de xiloglucano. Las XTHs se localizan en el apoplasto y, con la excepción de las proteínas deducidas de los locus clementine0.9_029891m.g, clementine0.9_021549m.g y clementine0.9_029891m.g (y de las proteínas parciales deducidas de los locus clementine0.9_029942m.g, clementine0.9_029950m.g, clementine0.9_031115m.g, clementine0.9_031948m.g y clementine0.9_035008m.g), 28 proteínas deducidas de $C$. clementina presentaban un péptido señal en su extremo amino-terminal (Figura S19 del Anexo 8 y Anexo 12) que dirige su secreción al espacio extracelular (Yokoyama y Nishitani, 2001). Las proteínas XTH de C. clementina contenían la secuencia conservada DEIDFEFLG (Figura S19 del Anexo 8), un motivo que se considera que funciona como sitio catalítico tanto para la actividad transferasa como para la actividad hidrolasa (Okazawa et al., 1993, Campbell y Braam 1999). Las potenciales proteínas XTH de $C$. clementina eran de tamaño moderado, entre 32 y $42 \mathrm{kDa}$, excepto las proteínas deducidas de los locus clementine0.9_022941m.g y clementine0.9_021549m.g que presentaban un tamaño de 22 y $24 \mathrm{kDa}$, respectivamente (ver Anexo 12). La secuencia conservada DEIDFEFLG de la proteína deducida del locus clementine0.9_022941m.g es imperfecta (Figura S19 del Anexo 8) aunque contiene un dominio Glyco_hydro_16 estadísticamente significativo $($ E-value $=1,10 \mathrm{e}-10)$.

La micromatriz de cDNA utilizada en este trabajo contiene sondas para 15 XTHs de cítricos (ver Figura 33 y Anexo 12), por tanto, cubre únicamente un $42 \%$ de las posibles XTHs presentes en el genoma de los cítricos. Doce sondas de cDNA son homólogas a genes localizados en el genoma haploide de C. clementina mientras que tres sondas de cDNA representan genes nuevos o alelos específicos de otras especies de cítricos (ver Anexo 12). La Figura 33 muestra el análisis filogenético de las proteínas de la familia XTH de cítricos y de las proteínas deducidas de genes de soja (Tucker et al., 2007), A. thaliana (Lashbrook y Cai, 2008), plátano (Mbéguié-A-Mbéguié et al., 2009) y tomate 
(Meir et al., 2010) asociados a la abscisión. Excepto para el caso del gen MaXET2 de plátano, las XTHs del Grupo I (AtXTH4, AtXTH6 y AtXTH7 de A. thaliana y aC02023G10SK_c, aCL6772Contig1 y aCL6641Contig1 de cítricos) se reprimen, mientras que las XTHs de los grupos II (AtXTH12 y AtXTH19 de A. thaliana, GmXET01 y GmXET02 de soja, MaXET1, MaXTH8 y MaXTH9 de plátano y XET-BRI de tomate) y III (aIC0AAA99CH05RM1_c de cítricos, AtXTH28 de A. thaliana y MaXTH6 de plátano) se inducen durante el proceso de abscisión. El tratamiento con etileno de frutos maduros inducía la expresión de la XTH del Grupo III aIC0AAA99CH05RM1_c (clementine0.9_013592m.g) exclusivamente en la ZAC durante las primeras 24 horas de tratamiento. Este gen estaba estrechamente relacionado con el gen MaXTH6 de plátano, inducido por el desarrollo en la zona de separación del fruto (Mbéguié-A-Mbéguié et al., 2009). Además, el etileno reprimía la expresión de tres genes del grupo I, aC02023G10SK_c (clementine0.9_017493m.g), aCL6772Contig1 (clementine0.9_017721m.g) y aCL6641Contig1 (clementine0.9_016046m.g) en la ZAC. Estos genes estaban estrechamente relacionados con los tres genes de A. thaliana que se reprimen en las células de la ZA de los estambres (Lashbrook y Cai, 2008). La represión de aC02023G10SK_c (clementine0.9_017493m.g) y de aCL6772Contig1 (clementine0.9_017721m.g) se producía exclusivamente en la ZAC, mientras que en el caso de aCL6641Contig1 (clementine0.9_016046m.g) la expresión se reprimía a las 12 horas de tratamiento en la ZAC y se inducía en la CF en el mismo periodo de tiempo. Por otra parte, el etileno inducía la expresión de dos XTHs del Grupo II, aC05133F09SK_c (clementine0.9_017816m.g) a las 12 horas de tratamiento y aCL107Contig2 a las 24 horas de tratamiento, exclusivamente en la CF. 


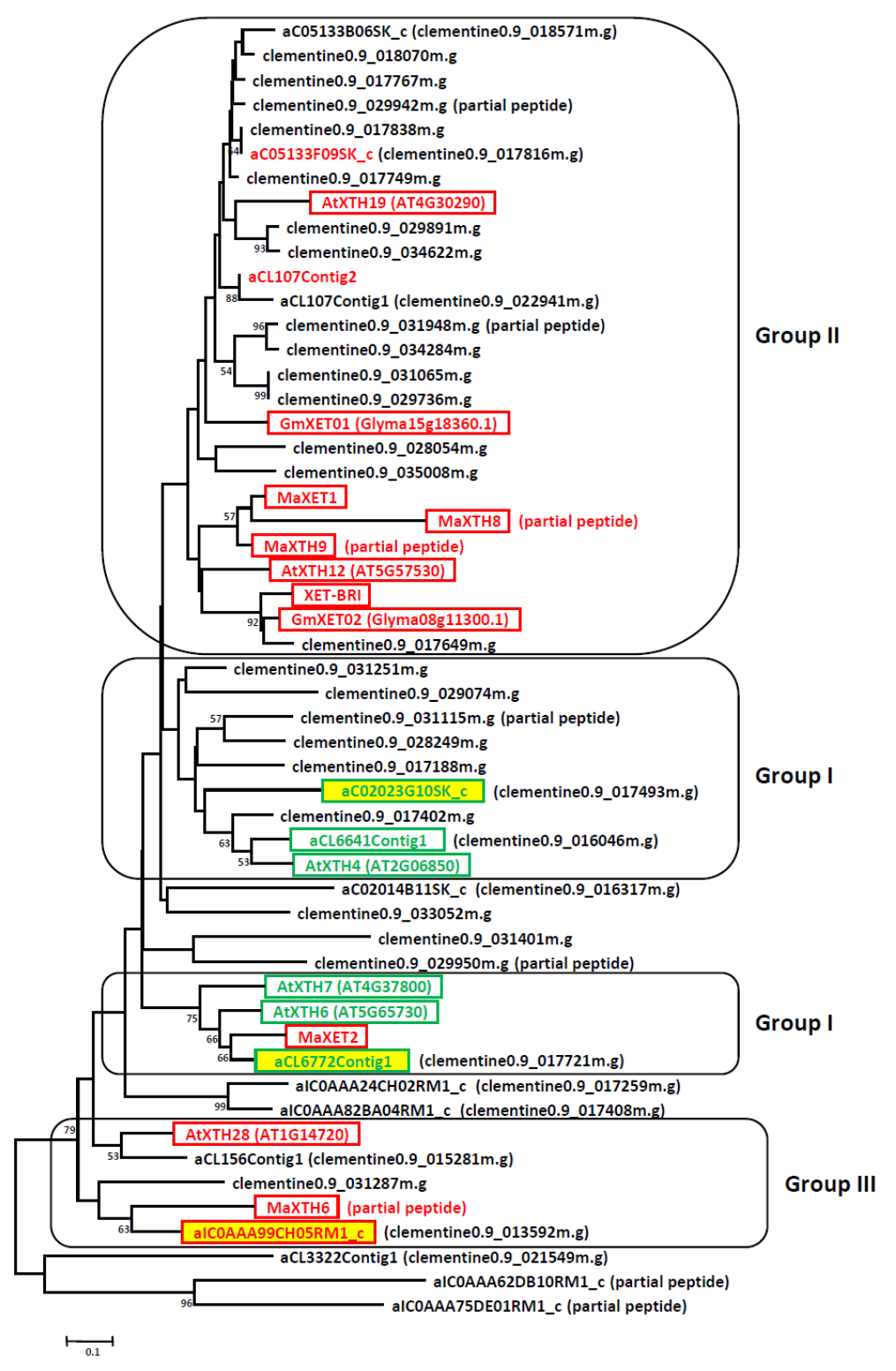

Figura 33. Relaciones filogenéticas entre las xiloglucano transglicosilasas/hidrolasas (GH16s) localizadas en el genoma haploide de Citrus clementina, las reguladas por etileno en las células de la ZAC y/o en las células parenquimáticas de la corteza del fruto maduro del naranjo 'Washington Navel' y las descritas en la literatura como asociadas a la abscisión (ver Anexo 12). El árbol filogenético está basado en alineamientos múltiples (ClustalW; http://www.ch.embnet.org/software/ClustalW-XXL.html) y se generó utilizando el programa MEGA 4.0 mediante el método Neighbor-Joining (complete deletion, Poisson correction). El soporte Bootstrap para 1000 réplicas se muestra en las ramificaciones del árbol. Clave de colores de los identificadores de las proteínas alineadas: (Citrus), inducción de la expresión por etileno exclusivamente en las células de la ZAC; (Citrus), represión de la expresión por etileno exclusivamente en las células de la ZAC; (Citrus), represión de la expresión por etileno en las células de la ZAC e inducción en las células parenquimáticas de la corteza del fruto; (Citrus), inducción de la expresión por etileno exclusivamente en las células parenquimáticas de la corteza del fruto; (XXXX), inducido durante la activación de las ZAs en diferentes órganos de otras especies vegetales; (XXXX), reprimido durante la activación de las ZAs en diferentes órganos de otras especies vegetales. 


\subsubsection{5. $\beta$-galactosidasas ( $\beta$-GALs; familias 2 y 35 de glicósido hidrolasas)}

Las $\beta$-galactosidasas ( $\beta$-GALs; EC 3.2.1.23) son enzimas de degradación de la pared celular que hidrolizan los residuos terminales no reducidos $\beta$-D-galactosilo de polímeros $\beta$ D-galactósido (Smith et al., 1998). Las enzimas $\beta$-GAL están implicadas en la liberación de energía almacenada necesaria para el crecimiento rápido, en la degradación de componentes de la pared celular durante la senescencia y en la liberación de galactosa durante el reciclaje metabólico de los galactolípidos, las glicoproteínas y los componentes de la pared celular (Wu y Burns, 2004). Las $\beta$-GALs pertenecen a las familias 35 o 2 de las glicósido hidrolasas (GH35; GH2; CAZy; http://www.cazy.org/fam/; Henrissat, 1991). La familia GH35 agrupa exclusivamente enzimas con actividad $\beta$-GAL, mientras que la familia GH2, además de $\beta$-GALs, agrupa enzimas con actividad $\beta$-manosidasa (EC 3.2.1.25) y $\beta$-glucuronidasa (EC 3.2.1.31). Las proteínas $\beta$-GAL de la familia GH35 contienen en su secuencia de aminoácidos un péptido señal, el dominio catalítico Glyco_hydro_35 (PF01301) y el dominio Gal_Lectin (PF02140), que se une a los Dgalactósidos. Las proteínas $\beta$-GAL de la familia GH2 están formadas por el dominio Glyco_hydro_2_N (PF02837), un péptido señal, el dominio Glyco_hydro_2 (PF00703), el dominio Glyco_hydro_2_C (PF02836) y el dominio ßgal_small_N (PF02929). El dominio Bgal_small_N se localiza en el extremo carboxilo-terminal y contiene un loop N-terminal que se inclina hacia el sitio activo cuando se une al ligando para producir una conformación cerrada.

El genoma de $A$. thaliana contiene 17 locus que codifican proteínas $\beta$-GAL de la familia GH35 y 2 locus que codifican $\beta$-GALs de la familia GH2 (ver Figura S5 del Anexo 7). En la versión v0.9 (6,5 equivalentes genómicos) del ensamblaje del genoma haploide de C. clementina se han localizado 23 ORFs (21 completas y 2 parciales) que potencialmente codifican $\beta$-GALs de la familia GH35, ya que presentan el dominio Glyco-hydro_35 en su secuencia deducida de aminoácidos, y 2 ORFs que codifican $\beta$-GALs de la familia GH2, pues presentan el dominio Glyco-hydro_2 en su secuencia deducida de aminoácidos (ver Figuras S20 y S21 del Anexo 8 y Anexo 13). En relación a las $\beta$-GALs de la familia GH35, todas las proteínas contenían un péptido señal, excepto las proteínas correspondientes a los locus clementine0.9_002546, clementine0.9_033922m.g y clementine0.9_031976, y el dominio Gal_Lectin, excepto las proteínas correspondientes a 
los locus clementine0.9_003023, clementine0.9_003301, clementine0.9_003390, clementine0.9_003540, clementine0.9_004407, clementine0.9_029867 (secuencia parcial), clementine0.9_030842 (secuencia parcial) y clementine0.9_031976 (ver Figuras S20 y S21 del Anexo 8 y Anexo 13). Por otra parte, atendiendo a la familia GH2, la proteína deducida del locus clementine0.9_002920m.g no contenía los dominios Glyco_hydro_2_N y Glyco_hydro_2, la proteína deducida del locus clementine0.9_001409m.g no contenía el

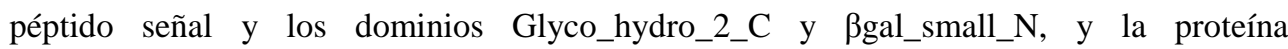
correspondiente al gen representado en la micromatriz aCL4443Contig1 carecía de péptido señal (ver Figuras S20 y S21 del Anexo 8 y Anexo 13).

La micromatriz de cDNA utilizada en este trabajo contiene sondas de $9 \beta$-GALs de cítricos (ver Figura 34 y Anexo 13), por tanto, cubre únicamente un 39\% de las posibles $\beta$ GALs presentes en el genoma de los cítricos. Siete sondas de cDNA son homólogas a genes localizados en el genoma haploide de C. clementina, mientras que dos sondas de cDNA (aCL4443Contig1 y aKN0AAP2YD24FM1_c) representan genes nuevos o alelos específicos de otras especies de cítricos (ver Anexo 13). La Figura 34 muestra el análisis filogenético de las $\beta$-GALs de las familia GH35 y GH2 de cítricos y de las proteínas deducidas de genes de A. thaliana (Lashbrook y Cai, 2008) relacionados con el proceso de abscisión. Dentro de la familia GH35, el gen aCL1378Contig1 (clementine0.9_003023m.g), homólogo al gen CsßGAL inducido durante la abscisión de hojas y frutos cítricos (Wu y Burns, 2004), se inducía exclusivamente en la CF tras 24 h de tratamiento, mientras que en la ZAC no experimentaba un cambio de expresión significativo. El gen aCL1378Contig1 (clementine0.9_003023m.g) se encontraba, además, próximo al gen aC01015E12SK_c (clementine0.9_002261m.g), reprimido en la ZAC tras 12 y $24 \mathrm{~h}$ de tratamiento con etileno e inducido en la CF tras $24 \mathrm{~h}$ de tratamiento, y al gen aC31805H10EF_c (clementine0.9_002229m.g), reprimido exclusivamente en la ZAC tras $12 \mathrm{~h}$ de tratamiento con etileno. En una rama próxima a este grupo de genes de cítricos se encontraba el gen AT5G56870 de A. thaliana, que se inducía durante la abscisión de los estambres (Lashbrook y Cai, 2008). Finalmente, en una rama más alejada se encontraba el gen de cítricos aCL4443Contig1 correspondiente a la familia GH2 de $\beta$-GALs que se inducía exclusivamente en la ZAC tras 12 y $24 \mathrm{~h}$ de tratamiento con etileno. 


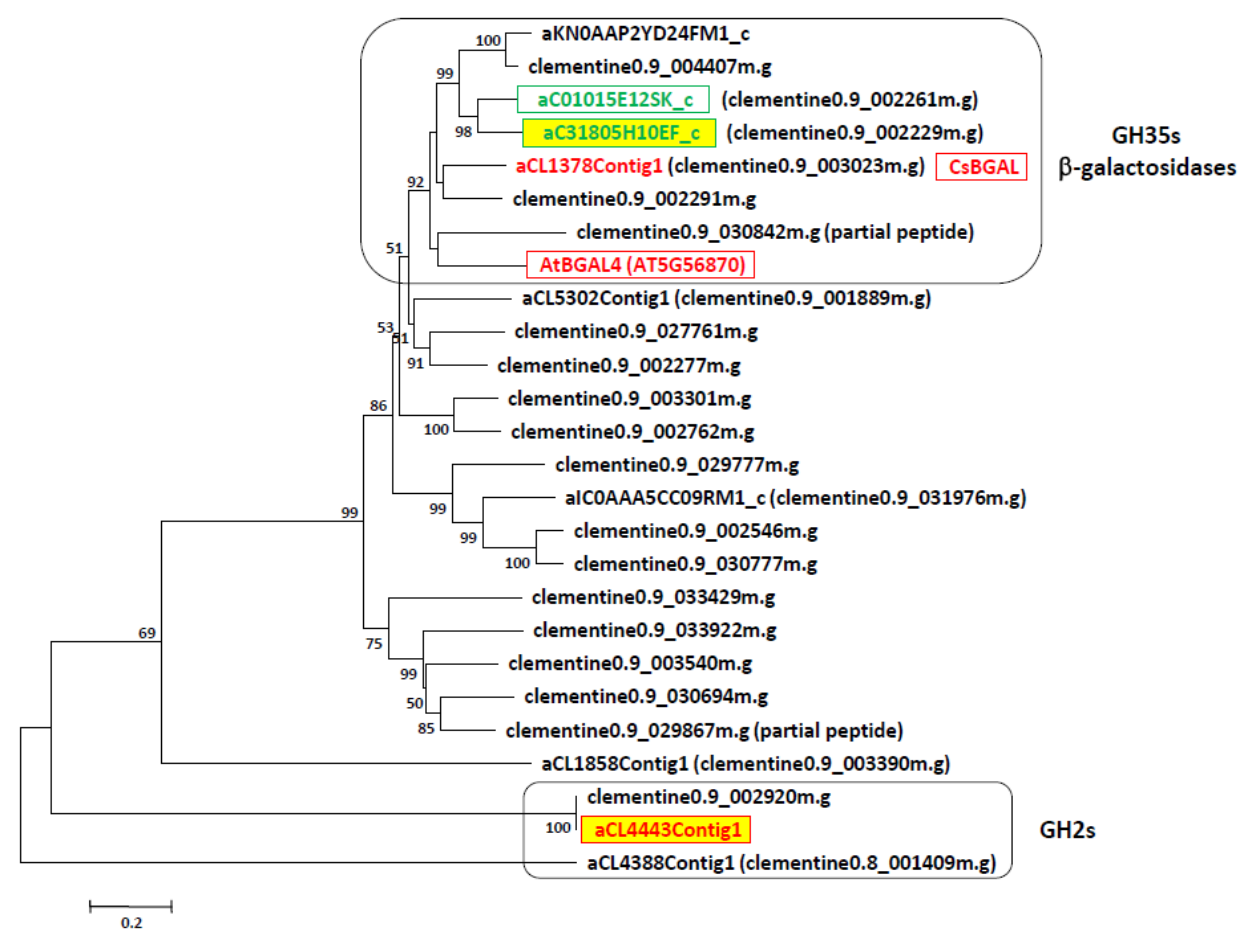

Figura 34. Relaciones filogenéticas entre las $\beta$-galactosidasas (GH35s) y las GH2s localizadas en el genoma haploide de Citrus clementina, las reguladas por etileno en las células de la ZAC y en las células parenquimáticas de la corteza del fruto maduro del naranjo 'Washington Navel' y las descritas en la literatura como asociadas a la abscisión en otras especies vegetales (ver Anexo 13). El árbol filogenético está basado en alineamientos múltiples (ClustalW; http://www.ch.embnet.org/software/ClustalW-XXL.html) y se generó utilizando el programa MEGA 4.0 mediante el método Neighbor-Joining (complete deletion, Poisson correction). El soporte Bootstrap para 1000 réplicas se muestra en las ramificaciones del árbol (solamente se muestran los valores superiores al 50\%). Clave de colores de los identificadores de las proteínas alineadas: (Citrus), inducción de la expresión por etileno exclusivamente en las células de la ZAC; (Citrus), represión de la expresión por etileno exclusivamente en las células de la ZAC; (Citrus), represión de la expresión por etileno en las células de la ZAC y en las células parenquimáticas de la corteza del fruto maduro del naranjo 'Washington Navel'; (XXXX), inducida durante la activación de las ZAs en diferentes órganos de otras especies vegetales. 


\subsubsection{Pectin metilesterasas (PMEs; familia 8 de carbohidrato esterasas)}

Las pectin metilesterasas (PMEs; EC 3.1.1.11) pertenecen a la familia 8 de las carbohidrato esterasas (CE8; CAZy; http://www.cazy.org/fam/CE8.html; Coutinho et al., 2003) y catalizan la eliminación específica de grupos metilo esterificados en los HGAs de la pared celular vegetal liberando metanol y protones y creando grupos carboxilo cargados negativamente. Los HGAs desmetilesterificados pueden, de esta manera, crear enlaces con iones calcio $\left(\mathrm{Ca}^{2+}\right)$ y formar geles o ser dianas de enzimas que degradan pectinas como las poligalacturonasas, afectando tanto a la textura como a la rigidez de la pared celular. Dado que la activación de la abscisión está acompañada de una disminución en el nivel de calcio en las ZAs (Poovaiah y Rasmussen, 1973), la formación de enlaces HGAs-Ca ${ }^{2+}$ debe ser escasa y, sin embargo, muy alta la posibilidad de que en estas condiciones actúen sobre los HGAs enzimas degradadoras de pectinas.

Las PMEs vegetales son pre-proteínas en las que la parte madura o activa (el dominio PME; Pectinesterase; PF01095) está precedida por una extensión amino-terminal, la región PRO, de longitud variable y bajo porcentaje de identidad de aminoácidos entre las distintas isoformas. La región PRO es similar al dominio PMEI (PF04043; Plant invertase/pectin methylesterase inhibitor; Pelloux et al., 2007). En función de la presencia o no de dominios PMEI, las PMEs se clasifican en dos grupos: PMEs del grupo 1 (o de tipo II), sin dominios PMEI, y PMEs del grupo 2 (o de tipo I), con dominios PMEI y un motivo de procesamiento (PM) para proteasas de tipo subtilisina RRLL/RKLL (Micheli, 2001). Las PMEs conforman, en las plantas dicotiledóneas, grandes familias multigénicas como, por ejemplo, la de A. thaliana con 66 miembros, de los cuales 18 pertenecen al grupo 1 y 48 al grupo 2 (Figura S6 del Anexo 7). En el genoma haploide de C. clementina se han localizado 52 ORFs (43 completas y 9 parciales) que codifican posibles PMEs ya que presentan el dominio PME en su secuencia de aminoácidos (ver Figuras S22 y $\mathbf{S 2 3}$ del Anexo 8 y Anexo 14). Del total de proteínas PME de C. clementina, 20 proteínas pertenecían al grupo 1 y 32 proteínas al grupo 2. Excepto los locus clementine0.9_028492m.g y clementine0.9_035129m.g, que al tratarse de secuencias parciales carecían de los dominios PMEI y RRLL, y los locus clementine0.9_031690m.g, clementine0.9_033611m.g, clementine0.9_031088m.g, clementine0.9_005730m.g y clementine0.9_006156m.g, que no contenían el dominio RRLL, todas las proteínas PME del grupo 2 deducidas presentaban 
los dos dominios característicos (ver Figura S23 del Anexo 8 y Anexo 14). Por otra parte, las PMEs pueden contener un péptido señal en su extremo amino-terminal que las etiqueta para ser exportadas a la pared celular o al espacio extracelular. Tal y como se puede observar en las Figuras S22 y S23 del Anexo 8, 19 proteínas deducidas (7 parciales) de $C$. clementina no presentaban péptido señal (ver también Anexo 14), aunque 7 de estas proteínas presentaban dominio transmembrana. Las PMEs sin péptido señal ni dominio transmembrana podrían catalogarse como posibles isoformas solubles (Pelloux et al., 2007). La comparación de las secuencias de aminoácidos de los dominios PME de diferentes PMEs muestra que contienen cinco secuencias características (GxYxE, QAVAL, QDTL, DFIFG y LGRPW), seis residuos de aminoácidos estrictamente conservados y siete residuos de aminoácidos aromáticos muy conservados que se consideran fundamentales a nivel funcional (Markovic y Janecek, 2004).

La micromatriz de cDNA empleada en este estudio contiene 2 PMEs del grupo 1 y 15 PMEs del grupo 2 (ver Figura 35 y Anexo 14), por tanto, cubre un 33\% de las posibles PMEs presentes en el genoma de los cítricos. La Figura 35 muestra el análisis filogenético de las proteínas de la familia PME de C. clementina y de las proteínas PME deducidas de $A$. thaliana (Lashbrook y Cai, 2008) y plátano (Mbéguié-A-Mbéguié et al., 2009) relacionadas con el proceso de abscisión. El tratamiento con etileno de frutos cítricos inducía la expresión de la PME del grupo 1 aCL1451Contig1 (clementine0.9_013443m.g) exclusivamente en la ZAC tras 12 y $24 \mathrm{~h}$ de tratamiento (ver Anexo 14). Contrariamente, la única PME del grupo 1 de A. thaliana (AT5G19730) estudiada en relación al proceso de abscisión, se reprime en la ZA de los estambres (Lashbrook y Cai, 2008). En relación al grupo 2 de PMEs, los genes aC05807A09SK_c (clementine0.9_007349m.g), aCL1691Contig1 (clementine0.9_006470m.g) y aCL4116Contig2 (clementine0.9_005431m.g), que se reprimían exclusivamente en la ZAC tras 12 y 24 h de tratamiento con etileno, se encontraban estrechamente relacionados con los genes AT3G43270, AT1G11580 y AT3G49220, respectivamente, que se reprimen en las células de la ZA de los estambres de A. thaliana (Lashbrook y Cai, 2008). Por otra parte, el etileno inducía la expresión de la PME del grupo 2 aCL2379Contig1 (clementine0.9_006156m.g) exclusivamente en la ZAC tras $24 \mathrm{~h}$ de tratamiento. Este gen se encontraba alejado filogenéticamente del resto de genes correspondientes a proteínas PME del grupo 2 
inducidos durante la abscisión en A. thaliana y plátano (Lashbrook y Cai, 2008; MbéguiéA-Mbéguié et al., 2009). 


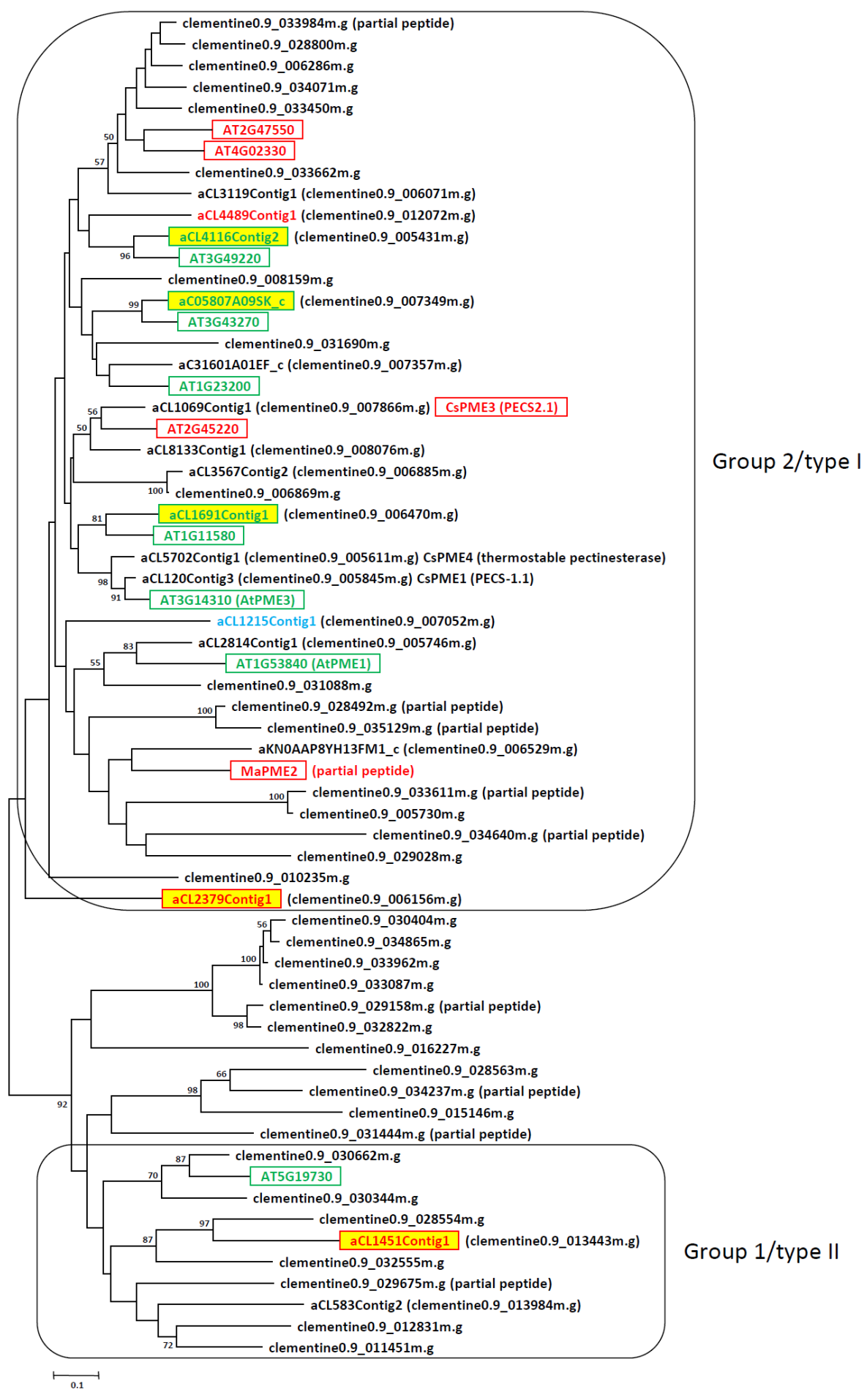


Figura 35 (página anterior). Relaciones filogenéticas entre las pectin metilesterasas (CE8s) localizadas en el genoma haploide de Citrus clementina, las reguladas por etileno en las células de la ZAC y/o en las células parenquimáticas de la corteza del fruto maduro del naranjo 'Washington Navel' y las descritas en la literatura como asociadas a la abscisión en otras especies vegetales (ver Anexo 14). El árbol filogenético está basado en alineamientos múltiples (ClustalW; http://www.ch.embnet.org/software/ClustalW-XXL.html) y se generó utilizando el programa MEGA 4.0 mediante el método Neighbor-Joining (complete deletion, Poisson correction). El soporte Bootstrap para 1000 réplicas se muestra en las ramificaciones del árbol (solamente se muestran los valores superiores al 50\%). Clave de colores de los identificadores de las proteínas alineadas: (Citrus), inducción de la expresión por etileno exclusivamente en las células de la ZAC; (Citrus), represión de la expresión por etileno exclusivamente en las células de la ZAC; (Citrus), inducción de la expresión por etileno en las células parenquimáticas de la corteza del fruto; (Citrus), presente en la micromatriz de cítricos de $20 \mathrm{~K}$ (Martínez-Godoy et al., 2008) pero sin resultados de la hibridación; (XXXX), inducido durante la activación de las ZAs en diferentes órganos de otras especies vegetales; (XXXX), reprimido durante la activación de las ZAs en diferentes órganos de otras especies vegetales. 


\subsubsection{Pectin acetilesterasas (PAEs; familia 13 de carbohidrato esterasas)}

Las pectinas están formadas por polímeros de ácido D-galacturónico unidos mediante enlaces $\alpha-(1 \rightarrow 4)$ que intercalan residuos de ácido metilgalacturónico, los cuales, alternativamente, pueden ser esterificados por grupos acetilo. El grado de acetilación modula las propiedades de las moléculas de pectina y contribuye a la complejidad estructural de la red de pectinas (Mc Neil et al. 1984). Las pectin acetilesterasas (PAEs; E.C 3.1.1.-.) pertenecen a la familia 13 de las carbohidrato esterasas (CE13; CAZy; http://www.cazy.org/fam/CE13.html) y catalizan la eliminación de grupos acetilo de las pectinas esterificadas. La desacetilación de las pectinas, que disminuye la hidrofobicidad del esqueleto de las pectinas, incrementa su solubilidad en el agua (Dea and Madden 1986). La eliminación de los acetil-ésteres hace a las pectinas más accesibles a las enzimas hidrolíticas de pectinas, como las pectato liasas (Vercauteren et al., 2002).

El genoma de A. thaliana contiene 12 locus que codifican proteínas PAE (ver Figura S7 del Anexo 7). En la versión v0.9 (6,5 equivalentes genómicos) del ensamblaje del genoma haploide de $C$. clementina se han localizado 8 ORFs (una de ellas de secuencia parcial) que potencialmente codifican PAEs, ya que presentan el dominio PAE (PF03283) en su secuencia deducida de aminoácidos (ver Figura S24 del Anexo 8 y Anexo 15). Como se puede observar en la Figura S24 del Anexo 8, todas las proteínas PAE deducidas presentaban un péptido señal en el extremo amino-terminal de su secuencia y excepto la proteínas correspondientes al locus clementine0.9_034885m.g, cuya secuencia era parcial, y al locus clementine0.9_017250m.g, que presentaba una deleción en el extremo carboxiloterminal del dominio PAE, todas presentaban el dominio PAE completo y altamente conservado.

La micromatriz de cDNA utilizada en este estudio contiene sondas de 6 PAEs de cítricos (ver Figura 36 y Anexo 15), por tanto, cubre un 75\% de las posibles PAEs presentes en el genoma de los cítricos. La Figura 36 muestra el análisis filogenético de las PAEs de las familia CE13 de C. clementina y de las proteínas deducidas de genes de A. thaliana (Lashbrook y Cai, 2008) relacionados con el proceso de abscisión. Los genes aCL7344Contig1 (clementine0.9_011126m.g) y aKN0AAP13YN19FM1_c (clementine0.9_011652m.g), que se reprimían exclusivamente en la ZAC tras $12 \mathrm{~h}$ de 
tratamiento con etileno, estaban estrechamente relacionados con los genes AT3G05910 y AT2G46930, respectivamente, que también se reprimen durante la abscisión de los estambres en $A$. thaliana (Lashbrook y Cai, 2008). Por otra parte, el unigen aCL67Contig4 (clementine0.9_012430m.g), que se inducía en la ZAC tras 12 y 24 h de tratamiento con etileno y se reprimía en la CF tras 12 h de tratamiento, no mostraba homología con otras PAEs relacionadas anteriormente con el proceso.

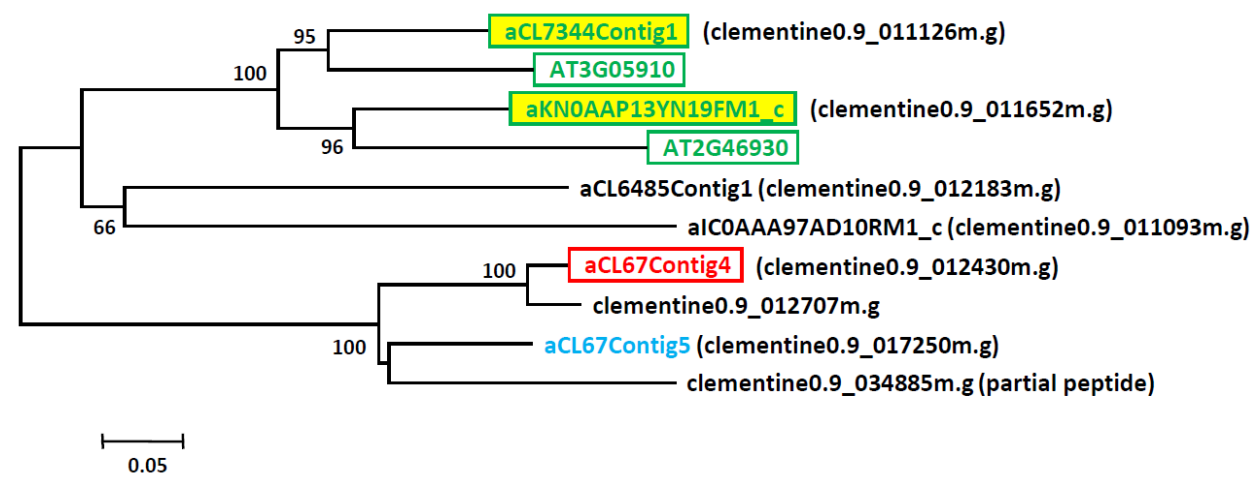

Figura 36. Relaciones filogenéticas entre las pectin acetilesterasas (CE13s) localizadas en el genoma haploide de Citrus clementina, las reguladas por etileno en las células de la ZAC y/o en las células parenquimáticas de la corteza del fruto maduro del naranjo 'Washington Navel' y las descritas en la literatura como asociadas a la abscisión en otras especies vegetales (ver Anexo 15). El árbol filogenético está basado en alineamientos múltiples (ClustalW; http://www.ch.embnet.org/software/ClustalW-XXL.html) y se generó utilizando el programa MEGA 4.0 mediante el método Neighbor-Joining (complete deletion, Poisson correction). El soporte Bootstrap para 1000 réplicas se muestra en las ramificaciones del árbol (solamente se muestran los valores superiores al $50 \%$ ). Clave de colores de los identificadores de las proteínas alineadas: (Citrus), represión de la expresión por etileno exclusivamente en las células de la ZAC; (Citrus), inducción de la expresión por etileno en las células de la ZAC y represión en las células parenquimáticas de la corteza del fruto; (Citrus), presente en la micromatriz de cítricos de $20 \mathrm{~K}$ (Martínez-Godoy et al., 2008) pero sin resultados de la hibridación; (XXXX), reprimido durante la activación de las ZAs en diferentes órganos de otras especies vegetales. 


\subsubsection{Pectato liasas (PLs; familia 1 de polisacárido liasas)}

Las pectato liasas (PLs; EC 4.2.2.2) catalizan la hidrólisis de la unión $\alpha-(1 \rightarrow 4)$ de los polímeros de ácido galacturónico que componen las pectinas (Sun y van Nocker, 2010) y, por tanto, participan en la despolimerización de las pectinas. La acción de las PLs no conlleva solamente la degradación de la pared celular sino también la activación de sistemas de defensa, supuestamente mediante la liberación de oligogalacturónidos desde la pared celular, los cuales actúan como elicitores de defensa (De Lorenzo et al., 1991). Las proteínas PL pertenecen a la familia 1 de polisacárido liasas (PL1; CAZy; http://www.cazy.org/fam/PL1.html) y pueden contener en su secuencia de aminoácidos un péptido señal o un dominio transmembrana, un dominio Pec_lyase_N (PF04431) y un dominio Pec_lyase_C (PF00544).

En base al análisis filogenético de sus secuencias de aminoácidos, las PLs de plantas se dividen en 5 grupos diferentes (grupos I, II, III, IV y V; Sun y van Nocker, 2010). Las PLs de los grupos I y III contienen un péptido señal o un dominio transmembrana y el dominio Pec_lyase_C, las PLs del grupo II contienen un péptido señal o un dominio transmembrana, el dominio Pec_lyase_N y el dominio Pec_lyase_C, y las PLs de los grupos IV y V contienen solamente el dominio Pec_lyase_C.

La familia PL1 de A. thaliana está formada por 25 proteínas, de las cuales 15 proteínas pertenecen al grupo I, 4 proteínas al grupo II, 4 proteínas al grupo III, 2 proteínas al grupo IV y una proteína al grupo V (ver Figura S8 del Anexo 7). En la versión v0.9 (6,5 equivalentes genómicos) del ensamblaje del genoma haploide de C. clementina se han localizado 19 ORFs que potencialmente codifican proteínas de la familia PL1, de las cuales 9 proteínas pertenecen al grupo I, 6 proteínas al grupo II, 2 proteínas al grupo III, una proteína al grupo IV y 2 proteínas al grupo V (ver Figura S8 del Anexo 7). Todas las PLs de cítricos contenían los dominios característicos de cada uno de los grupos en los que se divide la familia PL1 excepto la proteína correspondiente al locus clementine0.9_029857m.g que, a pesar de tener homología con las proteínas del grupo IV, contenía un péptido señal (ver Figura S25 del Anexo 8 y Anexo 16). Por otra parte, la PL deducida del locus clementine0.9_009058m.g contenía un péptido señal y un dominio transmembrana en su secuencia. 
La micromatriz de cDNA empleada en este trabajo contenía sondas correspondientes a 11 PLs de cítricos (ver Figura 37 y Anexo 16), por tanto, cubre un 58\% de las posibles PLs presentes en el genoma de los cítricos. La Figura 37 muestra el análisis filogenético de las proteínas de la familia PL de C. clementina y de las proteínas deducidas de genes de $A$. thaliana (Lashbrook y Cai, 2008), soja (Tucker et al., 2007), plátano (Mbéguié-A-Mbéguié et al., 2009) y rosa (Singh et al., 2011) asociados al proceso de abscisión. Como se observa en la Figura 37, todas las PLs relacionadas con la abscisión quedaban englobadas en los grupos I y V. En relación al grupo I, el gen aIC0AAA15AF11RM1_c (clementine0.9_011921m.g), que se inducía exclusivamente en la ZAC tras $24 \mathrm{~h}$ de tratamiento con etileno, se encontraba en la misma rama que dos PLs inducidas durante la abscisión foliar en soja (GmPL01 y GmPL02; Tucker et al., 2007), dos PLs inducidas en la zona de abscisión de los estambres de A. thaliana (AtPLL18 y AtPLL19; Lashbrook y Cai, 2008) y una PL inducida en la zona de separación del plátano (MaPEL1; Mbéguié-AMbéguié et al., 2009). En esta misma rama se encontraba también el gen de cítricos aCL2128Contig1 (clementine0.9_012004m.g), que se reprimía exclusivamente en la CF tras $12 \mathrm{~h}$ de tratamiento con etileno. Por otra parte, el gen aCL4999Contig1 (clementine0.9_007883m.g), que se inducía en la ZAC tras 24 h de tratamiento con etileno y en la CF tras 12 y 24 h de tratamiento, quedó agrupado en la misma rama que una PL inducida en la zona de separación del plátano (MaPEL2; Mbéguié-A-Mbéguié et al., 2009) , una PL inducida en la ZA de los pétalos de rosa (Singh et al., 2011), 2 PLs inducidas durante la abscisión de estambres en A. thaliana (AtPLL23 y AtPLL25; Lashbrook y Cai, 2008) y 2 PLs reprimidas durante la abscisión de estambres en A. thaliana (AtPLL20 y AtPLL21; Lashbrook y Cai, 2008). Próximo a este grupo se encontraba el gen aC03011D06SK_c (clementine0.9_012496m.g), que se reprimía exclusivamente en la ZAC a las 12 y $24 \mathrm{~h}$ de tratamiento con etileno. Por último, el único gen correspondiente a una PL del grupo V relacionado con la abscisión se reprimía en la ZA de los estambres en $A$. thaliana (AtPLL2; Lashbrook y Cai, 2008). 


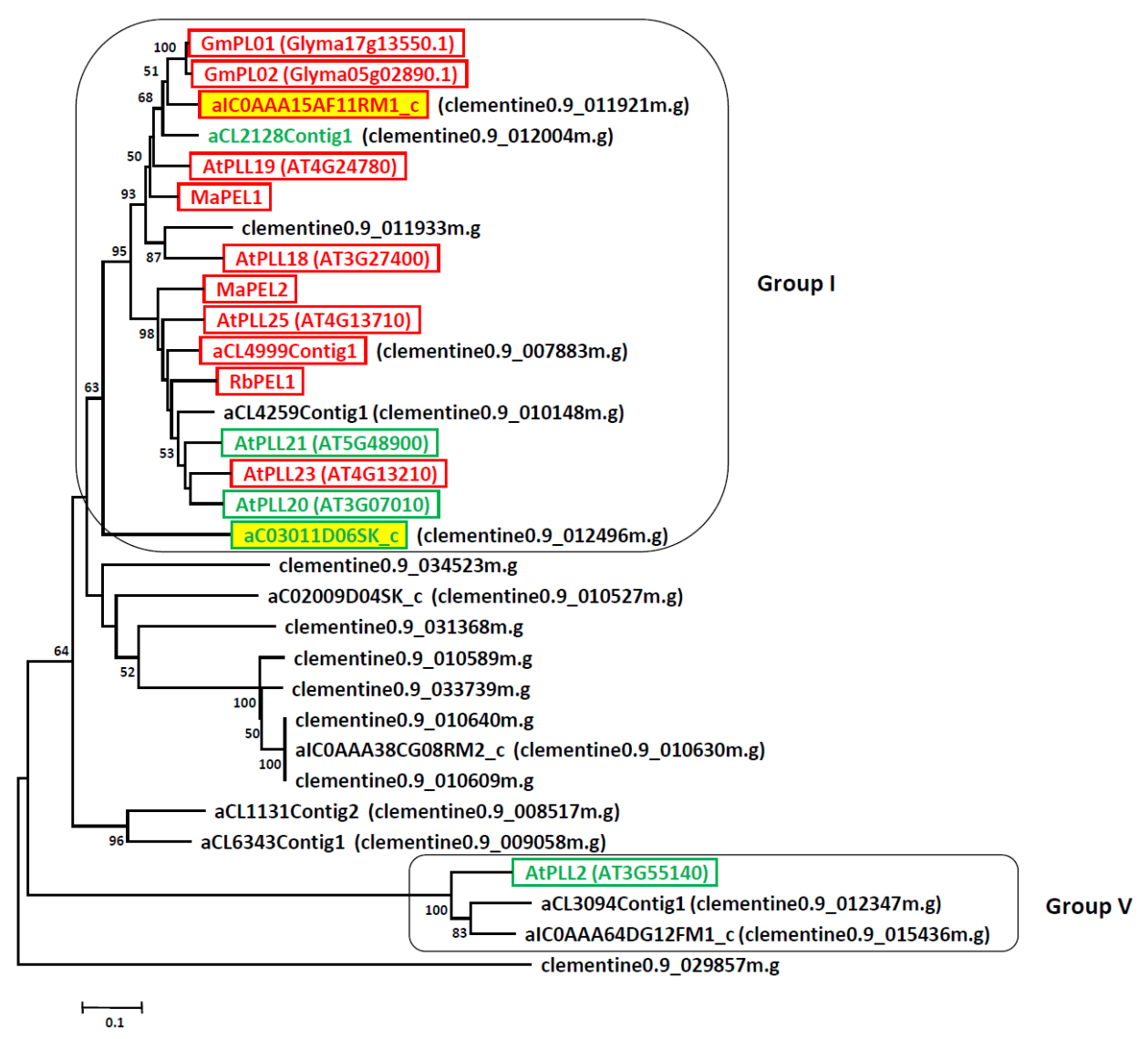

Figura 37. Relaciones filogenéticas entre las pectato liasas (PL1s) localizadas en el genoma haploide de Citrus clementina, las reguladas por etileno en las células de la ZAC y/o en las células parenquimáticas de la corteza del fruto maduro del naranjo 'Washington Navel' y las descritas en la literatura como asociadas a la abscisión en otras especies vegetales (ver Anexo 16). El árbol filogenético está basado en alineamientos múltiples (ClustalW; http://www.ch.embnet.org/software/ClustalW-XXL.html) y se generó utilizando el programa MEGA 4.0 mediante el método Neighbor-Joining (complete deletion, Poisson correction). El soporte Bootstrap para 1000 réplicas se muestra en las ramificaciones del árbol (solamente se muestran los valores superiores al 50\%). Clave de colores de los identificadores de las proteínas alineadas: (Citrus), inducción de la expresión por etileno exclusivamente en las células de la ZAC; (Citrus), represión de la expresión por etileno exclusivamente en las células de la ZAC; (Citrus), inducción de la expresión por etileno en las células de la ZAC y en las células parenquimáticas de la corteza del fruto; (Citrus), represión de la expresión por etileno en las células parenquimáticas de la corteza del fruto; (XXXX), inducido durante la activación de las ZAs en diferentes órganos de otras especies vegetales; $(\mathrm{XXXX)}$, reprimido durante la activación de las ZAs en diferentes órganos de otras especies vegetales. 


\subsubsection{Expansinas}

Las expansinas (EXPs) son proteínas de entre 250-275 aminoácidos que presentan un péptido señal en su extremo amino-terminal y dos dominios conservados (dominios I y II; Sampedro y Cosgrove, 2005). En base al análisis filogenético de sus secuencias de aminoácidos, las EXPs de plantas se agrupan en 4 subfamilias: $\alpha$-expansinas (EXPA), $\beta$ expansinas (EXPB), expansinas de tipo A (EXLA) y expansinas de tipo B (EXLB). Experimentalmente, se ha podido demostrar que las EXPA y las EXPB participan en la relajación de la estructura de la pared celular que ocurre a lo largo de diferentes procesos del desarrollo asociados a la modificación de la pared celular (McQueen-Mason et al., 1992; Cosgrove et al., 1997).

Las EXPs pertenecientes a las cuatro subfamilias comparten únicamente entre un 20$40 \%$ de identidad de secuencia. El dominio I (dominio Prosite expansin-EG45; PS50842 InterProScan/Prosite) presenta una cierta homología a las glicósido hidrolasas de la familia 45 (GH45), cuyos miembros son mayoritariamente $\beta$-1,4-D-endoglucanasas de hongos. El dominio expansin-EG45 comparte varios residuos de aminoácidos del sitio catalítico de las GH45, aunque las EXPA y las EXPB no presentan esta actividad hidrolítica.

Las EXPAs se diferencian del resto de EXPs por la presencia en el dominio I de una larga inserción y de una deleción a ambos lados de un motivo conservado HFDL, que es parte del sitio activo de las GH45. Las EXLAs y las EXLBs carecen del motivo HFDL lo que sugiere que su actividad debe de ser diferente de la de los otros dos grupos de EXPs. Además, las EXLAs presentan un motivo conservado único (CDRC) en el extremo aminoterminal del dominio I, y su dominio II presenta una extensión de alrededor de 17 aminoácidos, particular de este tipo de EXPs. El dominio II (dominio Prosite expansinCBD; PS50843 InterProScan/Prosite) presenta varios residuos de aminoácidos aromáticos altamente conservados que supuestamente formarían una zona de unión a polisacáridos de la pared celular (Cosgrove, 2000).

La familia EXP de A. thaliana está formada por 36 proteínas, de las cuales, 26 proteínas pertenecen a la subfamilia EXPA (AtEXPA19, es un pseudogen), 5 proteínas a la subfamilia EXPB, 3 proteínas a la subfamilia EXLA y una proteína a la subfamilia EXLB. 
En la versión v0.9 (6,5 equivalentes genómicos) del ensamblaje del genoma haploide de $C$. clementina se han localizado 31 ORFs (29 completas y 2 parciales) que potencialmente codifican EXPs (ver Figura S9 del Anexo 7). Un total de 20 proteínas EXP de $C$. clementina quedaron agrupadas en la subfamilia EXPA, 3 proteínas en la subfamilia EXPB, 3 proteínas en la subfamilia EXLA y 5 proteínas en la subfamilia EXLB (ver Figura S9 del Anexo 7). Como se puede observar en la Figura $\mathbf{S 2 6}$ del Anexo 8, todas las EXPs de $C$. clementina presentaban los dominios I y II en su secuencia de aminoácidos. Las EXPAs deducidas de $C$. clementina presentaban la extensión y deleción características a ambos lados del motivo HFDL. Las EXLAs deducidas de C. clementina contenían el motivo CDRC en el dominio I y la extensión característica en el extremo carboxilo-terminal del dominio II, a excepción de la proteína deducida del locus clementine0.9_019285m.g (aKN0AAQ1YG09RM1_c), que presentaba el motivo CDRC pero no la extensión del dominio II.

La micromatriz empleada en este trabajo contiene sondas de 14 EXPs de cítricos (ver Figura 38 y Anexo 17), por tanto, cubre únicamente un 45\% de las posibles EXPs presentes en el genoma de los cítricos. La Figura 38 muestra el análisis filogenético de las EXPs de C. clementina y de las proteínas deducidas de genes de A. thaliana (Lashbrook y Cai, 2008), soja (Tucker et al., 2007), rosa (Sane et al., 2007), saúco (Sambucus nigra; Belfield et al., 2005), Dondiego de noche (Mirabilis jalapa; Meir et al., 2006) y plátano (Mbéguié-A-Mbéguié et al., 2009) relacionados con el proceso de abscisión. La subfamilia EXPA agrupaba cuatro genes regulados significativamente en la ZAC y/o en la CF: aCL2131Contig1 (clementine0.9_019423m.g), aC02006G07SK_c (clementine0.9_019412m.g), aCL723Contig1 (clementine0.9_019155m.g) у aCL1430Contig1 (clementine0.9_019734m.g). El gen aCL2131Contig1 se inducía exclusivamente en la ZAC tras $24 \mathrm{~h}$ de tratamiento con etileno y estaba estrechamente relacionado con otras EXPAs implicadas en el proceso de abscisión en otras especies, como la proteína GmEXP08, que se inducía durante la abscisión foliar en soja (Tucker et al., 2007), la proteína RbEXPA1, que se inducía durante la abscisión de los pétalos en rosa (Sane et al., 2007), la proteína SniEXP4, que se inducía en la ZA del foliolo de saúco (S. Nigra; Belfield et al., 2005) y la proteína MaEXP1, que se inducía en la zona de separación del fruto en plátano (Mbéguié-A-Mbéguié et al., 2009). Como particularidad con respecto a la proteína deducida del locus clementine0.9_019423m.g (aCL2131Contig1), cabe resaltar 
que se sintetiza como una pre-proteína de 254 aminoácidos y 27,01 kDa con un posible péptido señal en su extremo amino-terminal de 26 aminoácidos, mientras que la proteína madura es de 228 aminoácidos y 24,27 kDs. El gen aC02006G07SK_c se indujo exclusivamente en la ZAC tras $24 \mathrm{~h}$ de tratamiento con etileno y quedó agrupado en la misma rama que una proteína EXPA reprimida durante la abscisión de los estambres en $A$. thaliana (AtEXPA11; Lashbrook y Cai, 2008). El gen aCL723Contig1, reprimido en la ZAC a las $12 \mathrm{~h}$ de tratamiento con etileno e inducido en la CF a las $24 \mathrm{~h}$ de tratamiento, mostraba homología con una EXPA inducida en la zona de abscisión de los estambres en $A$. thaliana (AtEXPA6; Lashbrook y Cai, 2008), una EXPA inducida en la ZA del foliolo en saúco (S. Nigra; SniEXP2; Belfield et al., 2005), dos EXPAs inducidas en la zona de separación del fruto en plátano (MaEXP4 y MaEXP5; Mbéguié-A-Mbéguié et al., 2009) y una EXPA inducida en la ZA de la hoja en soja (GmEXP03; Tucker et al., 2007). Por otra parte, el gen aCL1430Contig1, que se encontraba reprimido en la ZAC y en la CF tras $24 \mathrm{~h}$ de tratamiento con etileno, estaba situado en la misma rama que una EXPA reprimida durante la abscisión de la hoja en soja (GmEXP01; Tucker et al., 2007). En relación a la subfamilia EXLA, el gen aCL1709Contig1 (clementine0.9_019074m.g), que se reprimía en la ZAC tras 12 y $24 \mathrm{~h}$ de tratamiento y en la CF tras $24 \mathrm{~h}$ de tratamiento, estaba estrechamente relacionado con dos EXLAs, AtEXLA2 y MjEXP-B2, reprimidas también durante la abscisión en A. thaliana y Dondiego de noche (M. Jalapa), respectivamente (Lashbrook y Cai, 2008; Meir et al., 2006). Sin embargo, dentro de esta misma subfamilia se encontraba el gen aKN0AAQ1YG09RM1_c (clementine0.9_019285m.g), que se inducía exclusivamente en la ZAC tras 12 y $24 \mathrm{~h}$ de tratamiento con etileno. Dentro de la subfamilia EXLB, se encontraba un gen reprimido exclusivamente en la CF tras 12 y $24 \mathrm{~h}$ de tratamiento (aC18019D04Rv_c; clementine0.9_019843m.g) y un gen que no presentaba resultados de hibridación (aCL4602Contig1; clementine0.9_019847m.g). 


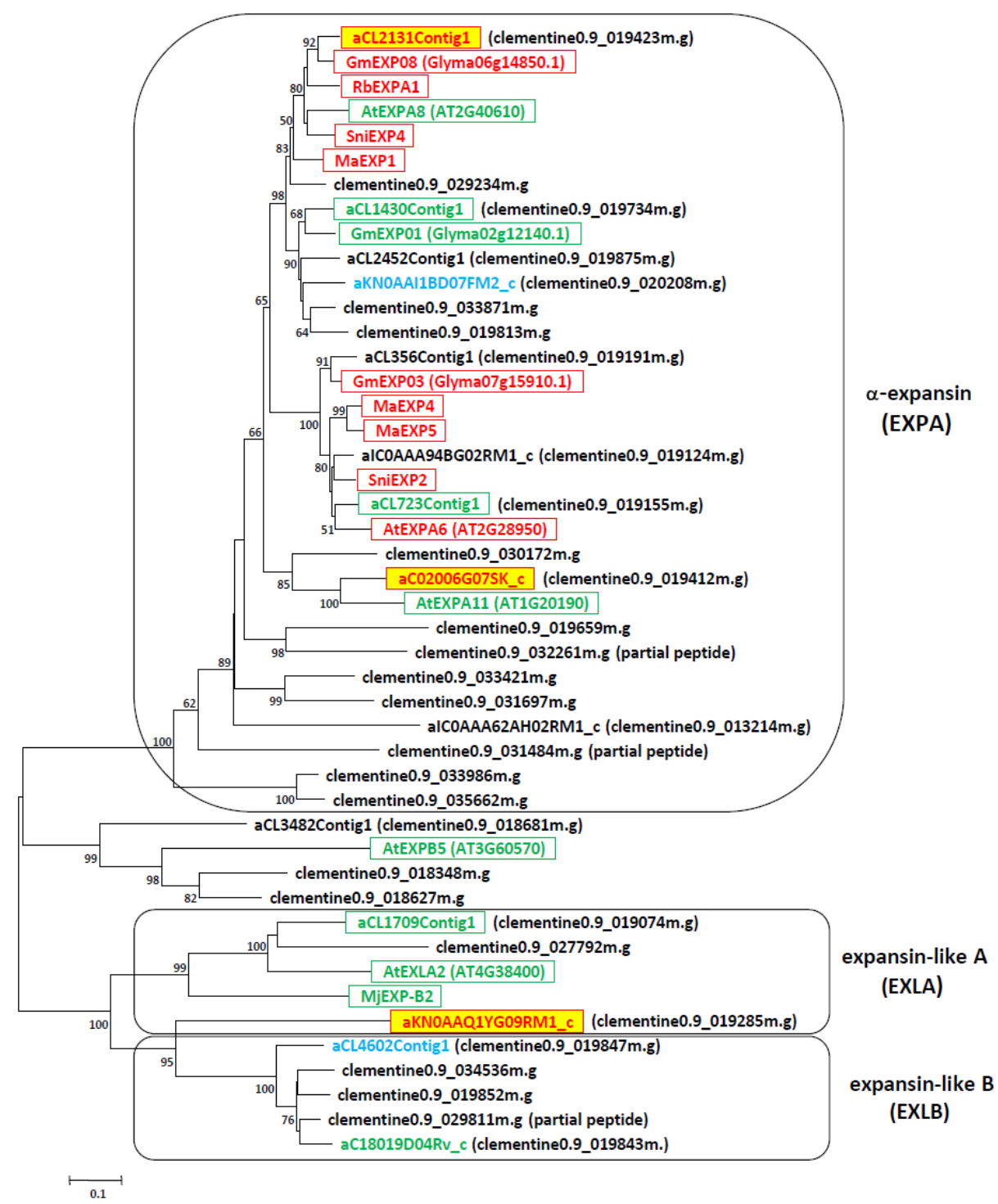

Figura 38. Relaciones filogenéticas entre las expansinas localizadas en el genoma haploide de Citrus clementina, las reguladas por etileno en las células de la ZAC y en las células parenquimáticas de la corteza del fruto maduro del naranjo 'Washington Navel' y las descritas en la literatura como asociadas a la abscisión en otras especies vegetales (ver Anexo 17). El árbol filogenético está basado en alineamientos múltiples (ClustalW; http://www.ch.embnet.org/software/ClustalW-XXL.html) y se generó utilizando el programa MEGA 4.0 mediante el método Neighbor-Joining (complete deletion, Poisson correction). El soporte Bootstrap para 1000 réplicas se muestra en las ramificaciones del árbol (solamente se muestran los valores superiores al 50\%). Clave de colores de los identificadores de las proteínas alineadas: (Citrus), inducción de la expresión por etileno exclusivamente en las células de la ZAC; (Citrus), represión de la expresión por etileno en las células de la ZAC y en las células parenquimáticas de la corteza del fruto maduro del naranjo 'Washington Navel'; (Citrus), represión de la expresión exclusivamente en las células de la corteza del fruto; (Citrus), presente en la micromatriz de cítricos de 20 K (Martínez-Godoy et al., 2008) pero sin resultados de la hibridación; (XXXX), inducido, y (XXXX), reprimido, durante la activación de las ZAs en diferentes órganos de otras especies vegetales. 
5.3.2. Detección de expresión génica diferencial en zonas de abscisión según la frecuencia de ESTs

Del conjunto de unigenes relacionados con la remodelación de la pared celular que se encuentran representados en la micromatriz de cDNA del CFGP, diez contenían ESTs procedentes de genotecas de abscisión. De estos diez unigenes, una $\beta$-galactosidasa (aCL1378Contig1), una celulasa ácida (aCL1347Contig1), una pectin acetilesterasa (aCL67Contig4) y dos poligalacturonasas (aCL675Contig4 y aKN0AAK1DH04FM2_c) podían atribuirse específicamente a genotecas de abscisión según el análisis llevado a cabo con el programa IDEG6 (Tabla 20). Es decir, sólo estos cinco unigenes se expresaban diferencialmente en zonas de abscisión con respecto a otros órganos/tejidos de cítricos y, por tanto, podrían ser específicos del proceso.

Tabla 20. Unigenes relacionados con la remodelación de la pared celular que contienen ESTs procedentes de genotecas de abscisión. * = unigenes que se expresan diferencialmente en zonas de abscisión según el programa IDEG6 (límite de significación del test de Audic y Claverie $=0.05$ ).

\begin{tabular}{|c|c|c|c|c|}
\hline CFGP singleton/contig & Descripción & $\begin{array}{c}\text { Posible } \\
\text { ortólogo de } \\
\text { A.thaliana } \\
\end{array}$ & $\begin{array}{c}N^{0} \text { ESTs en } \\
\text { genotecas de } \\
\text { abscisión } \\
\end{array}$ & $\begin{array}{c}\begin{array}{c}\text { Nivel de significación } \\
\text { (Test Audic y } \\
\text { Claverie) }\end{array} \\
\end{array}$ \\
\hline aCL1378Contig1 * & Beta-galactosidase [Citrus sinensis] & AT3G13750 & 2 & 0.0402 \\
\hline aCL1347Contig1 * & Acidic cellulase [Citrus sinensis] & AT4G02290 & 12 & 0.000001 \\
\hline aKN0AAK1AB05FM2_c & Basic cellulase [Citrus sinensis] & AT1G71380 & 1 & 0.0691 \\
\hline aCL2131Contig1 & Alpha-expansin [Citrus sinensis] & AT2G40610 & 1 & 0.0691 \\
\hline aCL1709Contig1 & Expansin-like A [Ricinus communis] & AT3G45970 & 1 & 0.0691 \\
\hline aCL67Contig4 * & $\begin{array}{l}\text { Pectinacetylesterase } \\
\text { [Ricinus communis] }\end{array}$ & AT5G26670 & 3 & 0.0047 \\
\hline aCL675Contig4 * & Polygalacturonase [Pyrus communis] & AT2G43870 & 3 & 0.0047 \\
\hline aKN0AAK1DH04FM2_c * & Polygalacturonase [Citrus unshiu] & AT3G59850 & 4 & 0.0012 \\
\hline aCL2029Contig1 & $\begin{array}{c}\text { Polygalacturonase } \\
{[\text { Populus trichocarpa }]}\end{array}$ & AT4G23820 & 1 & 0.1127 \\
\hline aCL107Contig2 & $\begin{array}{c}\text { Xyloglucan } \\
\text { endotransglucosylase/hydrolase } \\
{[\text { Ricinus communis }]}\end{array}$ & AT4G25810 & 2 & 0.0816 \\
\hline
\end{tabular}


5.3.3. Aislamiento $y$ análisis in silico de los promotores de posibles genes específicos del proceso de abscisión

La estrategia 'DNA Walking' descrita en el apartado 5.2.5 permitió aislar las regiones promotoras de los genes CitCEL (aCL1347Contig1) y CitPG (aCL675Contig4), genes potencialmente específicos del proceso de abscisión según los resultados obtenidos del análisis de expresión mediante micromatrices y del análisis in silico comentado en el apartado 5.2.5.5. Las regiones promotoras 5' aisladas de CitCEL y CitPG se extienden 896 y 822 pb aguas arriba de la putativa caja TATA, respectivamente. Las secuencias de ambos promotores se pueden consultar en el Anexo 19.

Un análisis riguroso de los nuevos promotores aislados requeriría el estudio de su actividad siguiendo estrategias basadas en genes delatores, con el objetivo de identificar genes que pudieran influir en la regulación de la actividad de los promotores (Oono et al., 1998). Sin embargo, el análisis in silico se utiliza de forma habitual para determinar posibles regiones reguladoras de manera fiable (Aparicio et al., 1995). Con este propósito, se analizaron las regiones promotoras aisladas utilizando la plataforma ConSite (http://asp.ii.uib.no:8090/cgi-bin/CONSITE/consite/), una herramienta informática que permite determinar elementos reguladores en cis de secuencias genómicas (Sandelin et al., 2004). Los resultados revelan que las secuencias promotoras presentan elementos reguladores con una elevada similitud a los reconocidos por factores de transcripción de la familia HD-Zip de Arabidopsis thaliana, como Athb-1 y ATHB5, de la familia MADSbox, como SQUA (Antirrhinum majus) y AGL3 (A. thaliana) o de la familia bZIP de A. majus (bZIP910) (Tabla 21). También contenían elementos reguladores con homología a los reconocidos por las proteínas HMG-IY de Pisum sativum, que regulan la expresión génica a través de la modificación de la cromatina (Gupta et al., 1997). 
Tabla 21. Posibles elementos reguladores en cis presentes en las secuencias de los promotores específicos de la zona de abscisión ( $p$ CitCEL y pCitPG). Se consideraron los factores de transcripción de plantas del programa ConSite y un intervalo de confianza del $85 \%$. + = cadena sentido, - = cadena complementaria antisentido.

\begin{tabular}{|c|c|c|c|c|c|}
\hline Promotor & $\begin{array}{c}\text { Factor de } \\
\text { transcripción }\end{array}$ & Secuencia & Posición & Score & Cadena \\
\hline \multirow[t]{13}{*}{ pCitCEL } & bZIP910 & ATGTCAT & $53-59$ & 7.07 & - \\
\hline & Athb-1 & TAATTATG & $74-81$ & 8.72 & + \\
\hline & Athb-1 & CATAATTT & $104-111$ & 8.16 & - \\
\hline & SQUA & ATTTCATTTTTTAT & $108-121$ & 10.24 & - \\
\hline & SQUA & CTTTATAATTTTGT & $168-181$ & 9.61 & - \\
\hline & ATHB5 & TAATAATGG & $188-196$ & 10.04 & - \\
\hline & Athb-1 & AATAATGG & $189-196$ & 9.50 & - \\
\hline & Athb-1 & CATTTATT & $334-341$ & 8.42 & + \\
\hline & bZIP910 & ACGTGAG & 493-499 & 7.07 & - \\
\hline & Athb-1 & AAATTATG & $531-538$ & 8.16 & + \\
\hline & bZIP910 & ACGGCAT & $579-585$ & 7.07 & - \\
\hline & HMG-IY & ATTTTTGCCTCTTTTA & $670-685$ & 10.26 & - \\
\hline & AGL3 & CCAAATTTAC & $843-852$ & 8.48 & + \\
\hline \multirow[t]{18}{*}{ pCitPG } & Athb-1 & TAATTAAT & $45-52$ & 8.13 & + \\
\hline & Athb-1 & ATTAATTA & $47-54$ & 8.13 & - \\
\hline & Athb-1 & TATAATTG & $152-159$ & 8.53 & - \\
\hline & HMG-IY & GGAAAAATGGAAAAAT & $176-191$ & 13.75 & + \\
\hline & SQUA & GGAAAAATGGAAAA & $176-189$ & 9.47 & + \\
\hline & AGL3 & CTTTTAATAG & $234-243$ & 8.72 & - \\
\hline & AGL3 & CTTTTAATAG & $234-243$ & 8.75 & + \\
\hline & Athb-1 & AATAGTTG & $239-246$ & 8.42 & - \\
\hline & Athb-1 & ATTAATTG & $282-289$ & 9.32 & - \\
\hline & Athb-1 & ATATTATT & $295-302$ & 8.67 & + \\
\hline & Athb-1 & CATAATTT & $457-464$ & 8.16 & - \\
\hline & HMG-IY & CAGAAAATGGAGAAGC & $483-498$ & 10.63 & + \\
\hline & AGL3 & CCATATGTGG & $630-639$ & 9.88 & - \\
\hline & AGL3 & CCATATGTGG & $630-639$ & 9.97 & + \\
\hline & HMG-IY & ATGTATGTATTTGTCG & $655-670$ & 10.54 & - \\
\hline & bZIP910 & CCGTCAT & $674-680$ & 7.07 & - \\
\hline & bZIP910 & ACGTCGT & $684-690$ & 7.07 & - \\
\hline & AGL3 & CCAAAATTCG & $755-764$ & 8.93 & + \\
\hline
\end{tabular}




\subsubsection{Composición de monosacáridos de las paredes celulares de la ZAC durante}

la abscisión inducida por etileno

El análisis mediante cromatografía gas-líquido permitió separar y cuantificar los monosacáridos más comunes de las paredes celulares: arabinosa (Ara), ramnosa (Rha), xilosa (Xyl), manosa (Man), galactosa (Gal), ácido galacturónico (GalUA) y glucosa (Glc). Tal y como se puede observar en la Tabla 22, el análisis de monosacáridos no reveló diferencias significativas relevantes entre la ZAC activada $(24$ y $48 \mathrm{~h}$ de tratamiento con etileno) y la ZAC no activada ( $0 \mathrm{~h}$ ) excepto para el caso de la Glc. Aunque la Glc puede provenir de la hidrólisis de la celulosa y del xiloglucano, no podemos considerar estos cambios como completamente asociados al desmantelamiento de la pared celular debido a que pueden provenir también de la hidrólisis parcial de los gránulos de almidón presentes en una parte de las células de la ZAC (ver Figura 15). De modo que, a pesar de la degradación de las paredes celulares observada a partir de las 24 h de tratamiento (Figuras 14 y 15), no se produjeron cambios sustanciales en la composición de azúcares de la ZAC durante la abscisión inducida por etileno.

Tabla 22. Cuantificación de los monosacáridos que componen la pared de las células de la ZAC activada por etileno mediante cromatografía gaslíquido. Los valores vienen dados en nmoles por $\mathrm{mm}^{3}$ de tejido microdiseccionado y son la media \pm ES de tres experimentos independientes.

\begin{tabular}{lccc}
\cline { 2 - 4 } & ZAC 0h & ZAC 24h & ZAC 48h \\
\hline Arabinosa & $12.5 \pm 5.0$ & $18.8 \pm 5.3$ & $12.1 \pm 1.9$ \\
Ramnosa & $2.5 \pm 1.5$ & $3.6 \pm 2.0$ & $1.2 \pm 0.4$ \\
Xilosa & $6.4 \pm 2.3$ & $8.5 \pm 1.6$ & $3.2 \pm 0.9$ \\
Manosa & $2.4 \pm 0.3$ & $4.3 \pm 0.3$ & $2.5 \pm 0.4$ \\
Galactosa & $11.3 \pm 4.1$ & $18.4 \pm 9.3$ & $24.5 \pm 4.1$ \\
$\begin{array}{l}\text { Ácido } \\
\text { galacturónico }\end{array}$ & $29.7 \pm 4.3$ & $43.5 \pm 11.6$ & $43.7 \pm 7.6$ \\
Glucosa & $36.0 \pm 9.9$ & $82.2 \pm 25.3$ & $60.2 \pm 5.8$ \\
\hline
\end{tabular}


5.3.5. Inmunolocalización de $(1 \rightarrow 4)-\beta$-D-galactano, $(1 \rightarrow 5)$ - $\alpha$-L-arabinano $y$ homogalacturonano en la ZAC inducida por ACC

La Figura 39 muestra la distribución espacial y temporal de polisacáridos pécticos en secciones longitudinales de la ZAC. Al inicio de la abscisión (0h), los epítopos reconocidos por los anticuerpos monoclonales LM5 [(1 $\rightarrow 4)-\beta$-D-galactano] y LM6 [( $1 \rightarrow 5)-\alpha-\mathrm{L}-$ arabinano] se detectaron con mayor intensidad en la pared primaria de las células de la ZAC (Figuras 39.A y 39.B), siendo más débil la fluorescencia en la lámina media; mientras que el anticuerpo JIM5 (HG parcialmente metil-esterificado o desesterificado) se localizaba también en la pared celular primaria y en la lámina media, aunque la intensidad era particularmente elevada en la lámina media y en las uniones entre células de los espacios intercelulares (Figura 39.C). En los tres casos, la distribución de la fluorescencia era homogénea a lo largo de la ZAC y se podían distinguir las nuevas paredes de las células que se localizan en la parte proximal de la ZAC (Figuras 39.A, 39.B y 39.C; ver también Figura 15).

Tras 24 h de tratamiento con ACC, las paredes primarias de las 2-3 capas de células de apariencia meristemática se distinguían con gran claridad debido a la mayor acumulación de LM5 y LM6 (Figuras 39.E y 39.F). Cabe destacar también que, a este tiempo de tratamiento con ACC, los tres anticuerpos se acumulaban en las células del área rica en almidón de la ZAC (Figuras 39.E, 39.F y 39.G). Concretamente, la fluorescencia se localizaba en las células de las 2-3 capas celulares adyacentes a la zona de apariencia meristemática, donde se produce principalmente la disolución de las paredes celulares y la lámina media y la consiguiente separación celular (ver Figura 39.I).

En los estados más avanzados del proceso de abscisión (36 y 48 h) se detectó mayor fluorescencia para los tres epítopos tanto en la parte proximal como distal de las capas celulares más próximas a la zona de separación (Figuras 39.H-39.S). Además, en las regiones donde la separación celular era completa se podía observar un material sin estructura aparente que presentaba fluorescencia muy intensa (Figuras 39.H, 39.I, 39.M, 39.Q, 39.R y 39.S). La presencia de dicho material correlacionaba con lo observado en la Figura 14.B. 


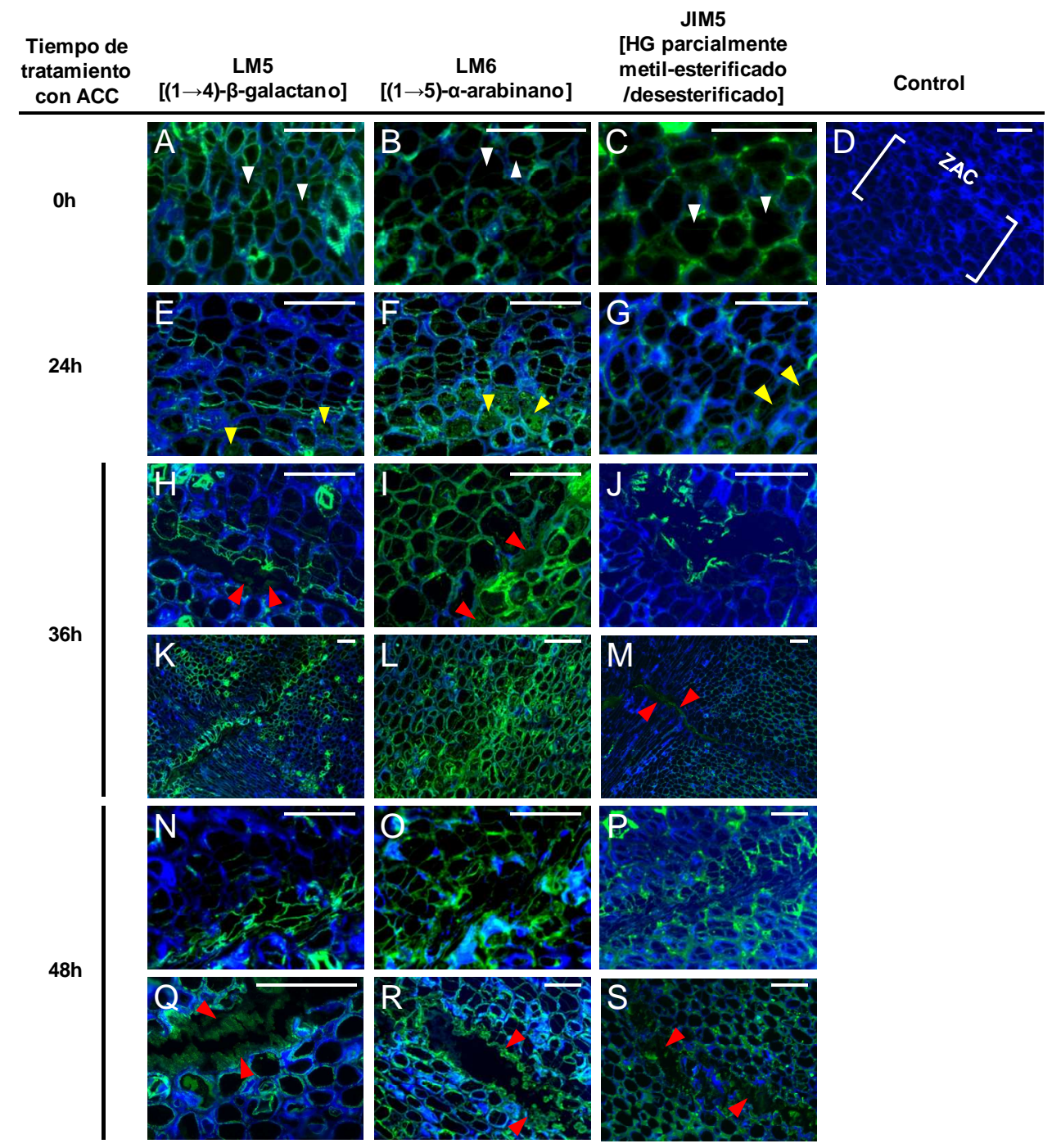

Figura 39. Detección por inmunofluorescencia indirecta de epítopos pécticos en la ZAC activada con ACC de frutos maduros de naranjo 'Navel Ricalate'. Se marcaron secciones longitudinales con los anticuerpos monoclonales LM5 (A, E, H, K, N y Q), LM6 (B, F, I, L, O y R) y JIM5 (C, G, J, M, P y S) para detectar $(1 \rightarrow 4)$ - $\beta$-D-galactanos, $(1 \rightarrow 5)$ - $\alpha$-L-arabinanos y HGs, respectivamente, tras $0,24,36$ y $48 \mathrm{~h}$ de tratamiento. El control no mostraba inmunofluorescencia (D). Barras: $5 \mu \mathrm{m}$. $\Lambda=$ paredes celulares del área con apariencia meristemática de la ZAC, $\quad=$ acumulación de anticuerpos en las células del área rica en almidón de la $\mathrm{ZAC}, \boldsymbol{\Delta}=$ materia amorfa procedente de los residuos pécticos de las paredes celulares y la lámina media degradadas. Las microfotografías representan la fusión de imágenes procedentes de la detección de epítopos pécticos mediante el uso de anticuerpos monoclonales específicos (verde) y de la detección de celulosa (azul) con Calcofluor White. 


\subsection{Discusión}

El análisis de expresión génica a gran escala descrito en el Capítulo III aportó información relevante acerca de la posible participación de un amplio grupo de genes en la abscisión de frutos activada con etileno. Tal y como se comentó en dicho capítulo, las categorías funcionales relacionadas con la remodelación de la pared celular se encontraban sobre-representadas específicamente en la ZAC (ver Tabla 4). En el presente capítulo se ha llevado a cabo un estudio más profundo sobre las familias génicas implicadas en la hidrólisis y la modificación de los polisacáridos de la pared celular y la lámina media con el propósito de determinar, dentro del elevado número de proteínas que normalmente conforman estas familias, aquellas enzimas que podrían actuar de manera específica en el proceso de abscisión.

En este estudio se han localizado en el genoma haploide de C. clementina los locus correspondientes a glicósido hidrolasas, polisacárido liasas, carbohidrato esterasas y expansinas. Considerando los genes que presentan sondas impresas en la micromatriz de cDNA del CFGP, esta información en conjunto ha permitido valorar el nivel de representación de cada familia en la micromatriz. Además, el análisis filogenético entre las proteínas de cada familia de C. clementina y las proteínas de A. thaliana ha permitido clasificar las proteínas de cítricos en las correspondientes subfamilias o grupos. Los perfiles de expresión de los genes asociados a estas familias que fueron regulados por el etileno en las células de la ZAC y/o de la corteza de frutos maduros de 'Washington Navel', junto con el análisis filogenético entre las proteínas de C. clementina, las proteínas reguladas por el etileno en la ZAC y/o en la CF y las proteínas descritas en la literatura como asociadas a la abscisión, así como la comparación de la estructura proteica de todos estos genes, ha aportado información relevante sobre la posible especificidad funcional de las proteínas de cítricos en la abscisión de frutos.

La micromatriz de cDNA utilizada en este estudio (Martínez-Godoy et al., 2008) contiene sondas para rastrear la expresión de solamente una cuarta parte de las glicósido hidrolasas de la familia 9, las CELs, localizadas en el genoma haploide de C. clementina. La CEL ácida aCL1347Contig1 (clementine0.9_008028m.g) se inducía exclusivamente en la ZAC tras 24 h de tratamiento con etileno. La proteína deducida del gen aCL1347Contig1 
estaba estrechamente relacionada con otras CELs inducidas durante el proceso de abscisión en aguacate (PaCEL1; Tonutti et al., 1995), tomate (SLGH9B4; Brumell et al., 1999), pimiento (CaCEL2; Ferrarese et al., 1995) y soja (GmCEL09; Tucker et al., 2007) (Figura 30). La CEL de cítricos aCL1347Contig1 se inducía, además, en la ZA de hojas y frutos tras el tratamiento con etileno en trabajos previos (Agustí et al., 2008, 2009; CsCEL-al; Burns et al., 1998). Estos genes pertenecían al grupo B de CELs, que englobaba la mayor parte de las CELs descritas en la literatura como inducidas durante la abscisión (ver Figura S11 del Anexo 8). Todos los miembros del grupo B presentaban un péptido señal en su secuencia deducida de aminoácidos que dirige la proteína a la pared celular (Figura S11 del Anexo 8). Por tanto, a pesar de que la micromatriz de cDNA empleada en este estudio únicamente ha permitido analizar la expresión de una cuarta parte de las posibles CELs presentes en el genoma de los cítricos, ha sido posible identificar una CEL (aCL1347Contig1) potencialmente implicada en la abscisión de frutos cítricos. Los genes aKN0AAK1AB05FM2_c (clementine0.9_008549m.g), aCL1594Contig1 (clementine0.9_008291m.g), aCL5093Contig1 (clementine0.9_004972m.g), aIC0AAA3AB03RM1_c (clementine0.9_004824m.g) y aCL5359Contig1 (clementine0.9_005121m.g) de cítricos con homología a CELs y representados en la micromatriz de cDNA no mostraron cambios de expresión significativos en la ZAC durante la activación del proceso, aunque quedaron agrupados con CELs de otras especies vegetales implicadas en el proceso de abscisión (ver Figura 30). Estos resultados sugieren que, a pesar de la relación filogenética existente entre CELs, pueden haber divergencias en cuanto a su participación en un proceso determinado. Algunos trabajos previos (Kim et al., 2006) sugieren que, dentro de una misma familia génica, los miembros relacionados filogenéticamente pueden presentar patrones de expresión espacio-temporales diferentes. En relación al gen aKN0AAK1AB05FM2_c cabe mencionar que en un estudio anterior (Burns et al., 1998) su gen homólogo, CsCEL-b1, se inducía en la ZA de hojas y frutos de naranjo 'Valencia'. Estas diferencias podrían deberse al método de aislamiento de la ZAC empleado en cada estudio. Por otra parte, los ortólogos en A. thaliana de aIC0AAA3AB03RM1_c y aCL5359Contig1 (AT1G65610 y AT5G49720, respectivamente) pertenecen a una clase de endoglucanasas implicadas en la biosíntesis de celulosa (KORRIGAN; Robert et al., 2005) que no han sido relacionadas hasta ahora con el proceso de abscisión. Por último, no podemos descartar la posibilidad de que algunos de los genes de C. clementina correspondientes a CELs que no están representados en la 
micromatriz de cDNA utilizada en este estudio, pero que se encuentran estrechamente relacionados con CELs implicadas en la abscisión en otras especies vegetales, como clementine0.9_008581m.g, relacionada con SLGH9B2 (Brummell et al., 1999; Lashbrook et al., 1994; Lashbrook y Cai, 2008), clementine0.9_032761m.g, relacionada con SLGH9B1 (Lashbrook et al., 1994; Lashbrook y Cai, 2008; Meir et al., 2010), SnCEL (Taylor et al., 1994), BAC (Tucker et al., 1988) y GmCEL1 (Tucker et al., 2007), clementine0.9_004972m.g, clementine0.9_007268m.g o clementine0.9_008434m.g, relacionadas con PpEG4 (Trainotti et al., 2006), GhCEL1 (Mishra et al., 2008) y AtGH9B8 (Lashbrook y Cai, 2008), o incluso clementine0.9_007932m.g, relacionada filogenéticamente con aCL1347Contig1 (ver Figura 30), puedan estar implicadas en la abscisión de frutos en los cítricos.

En relación a la familia de las poligalacturonasas (PGs; familia GH28), a pesar de que la micromatriz de cDNA empleada en este estudio únicamente cubría un tercio de las posibles PGs presentes en el genoma de los cítricos, el análisis de expresión permitió identificar un número importante de PGs reguladas por el etileno en las células de la ZAC (ver Figura 31 y Anexo 10). El grupo A de la familia GH28 englobaba la mayor parte de PGs descritas en la literatura como inducidas en la ZA o en la zona de dehiscencia (ZD) activadas de diferentes órganos en otras especies vegetales (Figura 31). En este grupo se encontraba el gen aCL675Contig4 (clementine0.9_012194m.g), que se inducía exclusivamente en la ZAC tras $24 \mathrm{~h}$ de tratamiento con etileno (Anexo 10) y se encontraba en la misma rama, aunque alejado, que TAPG1, TAPG2 y TAPG4 (Figura 31), tres genes inducidos durante la abscisión de hojas y flores en tomate (Kalaitzis et al., 1997). Por tanto, la PG aCL675Contig4 podría estar implicada en la abscisión de frutos cítricos. Sin embargo, el gen aKN0AAK1DH04FM2_c (clementine0.9_012391m.g), que se encontraba muy próximo al gen aCL675Contig4 (Figura 31), se inducía exclusivamente en las células de la $\mathrm{CF}$ tras $24 \mathrm{~h}$ de tratamiento. Por otra parte, el único gen de cítricos (aC01018C01SK_c; clementine0.9_014542m.g) representado en la micromatriz que se encontraba próximo a la rama que agrupaba la mayor parte de las PGs del grupo A inducidas durante los procesos de abscisión y dehiscencia en diferentes especies vegetales no mostró datos de hibridación (Figura 31 y Anexo 10). Este gen no contenía un péptido señal en su secuencia deducida de aminoácidos, de modo que, podría tratarse de una proteína soluble que no se localizaría en la pared celular. Sin embargo, los resultados del 
alineamiento de la proteína deducida de clementine0.9_014542m.g, más corta en el extremo amino-terminal que las otras proteínas de este grupo (ver Figura S14 del Anexo 8 y Anexo 10), sugieren un posible error de anotación automática en el genoma haploide de C. clementina. El número de PGs pertenecientes al grupo A incluídas en la micromatriz de cDNA de cítricos era muy reducido ( 8 de 46), lo que implica que otras PGs de cítricos relacionadas con las PGs implicadas en la dehiscencia del fruto y en la abscisión de órganos florales en A. thaliana y colza (B. napus) (González-Carranza et al., 2002, 2007; Kim et al., 2006; Ogawa et al., 2009; Petersen et al., 1996) y en la abscisión en manzano (Atkinson et al., 2002) y en soja (Tucker et al., 2007), como clementine0.9_010222m.g y clementine0.9_033174m.g, podrían estar también reguladas por etileno en la ZAC del fruto de los cítricos.

Las PGs del grupo B descritas hasta ahora en la literatura como relacionadas con la abscisión se reprimían en la ZA activada de diferentes órganos en otras especies vegetales. Este es el caso de AT3G16850 y AT4G23820, reprimidos en la ZA de los estambres de A. thaliana (Lashbrook y Cai, 2008), y de GmPG16, reprimido en la ZA de la hoja en soja (Tucker et al., 2007). El presente estudio ha aportado tres nuevas PGs del grupo B que se inducen durante la abscisión de frutos cítricos activada por etileno y muestran diferentes patrones de expresión: aCL5261Contig1 (clementine0.9_006745m.g) se inducía exclusivamente en la ZAC tras $12 \mathrm{~h}$ de tratamiento con etileno, aIC0AAA85AB02RM1_c (clementine0.9_008916m.g) se inducía exclusivamente en la ZAC tras 24 h de tratamiento con etileno y aCL3497Contig1 (clementine0.9_009866m.g), se inducía en la ZAC tras $24 \mathrm{~h}$ de tratamiento con etileno y en la CF tras 12 y $24 \mathrm{~h}$ de tratamiento. El gen clementine0.9_006745m.g (aCL5261Contig1) no presenta péptido señal en su secuencia deducida de aminoácidos, por tanto, podría tratarse de una proteína soluble que no se localizaría en la pared celular. Sin embargo, el ensamblaje de ESTs (>95\% identidad de secuencia) para aCL5261Contig1 proporcionaba una proteína deducida más corta en el extremo amino-terminal (que sí presenta péptido señal; ver Anexo 10) que la correspondiente a la secuencia del locus clementine0.9_006745m.g de C. clementina lo que, de nuevo, sugiere un posible error de anotación automática. Por otra parte, la PG del grupo C correspondiente al gen aCL1063Contig1 (clementine0.9_008942m.g), también se inducía exclusivamente en la ZAC tras 12 y 24 h de tratamiento con etileno. Estas PGs de cítricos de los grupos $\mathrm{B}$ y $\mathrm{C}$ son las únicas descritas hasta ahora como inducidas durante la 
abscisión de órganos. Los genes de cítricos aCL2029Contig1 (clementine0.9_010307m.g) y aKN0AAA3CH04ZM1_c (clementine0.9_008929m.g) (en ZAL aC20006H12SK_c) se inducen preferentemente en la zona de abscisión laminar (ZAL) de las hojas de cítricos tras el tratamiento con etileno (Agustí et al., 2008, 2009). Estos resultados contrastan con lo observado en la ZAC del fruto, en la que la expresión de aCL2029Contig1 se reprime tras el tratamiento con etileno mientras que la expresión de aKN0AAA3CH04ZM1_c no está afectada por el tratamiento con etileno. Por otra parte, el gen aCL3497Contig1, inducido tanto en la ZAC como en la CF, se inducía también en la ZAL tras el tratamiento con etileno según estos mismos estudios (Agustí et al., 2008, 2009). Por tanto, parece ser que el patrón de expresión de los genes aCL2029Contig1, aKN0AAA3CH04ZM1_c y aCL3497Contig1 es diferente en función del órgano/tejido de la planta. Por último, cabe mencionar que las PGs de C. clementina que no se encuentran representadas en la micromatriz de cítricos y que están próximas filogenéticamente a PGs implicadas en la abscisión en otras especies vegetales (Figura 31), como clementine0.9_028691m.g, clementine0.9_035213m.g, clementine0.9_028146m.g, clementine0.9_028138m.g, clementine0.9_010222m.g, clementine0.9_033174m.g y clementine0.9_029553m.g, o incluso a la PG de cítricos aCL675Contig4, como clementine0.9_012357m.g y clementine0.9_034100m.g, podrían estar implicadas en el proceso de abscisión en cítricos.

Atendiendo a la familia de las $\beta$-xilosidasas ( $\beta$-XYLs; familia GH3), el gen aCL271Contig1 (clementine0.9_002914m.g), que se inducía en la ZAC y en la CF tras 12 y $24 \mathrm{~h}$ de tratamiento con etileno, y el gen aCL2321Contig1 (clementine0.9_002988m.g), que se inducía en la ZAC tras $12 \mathrm{~h}$ de tratamiento y en la CF tras $24 \mathrm{~h}$ de tratamiento (Anexo 11), se encontraban estrechamente relacionados con la proteína AtBXL1 de A. thaliana (Figura 32), con actividad $\beta$-glucuronidasa dirigida a las ZAs de los órganos florales por su secuencia promotora específica (Goujon et al., 2003). Estos resultados sugieren que, a pesar de que la micromatriz de cDNA utilizada en este estudio cubre la mitad de las posibles $\beta$ XYLs presentes en el genoma de los cítricos, ha sido posible identificar dos $\beta$-XYLs (aCL271Contig1 y aCL2321Contig1) que podrían participar en la abscisión de frutos cítricos y, posiblemente, en otros procesos de separación asociados a la CF. Por otra parte, las $\beta$-XYLs aCL3345Contig1 (clementine0.9_002926m.g) y aCL8110Contig1 (clementine0.9_004996m.g) se reprimían exclusivamente en las células de la ZAC durante la abscisión promovida por el etileno (Figura 32). Es la primera vez que la represión de $\beta$ - 
XYLs se asocia a la abscisión de órganos vegetales. En relación a las familias ASD (familia GH51) y $\alpha$-XYL (familia GH31), ninguno de los genes representados en la micromatriz de cDNA empleada en este estudio mostró inducción durante la abscisión activada por etileno. Así, la única ASD de cítricos, aKN0AAP8YC15FM1_c (clementine0.9_004189m.g), que quedó agrupada con los genes AtASD1 y AtASD2 (Figura 32), con actividad $\beta$ glucuronidasa dirigida a las ZAs de los órganos florales de A. thaliana por su promotor específico (Fulton y Cobett, 2003), no mostró cambios significativos de expresión durante la abscisión de frutos activada por etileno (Anexo 10). Por último, dentro de la familia $\alpha$ XYL, el gen aCL6235Contig1 (clementine0.9_002017m.g), homólogo a la proteína AtXYL1 de A. thaliana (Figura 32) y cuya expresión se localiza en la ZA de órganos florales (Sampedro et al., 2010), se reprimía exclusivamente en la ZAC a las $12 \mathrm{~h}$ de tratamiento con etileno, mientras que aC08018A05SK_c (clementine0.9_034951m.g) también se reprimía en la ZAC, además de en la $\mathrm{CF}$, a las 24 horas de tratamiento con etileno. Estos resultados en relación a las familias ASD y $\alpha$-XYL ponen de manifiesto que el patrón de expresión puede variar de una especie a otra a pesar de tratarse de genes muy próximos filogenéticamente. Por otra parte, teniendo en cuenta el porcentaje de representación de la familia $\alpha$-XYL de cítricos $(56 \%)$ en la microamtriz de cDNA empleada en este trabajo, no se puede descartar la posible participación en el proceso de abscisión de otras $\alpha$-XYLs localizadas en el genoma de $C$. clementina, como podrían ser las $\alpha$-XYLs correspondientes a los genes clementine0.9_004774m.g, clementine0.9_002132m.g o clementine0.9_001891m.g, por su proximidad filogenética a la proteína AtXYL1 de A. thaliana (Figura 32).

Otra familia de glicósido hidrolasas regulada durante la abscisión de frutos activada por etileno fue la familia de las xiloglucano transglicosilasas/hidrolasas (XTHs; familia GH16). El único gen de cítricos perteneciente a esta familia cuya expresión aumentaba durante la abscisión de frutos fue aIC0AAA99CH05RM1_c (clementine0.9_013592m.g), que se inducía exclusivamente en la ZAC durante las primeras 24 horas de tratamiento con etileno. Este gen pertenecía al grupo III de la familia XTH que, como ocurre con el grupo II de las XTHs (ver Figura 33), agrupaba exclusivamente XTHs descritas en la literatura como inducidas en las ZAs de diferentes órganos/tejidos en otras especies vegetales. La XTH aIC0AAA99CH05RM1_c estaba estrechamente relacionada con el gen MaXTH6 de plátano (Figura 33), inducido por el desarrollo en la zona de separación del fruto 
(Mbéguié-A-Mbéguié et al., 2009). Por tanto, a pesar de que la micromatriz de cDNA empleada en este estudio cubre únicamente un $42 \%$ de las posibles XTHs presentes en el genoma de los cítricos, ha sido posible identificar una XTH potencialmente específica de la ZAC. La mayor parte de las XTHs del grupo III mostraba represión de la expresión durante la abscisión de órganos en diferentes especies vegetales, incluidas las XTHs aC02023G10SK_c (clementine0.9_017493m.g), aCL6772Contig1 (clementine0.9_017721m.g) y aCL6641Contig1 (clementine0.9_016046m.g) de cítricos (ver Figura 33), de modo que, es posible que este grupo de XTHs participe en otros procesos de separación celular. Así pues, multitud de trabajos previos han demostrado el aumento tanto de la actividad XTH como de la expresión de miembros de esta familia génica a lo largo de diferentes procesos del desarrollo vegetal en los que se produce la degradación de la pared celular, como la maduración del fruto (Arrowsmith y de Silva, 1995; Cutillas-Iturralde et al., 1994; Maclachlan y Brady, 1994; Redgwell y Fry, 1993; Rose y Bennett, 1999; Schröder et al., 1998) o la formación del aerénquima en la raíz (Saab y Sachs, 1996) y de espacios aéreos en el mesófilo de la hoja (Antosiewicz et al., 1997). Los genes de cítricos aCL6641Contig1 (clementine0.9_016046m.g), aC02014B11SK_c (clementine0.9_016317m.g) y aCL5100Contig1 (clementine0.9_017649m.g) se inducen preferentemente en la zona de abscisión laminar de hojas de cítricos a las 24 horas de tratamiento con etileno (Agustí et al., 2008, 2009). Estos resultados contrastan con los observados en la ZA del fruto, donde la expresión de aCL6641Contig1 se reprime en las células de la ZAC mientras que la expresión de aC02014B11SK_c no está afectada por el tratamiento con etileno. En el caso de aCL5100Contig1 (clementine0.9_017649m.g), que se encuentra en la misma rama (Figura 33) que los genes MaXET1, MaXTH8 y MaXTH9, que se inducen en la zona de separación del plátano (Mbéguié-A-Mbéguié et al., 2009), que el gen GmXET02, que se induce en el peciolo de la hoja de soja (Tucker et al., 2007), que el gen XET-BRI, que se induce en la ZA de la flor de tomate (Meir et al., 2010) y que AtXTH12, que se induce en las células de la ZA de los estambres de A. thaliana (Lashbrook y Cai, 2008), la micromatriz de $20 \mathrm{~K}$ de cítricos no posee sondas para estudiar la expresión de este gen y, por tanto, se desconoce si experimenta cambios en su expresión durante la activación de la ZA del fruto de los cítricos. La estrecha relación filogenética observada con estos genes implicados en el proceso de abscisión sugiere que la expresión de clementine0.9_017649m.g podría inducirse en las células de la ZAC de frutos cítricos tratados con etileno. Este mismo hecho podría considerarse en el caso de las XTHs 
correspondientes a los genes de cítricos clementine0.9_029891m.g y clementine0.9_034622m.g, pertenecientes al grupo II, o clementine0.9_031287m.g, perteneciente al grupo III, ya que no se encuentran representados en la micromatriz de cDNA empleada en este estudio pero se encuentran muy próximos filogenéticamente a XTHs inducidas en las ZAs de diferentes órganos/tejidos en otras especies vegetales (Figura 33). En general, los resultados obtenidos en cítricos sugieren que miembros específicos de las XTHs de los grupos II y III se inducen durante la abscisión de órganos vegetales mientras que las XTHs del grupo I se reprimen.

En relación a las $\beta$-galactosidasas ( $\beta$-GALs; familias GH2 y GH35), a pesar de que la micromatriz de cDNA utilizada en este estudio cubre únicamente un $39 \%$ de las posibles $\beta$ GALs presentes en el genoma de los cítricos, ha sido posible identificar un gen potencialmente implicado en la abscisión de frutos cítricos. Se trata del gen aCL4443Contig1 correspondiente a la familia GH2 de $\beta$-GALs, que se inducía exclusivamente en la ZAC tras 12 y $24 \mathrm{~h}$ de tratamiento con etileno (ver Anexo 13). La sonda de cDNA de este gen impresa en la micromatriz utilizada en este estudio muestra homología parcial a la secuencia proteica deducida para el locus clementine0.9_002920m.g del genoma haploide de $C$. clementina (ver Anexo 13). Por tanto, se trataría de un gen nuevo o un alelo específico de otras especies de cítricos. Además, aCL4443Contig1 representa la única $\beta$-GAL de la familia GH2 descrita hasta ahora en la literatura como implicada en el proceso de abscisión. Sin embargo, mientras la proteína deducida del locus clementine0.9_002920m.g sí que muestra la presencia de un péptido señal en su extremo amino-terminal, la proteína deducida de aCL4443Contig1 no muestra esta característica. Con respecto a la familia GH35 de $\beta$-GALs, el gen aCL1378Contig1 (clementine0.9_003023m.g), homólogo al gen Cs $\beta G A L$ inducido durante la abscisión de hojas y frutos cítricos (Wu y Burns, 2004), se inducía exclusivamente en la CF tras 24 h de tratamiento con etileno, mientras que en la ZAC no experimentaba un cambio de expresión significativo. En un estudio llevado a cabo por Agustí et al. (2009) en cítricos, este gen se reprimía preferentemente en la ZAL de la hoja tras $24 \mathrm{~h}$ de tratamiento con etileno. Las diferencias entre los trabajos podrían estar relacionadas con el método de aislamiento de la ZAC del fruto y la ZAL de la hoja empleado en cada caso. El gen aCL1378Contig1 se encontraba, además, próximo al gen aC01015E12SK_c (clementine0.9_002261m.g), reprimido en la ZAC tras 12 y $24 \mathrm{~h}$ de tratamiento con etileno e inducido en la CF tras $24 \mathrm{~h}$ 
de tratamiento, y al gen aC31805H10EF_c (clementine0.9_002229m.g), reprimido exclusivamente en la ZAC tras $12 \mathrm{~h}$ de tratamiento con etileno (Figura 34). Los resultados de expresión de aC31805H10EF_c contrastaban con lo observado en la ZAL de la hoja (Agustí et al., 2008; 2009), en la que aC31805H10EF_c se inducía tras el tratamiento con etileno. Estos resultados sugieren una posible especificidad de tejido para la $\beta$-GAL aC31805H10EF_c. A la vista de los resultados, ningún gen de la familia GH35 de $\beta$-GALs representado en la micromatriz de cDNA de cítricos estaría implicado en la abscisión de frutos, aunque no se puede descartar una posible participación del gen clementine0.9_030842m.g por su proximidad filogenética al gen AT5G56870 de A. thaliana (Figura 34), que se inducía durante la abscisión de los estambres (Lashbrook y Cai, 2008). Lo mismo podría ocurrir con la $\beta-G A L$ de la familia GH2 codificada por el gen clementine0.9_002920m.g, que se encontraba estrechamente relacionada a la $\beta$-GAL aCL4443Contig1 (Figura 34).

El etileno reguló también la expresión de genes que codifican pectin metilesterasas (PMEs; familia CE8). Así, a pesar de que la micromatriz de cDNA empleada en este estudio cubre únicamente un tercio de las posibles PMEs presentes en el genoma de los cítricos, se han identificado dos posibles PMEs específicas de la ZAC de frutos. Este es el caso de la PME del grupo 1 aCL1451Contig1 (clementine0.9_013443m.g), que se inducía exclusivamente en la ZAC tras 12 y $24 \mathrm{~h}$ de tratamiento. Hasta ahora es la única PME de este grupo implicada en el proceso de abscisión según la literatura existente, aunque no se puede descartar la posible participación de otras PMEs del grupo 1 localizadas en el genoma de $C$. clementina de las cuales la micromatriz de $20 \mathrm{~K}$ de cítricos no posee sondas para estudiar su expresión. Este podría ser el caso de los genes clementine0.9_028554m.g y clementine0.9_032555m.g, que están estrechamente relacionados con el gen aCL1451Contig1 (Figura 35). Por otra parte, el etileno inducía la expresión de la PME del grupo 2 aCL2379Contig1 (clementine0.9_006156m.g) exclusivamente en la ZAC tras $24 \mathrm{~h}$ de tratamiento. Este gen se encontraba alejado filogenéticamente del resto de genes correspondientes a proteínas PME del grupo 2 inducidos durante la abscisión (ver Figura 35), lo que sugiere que los miembros de una misma familia génica alejados filogenéticamente pueden estar implicados en el mismo proceso biológico. El grupo 2 de PME, además, englobaba mayoritariamente genes reprimidos durante la abscisión en otras especies vegetales, lo que indicaría también que en una misma familia génica existe 
especificidad funcional. Así, los genes aC05807A09SK_c (clementine0.9_007349m.g), aCL1691Contig1 (clementine0.9_006470m.g) y aCL4116Contig2 (clementine0.9_005431m.g), que se reprimían exclusivamente en la ZAC tras 12 y 24 h de tratamiento con etileno, y el gen aCL4489Contig1(clementine0.9_012072m.g), que se inducía exclusivamente en la CF tras 24 h de tratamiento con etileno, serían específicos de otros tejidos o procesos biológicos. Además, se encontraban muy próximos filogenéticamente a otras PMEs reprimidas filogenéticamente durante la abscisión en otras especies vegetales. Por último, cabe destacar que el gen aCL1069Contig1 (clementine0.9_007866m.g), homólogo a una PME inducida en la ZA de la hoja y del fruto de los cítricos tras el tratamiento con etileno (CsPME3; Nairn et al., 1998), no mostraba cambios significativos de expresión en la ZAC en el presente análisis. Este hecho podría deberse a la diferente metodología empleada para aislar la ZAC, tal y como se ha comentado anteriormente. Por otra parte, el gen aCL120Contig3 (clementine0.9_005845m.g) se induce en la zona de abscisión laminar de la hoja de los cítricos a las 24 h de tratamiento con etileno, sin embargo, en la ZAC del fruto no mostró cambios de expresión. Por tanto, el patrón de expresión de aCL120Contig3 varía en función del tejido de la planta. Además, en este estudio el gen aCL120Contig3 se encontraba estrechamente relacionado con el gen AtPME3 de A.thaliana (ver Figura 35), que se reprime en la ZA de los estambres.

Otra familia de carbohidrato esterasas regulada significativamente por el etileno fueron las pectin acetilesterasas (PAEs; familia CE13). La micromatriz de cDNA empleada en este estudio cubre un $75 \%$ de las posibles PAEs presentes en el genoma de los cítricos, por tanto, los resultados de expresión obtenidos proporcionan una visión muy completa de la actuación de esta familia génica en la abscisión de frutos cítricos. El tratamiento con etileno inducía únicamente la expresión de una PAE (aCL67Contig4; clementine0.9_012430m.g) en la ZAC que, además, se reprimía en la CF. Esta PAE no se encontraba relacionada filogenéticamente con otras PAEs inducidas durante el proceso de abscisión en otras especies vegetales (ver Figura 36). Por tanto, se trata de una nueva PAE que podría estar actuando de manera específica durante la abscisión de frutos cítricos. Por otra parte, aunque no se puede disponer de datos de expresión de clementine0.9_012707m.g porque la micromatriz de $20 \mathrm{~K}$ no contiene sondas de este gen, no se puede descartar una posible participación en el proceso de abscisión de frutos cítricos por su proximidad 
filogenética al gen aCL67Contig4. El resto de genes regulados por el tratamiento con etileno se reprimían exclusivamente en la ZAC y, además, mostraron proximidad a PAEs reprimidas también durante la abscisión en Arabidopsis thaliana (ver Figura 36). Este hecho indica que dentro de una misma familia génica existe especificidad funcional.

En relación a la familia de las pectato liasas (PLs, familia PL1), el presente trabajo ha permitido obtener datos de expresión únicamente de un $58 \%$ de las posibles PLs presentes en el genoma de los cítricos. Todas las PLs de cítricos reguladas por el tratamiento con etileno quedaron agrupadas en el grupo I, como la práctica totalidad de las PLs relacionadas con la abscisión en otras especies vegetales (Figura 37). El gen aIC0AAA15AF11RM1_c (clementine0.9_011921m.g), que se inducía exclusivamente en la ZAC tras $24 \mathrm{~h}$ de tratamiento con etileno, y el gen aCL4999Contig1 (clementine0.9_007883m.g), que se inducía en la ZAC tras $24 \mathrm{~h}$ de tratamiento con etileno y en la CF tras 12 y $24 \mathrm{~h}$ de tratamiento, se encontraban en las mismas ramas que otras PLs inducidas durante la abscisión de diferentes órganos/tejidos en otras especies vegetales (ver Figura 37). El gen aCL4999Contig1 se induce, además, en la ZAL de la hoja de los cítricos tras el tratamiento con etileno (Agustí et al., 2008, 2009). Por tanto, es muy probable que estos genes participen en el proceso de abscisión, y el gen aCL4999Contig1 podría estar implicado, además, en procesos de separación celular asociados a la CF. Por otra parte, el gen aC03011D06SK_c (clementine0.9_012496m.g), que se reprimía exclusivamente en la ZAC a las 12 y $24 \mathrm{~h}$ de tratamiento con etileno, se encontraba en una rama diferente al resto de PLs inducidas (Figura 37). En conjunto, estos resultados ponen de manifiesto que dentro de una misma familia génica pueden existir diferencias en el patrón espacial de expresión. Por último, cabe mencionar que el gen clementine0.9_011933m.g, del que no se dispone de datos de expresión por no estar representado en la micromatriz de cDNA empleada en este estudio, podría participar en el proceso de abscisión por su proximidad filogenética a PLs implicadas en el proceso de abscisión en diferentes especies vegetales, los cítricos entre ellas (ver Figura 37).

El tratamiento con etileno reguló la expresión de un grupo de expansinas (EXPs) en las células de la ZAC y/o de la CF y, a pesar de que la micromatriz de cDNA empleada en este estudio cubre únicamente un $45 \%$ de las posibles EXPs presentes en el genoma de los cítricos, se han podido identificar tres posibles EXPs inducidas exclusivamente en la ZAC. 
Dos de estos genes, aCL2131Contig1 (clementine0.9_019423m.g) y aC02006G07SK_c (clementine0.9_019412m.g), pertenecían a la subfamilia de las $\alpha$-expansinas (EXPAs), que agrupa todas las EXPs deducidas de genes inducidos en las ZAs de diferentes órganos/tejidos en otras especies vegetales (Figura 38). El gen aCL2131Contig1, que se inducía exclusivamente en la ZAC tras $24 \mathrm{~h}$ de tratamiento con etileno, estaba estrechamente relacionado con las EXPAs GmEXP08 (Tucker et al., 2007), RbEXPA1 (Sane et al., 2007), SniEXP4 (Belfield et al., 2005) y MaEXP1 (Mbéguié-A-Mbéguié et al., 2009), inducidas en las ZAs de diferentes órganos en otras especies (Figura 38). Por tanto, la EXPA de cítricos aCL2131Contig1 podría participar en la abscisión de frutos. El gen aC02006G07SK_c se inducía exclusivamente en la ZAC tras 24 h de tratamiento con etileno, aunque se encontraba en la misma rama que una proteína EXPA reprimida durante la abscisión de los estambres en A. thaliana (AtEXPA11; Lashbrook y Cai, 2008). Estos resultados sugieren que las proteínas muy próximas filogenéticamente pueden desempeñar funciones diferentes y que tales divergencias podría ser, además, consecuencia de la especiación vegetal. Dentro de esta subfamilia, cabe mencionar los genes clementine0.9_029234m.g y clementine0.9_030172m.g porque, aunque no ha sido posible analizar su expresión por no estar representados en la micromatriz de cDNA empleada en este estudio, podrían estar implicados en la abscisión por su proximidad filogenética a los genes MaEXP1 y aC02006G07SK_c, respectivamente (Figura 38). Los resultados referentes a la EXPA aCL1430Contig1, que se reprimía exclusivamente en la ZAC tras 24 $\mathrm{h}$ de tratamiento con etileno, contrastan con lo observado en el trabajo llevado a cabo por Agustí et al. (2009), en el que aCL1430Contig1 se induce preferentemente en la ZAL de la hoja tras 24 h de tratamiento con etileno. Por tanto, en relación a esta EXPA podría existir especificidad de tejido, de modo que actuaría exclusivamente en la abscisión de las hojas de los cítricos. Por otra parte, cabe resaltar la expansina de tipo A (EXLA) aKN0AAQ1YG09RM1_c (clementine0.9_019285m.g), que se inducía exclusivamente en la ZAC tras 12 y $24 \mathrm{~h}$ de tratamiento con etileno, ya que ninguna EXP perteneciente a esta subfamilia había sido implicada hasta el momento con la abscisión. Tanto las $\alpha$ - como las $\beta$-expansinas son capaces de relajar las estructura de las paredes celulares vegetales, sin embargo, este tipo de actividad aún no ha sido demostrada para la expansinas de los tipos A y B (Sampedro y Cosgrove, 2005). Este estudio no aportó información relevante acerca de las $\beta$-expansinas (EXPB) y de las expansinas de tipo B (EXLBs) ya que el único gen con homología a una EXPB, aCL3482Contig1, no mostró cambios de expresión significativos 
durante la abscisión, y los genes con homología a EXLBs, aC18019D04Rv_c (clementine0.9_019843m.g) y aCL4602Contig1 (clementine0.9_019847m.g), se reprimían exclusivamente en la CF tras 12 y $24 \mathrm{~h}$ de tratamiento con etileno o no presentaban resultados de hibridación, respectivamente.

Los resultados del análisis de expresión mediante micromatrices (Anexos 9-17) y del análisis filogenético (apartado 5.3.1) en relación a este tipo de enzimas fueron complementados con un análisis in silico de expresión génica diferencial utilizando el programa informático IDEG6 (Romualdi et al., 2003). Este programa permitió determinar aquellos genes que podrían ser específicos del proceso de abscisión en cítricos a partir del total de genes relacionados con la remodelación de la pared celular. De los diez unigenes que contenían ESTs presentes en genotecas de abscisión, solamente cinco se expresaban diferencialmente en ZAs (Tabla 20). La expresión diferencial en ZAs de los genes correspondientes a la celulasa ácida aCL1347Contig1, la poligacturonasa aCL675Contig4 y la pectin acetilesterasa aCL67Contig4 correlacionaba con los datos de expresión obtenidos mediante el análisis con micromatrices, es decir, se inducían exclusivamente en la ZAC (ver Anexos 9, 10 y 16, respectivamente) y, además, con la relación filogenética encontrada con otras enzimas de pared celular previamente descritas como inducidas en la literatura referente a la abscisión (ver Figuras 30, 31 y 36, respectivamente). Según este análisis in silico, la $\beta$-galactosidasa aCL1378Contig1 y la poligalacturonasa aKN0AAK1DH04FM2_c se expresaban también diferencialmente en las ZAs. Sin embargo, según el análisis de expresión mediante micromatrices, ambos genes se inducían exclusivamente en células de la CF (ver Anexos 13 y 10, respectivamente). A este respecto cabe resaltar que los ESTs de estas genotecas proceden de una mezcla de tejidos que contiene, además de la ZA, tejidos adyacentes a esta, ya que la ZA no se aisló en ninguno de los casos mediante MAL. Por tanto, los ESTs aislados de estas genotecas podrían proceder de la expresión génica de otros tejidos contenidos en la muestra de partida y no exclusivamente de la ZA como en el caso del estudio mediante micromatrices.

Los genes aCL1347Contig1 (CitCEL) y aCL675Contig4 (CitPG) presentaban una elevada probabilidad de ser específicos del proceso de abscisión, tanto por el nivel de inducción en la ZAC que experimentaron durante la activación del proceso de abscisión (Anexos 9 y 10, respectivamente) como por los resultados del análisis filogénetico y el 
análisis in silico de expresión diferencial llevados a cabo en el presente capítulo. Por esta razón, se seleccionaron para el aislamiento de las respectivas regiones promotoras y el posterior análisis in silico de las mismas. El análisis de elementos reguladores en cis determinó que los promotores clonados (ver secuencias en el Anexo 19) presentaban secuencias de unión de factores de transcripción pertenecientes a la familia HD-Zip, como Athb-1 y ATHB5, y a la familia MADS-box, como SQUA y AGL3 (Tabla 21). Estos resultados correlacionan con la inducción de tres factores HD-Zip (C02021F02, IC0AAA56DD03 y C31809D05) y un factor MADS-box (C02017D01) en la ZAC activada con etileno (Tabla 11, apartado 3.3.7), por lo que no se puede descartar una función de estos genes en la regulación de alguno de los promotores de las hidrolasas específicas de la ZAC. La única referencia existente en la literatura que implique a miembros de la familia HD-Zip con la abscisión está relacionada con la presencia de elementos en cis en el promotor de la celulasa BAC de judía que reconocen estos factores de transcripción (Whitelaw et al., 2001). Algunos factores MADS-box han sido también relacionados con la dehiscencia del fruto de Arabidopsis thaliana (Liljegren et al., 2000; Rajani y Sundaresan, 2001), proceso de separación celular que guarda una elevada similitud con la abscisión. Por otra parte, ambos promotores contenían elementos reguladores con homología a los reconocidos por los factores bZIP910, que se expresan en órganos florales de Antirrhinum majus, o por las proteínas HMG-IY en Pisum sativum que regulan la expresión génica a través de la modificación de la cromatina (Gupta et al., 1997). Sin embargo, no se encontraron datos de expresión significativos en el presente trabajo y, hasta el momento, tampoco se conocen referencias en la literatura que relacionen este tipo de proteínas con la abscisión.

La disposición de los promotores de dos genes específicos (CitCEL y CitPG) de un tejido especializado, como es la ZAC, permitiría dirigir la expresión de otros genes candidatos o de función desconocida en dicho tejido en trabajos futuros y así determinar su posible implicación en el proceso. Además, la identificación de secuencias reguladoras en un promotor ha permitido deducir los posibles factores de transcripción que se unen a ellas y que, por tanto, podrían regular la actividad de genes clave durante la abscisión.

Con el objetivo de complementar los resultados del análisis de expresión y del estudio filogenético de las familias génicas tratadas en este capítulo y de comprobar si, 
efectivamente, tal expresión se traducía en alguna evidencia de actividad enzimática, se utilizó una combinación de técnicas bioquímicas e inmunohistoquímicas (apartados 5.2.6 y 5.2.7). El análisis de la composición de monosacáridos de las paredes celulares de la ZAC mediante cromatografía gas-líquido mostró que durante la activación del proceso de abscisión con etileno ( 24 y 48 h) no se producían cambios significativos relevantes en los niveles de arabinosa, ramnosa, xilosa, manosa, galactosa o ácido galacturónico con respecto a las 0 h (ver Tabla 22). Los cambios en el contenido en glucosa (Glc) podrían ser, en parte, consecuencia de la hidrólisis parcial de almidón en las células de la región rica en almidón de la ZAC (Figura 15), por tanto, aunque la Glc puede provenir de la hidrólisis de la celulosa y del xiloglucano, no podemos considerar estos cambios como completamente asociados al desmantelamiento de la pared celular durante la abscisión. Sin embargo, la inmunolocalización de los polisacáridos pécticos $(1 \rightarrow 4)-\beta$-D-galactano, $(1 \rightarrow 5)-\alpha$-Larabinano y HG, reconocidos por los anticuerpos LM5, LM6 y JIM5, respectivamente, reveló alteraciones en su patrón de distribución en la ZAC durante el proceso de abscisión (ver Figura 39). Por tanto, parece ser que las modificaciones en las paredes celulares de la ZAC durante la abscisión se producen a nivel de polisacáridos. Es decir, al menos hasta las $48 \mathrm{~h}$ de tratamiento con etileno o ACC, no varía la composición en monosacáridos estructurales pero sí la organización de los polisacáridos y, como consecuencia, la estructura de las paredes celulares. Estas alteraciones serían suficientes para reducir la adhesión entre las células de la ZAC y permitir la separación efectiva del fruto.

Los epítopos reconocidos por los anticuerpos LM5 y LM6 eran más abundantes en la pared celular primaria que en la lámina media, tal y como se observa en las Figuras 39.A y 39.B. Mientras que, el epítopo reconocido por JIM5 se localizaba, fundamentalmente, en la lámina media y era muy abundante en las uniones entre células situadas junto a los espacios intercelulares (Figura 39.C). Las pectinas constituyen la familia más compleja y heterogénea de polisacáridos de la pared celular (Moller et al., 2008) y están compuestas de homogalacturonano (HG), que puede ser metil-esterificado y acetil-esterificado, ramnogalacturonano I (RG-I), ramnogalacturonano II (RG-II) y xilogalacturonano (Carpita y McCann, 2000). Los HGs están formados por monómeros de ácido D-galacturónico (GalUA) unidos por un enlace $\alpha-(1 \rightarrow 4)$ (Micheli, 2001). Los RG-I intercalan monómeros de $(1 \rightarrow 4)-\alpha$-D-GalUA y L-ramnosa (Rha) unidos por un enlace $\alpha$ - $(1 \rightarrow 2)$ y, además, presentan cadenas laterales que pueden estar formadas desde monómeros hasta largos 
oligosacáridos de $(1 \rightarrow 4)-\beta$-D-galactano, $(1 \rightarrow 5)$ - $\alpha$-L-arabinano o arbinogalactano de tipo I (Caffall y Mohnen, 2009). Por tanto, de las imágenes obtenidas de la ZAC a las $0 \mathrm{~h}$ (Figuras 39.A, 39.B y 39.C) se deduce que las paredes celulares primarias eran especialmente ricas en RG-I, mientras que en la lámina media predominaban los HG parcialmente metil-esterificados o desesterificados.

Tras 24 h de tratamiento con ACC, las células de las 2-3 capas ricas en almidón adyacentes a la región de apariencia meristemática de la ZAC acumulaban los polisacáridos de la pared celular que detectan los tres anticuerpos (Figuras 39.E, 39.F y 39.G). La fluorescencia observada podría ser resultado de la acumulación de los residuos de $(1 \rightarrow 4)$ - $\beta$ D-galactano, $(1 \rightarrow 5)$ - $\alpha$-L-arabinano y HG procedentes del inicio de la disolución de las paredes primarias.

Tras 36 y 48 h de tratamiento con ACC, la fluorescencia era considerablemente mayor en las capas celulares próximas a la zona de separación (Figuras 39.H, 39.J, 39.K, 39.N, 39.0 y 39.P), donde se observa mayor degradación de las paredes celulares y la lámina media así como degeneración celular (ver también Figura 15.I). Por tanto, la elevada fluorescencia podría ser la consecuencia de un estado más avanzado de la hidrólisis de las pectinas. El desmantelamiento de la compleja red que constituyen las pectinas podría hacer más accesibles los epítopos a los anticuerpos LM5, LM6 y JIM5, de ahí que se observe mayor fluorescencia en la ZAC. Además, especialmente a las 48 h de tratamiento con ACC, en las regiones donde la separación celular era completa (Figuras 39.Q, 39.R y 39.S) se observaba una materia amorfa de fluorescencia muy intensa resultado, posiblemente, de la acumulación de residuos de $(1 \rightarrow 4)$ - $\beta$-D-galactano, $(1 \rightarrow 5)-\alpha$-L-arabinano y HG procedentes de la disolución total de las paredes celulares y la lámina media.

La acción de las PMEs y las PAEs provoca la desesterificación de las pectinas que las hace más susceptibles a la subsiguiente acción de otras pectinasas (PLs y PGs) y enzimas relacionadas (Taiz y Zeiger, 2006). Por otra parte, las PLs y PGs hidrolizan el enlace $\alpha$ $(1 \rightarrow 4)$ de los polímeros de ácido galacturónico que componen las pectinas (Sun y van Nocker, 2010; Atkinson et al., 2002). Otras hidrolasas que actúan sobre los polisacáridos pécticos son las $\beta$-GALs, que hidrolizan el enlace $\beta$ - $(1 \rightarrow 4)$ de los polímeros que contienen $\beta$-D-galactano (Smith et al., 1998), y las arabinofuranosidasas (ASDs), que hidrolizan los 
residuos terminales no reducidos $\alpha$-L-arabinanofuranosil de diferentes polímeros pécticos y hemicelulósicos (arabinanos, arabinogalactanos, arabinoxilanos, etc.) (Beldman et al., 1996; Itai et al., 2003; Saha, 2000). En el presente estudio, se encontraron genes pertenecientes a algunas de estas familias inducidos en la ZAC, tal y como se ha comentado anteriormente. Las PMEs aCL2379Contig1 y aCL1451Contig1 y la PAE aCL67Contig4 podrían actuar en primer lugar hidrolizando los metil y acetil ésteres, respectivamente, de los HGs. A continuación, podrían actuar las PGs aCL675Contig4, aCL1063Contig1, aCL5261Contig1, aIC0AAA85AB02RM1_c y aCL3497Contig1 y las PLs aIC0AAA15AF11RM1_c y aCL4999Contig1 hidrolizando los HGs. Estos resultados de expresión correlacionan con los resultados de inmunodetección mediante el anticuerpo JIM5, que detecta HGs parcialmente metil esterificados o desesterificados. Por otra parte, la $\beta$-GAL aCL4443Contig1 podría actuar hidrolizando las cadenas laterales de $(1 \rightarrow 4)-\beta$-Dgalactano de los RG-I, hecho que correlaciona con los resultados de la inmunolocalización mediante el anticuerpo LM5. En relación a la inmunolocalización de $(1 \rightarrow 5)-\alpha-\mathrm{L}$ arabinanos, la ASD representada en la micromatriz de cítricos no se inducía en la ZAC, de modo que las alteraciones en la distribución de $(1 \rightarrow 5)$ - $\alpha$-L-arabinanos observadas en la ZAC podrían deberse a la acción de otras ASDs no incluídas en la micromatriz empleada en la presente tesis o a la acción de alguna otra glicósido hidrolasa con actividad $\alpha$-Larabinofuranosidasa. De hecho, aCL271Contig1 y aCL2321Contig1 (que se sobre-expresan en la ZAC) son homólogas a AtBXL1 (Figura 32), enzima que presenta actividad dual xilano 1,4- $\beta$-xilosidasa y $\alpha$-L-arabinofuranosidasa (Arsovski et al., 2009; Minic et al., 2006).

A continuación, se expone el modelo propuesto del modo de acción de estas enzimas sobre los polisacáridos pécticos estudiados por inmunolocalización (Figura 40). Este modelo explicaría el incremento de fluorescencia detectado en las paredes celulares y la lámina media de la ZAC fundamentalmente a las 36 y 48 h de tratamiento con ACC (ver Figura 40.C y Figura 39) y sería compatible con los datos del contenido en monosacáridos de las paredes de las células de la ZAC. 
A
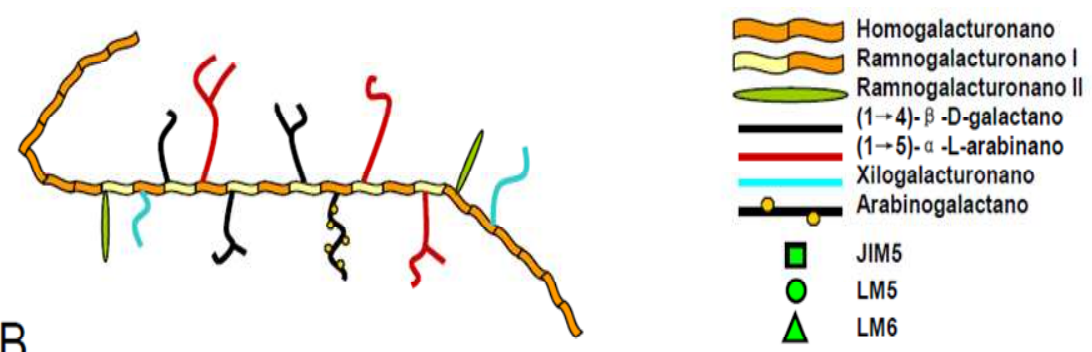

B

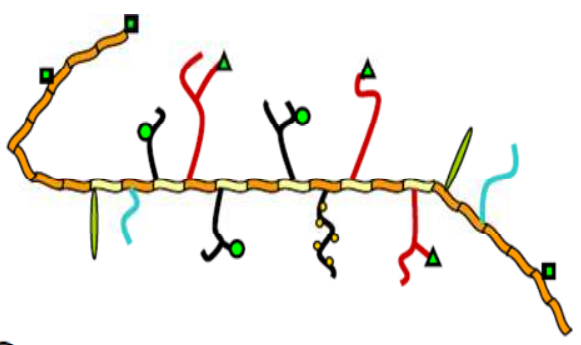

C

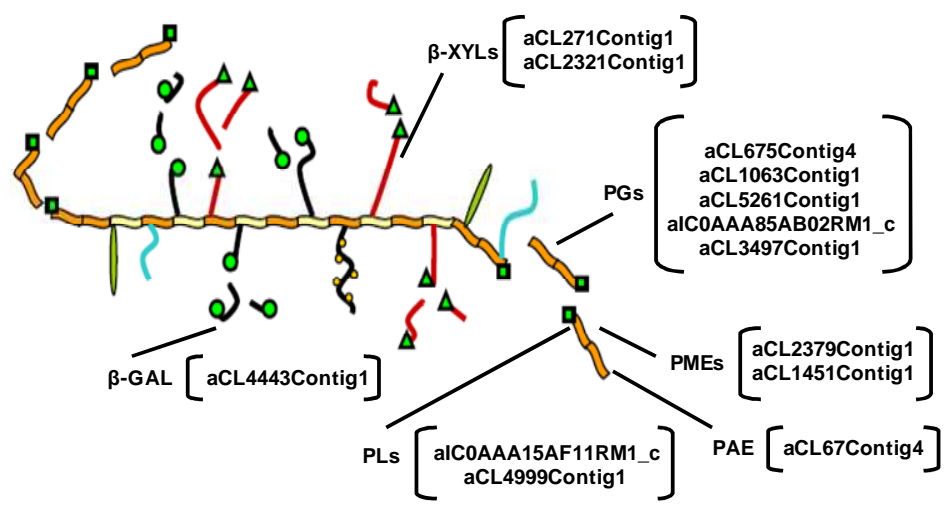

Figura 40. A. Organización de los polisacáridos pécticos de la pared celular (figura adaptada de Taiz y Zeiger, 2006). B. Detección de los epítopos $(1 \rightarrow 4)-\beta$-D-galactano, $(1 \rightarrow 5)$ - $\alpha$-L-arabinano y HG parcialmente metilesterificado o desesterificado mediante los anticuerpos LM5, LM6 y JIM5, respectivamente, al inicio del proceso de abscisión. C. Detección de los epítopos $(1 \rightarrow 4)-\beta$-D-galactano, $(1 \rightarrow 5)-\alpha$-L-arabinano y HG mediante anticuerpos tras la acción de PMEs, PAEs, PLs, PGs, $\beta$-GALs y $\beta$-XYLs durante el proceso de abscisión. 
En resumen, la combinación de técnicas de análisis de expresión diferencial mediante hibridación de micromatrices de cDNA y mediante programas informáticos de predicción de expresión diferencial, de análisis filogenético y de análisis de secuencias ha proporcionado, del total de familias génicas relacionadas con la modificación de la pared celular, un grupo de genes potencialmente implicados en la abscisión de frutos cítricos y, por tanto, de gran utilidad para desarrollar otros estudios en relación a este proceso fisiológico. Los resultados obtenidos han mostrado que gran parte de los genes de cítricos inducidos en la ZAC presentaban proximidad filogenética con genes descritos en la literatura como inducidos también en la ZA de diferentes tejidos/órganos en diferentes especies vegetales y que estos genes compartían, además, los dominios específicos de la familia génica correspondiente, hecho que refuerza la información obtenida del análisis de expresión mediante micromatrices. Asimismo, dentro de una misma familia génica, algunos miembros presentaban diferentes patrones de expresión espaciales y/o temporales o bien el patrón de expresión variaba en función de la especie vegetal, a pesar de la proximidad filogenética, lo que sugiere la existencia de una especialización funcional. Así, el análisis de expresión en las células de la CF tras el tratamiento con etileno ha revelado que, además de existir genes cuya expresión aumentaba exclusivamente en la ZAC y que, por tanto, constituyen isoformas específicas del proceso de abscisión, determinados genes experimentaban un incremento de expresión en ambos tejidos (ZAC y CF). Además, estos genes estaban estrechamente relacionados con otros descritos en la literatura como inducidos en ZAs de otras especies vegetales $\mathrm{y}$, por tanto, no se puede descartar su implicación en el proceso de abscisión. Por otra parte, la disposición de la secuencia del genoma de Citrus clementina ha permitido obtener el conjunto de genes que constituyen estas familias génicas y, aunque para muchos genes no se disponían de datos de expresión debido a que no se encuentran representados en la micromatriz empleada en este estudio, por su proximidad filogenética con otros genes implicados en el proceso de abscisión en diferentes especies vegetales deben tenerse en consideración para otros estudios en relación al proceso de abscisión. Finalmente, ha sido posible relacionar los resultados de expresión asociados a algunas de estas familias génicas con los cambios estructurales detectados en las paredes celulares de la ZAC durante la activación del proceso de abscisión. 


\subsection{Conclusiones}

Los resultados expuestos en este capítulo han permitido obtener las siguientes conclusiones:

1) El análisis de los perfiles de expresión de los genes relacionados con la remodelación de la pared celular en la zona de abscisión C (ZAC) y en la corteza del fruto (CF) durante la abscisión inducida por etileno, junto con el análisis filogenético entre las proteínas de Citrus clemetina, las proteínas reguladas por el etileno en la ZAC y/o en la CF y las proteínas descritas en la literatura como asociadas a la abscisión en otras especies vegetales, ha permitido identificar genes potencialmente específicos del proceso de abscisión. Entre estos genes se encuentran:

- una celulasa (aCL1347Contig1/CitCEL)

- cuatro poligalacturonasas (aCL675Contig4/CitPG, aCL1063Contig1,

aIC0AAA85AB02RM1_c y aCL5261Contig1)

- una xiloglucano endotransglicosilasa (aIC0AAA99CH05RM1_c)

- una $\beta$-galactosidasa (aCL4443Contig1)

- dos pectin metilesterasa (aCL1451Contig1 y aCL2379Contig1)

- una pectin acetilesterasa (aCL67Contig4)

- una pectato liasa (aIC0AAA15AF11RM1_c)

- dos $\alpha$-expansinas (aCL2131Contig1 y aC02006G07SK) y una

expansina de tipo A (aKN0AAQ1YG09RM1_c)

Se han identificado genes inducidos tanto en las células de la ZAC como de la CF que se encuentran estrechamente relacionados con genes implicados en el proceso de abscisión en otras especies vegetales y que, por tanto, desempeñarían una función en la abscisión además de estar implicados en otros procesos asociados a la CF. Entre estos genes se encuentran:

- una poligalacturonasa (aCL3497Contig1)

- dos $\beta$-xilosidasas (aCL2321Contig1 y aCL271Contig1)

- una pectato liasa (aCL4999Contig1) 
2) Los genes correspondientes a la celulasa aCL1347Contig1, la poligalacturonasa aCL675Contig4 y la pectin acetilesterasa aCL67Contig4 se encontraban, además, altamente representados en genotecas procedentes de diferentes zonas de abscisión de cítricos. Por tanto, dentro de las familias génicas asociadas a la modificación de la pared celular, son potencialmente importantes en el desarrollo del proceso de abscisión.

3) El aislamiento de la región promotora de los genes CitCEL (aCL1347Contig1) y CitPG (aCL675Contig4) ha permitido deducir los posibles factores de transcripción que regularían la expresión de dichos genes. Tres factores transcripcionales HD-Zip (C02021F02, IC0AAA56DD03 y C31809D05) y un factor MADS-box (C02017D01), inducidos en la ZAC activada con etileno, podrían desempeñar una función en la regulación de estas hidrolasas específicas de la ZAC.

4) El análisis de la composición de monosacáridos mediante cromatografía gas-líquido (GLC) y la inmunolocalización de polisacáridos en las paredes celulares de la ZAC ha revelado que los cambios en la organización de los polisacáridos son suficientes para reducir la adhesión entre las células de la ZAC. Los datos de expresión génica junto a los resultados obtenidos de la inmunolocalización sugieren que los cambios observados en los HGs parcialmente desesterificados son resultado de la acción de dos pectin metilesterasas, una pectin acetilesterasa, dos pectato liasas y cinco poligalacturonasas inducidas en la ZAC activada por etileno. Por otra parte, los cambios que se producen en los $(1 \rightarrow 4)-\beta$-Dgalactanos y en los $(1 \rightarrow 5)-\alpha$-L-arabinanos pueden deberse a la acción de una $\beta$ galactosidasa y dos $\beta$-xilosidasas con posible actividad $\alpha$-L-arabinofuranosidasa, respectivamente, inducidas en la ZAC. 
VI. Discusión general 
El conocimiento bioquímico y molecular actual asociado inequívocamente al proceso de abscisión de órganos vegetales ha sido generado, en parte, gracias al estudio de la abscisión de órganos florales en el sistema modelo Arabidopsis thaliana. Así, el estudio de mutantes en los que la abscisión está parcial o totalmente bloqueada o bien transcurre de forma anómala ha proporcionado información muy interesante sobre la función de diferentes genes en el proceso. Sin embargo, hoy en día existe un interés económico creciente por el desarrollo de aproximaciones moleculares centradas en la abscisión de órganos en especies con valor agronómico y comercial. Además, la dificultad que supone obtener material vegetal para estudios moleculares del proceso, debido al reducido número de capas celulares que conforman la zona de abscisión, ha contribuido a la utilización de otros sistemas vegetales más convenientes anatómicamente que A. thaliana, como Sambucus nigra, Solanum lycopersicon o Citrus spp.

En el caso de los cítricos, debido a que se trata de una especie de gran interés económico, es importante dirigir la investigación del proceso de abscisión hacia las estructuras reproductivas (flores, ovarios en desarrollo y frutos). Un conocimiento profundo de las rutas o procesos metabólicos implicados en la abscisión de los cítricos impulsaría el desarrollo de herramientas agronómicas y biotecnológicas encaminadas a la manipulación de este proceso, que sería de especial utilidad en el caso del fruto. Sin embargo, la ZA de los frutos (ZAC) se localiza en la región del cáliz y está flanqueada por otros tejidos, de modo que resulta difícil el aislamiento de células exclusivas de la ZA para estudios moleculares sin arrastrar una elevada contaminación de los tejidos adyacentes. Por el contrario, la zona de abscisión laminar (ZAL), localizada entre el limbo foliar y el peciolo, ha sido elegida tradicionalmente como sistema modelo para el estudio de la abscisión en cítricos (Addicott, 1982; Agustí et al., 2008, 2009; Burns et al., 1998; Iwahori y van Stevenink, 1976) debido a su cómodo acceso y fácil aislamiento y al hecho de que el material vegetal, las hojas, está disponible en cualquier época del año.

Hasta el momento, el estudio global del proceso de abscisión ha sido escaso debido, en parte, a la carencia general de recursos genómicos que existía, especialmente en relación a las especies de interés agronómico. Sin embargo, los avances recientes en el área de la genómica funcional han proporcionado un conjunto de herramientas que pueden ser de gran utilidad para afrontar nuevos retos y ampliar la información disponible sobre el proceso de 
abscisión, que es limitada si se compara con la cantidad de datos asociados a otros procesos biológicos. En el presente trabajo, con el propósito de caracterizar en un sentido amplio el proceso de abscisión de los frutos, se han empleado técnicas de análisis de expresión génica a gran escala tales como la hibridación de micromatrices. Complementariamente, la utilización de técnicas que posibilitan el aislamiento de tipos celulares concretos, como la microdisección asistida por láser, ha permitido solventar los problemas de muestreo que entraña la ZAC. Además, el estudio morfológico y anatómico de la ZAC mediante diferentes técnicas de microscopía e histoquímica así como la puesta a punto de métodos de análisis de metabolitos (HPLC-MS/MS y cromatografía gas-líquido) a partir de tejido microdiseccionado han enriquecido considerablemente los resultados de expresión génica asociados a la abscisión de frutos cítricos. Asimismo, la utilización de herramientas bioinformáticas (análisis filogenéticos, análisis de secuencias y análisis in silico de colecciones de ESTs) y la disposición de la secuencia del genoma haploide de Citrus clementina (versión v0.9; 6,5 equivalentes genómicos) ha sido de gran utilidad. En definitiva, la combinación de tales herramientas ha proporcionado información muy relevante sobre los cambios generales que se producen en este tejido tanto a nivel celular como a escala molecular y ha permitido identificar genes o familias génicas con una función reguladora potencial a distintos niveles dentro de la ruta de la abscisión.

Tradicionalmente, se ha utilizado la fitohormona etileno para acelerar la abscisión de órganos y poder llevar a cabo estudios enfocados a dilucidar la serie de eventos que tienen lugar durante el desarrollo del proceso (Addicott, 1982; Sexton y Roberts, 1982). Los tratamientos in vitro con etileno o con su precursor, el ácido 1-aminociclopropano-1carboxílico (ACC), han permitido sincronizar la abscisión de frutos, además de acelerar el proceso de abscisión. Se ha constatado también el efecto análogo de ambos tratamientos en una variedad de recolección temprana-media ('Washington Navel') y en una variedad de recolección media-tardía ('Ricalate Navel'). Por tanto, los resultados obtenidos se pueden extrapolar a otras variedades de cítricos que provocan también problemas en el calendario de recolección de la fruta, acontecimiento que se conoce como abscisión precosecha.

La caracterización morfológica y anatómica de la ZAC ha aportado información relevante sobre los cambios específicos que experimentan las células de la ZAC durante el desarrollo de la abscisión. Además, ha permitido delimitar con exactitud las capas celulares 
que conforman la ZAC. Así, la ZAC de los frutos cítricos está compuesta por 10-15 capas organizadas en dos áreas celulares: una con apariencia meristemática, en la parte proximal de la ZAC, y otra rica en gránulos de almidón, en la parte distal de la ZAC. Se ha comprobado también que en la ZAC, tras la separación celular, se produce expansión celular en localizaciones concretas de la parte proximal (tejido parenquimático del cáliz) y distal (haces vasculares), a diferencia del modelo propuesto en A. thaliana (Patterson, 2001) según el cual sólo se produce expansión celular en la parte proximal de la ZA, lo que refleja que pueden existir diferencias en el desarrollo del proceso según la especie.

El análisis de expresión génica global de la ZAC activada por etileno (Capítulo III) se ha abordado mediante el empleo de la micromatriz de cDNA de cítricos del CFGP (Martínez-Godoy et al., 2008). Tanto la microdisección asistida por láser, que ha permitido aislar células exclusivas de la ZAC, como la comparación con el análisis de expresión en las células de la corteza del fruto, que ha permitido identificar aspectos comunes y divergentes entre la ZAC y la CF (Capítulos IV y V), han proporcionado datos muy específicos del proceso de abscisión a nivel molecular.

Los resultados de expresión génica (Capítulo III) sugieren una regulación y actuación secuencial de la maquinaria celular durante el desarrollo del proceso de abscisión (Figura 41). Durante la primera etapa de la abscisión, las células de la ZAC reciben una serie de señales o estímulos que provocan cambios en su metabolismo y actividad. Estos primeros eventos se reflejan en la activación de la señalización mediada por hormonas. Concretamente, se indujeron genes implicados en la biosíntesis de etileno y ácido abscísico así como factores de transcripción de respuesta a etileno, auxinas y ácido abscísico. De modo que el balance entre estas hormonas podría estar controlando el proceso de abscisión. A este complejo de señalización hormonal se suma la activación de genes relacionados con la destoxificación de especies reactivas del oxígeno (ROS). El hecho de que aumente la expresión de este tipo de genes implica una sobreproducción de especies ROS en la ZAC, que han sido relacionadas previamente con la señalización durante la abscisión (Michaeli et al., 2001; Sakamoto et al., 2008). Por otra parte, se activa la expresión de genes que codifican quinasas de tipo 'serine/threonine kinase', quinasas de tipo receptor (RLK) y proteínas con repeticiones de leucina (LRR), que serían responsables de la transducción de estas señales. 
Esta cascada de eventos de señalización va acompañada de la activación de la regulación de la transcripción mediante la inducción de factores de transcripción, entre los que cabe destacar factores de las familias bHLH, MADS-box y MYB, implicadas en la regulación de procesos de separación celular (Steiner-Lange et al., 2003; van Nocker, 2009; Zhu et al., 2004).

Paralelamente, se inducen genes relacionados con la biogénesis de ribosomas y con el inicio de la traducción, al mismo tiempo que se activa la maquinaria proteolítica mediada por ubiquitina. La activación de ambos procesos (síntesis y degradación de proteínas) sugiere que durante el proceso de abscisión se produce un importante recambio de proteínas gracias al cual se eliminan proteínas antiguas o posibles represores del proceso y se sintetizan otras proteínas necesarias para poder afrontar el nuevo metabolismo de la zona de abscisión. La activación de la síntesis de proteínas va acompañada también de un aumento en la síntesis de vesículas y en la actividad de las proteínas que participan en el transporte de las mismas. Los resultados del Capítulo IV revelaron que las células de la ZAC promueven, mayoritariamente, la ruta secretora y reducen la actividad de las vías de tráfico endocítico, vacuolar y de reciclaje. Este transporte podría estar relacionado con el aporte extracelular de enzimas necesarias para la separación celular. Además, el análisis complementario de los perfiles de expresión de estos genes en las células de la CF (Capítulo IV) ha permitido definir qué genes relacionados con el transporte de vesículas actuarían de manera específica en la ZAC y, por tanto, en el proceso de abscisión, y qué genes participarían en procesos relacionados con la separación celular comunes a otros aspectos del desarrollo vegetal, como la maduración, la senescencia o la expansión celular.

Tras la integración de las señales inductoras de la abscisión, la activación de la regulación de la transcripción, la modificación del escenario proteico y la distribución celular de nuevas proteínas prosiguen una serie de procesos encaminados a facilitar la separación celular y, en última instancia, el desprendimiento del órgano, actividad para la que está programado este tejido. En este sentido, las células de la ZAC activaron el metabolismo de la pared celular tanto a nivel de degradación como de biosíntesis. En lo referente a la disolución de la pared celular, se indujeron una serie de genes que codifican enzimas que hidrolizan los polisacáridos de la pared celular y/o la lámina media y alteran 
sus propiedades mecánicas, como las celulasas, las poligalacturonasas, las pectato liasas, las pectin esterasas, las xilosidasas, las xiloglucano transglicosilasas, las $\beta$-galactosidasas y las expansinas. La utilización de herramientas de análisis in silico ha enriquecido la información de la que se disponía hasta el momento acerca de estas familias génicas y su contribución en el proceso de abscisión. Además, el análisis en paralelo de la expresión de estos genes en la CF ha permitido caracterizar la localización de este complejo de genes y determinar su especificidad en el proceso. Complementariamente, el análisis de monosacáridos de pared mediante cromatografía gas-líquido sugiere que en la ZAC del fruto de los cítricos no se producen cambios en la composición de las paredes celulares durante la abscisión, mientras que la inmunolocalización de polisacáridos estructurales en las células de la ZAC (Capítulo V) ha aportado información relevante acerca de las alteraciones que se producen en el patrón de distribución de los polisacáridos de pared en la ZAC. A su vez, estas técnicas bioquímicas han permitido establecer un modelo sobre el modo de acción de estas enzimas durante el proceso de abscisión (Figura 40).

En relación a la biogénesis de pared, se activó la maquinaria de biosíntesis de celulosa y otros polisacáridos de la pared celular y el metabolismo de azúcar-nucleótidos, que regulan esta biosíntesis. Como se ha comentado anteriormente, en el plano de fractura de la ZAC se observa expansión celular a las 96 h de tratamiento con etileno (ver Figuras 14.D y 14.E). Este crecimiento celular puede colaborar en la separación celular o puede estar relacionado con la creación de capas protectoras en las partes del cáliz que van a quedar expuestas tras la abscisión. Por tanto, estos genes asociados a la biosíntesis de pared estarían relacionados con la última etapa del proceso de separación celular.

Además de estas modificaciones extracelulares, se observa también una activación de la síntesis de lignina en la ZAC. La baja especificidad de los métodos de detección de la lignina ha provocado que la implicación de este polímero en la abscisión haya sido un motivo de controversia. Sin embargo, la inducción de varios genes de biosíntesis de lignina en la ZAC junto con los resultados de la tinción con phloroglucinol y del análisis de intermediarios de la ruta de biosíntesis mediante HPLC-MS/MS (Capítulo III) demuestran que, efectivamente, se sintetiza lignina en la ZAC y seguidamente se deposita en el plano de fractura, concretamente, en su parte distal. Este hecho sugiere que la deposición de lignina durante la abscisión de los frutos parece estar relacionada con la generación de una 
tensión en la zona de separación que posibilite la rotura mecánica de las paredes celulares, más que con la formación de una barrera defensiva de tipo físico. Los resultados de expresión muestran que, complementariamente, se inducían genes de la ruta de biosíntesis de cutina y, además, se detectó deposición de este polímero en el plano de fractura de la ZAC (Capítulo III). Esta deposición de cutina podría estar relacionada con la impermeabilización y el sellado de la herida resultante de la abscisión.

Como ya se ha comentado, paralelamente a la síntesis de proteínas se activa la ruta secretora en la ZAC. Este transporte podría estar relacionado con el aporte extracelular de enzimas de modificación de la pared necesarias para la separación celular y con el aporte de monómeros de lignina y cutina al plano de fractura.

Por último, las células de la ZAC activan una serie de genes que codifican proteínas relacionadas con la defensa frente a patógenos (quitinasas, proteínas PR y proteínas de tipo NBS-LRR). Esta activación de rutas defensivas ocurriría como medida preventiva ya que la herida que se produce en la planta tras el desprendimiento del fruto constituye un lugar propicio para el ataque patogénico.

En definitiva, los resultados obtenidos en este estudio han permitido establecer la secuencia de eventos que, de manera ordenada, dirige la actividad de las células de la ZAC desde su activación hasta la separación celular (Figura 41). La combinación de herramientas genómicas y bioinformáticas, de técnicas de histoquímica y microscopía y de técnicas de análisis bioquímico, junto con el empleo de la microdisección asistida por láser, han proporcionado una visión global de los cambios moleculares, bioquímicos y anatómicos que se producen durante el proceso de abscisión de los frutos cítricos. El trabajo desarrollado en la presente tesis supone, por tanto, un abordaje del proceso de abscisión del fruto muy completo y exhaustivo en una especie vegetal con elevado valor agronómico y comercial como son los cítricos. 

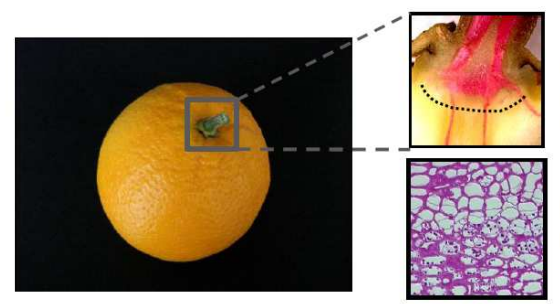

Cáliz

Zona de abscisión C (ZAC)

Corteza del fruto (CF)

亿

Región de apariencia meristemática

Región rica en almidón

ETILENO

I

$12 \mathrm{~h}$ - Señalización (fitohormonas, ROS, RLKs, LRR-RLKs)

- Regulación de la transcripción

- Metabolismo de proteínas

$24 \mathrm{~h}$-Tráfico intracelular de vesículas

- Biosíntesis de lignina

- Biosíntesis de cutina

- Remodelación de la pared celular

- Biosíntesis de pared celular

- Defensa frente al ataque de patógenos

$48 \mathrm{~h}$

Remodelación de la pared

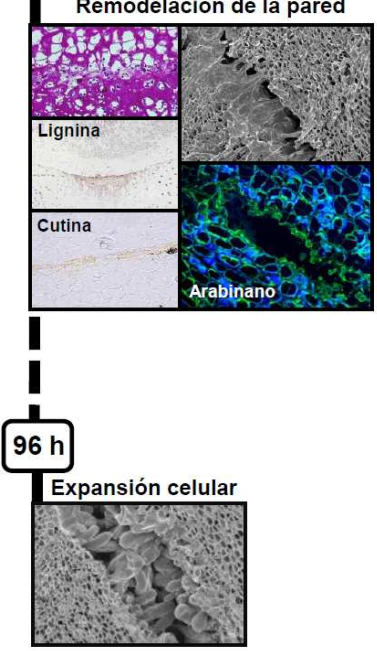

Figura 41. Modelo propuesto sobre el proceso de abscisión de frutos cítricos activado por etileno. La ZAC de los frutos está formada por 10-15 capas celulares organizadas en dos áreas fácilmente distinguibles: una con apariencia meristemática en la parte proximal de la ZAC y otra rica en gránulos de almidón en la parte distal de la ZAC. Las primeras respuestas al tratamiento con etileno en la ZAC (12 h) a nivel transcripcional consisten en la activación de la señalización mediada por hormonas y especies reactivas del oxígeno (ROS), la transducción de señales, la regulación de la transcripción y el metabolismo de proteínas. A las $24 \mathrm{~h}$ de tratamiento con etileno prosigue la activación de una serie de procesos encaminados a facilitar la separación celular y la protección frente al ataque de patógenos: el tráfico intracelular de vesículas, la biosíntesis de lignina y cutina, la remodelación de la pared celular, la biosíntesis de polisacáridos de pared y la resistencia frente a patógenos. Estos resultados de expresión génica se traducen en cambios a nivel celular como el desmantelamiento de la pared celular y la deposición de lignina y cutina observada en la ZAC durante las $48 \mathrm{~h}$ de tratamiento con etileno y la expansión celular observada a las $96 \mathrm{~h}$ en el plano de fractura de la ZAC. 
VII. Conclusiones generales 
Los resultados obtenidos en el presente estudio han permitido establecer las siguientes conclusiones:

1) La zona de abscisión $\mathrm{C}$ (ZAC) de los frutos cítricos está compuesta por 10-15 capas celulares organizadas en dos áreas fácilmente distinguibles: una con apariencia meristemática en la parte proximal de la ZAC y otra rica en gránulos de almidón en la parte distal de la ZAC. El desmantelamiento de los polisacáridos que constituyen la lámina media y las paredes de las células de la ZAC se produce exclusivamente en las capas celulares de la región rica en gránulos de almidón.

2) Se han delimitado los cambios específicos que se producen a nivel celular en la ZAC activada por etileno. A las $48 \mathrm{~h}$ de tratamiento con etileno se produce la disolución de las paredes celulares y la lámina media y la consiguiente separación celular, así como la deposición de polímeros extracelulares (lignina y cutina). A las 96 h de tratamiento con etileno se produce la expansión celular en la parte proximal (tejido parenquimático), posiblemente en las células de la región de tipo meristemático, y distal (haces vasculares) de la ZAC.

3) El tratamiento con etileno in vitro sobre frutos maduros induce la expresión de genes relacionados con la activación de la ZAC. Así, a las 12 h de tratamiento se activa:

- la señalización mediada por hormonas y especies reactivas del oxígeno

- la transducción de señales

- la regulación de la transcripción

- el metabolismo de proteínas

Por otra parte, se inducen genes relacionados con el desarrollo de la abscisión. Así, a las $24 \mathrm{~h}$ de tratamiento se activa:

- el tráfico intracelular de vesículas

- la degradación de la pared celular y la lámina media

- la biogénesis de polisacáridos de la pared celular

- la biosíntesis de lignina y cutina

- la defensa frente a patógenos 
4) Las células de la ZAC promueven mayoritariamente el transporte extracelular de proteínas en detrimento de otros procesos de transporte (tráfico endocítico, vacuolar y de reciclaje). Los genes relacionados con la secreción de proteínas que participarían específicamente en el proceso de abscisión codifican:

- una COPI

- una Arf-GTPasa

- una Arf-GEF

- una Arf-GAP

- tres Rab-GTPasas

Por otra parte, se han identificado genes relacionados con el aporte extracelular de proteínas que participarían en la abscisión y en otros procesos asociados a la CF también regulados por el etileno. Entre estos genes se encuentran:

- una COPI

- una COPII

- tres Rab-GTPasas

- dos proteínas SNARE

- una proteína Sec15-like

5) Se han identificado genes relacionados con la disolución y modificación de la pared celular que podrían participar específicamente en el proceso de abscisión. Entre estos genes se encuentran:

- una celulasa

- cuatro poligalacturonasas

- una xiloglucano transglicosilasa

- una $\beta$-galactosidasa

- dos pectin metilesterasas,

- una pectin acetilesterasa

- una pectato liasa

- tres expansinas

Por otra parte, se han identificado genes relacionados con la remodelación de la pared celular que desempeñarían una función en la abscisión y en otros procesos asociados a la $\mathrm{CF}$ también regulados por el etileno. Entre estos genes se encuentran: 
- una poligalacturonasa

- una pectato liasa

- dos $\beta$-xilosidasas

6) Los datos de expresión génica junto a los resultados obtenidos de la localización de epítopos pécticos en las paredes celulares de la ZAC sugieren que los cambios observados en los HGs parcialmente desesterificados son resultado de la acción de, al menos, dos pectin metilesterasas, una pectin acetilesterasa, dos pectato liasas y cinco poligalacturonasas inducidas en la ZAC activada por etileno. Por otra parte, los cambios que se producen en los $(1 \rightarrow 4)$ - $\beta$-D-galactanos y en los $(1 \rightarrow 5)$ - $\alpha$-L-arabinanos pueden deberse a la acción de una $\beta$-galactosidasa y dos $\beta$-xilosidasas con posible actividad $\alpha$-Larabinofuranosidasa, respectivamente, inducidas en la ZAC. 
VIII. Referencias bibliográficas 
Achyuthan, K.E., Achyuthan, A.M., Adams, P.D., Dirk, S. M., Harper, J.C., Simmons, B.A., Singh, A.K. 2010. Supramolecular self-assembled chaos: polyphenolic lignin's barrier to cost-effective lignocellulosic biofuels. Molecules, 15 (12): 8641-8688.

Addicott, F. T. 1982. Abscission. University of California Press, Berkeley, California.

Agustí, J., Merelo, P., Cercós, M., Tadeo, F.R., Talón, M. 2008. Ethylene-induced differential gene expression during abscission of citrus leaves. Journal of Experimental Botany, 19: 2717-2733.

Agustí, J., Merelo, P., Cercós, M., Tadeo, F.R., Talón, M. 2009. Comparative transcriptional survey between laser-microdissected cells from laminar abscission zone and petiolar cortical tissue during ethylene-promoted abscission in citrus leaves. BMC Plant Biology, 9: 127.

Agustí, M. 2003. Citricultura. Ed. Mundi-Prensa, Madrid, España.

Agustí, M., El-Otmani, M., Aznar, M., Juan, M., Almela, V. 1995. Effect of 3,5,6trichloro-2-pyridyloxyacetic acid on clementine early fruitlet development and on fruit size at maturity. Journal of Horticultural Science, 70: 955-962.

Agustí, M., García-Marí, F., Guardiola, J.L. 1982. The influence of flowering intensity on the shedding of reproductive structures in sweet orange. Scientia Horticulturae, 17: 343352 .

Altschul, S.F., Gish, W., Miller, W., Myers, E.W., Lipman, D.J. 1990. Basic local alignment search tool. Journal of Molecular Biology, 215: 403-410.

Amorós, M. 2003. Producción de agrios. Ediciones Mundi-Prensa, Madrid, España.

Antosiewicz, D.M., Purugganan, M.M., Polisensky, D.H., Braam, J. 1997. Cellular localization of Arabidopsis xyloglucan endotransglycosylase-related proteins during development and after wind stimulation. Plant Physiology, 115: 1319-1328.

Aparicio, S., Morrison, A., Gould, A., Gilthorpe, J., Chaudhuri, C., Rigby, P., Krumlauf, R., Brenner, S. 1995. Detecting conserved regulatory elements with the model genome of the Japanese puffer fish, Fugu rubripes. Proceedings of the National Academy of Sciences of the United States of America, 92:1684-1688.

Arrowsmith, D.A., de Silva, J. 1995. Characterisation of two tomato fruit-expressed cDNAs encoding xyloglucan endo-transglycosylase. Plant Molecular Biology, 28: 391-403.

Arsovski, A.A., Popma, T.M., Haughn, G.W., Carpita, N.C., McCann, M.C., Tamara, L., Western, T.L. 2009. AtBXL1 Encodes a Bifunctional $\beta$-D-Xylosidase/ $\alpha$-LArabinofuranosidase Required for Pectic Arabinan Modification in Arabidopsis Mucilage Secretory Cells. Plant. Physiology. 150: 1219-1234. 
Assaad, F.F., Huet, Y., Mayer, U., Jürgens, G. 2001. The cytokinesis gene KEULE encodes a Sec1 protein that binds the syntaxin KNOLLE. The Journal of Cell Biology, 152(3): 531-543.

Atkinson, R.G., Schröder, R., Hallett, I.C., Cohen, D., MacRae, E.A. 2002. Overexpression of polygalacturonase in transgenic apple trees leads to a range of novel phenotypes involving changes in cell adhesion. Plant Physiology. 129: 122-133. Molecules. 15: 8641-8688.

Audic, S., Claverie, J.M. 1997. The significance of digital gene expression profiles. Genome Research, 7(10): 986-995.

Barlowe, C., Orci, L., Yeung, T., Hosobuchi, M., Hamamoto, S., Salama, N., Rexach, M.F., Ravazzola, M., Amherdt, M., Schekman, R. 1994. COPII: a membrane coat formed by Sec proteins that drive vesicle budding from the endoplasmic reticulum. Cell, 77: 895-907.

Bartuszevige, A.M., Hughes, M.R., Bailer, A.J., Gorchov, D.L. 2006. Weather-related patterns of fruit abscission mask patterns of frugivory. Can J Bot., 84: 869-875.

Bassham, D.C., Brandizzi, F., Otegui, M.S., Sanderfootd, A.A. 2008. The secretory system of Arabidopsis. The Arabidopsis Book.

Batoko, H., Zheng, H.Q., Hawes, C., Moore, I. 2000. A Rab1 GTPase is required for transport between the endoplasmic reticulum and Golgi apparatus and for normal Golgi movement in plants. Plant Cell, 12: 2201-2217.

Batt, T., Woolhouse, H.W. 1975. Changing activities during senescence and sites of synthesis of photosynthetic enzymes in leaves of labiate, Perilla frutenscens (L.) Britt. Journal of Experimental Botany, 26: 569-579.

Baumann, M.J., Eklöf, J.M., Michel, G., Kalla, A.M., Teeri, T.T., Czjzek, M., Brumer III, H. 2007. Structural evidence for the evolution of xyloglucanase activity from xyloglucan endo-transglycosylases: Biological implications for cell wall metabolism. The Plant Cell, 19: 1947-1963.

Bednarek, S.Y., Reynolds, T.L., Schroeder, M., Grabowski, R., Hengst, L., Gallwitz, D., Raikhel, N.V. 1994. A small GTPbinding protein from Arabidopsis thaliana functionally complements the yeast YPT6 null mutant. Plant Physiol., 104: 591-596.

Beldman, G., Osuga, D., Whitaker, J.R. 1996. Some characteristics of $\beta$-Dxylopyranosidase, $\alpha$-L-arabinofuranosidases and arabinoxylan $\alpha$-L-arabinofuranosidase from wheat bran and germinated wheat. Journal of Cereal. Science, 23: 169-180.

Belfield, E.J., Ruperti, B., Roberts, J.A, McQueen-Mason, S. 2005.Changes in expansin activity and gene expression during ethylene-promoted leaflet abscission in Sambucus nigra. Journal of Experimental Botany, 56(413):817-23. 
Ben-Cheikh, W., Pérez-Botella, J., Tadeo, F.R., Talón, M., Primo-Millo, E. 1992. Pollination Increases Gibberellin Levels in Developing Ovaries of Seeded Varieties of Citrus. Plant physiology, 114: 557-564.

Beno-Moualem, D., Gusev, L., Dvir, O., Pesis, E., Meir, S. , Lichter, A. 2004. The effects of ethylene, methyl jasmonate and 1-MCP on abscission of cherry tomatoes from the bunch and expression of endo-1,4-b-glucanases. Plant Science, 167: 499-507.

Bewley, J.D., Burton, R.A., Morohashi, Y., Fincher, G.B. 1997. Molecular cloning of a cDNA encoding a (1-4)-beta-mannan endohydrolase from the seeds of germinated tomato (Lycopersicon esculentum). Planta. 203: 454-459.

Binder, B.M., Patterson, S.E. 2009. Ethylene-dependent and -independent regulation of abscission. Stewart Postharvest Review, 5: 1-10.

Bleecker, A.B., Patterson, S.E. 1997. Last exit: senescence, abscission and meristem arrest in Arabidopsis. Plant Cell, 9:1169-79.

Blume, B., Grierson, D. 1997. Expression and ACC oxidase promoter-GUS fusions in tomato and Nicotiana plumbaginifolia regulated by developmental and environmental stimuli. Plant Journal, 12:731-746.

Bonifacino, J.S., Glick, B.S. 2004. The mechanisms of vesicle budding and fusion. Cell, 116: $153-166$.

Bonifacino, J.S., Lippincott-Schwartz, J. 2003. Coat proteins: shaping membrane transport. Nat. Rev. Mol. Cell Biol., 4: 409-414.

Bornman, C.H., Addicott, F.T., Spurr, A.R. 1966. Auxin and gibberellin effects on cell growth and starch during abscission in cotton. Plant Physiology, 41: 871-876.

Boureux, A., Vignal, E., Faure, S., Fort, P. 2007. Evolution of the Rho family of ras-like GTPases in eukaryotes. Mol. Biol. Evol., 24(1): 203-216.

Brembu, T., Winge, P., Bones, A.M., Yang, Z. 2006. A RHOse by any other name: a comparative analysis of animal and plant Rho GTPases. Cell Research, 16: 435-445.

Brown, K.M. 1997. Ethylene and abscission. Physiologia Plantarum, 100:567-76.

Brummell, D.A., Hall, B.D., Bennett, A.B. 1999. Antisense suppression of tomato endo1,4- $\beta$-glucanase Cel2 mRNA accumulation increases the force required to break fruit abscission zones but does not affect fruit softening. Plant Molecular Biology, 40: 615-22.

Buchanan-Wollaston, V. 1994. Isolation of cDNA clones for genes that are expressed during leaf senescence in Brassica napus - Identification of a gene encoding a senescencespecific metallothionein-like protein. Plant Physiology, 105: 839-846. 
Burkey, K.O., Wells, R. 1991. Response of soybean photosynthesis and chloroplast membrane function to canopy development and mutual shading. Plant Physiology, 97: 245252.

Burns, J.K. 2002. Using molecular biology tools to identify abscission materials for citrus. Horticultural Science, 37:459-463.

Burns, J.K., Lewandowski, D.J., Nairn, C.J. y Brown, G.E. 1998. Endo-1,4- $\beta$ glucanase gene expression and cell wall hydrolase activities during abscission in Valencia orange. Physiologia Plantarum, 102: 217-225.

Burns, J.K., Pozo, L.V., Yuan, R., Hockema, B. 2003. Guanfacine and clonidine reduce defoliation and phytotoxicity associated with abscission agents. Journal of the American Society for Horticultural Science, 128: 42-47.

Burns, J.K., Roka, F.M, Li, K-T., Pozo, L., Bucker, R.S. 2006. Late-season 'Valencia' orange mechanical harvesting with an abscission agent and low-frequency harvesting. Horticultural Science, 41: 660-663.

Butenko, M.A., Patterson, S.E., Grini, P.E., Stenvik, G.E., Amundsen, S.S., Mandal, A., Aalen, R.B. 2003. INFLORESCENCE DEFICIENT IN ABSCISSION controls floral organ abscission in Arabidopsis and identifies a novel family of putative ligands in plants. Plant Cell, 15: 2296-2307.

Caffall, K.H., Mohnen, D. 2009. The structure, function, and biosynthesis of plant cell wall pectic polysaccharides. Carbohydr Res., 344: 1879-1900.

Cai, H., Reinisch, K., Ferro-Novick, S. 2007. Coats, tethers, Rabs, and SNAREs work together to mediate the intracellular destination of a transport vesicle. Developmental Cell, 12(5):671-82.

Cai, S., Lashbrook, C.C. 2008. Stamen abscission zone transcriptome profiling reveals new candidates for abscission control: Enhanced retention of floral organs in transgenic plants overexpressing Arabidopsis ZINC FINGER PROTEIN2. Plant Physiology, 146: 1305-1321.

Campbell, P., Braam, J. 1999. In vitro activities of four xyloglucan endotransglycosylases from Arabidopsis. Plant J., 18: 371-382.

Cantarel, B.L., Coutinho, P.M., Rancurel, C., Bernard, T., Lombard, V., Henrissat, B. 2009. The Carbohydrate-Active EnZymes database (CAZy): an expert resource for Glycogenomics. Nucleic Acids Research, 37: D233-D238.

Carpita, N., McCann, M. 2000. The cell wall. En: Biochemistry and Molecular Biology of Plants. Ed. Buchanan BB, Wilhelm G, Jones RL. (Eds.), American Society of Plant Physiologists, 52-108. 
Catala, C., Rose, J.K.C. and Bennett, A.B. 1997. Auxin regulation and spatial localization of an endo-1,4- $\beta$-D-glucanase and a xyloglucan endotransglycosylase in expanding tomato hypocotyls. The Plant Journal, 12: 417-426.

Chao, Q., Rothemberg, M., Solano, R., Roman, G., Terzaghi, W., Ecker, J.R. 1997. Activation of the ethylene gas response pathway in Arabidopsis by the nuclear protein ethylene insensitive 3 and related proteins. Cell, 89: 1133-1144.

Chatre, L., Brandizzi, F., Hocquellet, A., Hawes, C., Moreau, P. 2005. Sec22 and Memb11 Are v-SNAREs of the anterograde endoplasmic reticulum-Golgi pathway in tobacco leaf epidermal cells. Plant Physiology, 139: 1244-1254.

Chen, H., Xiong, L. 2008. Role of HY5 in abscisic acid response in seeds and seedlings. Plant Signaling and Behavior, 3(11): 986-988.

Chen, Y., Shin,Y.K., and Bassham, D.C. 2005. YKT6 is a core constituent of membrane fusion machineries at the Arabidopsis trans-Golgi network. J. Mol. Biol., 350: 92-101.

Cho, S.K., Larue, C.T., Chevalier, D., Wan,g H., Jinn, T-L, Zhang, S., Walker, J.C. 2008. Regulation of floral organ abscission in Arabidopsis thaliana. Proceedings of the National Academy of Sciences USA, 105: 15629-15634.

Chong, Y.T., Gidda, S.K., Sanford, C., Parkinson, J., Mullen, R.T., Goring, D.R. 2009. Characterization of the Arabidopsis thaliana exocyst complex gene families by phylogenetic, expression profiling, and subcellular localization studies. New Phytologist, 185: 401-419.

Churchill, G.A. 2002. Fundamentals of experimental design for cDNA microarrays. Nature Genetics Supplement, 32: 490-495.

Clark, D.G., Richards, C., Hilioti, Z., Lind-Iversen, S., Brown, K. 1997. Effect of pollination on accumulation of ACC synthase and ACC oxidase transcripts, ethylene production and flower petal abscission in geranium (Pelargonium hortorum L.H. Bailey). Plant Molecular Biology, 34: 855-865.

Cluis, C.P., Mouchel, C.F., Hardtke, C.S. 2004. The Arabidopsis transcription factor HY5 integrates light and hormone signaling pathways. The Plant Journal, 38: 332-347.

Cosgrove, D.J. 2000. Loosening of plant cell walls by expansins. Nature, 407: 321-326.

Cosgrove, D.J., Bedinger, P., Durachko, D.M. 1997. Group I allergens of grass pollen as cell wall-loosening agents. Proc. Natl. Acad Sci. USA., 94: 6559-6564.

Coughlan, M.P., Hazlewood, G.P. 1993. beta-1,4-D-Xylan-degrading enzyme systems: biochemistry, molecular biology and applications. Biotechnol. Appl. Biochem., 17: 259289. 
Coupe, S.A., Taylor, J.E., Roberts, J.A. 1995. Characterization of an mRNA encoding a metallothionein-like protein that accumulates during ethylene-promoted abscission of Sambucus nigra L. leaflets. Planta, 197: 442-47.

Coutinho, P.M., Stam, M., Blanc, E., Henrissat, B. 2003. Why are there so many carbohydrate-active enzyme-related genes in plants? Trends Plant Science, 8:563-565.

Cutillas-Iturralde, A., Zarra, I., Fry, S.C., Lorences, E.P. 1994. Implication of persimmon fruit hemicellulose metabolism in the softening process. Importance of xyloglucan endotransglycosylase. Physiologia Plantarum, 91: 169-176.

D'Haeze, W., De Rycke, R., Mathis, R., Goormachtig, S., Pagnotta, S., Verplancke, C., Capoen, W., Holsters, M. 2003. Reactive oxygen species and ethylene play a positive role in lateral root base nodulation of a semiaquatic legume. Proc Natl Acad Sci USA., 100: 11789-11794.

Davis, J., Brandizzi, F., Liepman, A.H., Keegstra, K. 2010. Arabidopsis mannan synthase CSLA9 and glucan synthase CSLC4 have opposite orientations in the Golgi membrane. The Plant Journal, 64:1028-1037.

de Graaf, B.H., Cheung, A.Y., Andreyeva, T., Levasseur, K., Kieliszewski, M.,Wu, H.M. 2005. Rab11 GTPase-regulated membrane trafficking is crucial for tip-focused pollen tube growth in tobacco. Plant Cell, 17: 2564-2579.

De Lorenzo, G., Cervone, F., Hahn, M.G., Darvill, A., Albersheim, P. 1991. Bacterial endopectate lyase: evidence that plant cell wall $\mathrm{pH}$ prevents tissue maceration and increases the half-life of elicitor-active oligogalacturonides. Physiol. Mol. Plant Pathol., 39:335-344.

Dea, I. C. M., Madden, J. K. 1986. Acetylated pectic polysaccharides of sugar beet. Food Hydrocolloids, 1:71-88.

del Campillo, E., Bennett, A.B. 1996. Pedicel breakstrength and cellulase gene expression during tomato flower abscission. Plant Physiology, 111: 813-20.

del Campillo, E., Lewis, L.N. 1992. Identification and kinetics of accumulation of proteins induced by ethylene in bean abscission zones. Plant Physiology, 98: 955-61.

Desikan, R., Hancock, J.T., Bright, J., Harrison, J., Weir, I., Hooley, R., Neill, S.J. 2005. A role for ETR1 in hydrogen peroxide signaling in stomatal guard cells. Plant Physiology, 137: 831-834.

Dilcher, M., Veith, B., Chidambaram, S., Hartmann, E., Schmitt, H.D., Fischer von Mollard, G. 2003. Use1p is a yeast SNARE protein required for retrograde traffic to the ER. EMBO J., 22: 3664-3674.

Dinneny, J.R., Weigel, D., Yanofsky, M.F. 2005. A genetic framework for fruit patterning in Arabidopsis thaliana. Development, 132: 4687-4696. 
Ecker, J.R., Theologis, A. 1994. Ethylene: a unique plant signaling molecule. En: Arabidopsis. Meyerowitz, E.M., Somerville, C.R. (Eds.), Cold Spring Harbor Press, New York. 485-521.

Ellis, C.M., Nagpal, P., Young, J.C., Hagen, G., Guilfoyle, T.J., Reed, J.W. 2005. AUXIN RESPONSE FACTOR1 and AUXIN RESPONSE FACTOR2 regulate senescence and floral organ abscission in Arabidopsis thaliana. Development, 132: 4563-4574.

Erikson, L.C., Brannaman, B.L. 1960. Abscission of reproductive structures and leaves of orange trees. Proc. Am. Soc. Hort. Sci., 75: 222-229.

Falchi, R., Cipriani, G., Marrazzo, T., Nonis, A., Vizzotto, G., Ruperti, B. 2010. Identification and differential expression dynamics of peach small GTPases encoding genes during fruit development and ripening. Journal of Experimental Botany, 61(10): 2829-2842.

Fanutti, C., Gidley, M.J., Reid, J.S.G. 1993. Action of a pure xyloglucan endotransglycosylase (formerly called xyloglucan-specific endo-(1-4)-beta-D-glucanase) from the cotyledons of germinated nasturtium seeds. Plant J., 3: 691-700.

Fernandez, D.E., Heck, G.R., Perry, S.E., Patterson, S.E., Bleecker, A.B., Fang, S.C. 2000. The Embryo MADS Domain Factor AGL15 Acts Postembryonically: Inhibition of Perianth Senescence and Abscission via Constitutive Expresión. The Plant Cell, 12: 183197.

Fernández-Chacón, R., Achiriloaie, M., Janz, R., Albanesi, J.P., Sudhof, T.C. 2000. SCAMP1 function in endocytosis. J. Biol. Chem., 275: 12752-12756.

Ferrándiz, C. 2002. Regulation of fruit dehiscence in Arabidopsis. Journal of Experimental Botany, 53: 2031-2038.

Ferrándiz, C., Liljegren, S.J., Yanofsky, M.F. 2000. Negative regulation of the SHATTERPROOF genes by FRUITFULL during Arabidopsis fruit development. Science, 289:436-438.

Ferrarese, L., Trainotti, L., Moretto, P., Polverino de Laureto, P., Rascio, N., Casadoro, G. 1995. Differential ethylene-inducible expression of cellulase in pepper plants. Plant Molecular Biology, 29: 735-47

Foresti, O., Denecke, J. 2008. Intermediate Organelles of the plant secretory pathway: identity and function. Traffic, 9: 1599-1612.

Fry S.C., Smith R.C., Renwick K.F., Martin D.J., Hodge S.K., Matthews K.G. 1992. Xyloglucan endotransglycosylase, a new wall-loosening enzyme activity from plants. Biochemical Journal, 282: 821-828.

Fry, S.C. 2004. Primary cell wall metabolism: tracking the careers of wall polymers in living plant cells. New Phytologist, 161: 641-675. 
Fulton, L.M., Cobett, C.S. 2003. Two $\alpha$-L-arabinofuranosidase genes in Arabidopsis thaliana are differentially expressed during vegetative growth and flower development. Journal of Experimental Botany, 54: 2467-2477.

Gahagan, H.E., Holm, R.E., Abeles, F.B. 1968. Effect of ethylene on peroxidase activity. Physiologia Plantarum, 21: 1270-1279.

Gaspar, T., Goren, R., Huberman, M., Dubueq, M.1978. Citrus leaf abscission. Regulatory role of exogenous auxin and ethylene on peroxidases and endogenous growth substances. Plant Cell and Environment, 1:225-30.

Gattolin, S., Alandete-Saez, M., Elliott, K., Gonzalez-Carranza, Z. Naomab, E., Powell, C., Roberts, J.A. 2006. Spatial and temporal expression of the response regulators ARR22 and ARR24 in Arabidopsis thaliana. Journal of Experimental Botany, 57 (15): $4225-4233$.

Geldner, N. 2004. The plant endosomal system-its structure and role in signal transduction and plant development. Planta, 219: 547-560.

Gentleman, R.C., Carey, V.J., Bates, D.M., Bolstad, B., Dettling, M., Dudoit, S., Ellis, B., Gautier, L., Ge, Y., Gentry, J., Hornik, K., Hothorn, T., Huber, W., Iacus, S., Irizarry, R., Leisch, F., Li, C., Maechler, M., Rossini, A.J., Sawitzki, G., Smith, C., Smyth, G., Tierney, L., Yang J.Y.H., Zhang, J. 2004. Bioconductor: Open software development for computational biology and bioinformatics. Genome Biology, 5: R80.

Gómez-Cadenas, A., Mehouachi, J., Tadeo, F.R., Primo-Millo, E., Talón, M. 2000. Hormonal regulation of fruitlet abscisión induced by carbohydrate storage in citrus. Planta, 210: 636-643.

Gómez-Cadenas, A., Tadeo, F. R., Talón, M., Primo-Millo, E. 1996. Leaf abscission induced by ethylene in water-stressed intact seedlings of cleopatra mandarin requires previous abscisic acid accumulation in roots. Plant Physiology, 112: 401-408.

Gómez-Cadenas, A., Tadeo, F.R., Primo-Millo, E., Talón, M. 1998. Involvement of abscisic acid and ethylene in the responses of citrus seedlings to salt shock. Physiologia Plantarum, 103: 475-484.

González-Bosch, C., del Campillo, E., Bennett, A.B. 1997. Immunodetection and characterization of tomato endo- $\beta$-1,4-glucanase cell protein in flower abscission zones. Plant Physiology, 114: 1541-1546.

González-Carranza, Z.H., Elliot, K.A., Roberts, J.A. 2007. Expression of polygalacturonases and evidence to support their role during cell separation processes in Arabidopsis thaliana. Journal of Experimental Botany, 58: 3719-3730.

González-Carranza, Z.H., Whitelaw, C.A., Swarup, R., Roberts, J.A. 2002. Temporal and spatial expression of a polygalacturonase during leaf and flower abscission in oilseed rape and Arabidopsis. Plant Physiology, 128: 534-543. 
González-Dugo, V., Orgaz, F., Fereres, E. 2007. Responses of pepper to deficit irrigation for paprika production. Scientia Horticulturae, 114:77-82.

Goren, R., Dagan, E., Sagee, O., Riov, J. 1993. Abscission in citrus leaf explants: role of ABA-induced ethylene. Acta Horticulturae, 329: 43-50.

Goren, R., Huberman, M. 1976. Effects of ethylene and 2,4-D on the activity of cellulase isoenzymes in abscission zones of the developing orange fruit. Physiologia Plantarum, 37: 123-130.

Goujon, T., Minic, Z., El Amrani, A., Lerouxel, O., Aletti, E., Lapierre, C., Joseleau, J.P., Jouanin, L. 2003. AtBXL1, a novel higher plant (Arabidopsis thaliana) putative $\beta$ xylosidase gene, is involved in secondary cell wall metabolism and plant development. Plant J., 33: 677-690.

Greenberg, J., Goren, R., Riov, J. 1975. The abscission of young and mature Shamouti orange fruits. Physiologia Plantarum, 39: 1-7.

Gu, Q., Ferrandiz ,C., Yanofsky, M.F., Martienssen, R. 1998. The FRUITFULL MADS-box gene mediates cell differentiation during Arabidopsis fruit development. Development, 125:1509-1517.

Guilioni, L., Wery, J., Tardieu, F. 1997 Heat stress-induced abortion of buds and flowers in pea: is sensitivity linked to organ age or to relations between reproductive organs? Annals of Botany, 80:159-168.

Gupta, R., Webster, C.I., Gray, J.C. 1997. The single-copy gene encoding high-mobilitygroup protein HMG-I/Y from pea contains a single intron and is expressed in all organs. Plant Molecular Biology, 35: 987-992.

Haas, T.J., Sliwinski, M.K., D.E., M., Preuss, M., Ebine, K., Ueda, T., Nielsen, E., Odorizzi, G., Otegui, M.S. 2007. The Arabidopsis AAA ATPase SKD1 is involved in multivesicular endosome function and interacts with its positive regulator LYSTINTERACTING PROTEIN5. Plant Cell, 19: 1295-1312.

Handford, M.G., Baldwin, T.C., Goubet, F., Prime, T.A., Miles, J., Yu, X., Dupree, P. 2003. Localisation and characterisation of cell wall mannan polysaccharides in Arabidopsis thaliana. Planta, 218: 27-36.

Harris, N., Taylor, J.E., Roberts, J.A. 1997. Characterization and expression of an mRNA encoding a wound-induced (Win) protein from ethylene-treated tomato leaf abscission zone tissue. Journal of Experimental Botany, 48: 1223-1227.

Hartmond, U., Yuan., R., Burns, J.K., Grant, A., Kender, W.J. 2000. Citrus fruit abscission induced by methyl-jasmonate. Journal of the American Society of Horticultural Science, 125: 547-552.

Hayashi, T., Marsden, M.P.F., Delmer, D.P. 1987. Pea xyloglucan and cellulose V. Xyloglucan-cellulose interactions in vitro and in vivo. Plant Physiology, 83: 384-389. 
Heck, G.R., Perry, S.E., Nichols, K.W., Fernandez, D.E. 1995. AGL-15, a MADS domain protein expressed in developing embryos. Plant Cell, 7: 1271-1282.

Heisler, M.G.B., Atkinson, A., Bylstra, Y.H., Walsh, R., Smyth, D.R. 2001. SPATULA, a gene that controls development of carpel margin tissues in Arabidopsis, encodes a bHLH protein. Development, 128: 1089-1098.

Henrissat, B. 1991. A classification of glycosyl hydrolases based on amino acid sequence similarities. Biochem. J., 280: 309-316.

Henry, E.W. 1975. Peroxidases in tobacco abscission zone tissue III. Ultraestructural localization in thylakoids and membrane-bound bodies of chloroplasts. Journal of Ultrastructural Research, 52:289-299.

Hensel, L.L., Grbic, V., Baumgarten, D.A., Bleecker, A. 1993. Developmental and agerelated processes that influence the longevity and senescence of photosynthetic tissues in Arabidopsis. Plant Cell, 5:553-564.

Heredia, A. 2002. Biophysical and biochemical characteristics of cutin, a plant barrier biopolymer.Biochimica et Biophysica Acta, 1620:1-7.

Hirst, J., Lui,W.W., Bright, N.A., Totty, N., Seaman, M.N., Robinson, M.S. 2000. A family of proteins with gamma-adaptin and VHS domains that facilitate trafficking between the trans-Golgi network and the vacuole/lysosome. J. Cell Biol., 149: 67-80.

Horton, R.F., Osborne, D.J. 1967. Senescence, abscission and cellulose activity in Phaseolus vulgaris. Nature, 214: 1086-1088.

Huber, D.J. 1983. The role of cell wall hydrolases in fruit softening. Horticultura Review, $5: 169-215$.

Huberman, M., Goren, R. 1979. Exo- and endo-cellular cellulase and polygalacturonase in abscission zones of developing orange fruits. Physiologia Plantarum, 45: 189-196.

Huberman, M., Goren, R., Zamski, E. 1983. Anatomical aspects of hormonal regulation of abscission in citrus - The shoot-peduncle abscission zone in the non-abscising stage, 59 (3): 445-454.

Hunter, T. 1995. Protein kinases and phosphatases: the yin and yang of protein phosphorylation and signalling. Cell, 80: 225-236.

Hwang, I. 2008. Sorting and anterograde trafficking at the Golgi apparatus. Plant Physiology, 148: 673-683.

Hwang, I., Robinson, D.G. 2009. Transport vesicle formation in plant cells. Current Opinion in Plant Biology, 12: 660-669. 
Inaba, T., Nagano, Y., Nagasaki, T., Sasaki, Y. 2002. Distinct localization of twoclosely related Ypt3/Rab11 proteins on the trafficking pathway in higher plants. J. Biol. Chem., 277: 9183-9188.

Itai, A., Ishihara, K., Bewley, J.D. 2003. Characterization of expression, and cloning, of $\beta$-D-xylosidase and $\alpha$-L-arabinofuranosidase in developing and ripening tomato (Lycopersicon esculentum Mill.) fruit. Journal of Experimental Botany, 54 (393): 26152622.

Iwahori, S., van Stevenink, R.F.M. 1976. Ultrastructural observation of lemon fruit abscission. Scientia Horticulturae, 4: 235-246.

Jackson, M.B., Osborne, D.J. 1970. Ethylene, the natural regulator of leaf abscission. Nature, 225:1019-22.

Jaffe, M.J., Goren, R.1979. Auxin and early stages of the abscission process of citrus leaf explants. Bot Gaz., 140:378-83.

Janzen, D.H. 1970. Jaquinia pungens, a heliophile from the understory of tropical deciduous forest. Biotropica, 2:112-19.

Jarvis, M.C., Briggs, S.P.H., Knox, J.P. 2003. Intercellular adhesion and cell separation in plants. Plant, Cell \& Environment, 26: 977-989.

Jenkins, E.S., Paul, W., Craze, M., Whitelaw, C.A.,Weigand, A., Roberts, J.A. 1999. Dehiscence-related expression of an Arabidopsis thaliana gene encoding a polygalacturonase in transgenic plants of Brassica napus. Plant, Cell \& Environment, 22:159-67.

Ji, H., Kim, S-R., Kim, Y-H., Kim, H., Eun, M.Y., et al. 2010. Inactivation of the CTD phosphatase-like gene OsCPL1 enhances the development of the abscission layer and seed shattering in rice. The Plant Journal, 61: 96-106.

Jiang, C., Lu, F., Imsabai, W., Meir, S., Reid, M. 2008. Silencing polygalacturonase expression inhibits tomato petiole abscission. Journal of Experimental Botany, 59: 973979.

Jinn, T.L., Stone, J.M., Walker, J.C. 2000. HAESA, an Arabidopsis leucine-rich repeat receptor kinase, controls floral organ abscission. Genes \& Development, 14:108-117.

Jones, L., Seymour, G.B., Knox, J.P. 1997. Localization of pectic galactan in tomato cell walls using a monoclonal antibody specific to (1-4)-[beta]-D-galactan. Plant Physiology, 113: $1405-1412$.

Kaida, R., Serada, S., Norioka, N., Norioka, S., Neumetzler, L., Pauly, M., et al. 2010. Potential role for puple acid phospatase in the dephosphorilation of wall proteins in tobacco cells. Plant Physiology, 153: 603-610. 
Kalaitzis, P., Hong, S-B., Solomos, T., Tucker, M.L. 1999. Molecular characterization of a tomato endo- $\beta$-1,4-glucanase gene expressed in mature pistils, abscission zones and fruit. Plant Cell Physiology, 40(8): 905-908.

Kalaitzis, P., Koehler, S.M., Tucker, M.L. 1995. Cloning of tomato polygalacturonase expressed in abscission. Plant Molecular Biology, 28: 647-56.

Kalaitzis, P., Solomos, T., Tucker, M.L. 1997. Three different polygalacturonases are expressed in tomato leaf and flower abscission, each with a different temporal expression pattern. Plant Physiol, 113: 1303-1308.

Kalde, M., Nühse, T.S., Findlay, K., Peck, S.C. 2007. The syntaxin SYP132 contributes to plant resistance against bacteria and secretion of pathogenesis-related protein 1. Proc. Natl. Acad. Sci. USA., 104: 11850-11855.

Kanaya, E., Watanabe, K., Nakajima, N., Okada, K., Shimura, Y. 2001. Zinc release from the $\mathrm{CH} 2 \mathrm{C} 6$ zinc finger domain of FILAMENTOUS FLOWER protein from Arabidopsis thaliana induces self-assembly. The Journal of Biological Chemistry, 276(10): 7383-7390.

Kaneda, M., Rensing, K.H., Wong, J.C., Banno, B., Mansfield, S.D., Samuels, A.L. 2008. Tracking monolignols during wood development in lodgepole pine. Plant Physiol., 147: $1750-1760$.

Kepinski, S., Leyser, O. 2005. The Arabidopsis F-box protein TIR1 is an auxin receptor. Nature, 26; 435(7041): 446-51.

Kim, J., Shiu, S-H., Thoma, S., Wen-Hsiung Li, W-H., Patterson, S.E. 2006. Patterns of expansion and expression divergence in the plant polygalacturonase gene family. Genome Biology, 7: R87.

Kirchhausen, T. 2000. Three ways to make a vesicle. Nat. Rev. Mol. Cell Biol., 1: 187198.

Knox, J.P., Linstead, P. J., King, J., Cooper, C., Roberts, K. 1990. Pectin esterification is spatially regulated both within cell walls and between developing tissues of root apices. Planta, 181 (4): 512-521.

Koehler, S.M., Matters, G.L., Nath, P., Kemmerer, E.C., Tucker, M.L. 1996. The gene promoter for a bean abscission cellulase is ethylene-induced in transgenic tomato and shows high sequence conservation with a soybean abscission cellulase. Plant Molecular Biology, 31: 595-606.

König, R., Baldessari, D., Pollet, N., Niehrs, C., Eils, R. 2004. Reliability of gene expression ratios for cDNA microarrays in multiconditional experiments with a reference design. Nucleic Acids Research, 32: e29.

Konishi, S., Izawa, T., Lin, S.Y., Ebana, K., Fukuta, Y., Sasaki, T., Yano, M. 2006. An SNP cause loss of seed shattering during rice domestication. Science, 312: 1392. 
Kostenyuk, I.A., Zon, J., Burns, J.K. 2002. Phenylalanine ammonia lyase gene expression during abscission in citrus. Physiologia Plantarum, 116:106-112.

Kraft, E., Stone, S.L., Ma, L., Su, N., Gao, Y., Lau, O-S., Deng, X-W., Callis, J. 2005. Genome analysis and functional characterization of the E2 and RING-Type E3 ligase ubiquitination enzymes of Arabidopsis. Plant Physiology, 139: 1597-1611.

Kraut, D.A., Prakash, S., Matouschek, A. 2007. To degrade or realease: ubiquitin-chain remodeling. Trends in Cell Biology, 17: 9.

Kulkarni, N., Shendye, A., Rao, M. 1999. Molecular and biotechnological aspect of xylanases. FEMS Microbiol. Rev., 23: 411-456.

Kunst, L., Samuels, A.L. 2003. Biosynthesis and secretion of plant cuticular wax. Progress in Lipid Research, 42: 51-80.

Kwak, J.M., Nguyen, V., Schroeder, J.I. 2006. The Role of Reactive Oxygen Species in Hormonal Responses. Plant Physiology, 141: 323-329.

Lamb, C.J. 1994. Plant disease resistance genes in signal perception and transduction. Cell,76: 419-422.

Langhans, M., Marcote, M.J., Pimpl, P., Virgili-Lopez, G., Robinson, D.G., Aniento, F. 2008. In vivo trafficking and localization of p24 proteins in plant cells. Traffic, 9:770 785 .

Lashbrook, C.C. 2009. Functional genomics approaches to abscission. Stewart Postharvest Review, 1:4.

Lashbrook, C.C., Cai, S. 2008. Cell wall remodeling in Arabidopsis stamen abscission zones. Temporal aspects of control inferred from transcriptional profiling. Plant Signaling \& Behavior, 3: 733-736.

Lashbrook, C.C., Giovannoni, J.J., Hall, B.D., Fischer, R.L., Bennett, A.B. 1998. Transgenic analysis of tomato endo-b-1,4-glucanase gene function. Role of cel1 in floral abscission. Plant Journal, 13: 303-310.

Lashbrook, C.C., Gonzalez-Boch, C., Bennett, A.B. 1994. Two divergent endo- $\beta-1,4-$ glucanase genes exhibit overlapping expression in ripening fruit and abscising flowers. Plant Cell, 6: 1485-1493.

Latijnhouwers, M., Gillespie, T., Boevink, P., Kriechbaumer, V., Hawes, C., Carvalho, C.M. 2007. Localization and domain characterization of Arabidopsis golgin candidates. J. Exp. Bot., 58: 4373-4386.

Lazarova, G., Zeng, Y., Kermode, A.R. 2002. Cloning and expression of an ABSCISIC ACID-INSENSITIVE (ABI3) gene homologue of yellow cedar (Chamaecyparis nootkatensis). Journal of Experimental Botany, 53(371): 1219-1221. 
Ledger, S.E., Gardner, R.C. 1994. Cloning and characterization of five cDNAs for genes differentially expressed during fruit development of kiwifruit (Actinidia deliciosa var. deliciosa). Plant Molecular Biology, 25: 877-886.

Lee, G-J., Kim, H., Kang, H., Jang, M., Lee, D.W., Lee, S., Hwang, I. 2007. EpsinR2 interacts with clathrin, adaptor protein-3, AtVTI12, and phosphatidylinositol-3-phosphate. implications for EpsinR2 function in protein trafficking in plant cells. Plant Physiology, 143: $1561-1575$.

Leslie, M.E, Lewis, M.W., Youn, J-Y., Daniels, M.J., Liljegren, S.J. 2010. The EVERSHED receptor-like kinase modulates floral organ shedding in Arabidopsis. Development, 137: 467-476.

Letourneur, F., Gaynor, E.C., Hennecke, S., Demolliere, C., Duden, R., Emr, S.D., Riezman, H., Cosson, P. 1994. Coatomer is essential for retrieval of dilysine-tagged proteins to the endoplasmic reticulum. Cell, 79: 1199-1207.

Letunic, I., Doerks, T., Bork, P. 2008. SMART 6: recent updates and new developments. Nucleic. Acids. Res., 37 (1): D229-D232.

Lewis, M.W., Leslie, M.E., Liljegren, S.J. 2006. Plant separation: 50 ways to leave your mother. Current Opinion in Plant Biology, 9: 59-65.

Li, C., Ahou, A., Sang, T. 2006. Rice domestication by reducing shattering. Science, 311: 1936.

Li, J., Yuan, R. 2008. NAA and ethylene regulate expression of genes related to ethylene biosynthesis, perception, and cell wall degradation during fruit abscission and ripening in 'Delicious' apples. J. Plant Growth Regul., 27: 283-295.

Libertini, E., Li, Y., McQueen-Mason, S.J. 2004. Phylogenetic analysis of the plant endo-b-1,4-glucanase gene family. J. Mol. Evol., 58: 506-515.

Lieberman, S.J.,Valdovinos, J.G., Jensen, T.E. 1983. A morphometric study on the effects of ethylene treatment in promoting abscission of tobacco flower pedicels. Plant Physiology, 72: 583-585.

Liljegren, S. J., Leslie, M. E., Darnielle, L., Lewis, M. W., Taylor, S. M., Luo, R., Geldner, N., Chory, J., Randazzo, P. A., Yanofsky, M. F., et al. 2009. Regulation of membrane trafficking and organ separation by the NEVERSHED ARF-GAP protein. Development, 136: 1909-1918.

Liljegren, S., Ditta, G., Eshed, Y., Savidge, B., Bowman, J., Yanofsky, M. 2000. Control of fruit dehiscence in Arabidopsis by the SHATTERPROOF MADS-box genes. Nature, 404: 766-769.

Liljegren, S.J., Roeder, A.H.K., Kempin, S.A., Gremski, K., Østergaard, L., Guimil, S., Reyes, D.K., Yanofsky, M.F. 2004. Control of fruit patterning in Arabidopsis by INDEHISCENT. Cell, 116: 843-853. 
Lim, M.A.G., Kelly, P., Sexton, R., Trewavas, A.J. 1987. Identification of chitinase mRNA in abscission zones from bean. Plant Cell and Environment, 10:741-46.

Lin, Z., Alexander, L., Hackett, R., Grierson, D. 2008. LeCTR2, a CTR1-like protein kinase from tomato, plays a role in ethylene signalling, development and defence. The Plant Journal, 54: 1083-1093.

Lin, Z., Ho, C-W., Grierson, D. 2009. AtTRP1 encodes a novel TPR protein that interacts with the ethylene receptor ERS1 and modulates development in Arabdopsis. Journal of Experimental Botany, 60 (13): 3697-3714.

Lu, C., Zainal, Z., Tucker, G.A., Lycett, G.W. 2001. Developmental abnormalities and reduced fruit softening in tomato plants expressing an antisense Rab11 GTPase gene. The Plant Cell, 13: 1819-1833.

Lycett, G. 2008. The role of Rab GTPases in cell wall metabolism. Journal of Experimental Botany, 59: 4061--4074.

Maclachlan, G., Brady, C. 1994. Endo-1,4-[beta]-Glucanase, Xyloglucanase, and Xyloglucan Endo-Transglycosylase Activities Versus Potential Substrates in Ripening Tomatoes. Plant Physiology, 105: 965-974.

Malladi, A., Burns, J.K. 2008. CsPLD $\alpha 1$ and CsPLD $\gamma 1$ are differentially induced during leaf and fruit abscission and diurnally regulated in Citrus sinensis. Journal of Experimental Botany, 58: 3729-3739.

Mao, L., Begum, D., Chuang, H., Budiman, M.A., Szymkowiak, E.J., et al. 2000. JOINTLESS is a MADS-box gene controlling tomato flower abscission zone development. Nature, 406: 910-13.

Mao, Z., Craker, L.E., Decoteau, D.R. 1989. Abscission in Coleus: Light and phytohormonal control. Journal of Experimental Botany, 40:1273-1277.

Markovic, O., Janecek, S. 2001. Pectin degrading glycoside hydrolases of family 28: sequence-structural features specificities and evolution. Prot. Eng., 14: 615-631.

Martínez-Godoy, M.A., Mauri, N., Juárez, J., Marques, M.C., Santiago, J., Forment, J., Gadea, J. 2008. A genome-wide $20 \mathrm{~K}$ citrus microarray for gene expression analysis. BMC Genomics, 9: 318.

Master, E.M., Rudsander, U.J., Zhou, W., Henriksson, H., Divne, C., Denman, S., Wilson, D.B., Teeri, T.T. 2004. Recombinant expression and enzymatic characterization of PttCel9A, a KOR homologue from Populus tremula x tremuloides. Biochemistry, 43: 10080-10089.

Matheson, L.A, Suri, S.S., Hanton, S.L., Chatre, L., Brandizzi, F. 2008. Correct targeting of plant ARF GTPases relies on distinct protein domains. Traffic, 9: 103-120. 
Mbéguié-A-Mbéguié, D., Hubert, O., Baurens, F. C., Matsumoto, T., Chillet, M., FilsLycaon, B., Sidibé-Bocs, S. 2009. Expression patterns of cell wall-modifying genes from banana during fruit ripening and in relationship with finger drop. Journal of Experimental Botany, 60 (7): 2021-2034.

Mc Neil, M., Darvill, A. G., Fry, S. C., Albersheim, P. 1984. Structure and function of the primary cell wall of plants. Annu. Rev. Biochem., 53:625-663.

McKim, S.M., Stenvik, G-E., Butenko, M.A., Kristiansen, W., Cho, S.K., Hepworth, S.R., Aalen, R.B., Haughn, G.W. 2008. The BLADE-ON-PETIOLE genes are essential for abscission zone formation in Arabidopsis. Development, 135: 1537-1546.

McMahon, H.T., Mills, I.G. 2004. COP and clathrin-coated vesicle budding: different pathways, common approaches. Curr. Opin. Cell Biol., 16: 379-391.

McManus, M.T. 1994. Peroxidases in the separation zone during ethylene-induced bean leaf abscission. Phytochemistry, 35: 567-572.

McQueen-Mason, S.J., Cosgrove, D.J. 1995. Expansin mode of action on cell walls: analysis of wall hydrolysis, stress-relaxation, and binding. Plant Physiology, 107: 87-100.

McQueen-Mason, S.J., Durachko, D.M., Cosgrove, D.J. 1992. Two endogenous proteins that induce cell-wall extension in plants. Plant Cell, 4: 1425-1433.

Mehouachi, J., Serna, D., Zaragoza, S., Agustí, M., Talón, M., Primo-Millo, E. 1995. Defoliation increases fruit abscission and reduces carbohydrate levels in developing fruits and woody tissues of Citrus unshiu. Plant Science, 107: 189-197.

Meir, S., Hunter, D.A., Chen, J-C., Halaly, V., Reid, M.S. 2006. Molecular Changes Occurring during Acquisition of Abscission Competence following Auxin Depletion in Mirabilis jalapa. Plant Physiology, 141: 1604-1616.

Meir, S., Philosoph-Hadas, S., Sundaresan, S., Vijay Selvaraj, K.S., Burd, S., Ophir, R., Kochanek, B., Reid, M.S., Jiang, C-Z., Lers, A. 2010. Microarray analysis of the abscission-related transcriptome in the tomato flower abscission zone in response to auxin depletion. Plant Physiology, 154: 1929-1956.

Mellman, I., Warren, G. 2000. The road taken: past and future foundations of membrane traffic. Cell, 100: 99-112.

Michaeli, R., Philosoph-Hadas, S., Riov, J., Shahak, Y., Ratner, K., Meir, S. 2001. Chilling-induced leaf abscission of Ixora coccinea plants. III. Enhancement by high light via increased oxidative stress. Physiol. Plant., 113: 338-345.

Micheli, F. 2001. Pectin methylesterases: cell wall enzymes with important roles in plant physiology. Trends Plant Sci., 6: 414-419. 
Minic, Z., Do, C.T., Rihouey, C., Morin, H., Lerouge, P., Jouanin, L. 2006. Purification, functional characterization, cloning, and identification of mutants of a seed-specific arabinan hydrolase in Arabidopsis. J. Exp. Bot. 57: 2339-2351.

Mishra, A., Khare, S., Trivedi, P.K., Nath, P. 2008. Ethylene induced cotton leaf abscission is associated with higher expression of cellulase (GhCel1) and increased activities of ethylene biosynthesis enzymes in abscission zone. Plant Physiology and Biochemistry, 46: 54-63.

Miyamoto, K., Oka, M., Ueda, J. 1997. Update on the possible mode of action of the jasmonates - Focus on the metabolism of cell wall polysaccharides in relation to growth and development. Physiologia Plantarum, 100: 631-638.

Moller, I., Marcus, S.E., Haeger, A., Verhertbruggen, Y., Verhoef, R., Schols, H., Mikklesen, J.D., Knox, J.P., Willats, W. 2008. High-throughput screening of monoclonal antibodies against plant cell wall glycans by hierarchial clustering of their carbohydrate microarray binding profiles. Glycoconjugate J., 25: 49-58.

Nagano, Y., Okada, Y., Narita, H., Asaka, Y., Sasaki, Y. 1995. Location of lightrepressible, small GTP-binding protein of the YPT/rab family in the growing zone of etiolated pea stems. Proc. Natl. Acad. Sci. USA., 92: 6314-6318.

Nairn, C.J., Lewandowski, D.J., Burns, J.K. 1998. Genetics and expression of two pectinesterase genes in Valencia orange. Physiologia Plantarum, 102: 226-235.

Nemhauser, J.L., Hong, F., Chory, J. 2006. Different plant hormones regulate similar processes through largely nonoverlapping transcriptional responses. Cell, 126:467-475.

Novoradovskaya, N., Whitfield, M.L., Basehore, L.S., et al. 2004. Universal reference RNA as a standard for microarray experiments. BMC Genomics, 5: 20.

Ogawa, M., Kay, P., Wilson, S., Swain, S.M. 2009. ARABIDOPSIS DEHISCENCE ZONE POLYGALACTURONASE1 (ADPG1), ADPG2, and QUARTET2 are polygalacturonases required for cell separation during reproductive development in Arabidopsis. The Plant Cell, 21: 216-233.

Ohno, C.K., Reddy, G.V., Heisler, M.G.B., Meyerowitz, E.M. 2004. The Arabidopsis JAGGED gene encodes a zinc finger protein that promotes leaf tissue development. Development, 131(5): 1111-1122.

Okazawa, K., Sato, Y., Nakagawa, T., Asada, K., Kato, I., Tomita, E., Nishitani, K. 1993. Molecular cloning and cDNA sequencing of endoxyloglucan transferase, a novel class of glycosyltransferase that mediates molecular grafting between matrix polysaccharides in plant cell walls. J Biol. Chem., 268: 25364-25368.

Okushima, Y., Mitina, I., Quach, H.L., Theologis, A. 2005a. AUXIN RESPONSE FACTOR 2 (ARF2): a pleiotropic developmental regulator. Plant Journal, 43: 29-46. 
Okushima, Y., Overvoorde, P.J., Arima, K., Alonso, J.M., Chan, A., Chang, C., Ecker, J.R., Hughes, B., Lui, A., Nguyen, D., et al. 2005b. Functional genomic analysis of the AUXIN RESPONSE FACTOR gene family members in Arabidopsis thaliana: unique and overlapping functions of ARF7 and ARF19. Plant Cell, 17: 444-463.

Onishi, K., Takagi, K., Kontani, M., Tanaka, T., Sano, Y. 2007. Different patterns of genealogical relationships found in the two major QTLs causing reduction of seed shattering during rice domestication. Genome, 50: 757-766.

Oono, Y., Chen, Q.G., Overvoorde, P.J., Kohler, C., Theologis, A. 1998. age mutants of Arabidopsis exhibit altered auxin-regulated gene expression. Plant Cell, 10: 1649-1662.

Osborne, D.J. 1989. Abscission. Crit. Rev. Plant Sci., 8: 103-129.

Owen, D.J., Collins, B.M., Evans, P.R. 2004. Adaptors for clathrin coats: structure and function. Annu. Rev. Cell Dev. Biol., 20: 153-191.

Park, K.C., Kwon, S.J., Kim, P.H., Bureau, T., Kim, N.S. 2008. Gene structure dynamics and divergence of polygalacturonase gene family of plants and fungus. Genome, 51: $30-40$.

Patterson, S.E. 2001. Cutting loose. Abscission and dehiscence in Arabidopsis. Plant Physiology, 126: 494-500.

Patterson, S.E., Bleecker, A.B. 2004. Ethylene-dependent and independent processes associated with floral organ abscission in Arabidopsis. Plant Physiology, 134:194-203.

Patterson, S.E., Smith, A.R., Bolivar, J. 2010. SCAMPs and abscission. Workshop 17 (Abscission regulation and its application in horticulture), abstract 5. 28th International Horticultural Congress, Lisbon, Portugal.

Pearse, B.M. 1975. Coated vesicles from pig brain: purification and biochemical characterization. J. Mol. Biol., 97: 93-98.

Pelloux, J., Rustérucci, C., Mellerowicz, E.J. 2007. New insights into pectin methylesterase structure and function. Trends in Plant Science, 12:267-277.

Peng, J., Richards, D.E., Hartley, N.M., Murphy, G.P., Devos, K.M., et al. 1999. "Green revolution" genes encode mutant gibberellin response modulators. Nature, 400: 256-61.

Pereira-Leal, J.B. 2007. The Ypt/Rab family and the evolution of trafficking in fungi. Traffic, 9: 27-38.

Petersen, M., Sander, L., Child, R., van Onckelen, H., Ulvsko, P., Borkhardt, B. 1996. Isolation and characterisation of a pod dehiscence zone-specific polygalacturonase from Brassica napus. Plant Molecular Biology, 31: 517-527. 
Pimpl, P., Hanton, S.L., Taylor, J.P., Pinto-daSilva, L.L., Denecke, J. 2003. The GTPase ARF1p controls the sequence-specific vacuolar sorting route to the lytic vacuole. Plant Cell, 15:1242-1256.

Poovaiah, B.W., Rasmussen, H.P. 1973. Calcium distribution in the abscission zone of bean leaves. Electron microprobe X-ray analysis. Plant Physiology, 52:683-684.

Pozo, L., Yuan, R., Kostenyuk, Y., Alférez, F., Zhong, G., Burns, J.K. 2004. Differential effects of 1-methylcyclopropene on citrus leaf and mature fruit abscission. Journal of the American Society of Horticultural Science, 129: 473-478.

Prade, R.A. 1996. Xylanases: from biology to biotechnology. Biotechnol. Genet. Eng. Rev., 13: 101-131.

Preuss, M.L., Schmitz, A.J., Thole, J.M., Bonner, H.K., Otegui, M.S., Nielsen, E. 2006. A role for the RabA4b effector protein PI-4Kinase-b1 in polarized expansion of root hair cells in Arabidopsis thaliana. J Cell Biol., 172: 991-998.

Rahman, A.K., Sugitani, N., Hatsu, M., Takamizawa, K. 2003. A role of xylanase, $\alpha$-Larabinofuranosidase, and xylanase in xylan degradation. Can. J. Microbiol., 49: 58-64.

Rajani, S., Sundaresan, V. 2001. The Arabidopsis myc/bHLH gene ALCATRAZ enables cell separation in fruit dehiscence. Current Biology, 11:1914-1922.

Rayle, D.L., Cleland, R.E. 1992. The acid growth theory of auxin-induced cell elongation is alive and well. Plant Physiology, 99: 1271-1274.

Redgwell, R.J., Fry, S.C. 1993. Xyloglucan Endotransglycosylase Activity Increases during Kiwifruit (Actinidia deliciosa) Ripening (Implications for Fruit Softening). Plant Physiology, 103: 1399-1406.

Rehman, R.U., Stigliano, E., Lycett, G.W., Sticher, L., Sbano, F., Faraco, M., Dalessandro, G., Di Sansebastiano, G.P. 2008. Tomato Rab11a characterization evidenced a difference between SYP121- dependent and SYP122-dependent exocytosis. Plant and Cell Physiology, 49: 751-766.

Renard, C.M, Lomax, J.A, Boon, J.J. 1992. Apple-fruit xyloglucans: a comparative study of enzyme digests of whole cell walls and their alkaliextracted xyloglucans. Carbohydr. Res., 232: 303-320.

Revilla, G., Zarra, I. 2008. Fisiología vegetal. Introducción a las células de las plantas: membranas y pared. En: Fundamentos de Fisiología Vegetal (Azcón-Bieto J, Talón M, Eds.), pp. 3-24. McGraw-Hill Interamericana, ISBN 978-84-481-5168-3.

Ritcher, S, Voß, U., Jürgens, G. 2009. Post-Golgi traffic in plants. Traffic, 10: 819-828.

Robatzek, S. 2007. Vesicle trafficking in plant immune responses. Cellular Microbiology, 9(1): 1-8. 
Robert, S., Bichet, A., Grandjean, O., Kierzkowski, D., Satiat-Jeunemaître, B., Pelletier, S., Hauser, M-T., Höfte, H., Vernhettesa, S. 2005. An Arabidopsis endo-1,4- $\beta$ D-Glucanase involved in cellulose synthesis undergoes regulated intracellular cycling. The Plant Cell, 17: 3378-3389.

Roberts, J.A., Coupe, S.A., Taylor, J.E., Whitelaw, C.A. 1997. Spatial and temporal expression of abscission-related genes during ethylene-promoted organ shedding. En: Kanellis A.K., Chang C., Kende H., Grierson D., (Eds.). Biology and biotechnology of the plant hormone ethylene. NATO Series, 185-190.

Roberts, J.A., Elliot, K.A., González-Carranza, Z.H. 2002. Abscission, dehiscence, and other cell separation processes. Annual Review of Plant Biology, 53:131-58.

Roberts, J.A., Whitelaw, C.A., González-Carranza, Z.H., McManus, M.T. 2000. Cell separation processes in plants-models, mechanisms and manipulation. Annals of Botany, 86: 223-235.

Roeder, A.H.K., Ferrándiz, C., Yanofsky, M.F. 2003. The role of the REPLUMLESS homeodomain protein in patterning the Arabidopsis fruit. Current Biology, 13: 1630-1635.

Romualdi, C., Bortoluzzi, S., D’Alessi, F., Danieli, G.A. 2003. IDEG6: a web tool for detection of differentially expressed genes in multiple tag sampling experiments. Physiol. Genomics, 12(2): 159-162.

Rose, J.C., Bennett, A.B. 1999. Cooperative disassembly of the cellulose-xyloglucan network of plant cell walls: Parallels between cell expansion and fruit ripening. Trends in Plant Sci., 4:176-183.

Rose, J.K.C., Braam, J., Fry, S.C., Nishitani, K. 2002. The XTH family of enzymes involved in xyloglucan endotransglucosylation and endohydrolysis: current perspectives and a new unifying nomenclature. Plant Cell Physiol., 43: 1421-1435.

Rose, J.K.C., Lee, H.H., Bennett, A.B. 1997. Expression of a divergent expansin gene is fruit-specific and ripening-regulated. Proceedings of the National Academy of Sciences, USA, 94: 5955-5960.

Rösti, J., Barton, C.J., Albrecht, S., Dupree, P., Pauly, M., Findlay, K., Keith Roberts, K., Seifert, G.J. 2007. UDP-Glucose 4-Epimerase Isoforms UGE2 and UGE4 Cooperate in Providing UDP-Galactose for Cell Wall Biosynthesis and Growth of Arabidopsis thaliana. The Plant Cell, 19: 1565-1579.

Rungruchkanont, K., Ketsa, S., Chatchawankanphanich, O., van Doorn, W.G. 2007. Endogenous auxin regulates the sensitivity of Dendrobium (cv. Miss Teen) flower pedicel abscission to ethylene. Functional Plant Biology, 34: 885-894.

Russell, C., Stagg, S.M. 2010. New insights into the structural mechanisms of the COPII coat. Traffic, 11: 303-310. 
Saab, I.N., Sachs, M.M. 1996. A flooding-induced xyloglucan endo-transglycosylase homolog in maize is responsive to ethylene and associated with aerenchyma. Plant Physiology, 112: 385-391.

Saha, B.C. 2000. $\alpha$-L-Arabinofuranosidases: biochemistry, molecular biology and application in biotechnology. Biotechnol. Adv., 18: 403-423.

Sakamoto, M., Munemura, I., Tomita, R., Kobayashi, K. 2008. Involvement of hydrogen peroxide in leaf abscission signaling, revealed by analysis with an in vitro abscission system in Capsicum plants. The Plant Journal, 56: 13-27.

Sambrook, J., Fritsch, E.F., Maniatis, T. 1989. Molecular cloning: a laboratory manual. Cold Spring Harbor Laboratory Press, Cold Spring Harbor, NY.

Sampedro, J., Cosgrove, D.J. 2005. The expansin superfamily. Genome Biology, 6: 242.

Sampedro, J., Pardo, B., Gianzo, C., Guitián, E., Revilla, G., Zarra, I. 2010. Lack of $\alpha$ xylosidase activity in Arabidopsis alters xyloglucan composition and results in growth defects. Plant Physiology, 154: 1105-1115.

Sandelin, A., Wasserman, W.W, Lenhard, B. 2004. ConSite: web-based prediction of regulatory elements using cross-species comparison. Nucleic Acids Research, 32: W249W252.

Sander, L., Child, R., Ulvskov, P., Albrechtsen, M., Borkhardt, B. 2001. Analysis of a dehiscence zone endo polygalacturonase in oilseed rape (Brassica napus) and Arabidopsis thaliana: evidence for roles in cell separation in dehiscence and abscission zones, and in stylar tissues during pollen tube growth. Plant Molecular Biology, 46: 469-79.

Sanderfoot, A.A. 2007.The expansion of SNARE gene families parallels the rise of multicellularity among the green plants. Plant Physiol., 144: 6-17.

Sanderfoot, A.A., Kovaleva, V., Bassham, D.C., Raikhel, N.V. 2001. Interactions between syntaxins identify at least five SNARE complexes within the Golgi/prevacuolar system of the Arabidopsis cell. Mol. Biol. Cell, 12: 3733-3743.

Sane, A.P., Tripathi, S.K., Nath, P. 2007. Petal abscission in rose (Rosa bourboniana var Gruss an Teplitz) is associated with the enhanced expression of an alpha expansin gene, RbEXPA1. Plant Science, 172: 481-487.

Sanmartín, M., Ordóñez, A., Sohn, E.J., Robert, S., Sánchez-Serrano, J.J., Surpin, M.A., Raikhel, N.V., Rojo, E. 2007. Divergent functions of VTI12 and VTI11 in trafficking to storage and lytic vacuoles in Arabidopsis. Proc. Natl. Acad. Sci. USA, 104(9): 3645-3650.

Santos, C., Gaspar , M., Caeiro, A., Cristina Branco-Price, C., Teixeira, A., Ferreira, R.B. 2006. Exposure of Lemna minor to arsenite: expression levels of the components and intermediates of the ubiquitin/proteasome pathway. Plant and Cell Physiology, 47(9): 1262-1273. 
Sarkar, P., Bosneaga, E., Auer, M. 2009. Plant cell walls throughout evolution: towards a molecular understanding of their design principles. J. Exp. Bot., 60: 3615-3635.

Schröder, R., Atkinson, R.G., Langenkämper, G., Redgwell, R.J. 1998. Biochemical and molecular characterisation of xyloglucan endotransglycosylase from ripe kiwifruit. Planta, 104: 242-251.

Schultz, J., Milpetz, F., Bork, P., Ponting, C.P. 1998. SMART, a simple modular architecture research tool: Identification of signaling domains. PNAS., 95: 5857-5864.

Schumacher, K., Schmitt, T., Rossberg, M., Schmitz, G., Theres, K. 1999. The Lateral suppressor $(L s)$ gene of tomato encodes a newmember of the VHIID protein family. Proc. Natl. Acad. Sci. USA, 96:290-95.

Segev, N. 2001. Ypt and Rab GTPases: insight into functions through novel interactions. Curr Opin Cell Biol., 13:500-511.

Sexton, R. 1979. Spatial and temporal aspects of cell separation in the floral abscission in Impatiens sultani. Planta, 128:49-58.

Sexton, R., Hall, J.R. 1974. Fine structure and cytochemistry of the abscission zone cells of Phaseolus leaves. I. Ultraestructural changes occurring during abscission. Ann. Bot., 38; 849-54.

Sexton, R., Jamieson, G.G.C., Allan, M.H.I.L. 1977. An ultrastructural study of abscission zone cells with special reference to the mechanism of enzyme secretion. Protoplasma, 91: 369-87.

Sexton, R., Redshaw, A.J. 1981. The role of cell expansion in the abscission of Impatiens leaves. Annals of Botany, 48: 745-57.

Sexton, R., Roberts, J.A. 1982. Cell biology of abscission. Annual Review of Plant Physiology, 33:133-62.

Shiraishi, M., Yanagisawa, T. 1988. Anatomical and histochemical studies of starch distribution during abscission in filaments and petals of Wase Satsuma mandarin. J. Japan Soc. Hort. Sci., 56 (4): 365-374.

Shy, G., Ehler, L., Herman, E., Galili, G. 2001. Expression patterns of genes encoding endomembrane proteins supports a reduced function of the Golgi in wheat endosperm during the onset of storage protein deposition. Journal of Experimental Botany, 52(365): 2387-2388.

Siebert, P.D., Chenchik, A., Kellogg, D.E., Lukyanov, K.A., Lukyanov. S.A. 1995. An improved PCR method for walking in uncloned genomic DNA. Nucleic Acids Res., 23: 1087-1088. 
Siegfried, R.S., Eshed, Y., Baum, S.F., Otsuga, D., Drews, G.N., Bowman, J.L. 1999. Members of the YABBY gene family specify abaxial cell fate in Arabidopsis. Development. 126: 4117-4128.

Singh, A.P., Pandeya, S.P., Rajluxmia, Pandeya, S., Natha, P., Sane, A.P. 2011. Transcriptional activation of a pectate lyase gene, RbPell, during petal abscission in rose. Postharvest Biology and Technology, 60 (2): 143-148.

Smith, D.L., Starrett, D.A., Gross, K.C. 1998. A gene coding for tomato fruit $\beta$ galactosidase II is expressed durin fruit ripening. Cloning, characterization, and expression pattern. Plant Physiology, 117: 417-423.

Söllner, T., Bennett, M., Whiteheart, S.W., Scheller, R.H., Rothman, J.E. 1993. A protein assembly-disassembly pathway in vitro that may correspond to sequential steps of synaptic vesicle docking, activation, and fusion. Cell, 75: 409-418.

Speth, E.B., Imboden, L., Hauck, P., He, S.Y. 2009. Subcellular localization and functional analysis of the Arabidopsis GTPase RabE. Plant Physiology, 149: 1824-1837.

Springer, S., Spang, A., Schekman, R. 1999. A primer on vesicle budding. Cell, 97: 145148.

Stefano, G., Renna, L., Chatre, L., Hanton, S.L., Moreau, P., Hawes, C., and Brandizzi, F. 2006. In tobacco leaf epidermal cells, the integrity of protein export from the endoplasmic reticulum and of ER export sites depends on active COPI machinery. Plant J., 46: $95-110$

Steiner-Lange, S., Unte, U.S., Eckstein, L., Yang, C., Wilson, Z.A., Schmelzer, E., Dekker, K., Saedler, H. 2003. Disruption of Arabidopsis thaliana MYB26 results in male sterility due to non-dehiscent anthers. Plant Journal, 34: 519-528.

Stenvick, G.E., Butenko, M.A., Aalen, R.B. 2008. Identification of a putative receptorligand pair controlling cell separation in plants. Plant Signaling and Behaviour, 3: 11091110.

Sullivan, J.A., Shirasu, K., Deng, X.W. 2003. The diverse roles of ubiquitin and the 26S proteasome in the life of plants. Nat. Rev. Genet., 4: 948-958.

Sun, L., van Noker, S . 2010. Analysis of promoter activity of members of the PECTATE LYASE-LIKE (PLL) gene family in cell separation in Arabidopsis. BMC Plant Biology, 10: 152.

Sunna, A., Antranikian, G. 1997. Xylanolytic enzymes from fungi and bacteria. Crit. Rev. Biotechnol., 17: 39-67.

Suvorova, E.S., Duden, R., Lupashin, V.V. 2002. The Sec34/Sec35p complex, a Ypt1p effector required for retrograde intra-Golgi trafficking, interacts with Golgi SNAREs and COPI vesicle coat proteins. The Journal of Cell Biology, 157(4): 631-643. 
Swingle, W.T. 1967. The Botany of Citrus and its wild relatives. En: The Citrus Industry, vol.1. Reuther, W., Batchelor, L.D. y Webber, H.J. (Eds.), Univ. Calif., Div. Agr. Sci., California, EE.UU.

Sztul, E., Lupashin, V. 2006. Role of tethering factors in secretory membrane traffic. Am. J. Physiol. Cell Physiol., 290: C11-C26.

Tadeo, F.R. 1988. Cambios ultraestructurales y bioquímicos que ocurren en el gineceo de los cítricos durante los periodos de floración y cuajado. Tesis Doctoral. Universidad de Valencia.

Tadeo, F.R. 2000. Fisiología de las plantas y el estrés. En: Fundamentos de Fisiología Vegetal. Azcón-Bieto, J., Talón, M. (Eds), McGraw-Hill/Interamericana. Madrid. 481-498.

Tadeo, F.R., Gómez-Cadenas, A. 2008. Fundamentos de Fisiología Vegetal. Ed. McGraw-Hill-Interamericana.

Tadeo, F.R., Moya, J.L., Iglesias, D.J., Talón, M., Primo.Millo, E. 2003. Histología y citología de cítricos. Conselleria de agricultura, pesca y alimentación. Valencia.

Taghizadeh, M.S., Crawford, S., Nicolas, M.E., Cousens, R.D. 2009. Water deficit changes the anatomy of the fruit abscission zone in Raphanus raphanistrun (Brassicaceae). Australian Journal of Botany, 57: 708-714.

Taiz, L., Zeiger, E. 2006. Plant Physiology (4 ${ }^{\text {th }}$ Edition). Ed. Sinauer. Sunderland, Massachusetts.

Talón, M., Tadeo, F.R., Ben-Cheikh, W., Gómez-Cadenas, A., Mehouachi, J., PérezBotella, J., Primo-Millo, E. 1997. Hormonal regulation of fruit set and abscission in citrus: Clasical aspects and new evidance. Acta Horticulturae, 463: 209-217.

Talón, M., Zacarías, L., Primo-Millo, E. 1990. Hormonal changes associated with fruit set and development in mandarins differing in their parthenocarpic ability. Physiologia Plantarum, 79: 400-406.

Talón, M., Zacarías, L., Primo-Millo, E. 1992. Gibberellins and Parthenocarpic Ability in Developing Ovaries of Seedless Mandarins. Plant Physiology, 99: 1575-1581.

Tamura, K., Dudley, J., Nei, M., Kumar, S. 2007. MEGA4: Molecular Evolutionary Genetics Analysis (MEGA) Software Version 4.0. Mol. Biol. Evol., 24(8): 1596-1599.

Taylor, J.E., Coupe, S.A., Picton, S.J., Roberts, J.A. 1994. Isolation and expression of a mRNA encoding an abscission-related $\beta-1,4$-glucanase from Sambucus nigra. Plant Molecular Biology, 24: 961-964.

Taylor, J.E., Whitelaw, C.A. 2001. Signals in abscission. New Phytologist, 151:323-39. 
Tonutti, P., Cass, L.G., Christoffersen, R.E. 1995. The expression of cellulase gene family members during induced avocado fruit abscission and ripening. Plant, Cell \& Environment, 18 (6): 709-713.

Trainotti, l., Pavanello, A., Zanin, D. 2006. PpEG4 is a peach endo-b-1,4-glucanase gene whose expression in climacteric peaches does not follow a climacteric pattern. Journal of Experimental Botany, 57: 589-598.

Tucker, M.L., Sexton, R., del Campillo, E., Lewis, L.N. 1988. Bean abscission cellulase: characterization of a cDNA clone and regulation of gene expression by ethylene and auxin. Plant Physiology, 88:1257-62.

Tucker, M.L., Burke, A., Murphy, C.A., Thai, V.K., Ehrenfried, M.L. 2007. Gene expression profiles for cell wall-modifying proteins associated with soybean cyst nematode infection, petiole abscission, root tips, flowers, apical buds, and leaves. Journal of Experimental Botany, 58 (12): 3395-3406.

Tudela, D., Primo-Millo, E. 1992. 1-Aminocyclopropane-1-carboxylic acid transported from roots to shoots promotes leaf abscission in Cleopatra mandarin (Citrus unshiu Hort. ex Tan.) seedlings rehydrated after water stress. Plant Physiology, 100: 131-137.

Tuncer, M., Ball, A.S. 2003. Co-operative actions and degradation analysis of purified xylose-degrading enzymes from Thermonospora fusca BD25 on spelt xylan. J. Appl. Microbiol., 94: 1030-1105.

Ueda, J., Miyamoto, K., Hashimoto, M. 1996. Jasmonates promote abscission in bean petiole explants - Its relationship to the metabolism of cell wall polysaccharides and cellulase activity. Journal of Plant Growth Regulation, 15: 189-195.

Urbanowicz, B.R., Bennett, A.B., del Campillo, E., Catalá, C., Hayashi, T., Henrissat, B., et al. 2007. Structural Organization and a Standardized Nomenclature for Plant Endo1,4-b-Glucanases (Cellulases) of Glycosyl Hydrolase Family 9. Plant Physiology, 144: $1693-1696$.

Valdovinos, J.G., Jensen,T.E., Sicko, L.M. 1972. Fine structure of abscission zones. IV. Effect of ethylene on the ultrastructure of abscission cells of tobacco flower pedicels. Planta, 102: 324-333.

van der Vlugt-Bergmans, C. J. B., Meeuwsen, P.J.A., Voragen, A.G.J., van Ooyen, A. J. J. 2000. Endo-Xylogalacturonan Hydrolase, a Novel Pectinolytic Enzyme. Applied and Environmental Microbiology, 66 (1): 36-41.

Van Meeteren, U., de Proft, M. 1982. Inhibition of flower bud abscission and ethylene evolution by light and silver thiosulphate in Lilium. Physiologia Plantarum, 56: 236-240.

van Nocker, S. 2009. Development of the abscission zone. Stewart Postharvest Review, 1: 5 . 
Vanderhoef, L.N., Dute, R.R. 1981. Auxin-regulated wall loosening and sustained growth in elongation. Plant Physiology, 67: 146-149.

Vaquerizas, J.M., Conde, L., Yankilevich, P., Cabezón, A., Minguez, P., Díaz-Uriarte, R., Al-Shahrour, F., Herrero, J., Dopazo, J. 2005. GEPAS, an experiment-oriented pipeline for the analysis of microarray gene expression data. Nucleic Acids Research, 33: 612-616.

Vercauteren, I., de Almeida Engler, J., De Groodt, R., Gheysen, G. 2002. An Arabidopsis thaliana pectin acetylesterase gene is upregulated in nematode feeding sites induced by root-knot and cyst nematodes. MPMI., 404-407.

Vernoud, V., Horton, A., Yang, Z., Nielsen, E. 2003. Analysis of the small GTPase gene family of Arabidopsis thaliana. Plant Physiol., 131: 1191-1208.

Vierstra, R.D. 2003. The ubiquitin/26S proteasome pathway, the complex last chapter in the life of many plant proteins. Trends in Plant Science, 8: 135-142.

Vincken, J.P., Schols, H.A., Oomen, R.J., McCann, M.C., Ulvskov, P., Voragen, A.G., Visser, R.G. 2003. If homogalacturonan were a side chain of rhamnogalacturonan I. Implications for cell wall architecture. Plant Physiology, 132:1781-1789.

Vissenberg, K., Feijó, J.A., Weisenseel, M.H., Verbelen, J-P. 2001. Ion fluxes, auxin and the induction of elongation growth in Nicotiana tabacum cells. Journal of Experimental Botany, 52(364): 2161-2167.

Wang, H., Tse, Y.C., Law, A.H.Y., Sun, S.M.S., Sun, Y-B., Xu, Z-F., Hillmer, S., Robinson, D.G., Jiang, L. 2010. Vacuolar sorting receptors (VSRs) and secretory carrier membrane proteins (SCAMPs) are essential for pollen tube growth. The Plant Journal, 61: 826-838.

Wang, X.Q., Xu, W.H., Ma, L.G., Fu, Z.M., Deng, X.W., Li, J.Y., Wang, Y.H. 2006. Requirement of KNAT1/BP for the development of abscission zones in Arabidopsis thaliana. Journal of Integrative Plant Biology, 48: 15-26.

Waters, M.G., Serafini, T., Rothman, J.E. 1991. 'Coatomer': a cytosolic protein complex containing subunits of non-clathrin-coated Golgi transport vesicles. Nature, 349: 248-251.

Wei, P-C., Tan, F., Gao, X-Q., Zhang, X-Q., Wang, G-Q., Xu, H., Li, L-J., Chen, J., Wang, X-C. 2010. Overexpression of AtDOF4.7, an Arabidopsis DOF family transcription factor, induces floral organ abscission deficiency in Arabidopsis. Plant Physiology, 153(3): 1031-1045.

Whitelaw, C.A., Lyssenko, N.N., Thai, V.A., Tucker, M.L. 2001. Functional analysis of regulatory sequences and isolation of protein factors controlling expression of an abscission-specific cellulase from bean (Phaseolus vulgaris). Poster en Plant Biology Meeting of 2001 (American Society of Plant Biologists). 
Whyte, J.R., Munro, S. 2002. Vesicle tethering complexes in membrane traffic. J. Cell Sci., 115: 2627-2637.

Wien, H.C., Turner, A.D. 1989. Hormonal basis for low light intensity-induced flower bud abscission of pepper. Journal of the American society of Horticultural Science, 114: 981-85.

Willats, W.G.T., Marcus, S.E., Knox, J.P. 1998. Generation of a monoclonal antibody specific to $(1 \rightarrow 5)-\alpha-L-a r a b i n a n$. Carbohydr. Res., 308: 149-152.

Williamson, G., Kroon, P.A., Faulds, C.B. 1998. Hairy plant polysaccharides: a close shave with microbial esterases. Microbiology, 144:2011-2023.

Wright, M., Osborne, D.J. 1974. Abscission in Phaseolus vulgaris. The positional differentiation and ethylene-induced expansion growth of specialised cells. Planta, 120: $163-170$.

Wu, Z., Burns, J.K. 2003. Isolation and characterization of a cDNA encoding a lipid transfer protein expressed in 'Valencia' orange during abscission. Journal of Experimental Botany, 54: 1183-1191.

Wu, Z., Burns, J.K. 2004. A $\beta$-galactosidase gene is expressed during mature fruit abscission of 'Valencia' orange (Citrus sinensis). Journal of Experimental Botany, 402: 1483-1490.

Xu, J., Scheres, B. 2005. Dissection of Arabidopsis ADP-RIBOSYLATION FACTOR 1 function in epidermal cell polarity. Plant Cell, 17: 525-536.

Yang, W., Pollard, M., Li-Beisson, Y., Beisson, F., Feig, M., Ohlrogge, J. 2010. A distinct type of glycerol-3-phosphate acyltransferase with sn-2 preference and phosphatase activity producing 2-monoacylglycerol. Proceedings of the National Academy of Sciences USA, 107 (26): 12040-12045.

Yokoyama, R., Nishitani, K. 2001. Endoxyloglucan Transferase is Localized both in the Cell Plate and in the Secretory Pathway Destined for the Apoplast in Tobacco Cells. Plant \& Cell Physiology, 42: 292-300.

Yoshida, K., Komae, K. 2006. A rice family 9 glycoside hydrolase isozyme with broad substrate specificity for hemicelluloses in type II cell walls. Plant Cell Physiol., 47: 15411554 .

Yuan, R., Hartmond, U., Kender, W.J. 2001. Physiological factors affecting response of mature 'Valencia' orange fruit to CMN-pyrazole. II. Endogenous concentrations of Indole3-Acetic Acid, Abscisic Acid, and Ethylene. Journal of the American Society of Horticultural Science, 126: 420-426.

Yuan, R., Kender, W.J., Burns, J.K. 2003. Young fruit and auxin transport affect the response of mature 'Valencia' orange fruit to abscission materials via changing endogenous plant hormones. Journal of the American Society of Horticultural Science, 128: 302-308. 
Yuan, R., Wu, Z., Kostenyuk, I.A., Burns, J.K. 2005. G-protein-coupled $\alpha_{2 A^{-}}$ adrenoreceptor agonists differentially alter citrus leaf and fruit abscission by affecting expression of ACC synthase and ACC oxidase. Journal of Experimental Botany, 56: 18671875.

Zaragoza, S. 1993. Pasado y presente de la citricultura española. Ed. Generalitat Valenciana, Serie Div. Téc., nº 8, Valencia, España, pp: 11-50.

Zheng, H., Camacho, L., Wee, E., Batoko, H., Legen, J., Leaver, C.J. Malhó, R., Hussey, P.J., Moore, I. 2005. A Rab-E GTPase mutant acts downstream of the Rab-D subclass in biosynthetic membrane traffic to the plasma membrane in tobacco leaf epidermis. The Plant Cell, 17: 2020-2036.

Zhou, C., Lakso, A.N., Robinson, T.L., Gan, S. 2008. Isolation and characterization of genes associated with shade-induced apple abscission. Mol. Genet. Genomics, 280: 83-92.

Zhu, Q.H., Ramm, K., Shivakkumar, R., Dennos, E.S., Upadhyaya, N.M. 2004. The ANTHER INDEHISCENCE1 gene encoding a single MYB domain protein is involved in anther development in rice. Plant Physiology, 135: 1514-1525. 